\title{
THE TRANSITION FROM SHAMANISM TO RUSSIAN ORTHODOXY
}

\author{
IN ALASKA
}

by Soterios A. Mousalimas

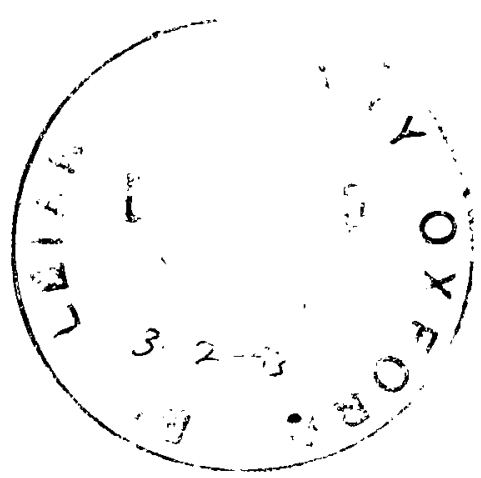

M. Div. Holy Cross Greek Orthodox School of Theology

M. St. Social Anthropology, Oxford University

B. A. Humanities, Hellenic College

Dissertation submitted for the degree of D.Phil. in Theology, Oxford University 


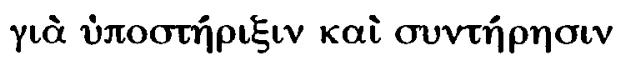

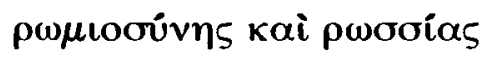

$+$

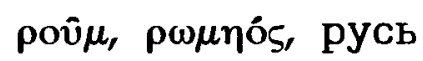




\section{ACKOWLEDGEMENTS}

( post-viva )

I am respectfully grateful to my supervisors over this thesis: Kallistos Ware, Faculty of Thelogy, University of Oxford, and Lydia T. Black, Department of Anthropology, University of Alaska at Fairbanks.

No institution or foundation has funded this research: the thesis is free from patronage. The finanicial assistance that I have received to supplement my own resources, has derived from personal donations from my parents and also from Mr. Nicholas Gavrilov-Gozzard, the three of whom I acknowledge with gratitude. 


\section{ABSTRACT \\ LIST OF ABBREVIATIONS \\ METHOD OF NOTATION FOR PATRISTIC TEXTS \\ p. vi \\ p. $x i$ \\ p. xii \\ INTRODUCTION: \\ p. 1}

(1) The People.

(2) Initial Definitions.

(3) Substantiation of the Premise.

(4) Summary Chronology.

(5) Method of Study: (i) Theology.

(ii) Social Anthropology.

(iii) History.

(6) Transliteration, Personal Names, and Place Names.

CHAPTER 1: INITIAL CONTACTS, FIRST BAPTISMS:

p. 35

(1-4) The Aleutian Islands.

(5-8) The Kodiak Area.

(9) Conclusions.

CHAPTER 2: CORRESPONDENCE:

(1) A Positive Outlook for a Theory of Correspondence:

Precedents in Patristics.

(2) A Negative Outlook.

(3) The Positive Outlook Applied.

(4) A Concluding Word about the Positive Outlook, as neither naive nor sentimental.

(5) A Test Case for a Theory of Correspondence.

(6) The Usefulness of the Theory.

(7) Conclusions.

CHAPTER 3: POINT OF COMPREHENSION:

p. 154

(1) "Panentheism" Defined.

(2) Divine Participation: a Concept in the Ecumenical Councils.

(3) Panentheistic Participation: Dynamics in Orthodox Christian Cultures.

(4) Participation through lcons and Ritual Masks: a Comparison.

(5) Conclusions.

CHAPTER 4: ECSTASY:

p. 194

(1) "Ecstasy" Defined.

(2) Patristic Criteria for a

Discernment between Ecstatic Experiences.

(3) An Example of Discernment from the Field (Alaska).

(4) Conclusions. 
(1) "Shamans" Defined.

(2) An Ethnographic Perspective: Shamans-of-old in Southern Alaska.

(3) A Social Perspective: Two Examples of Transformation.

(4) Conclusions.

CHAPTER 6: TRANSFORMATION, II.

(1) Biography of a Monastic Missionary, St. Herman of Alaska.

(2) Sources for the Missionary's Attributes.

(3) Definitions: Vocabulary in the Sources.

(4) Selected Descriptions of the Attributes.

(5) A Line of Tradition.

(6) Conclusions.

(7) Epilogue.

\section{CONCLUSIONS:}

"The Christianization of the Religion of their Ancestors".

\section{BIBLIOGRAPHY.}




\title{
THE TRANSITION FROM SHAMANISM TO RUSSIAN ORTHODOXY
}

\section{IN ALASKA}

\begin{abstract}
Responding to twofold question -- how did the transition occur; and what were its implications for the ancient cultures? - this thesis places an emphasis upon the transition as an indigenous movement, involving a transformation of the ancient.

The primary focus is comprised of the Aleut and Alutiiq peoples who converted virtually as whole nations in the later 18 th century. They then maintained this faith themselves within their village structures, a premise that will be substantiated in the Introduction. While a similar ingrafting occurred among other Alaskan peoples as well, an amount of published evidence is available for the Aleuts and Alutiiqs that can render the premise especially secure for them. These other Alaskan peoples - the Yupiit, the "Ingalik" Athapascans, the Kolchan Athapascans, the Dena'ina Athapascans, the historical Eyak, and the Tlingit - have provided corroborative ethnographical and social anthropological material; and the main concepts articulated in this study could potentially be extended to them as well, and extended further to peoples of similar cultures across northern Eurasia who were part of this history (as explained in Chapter 1 and in the epilogue in Chapter 6).

The following concepts have been developed in this study to reach its conclusion, their numeration here being equivalent to the chapter numbers where the evidence is presented:
\end{abstract}

(1) An "indigenous and corporate movement". The transition involved indigenous spiritual and social processes and occurred through the whole bodies of 
peoples' societies or kinship polities as the new faith and its practices were communicated initially from northeast Asians and northern Eurasians, thus from "like to like".

(2) A theory of correspondence. For a transition of this sort to have taken place, a correspondence must have existed between vital dynamics within these ancestral cultures and vital dynamics within Orthodox Christianity. "Correspondence" signifies a similarity not necessarily an equivalence. The possibility of this correspondence is substantiated theoretically with reference to principles within patristic theology; and the actuality is then tested practically through comparisons between sociaI anthropologicaI material relating to Alaska and theological material.

(3) Panentheistic Participation. A theory of correspondence established, a particular "point of comprehension" can be identified where these ancient cultures could engage and retain the new faith and its practices. This "point of comprehension" is comprised of the dynamics of divine participation.

Differences at this point can be signified with differing terms. If the term "nature" is specified for manifold dimensions including "fallen nature" (disease and other forms of destruction) on the one hand and, on the other hand, the term "cosmos" indicates harmonious nature, then the difference can be communicated between: (a) "divine participation in nature", a phrase that could include naive pantheism on the one hand, without being limited to it; and, on the other hand, (b) "divine participation in the cosmos" that precludes pantheism and focuses instead upon the concept of panentheism. The latter will be described as a characteristic of Greek Orthodox Christianity. 
The ancient Aleut and Alutiiq cultures had the ability to comprehend the dynamics of "panentheistic divine participation in the cosmos". Occurring among them, this ability is not developed universally; and an antithesis is indicated where these dynamics had been denied in another type of society and thus remained incomprehensible there in contrast.

(4) A definition of "ecstasy" and a mode of discernment. As shamans manifested a propensity for a type of "participation" and were themselves "central societal phenomena" in these ancient far northern cultures, attention will be focused upon them to discover whether the "theory of correspondence" could be extended, and a transformation could be expected, with regard to them. (The term "shaman" is defined in Chapter 5 from words in Alaskan languages.) Although the dynamics of participation were not limited to them or to their types of practices, yet they present a special challenge because a number of shamans and their practices were highly visible, and also because the typical shamans' rites were ecstatic, or were referred to as "ecstatic". The challenge is to discover whether ecstasy can be defined in a way that would allow the scope for transformation; and then to gain, from patristic insights, a mode of discernment between ecstatic experiences within this scope.

(5) Two perspectives upon shamans-of-old. The discernment between ecstatic experiences relates to a distinction that can be achieved between perspectives upon shamans-of-old in southern Alaska. Instances of tranformation become visible through a social perspective as baptized men, an Aleut and an Alutiiq, each associated explicitly, and in one instance exemplarily, with Orthodox Christianity were being referred to as "shamans", the significant differences from other shamans as perceived through an ethnographic perspective notwithstanding. In the most exemplary instance 
of this transformation, the form and content of the ecstasy were manifestly patristic and Biblical.

(6) A case study of a monastic missionary. A third example of this aspect of transformation is provided by an initial missionary in the Kodiak area, an anchorite who had been steeped in patristic traditions at Valaam Monastery in the forest of Karelia, and who is venerated as a saint at Valaam and in Alaska today. Scholarly standards are established for objective statements about him; and he is placed within the context of the indigenous corporate transition as the main social tasks that were associated with shamans-of-old as evident through the social perspective were attributed also to him, without the set of characteristics that typified shamans-of-old through the ethnographic perspective. While it would be a misrepresentation of the source material to refer to him in any sense as a "shaman" himself -- there is no indication that he was referred to in this way by anyone -- these attributes were described about him by numerous sources nonetheless; and the correspondence is important for an understanding of the transition.

In the final Conclusions, the thesis is reiterated that the transition was indigenous: this religion became and remains these peoples' own. I am aware of the misinterpretation that could occur should my emphasis upon the indigenous quality of the transition appear to convey an insularity. Where cultural insularity has been instilled as an operative value, "indigenization" might appear to imply self-containment. But the latter is not the concept I am describing. Throughout my study a mutual coinherence of multilingual cultures is described; and this coinherence is contrasted in Chapter 2 with an antipodal model of social organization predicated on monoculturalism instead. 
There are two primary reasons for my emphasis upon the transition as an indigenous movement. Firstly, it may open an area for further discovery - or, for some people, rediscovery - of Orthodox Christianity as a far northern phenomenon. The sum effect could be to stimulate an awareness of the relationships between theology and the varied cultures of the peoples in the Greek Orthodox ecumene: be they societies of herders or seasonal hunters of the tundra and taiga, sea-hunters and gatherers of the islands, agrarian folk of the steppes, pastoralists of the mountains, merchants of the East, or even fishermen.

More importantly, as my final reason for the emphasis, it may offer Alaskans and other far northern peoples an insight into, and a mode of interpretation for, the history of their religion. 


\section{LIST OF ABBREVIATIONS}

Due to the form of notation employed in this study, abbreviations are unnecessary except for the unpublished archival material as follows.

HRS/RR/LCM: Holy Ruling Synod Documents [HRS] filed among "Russian Reproductions" [RR] in the United States Library of Congress Manuscript Division [LCM].

VM/RR/LCM: $\quad$ Valaam Monastery Documents [VM] filed among "Russian Reproductions" [RR] in the United States Library of Congress Manuscript Division [LCM].

RAC/Iudin/LCM: Russian American Company Documents [RAC] in the Gennadii V. ludin, or "Yudin", collection in the Library of Congress Manuscript Division [LCM].

Information regarding these transcripts in the $L C M$, and providing the location of the manuscripts in Russian archives, is given in my lntroduction, section 5, subsection (iii). 


\section{METHOD OF NOTATION FOR PATRISTIC TEXTS}

Parts of a published patristic text will be signified in descending order by differing types of numerals, as follows:

Book: $\quad$ Upper case Roman numeral

Chapter: Lower case Roman numeral

Section: Arabic numeral

Line(s): Arabic numeral(s) following a point.

For example:

I, ii, 3.4-5 = Book 1, chapter 2, part 3, lines 4-5.

or:

vi, $7=$ Chapter 6 , part 7 .

In the latter example, the text is comprised of a single book, and the reference does not require the citing of the lines. A reference can be to a chapter alone.

Whenever the numbering of lines differs between editions, then the line numbers will be specified after the page number; for example, Ap. viii, 9 (1900:10, lines 11-12; 1990:13) would signify line 11-12 on page 10 of the 1900 edition of a text whose lines were not numbered in the later edition. 

. 


\section{INTRODUCTION}

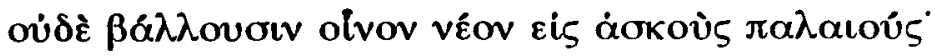

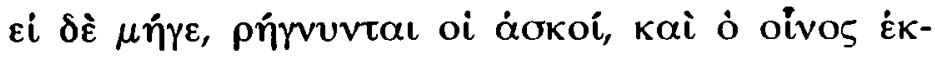

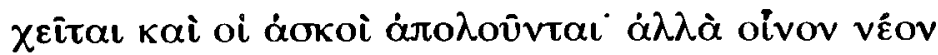

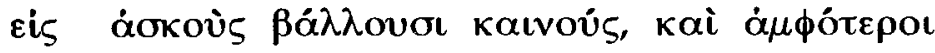

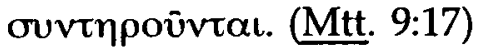

There comes a time to emphasize the continuity implicit in this parable: neither do men put new wine into old wineskins, else the wineskins break, and the wine runneth out, and the wineskins perish: but they put new wine into new wine-skins, and both are preserved.

It does not describe, and therefore does not advise, the breaking of the old wineskins which would be a wanton deed unless they had turned sour; for the old is valuable and can be transformed to deeper qualities with care. The verse describes a destructive effect upon the old and the new alike wrought by an untoward syncretism. Implicit is the preservation of the old with the new, as if by those who are informed about the care of wineskins and of the wine.

A preservation, or continuity, of the old as well as its transformation will be emphasized in this study, as the new was introduced in the transition to Russian Orthodoxy among (principally in this study) the Aleut and Alutiiq peoples of Alaska. 
The Aleut people derive mainly from the tip of the Alaska Peninsula and the long arc of the Aleutian Island archipelago, the latter comprising a chain of islands, many volcanic, extending for more than 1500 miles from Asia to North America. During the Russian period, the Pribylov Islands in the Bering Sea and the Commander Islands near the Kamchatka Peninsula were also settled by Aleuts and by other peoples assimilated to them.

Distinct from the Aleuts, the Alutiiq people derive from Kodiak Island and its archipelago, a region known collectively as the Kodiak area, approximately four hundred miles east of the Aleutians. They also derive from the mainland coast nearby and from the Chugach Bay area. Theirs is a distinctly North Pacific rim culture with a strong Russian infusion; however as their language is classed as "Eskimoan" because it is related most closely to the more northern Yup'ik and Inupiaq (Inuit) languages, these people have been categorized as "Pacific Eskimos" in some mid-20th century literature. It is an academic term. Another term sometimes applied to the Kodiak area Alutiigs in anthropological literature today is "Koniag", a term that derives from 18th century Russian sources who, coming eastward, assimilated an Aleutian Island word "Kanaagin" for the Kodiak area people. In this study, I shall transliterate their self-designation Alutiiq from their own language. The word is often (in my experience) pronounced as "Aleut" by Alutiiqs speaking English; yet 1 shall write the transliteration to render a visible distinction from the Aleutian/Pribylov Island people and culture.

During the Russian era in Alaska, these peoples assimilated the term Алеут (Aleut) from a civil status designated by that term. Another civil status from that era, Kpeor (Kreol), has been maintained (in my experience) as a social distinction by members of the eldest generation until today; but otherwise the latter term has been absorbed more-or-less into the former, Алеут. Other southern Alaskan peoples 
likewise assimilated these terms for themselves, most notably the Yupiit of the Nushagak and Bristol Bay areas; but they will not be included in this study because not enough material, neither historical nor ethnographical, has been written about them.

As peoples who are each distinct from other as groups in language and in other cultural aspects, such as traditional clothing and music, all maintain this self-designation, it indicates that they became inter-related through a similar, but not identical, history and arguably through an infusion of Russian Orthodoxy into their respective cultures. The genesis of "Aleut" and "Alutiiq" identity along these lines has begun to be articulated in research by $M$. J. Oleksa. In my view, the interpretation

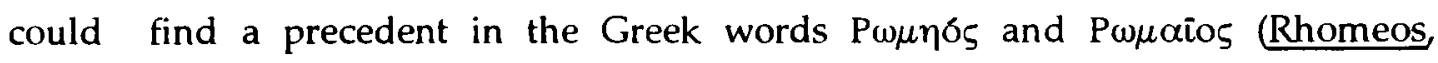
Rhomaios) with their Arabic and Turkic cognate Poũ $\mu$. Originally signifying a Graeco-Roman civil status, then becoming progressively from the later first and throughout most of the second millenia A.D. to designate Greek Orthodox Christians in mainly the eastern Mediterranean, this term encompasses differing ethnic (including language) groups. A precedent can perhaps be found furthermore in the word Русь and Русский (Rus' and $\underline{\text { Russki) }}$ as these terms indicate Orthodox Christian identities across Eurasia. The interpretation could well be predicated upon patristic theological models: an appropriate one being the Trinitarian prototype with the inherent divine nature analogous with the shared cultural nature that is signified

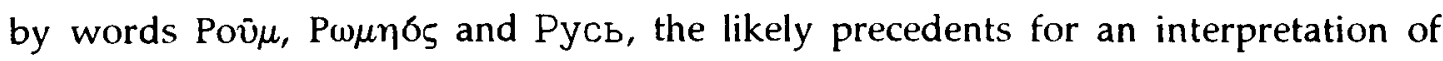
Алеут; and with the coinherent trinitarian hypostases analogous with the distinct ethnic groups.

General distinctions between Aleut groups were rendered in 18th century Russian language sources by predicating the term with regional distinctions, for example "Atka Aleut", "Fox Island Aleut", "Kodiak Aleut". And I shall do the same 
although with other regional designations and also by distinguishing "Aleut" from "Alutiiq" as follows: "western Aleut", "central Aleut", and "eastern Aleut"; "Kodiak Alutiiq" and "Chugach Alutiiq".

\section{(2) Initial Definitions.}

Two terms in this study's title will be explained initially, while other definitions are provided in the chapters.

(i) "Russian Orthodoxy" is the English language designation preferred by the Native Alaskans for their religion, in my experience; ${ }^{1}$ and they will often pronounce the phrase as if it were a single word. Implicitly it emphasizes their religious history, as this faith and its practices were communicated to their ancestors initially from easternmost Russia. People are aware of this history. For example after Vespers in the Tlingits' church in Juneau in 1981, four people were chanting troparia as others present were venerating the icons, according the tradition there. It happened that these four were a Tlingit (the choir master), an Aleut, a Russian, and a Greek. Some of the more senior people who were present said afterwards, "We have just seen history". They were referring to the communication of this faith and its practices from Greeks to Russians to Aleuts then eastward to the Tlingits. The symbol was recognized because the history was known.

"Russian Orthodoxy" also expresses the traditional liturgical language in Alaska: Slavonic. It was maintained within community chapels and churches, mostly by these people themselves from the introduction of this faith and its practices

' For published substantation see McClanahan (1986): "Russian Orthodox" is found in the transcribed interviews of elder Native Alaskans from various regions residing at the time of these interviews in the Cook lnlet region. 
beginning in the late 18 th century until just recently. In the 1970 s clerical institutions began displacing these traditions through English-only practices. ${ }^{2}$

The phrase "Greek Orthodoxy" will be incorporated to highlight a continuity from the Biblical and patristic world, and furthermore to highlight an inter-relatedness among the various cultures within the Greek Orthodox ecumene.

The term "Orthodoxy" will be employed only on occasions when theological formulations and/or liturgics alone are meant to be indicated. Otherwise this term will be set aside, because it might convey a doctrinaire partiality, bereft of the more comprehensive cultural context.

It seems to me that where Christianity has become embodied culturally, an attempt to extract "Orthodox Christianity" from this context is rather like alchemy attempting to extract an essence; or in christological imagery, rather like Nestorianism attempting to abstract the divine nature. Within a simile of an embodiment, theologizing can be likened to mental processes, liturgizing to affective and ingestive processes. Can these bodily processes be extracted with the "brains" and "bowels"? Imagining the organs to be the processes themselves, or yet the very essence of the body, would be absurd; and so would any attempt to grasp these processes by extracting these organs. Just as the living body is more than a collection of its main organs, Orthodox Christianity as a lived culture, is more than the sum of its primary parts. Therefore to mitigate a presumptious dissecting of the body, 1 have put the term "Orthodoxy" aside, except when theological formulations and/or liturgics alone are meant to be signified.

\footnotetext{
${ }^{2}$ For substantiation see Davis (1984:201). Also see Kodiak (anon. 1985:6) in which the following fact is acknowledged: "in many areas, English was not the language of the people" in 1972. For those few regions were it had become the dominant language, see Chapter 2 at note 39 , below.
} 
(ii) "Shamanism" can signify the belief system within which the shamans' practices occur, ${ }^{3}$ or that can indicate the more comprehensive cosmological relationships within the culture as a larger whole." Both these meanings are implied in the title.

Outside the title however, the term "shamanism" will be excluded from this study for the following reasons. This term has become too diffused, or indefinite. Entering the Russian from a Tungusic (Evenk) term for the type of functionary known in the latter language as a shaman, ${ }^{5}$ the term was rendered into the gerund and was extended to designate similar types of functionaries and practices throughout Russian Asia and Russian-America (Alaska). The terms "shaman" and "shamanism" then entered modern anthropological literature, but for things as diverse as "magic" and "Hassidism".

Another reason for excluding the term beyond the title is that "shamanism" exaggerates a single culture complex that constellates around the "shaman". The exaggeration becomes particularly pronounced within southern Alaska where the "shamans' practices" remained circumscribed, certainly vital but limited in social scope nevertheless.' The exaggeration is rather like that which would result if the term "clericalism" or "mysticism" were posited for Christian cultures because "clergy" or "mystics" had captured the attention of some observers.

S See e.g. Eliade (1964).

${ }^{4}$ See e.g. Pyong-choon (1988).

5 Shirokogoroff (1935:268); Eliade (1964:4; 1987:202). Also see Tugolukov (1978:426). The term occurs in the Manchu language also.

-Gershom (1987). The author has the title "Rabbi" in the by-line. He is obscure, and has been included only for the purpose of this note.

"See "The Ethnographic Perspective on Shamans-of-Old in Southern Alaska", Chapter 5, section 2, below. 
Instead of the term "shamanism", I shall employ the phrase "Far Northern hunters' culture" in the text of this study to convey the wider meaning of cosmology and social relationships; and 1 shall employ the phrase "shamans' practices" to indicate specifically the function of that particular type of ritualist specialist. The latter will be described within culturally specific characteristics in Chapter 5 .

Why allow the term "shamanism" into the title at all? It is expedient. Shamans were colourful beings themselves who still attract attention and stimulate imagination: and is this not in part the purpose of a title, to attract and to stimulate?

\section{(3) Substantiation of the premise.}

The premise upon which the study has been based is that the transition was actual: Russian Orthodoxy became these peoples' religion and has been their own for generations now. This premise can be substantiated with numerous references for the Aleuts $^{8}$ and for the Alutiiqs ${ }^{9}$ from academic, U.S. governmental and government-affiliated sources. They all derive from the American period, after the

${ }^{8}$ The sources in this note and in note 42 , below, will be cited instead of quoted so that the thesis remains within the word-limit. For the quotations see "Substantiation of the Premise", a paper included among the supplementary material submitted for the Examiners, should they wish to have recourse to it.

Applegate in Porter (1893:82); Berreman (1953:148, 151, 152; 1955:51, 134-135); Black (1977a:95, 105; 1981b:131-137); Bryant (1870:8, 22); Buynitzky (1871:6); Elliot (1881: 21, 22); Hutchinson (1942:87-88, 122, 150-151); Jones (1976:80-82; 1980:168); Mclntyre $(1870: 8 ; 12)$; Oliver $(1988: 256,42)$; Petroff $(1881: 14,18,21$; but for Petroff, see Sherwood 1963; 1964 and Pierce 1964); Pinart (187969); Porter (1893:187); Ransom (1945: 333 ftnt. 3, 337, 340); Shade (1949:96); Spaulding (1955:134-135); Sweetland (ms.).

${ }^{9}$ Befu (1970:31, 38, 40); Birket-Smith (1953:132); Davis (1970:125, 128-129, 145; 1971:78, 189-190); Hammerich (1954:424); Huggins (1981:12-15, 21, 27, 28, 30); Petroff (1884:28, 42); Oliver (1988:9); Pinart (1873b:673); Rathburn (1981); Taylor (1966:121, 212). 
sale of the territory to Washington, D.C., in 1867; and have been found through library research into ethnographical and anthropological material.

A few exceptions exist. Evidently for the sake of academic definition or classification, the designation of the Aleuts' religion has been altered. In a "comparative survey of Eskimo-Aleut religion", it was defined as "pure animism" without any reference to their Christianity. ${ }^{10}$ More recently, thirty years after that publication, their Christianity has been acknowledged in a multivolume reference work on Native American groups by the Smithsonian Institution; but the acknowledgement consists of merely a paragraph while the article then proceeds to describe a type of animistic shamanism from early historic sources as if that were the belief system proper to these "natives"." The principal source in both those publications was an ethnography by Ivan Veniaminov who had been writing retrospectively in the 1830 s regarding protohistoric phenomena according to information he received from old people who had had experience in the previous century. But the contemporary Aleuts, in the 1830s, were described by him as "exemplary Christians". ${ }^{2}$

Statements by Aleuts themselves could be included to substantiate the premise. For example a statement dated September 1987 at Atka written by the bilingual educator Moses Dirks could be quoted as follows: ${ }^{13}$

The church is still a very important part of the community. Traditional Russian Orthodox holidays are

\footnotetext{
${ }^{10}$ Marsh $(1954 ; 1967)$. See the photograph of him, tak ${ }^{\text {en }}$ during his fieldwork at Umnak, in Laughlin (1980:139).

"Lantis (1984:177-179).

${ }^{12}$ Veniaminov (1840b:144; 1984:229). Also see heiromonk Gideon (1989:122) who recognized Orthodoxy among the Aleuts even earlier, in 1807. These sources will be repeated in historical context in my Chapter 1.

${ }^{13}$ Dirks (1988:xiv).
} 
still observed. There is still no priest residing at Atka; lay readers conduct services regularly, and a priest periodically travels to Atka from Unalaska to conduct divine liturgy and perform weddings in church, baptisms, etc.

Or Illarion Merculieff from St. Paul, Pribilovs, former Commissioner of the Department of Commerce and Economic Development for the State of Alaska, could be cited as he likened the St. Paul village community to a family in 1984, and stated "the center of our family is the church."14 Or Alice Petrivelli, President of the Aleut Foundation, could be quoted as she stated in 1990: this religion "has sustained our people". ${ }^{15}$ Moreover, the million dollars the Aleuts corporately designated in 1989 for the restoration of their churches should be cited: a sum that was designated from the monetary partial compensation they had received from the federal government for wanton destruction of Aleut property by the U.S. military forces which, having deported the Aleuts (the only wholesale deportation of the population in history), occupied the Aleutian Islands during the Second World War. ${ }^{16}$

Evidence could be presented from Alutiiqs as well. In the summer of 1990 during the "clean-up" of the Exxon oil spill in the Chugach Bay area for example,

\footnotetext{
${ }^{14}$ Merculieff (1984).

${ }^{15}$ Petrivelli (n.d.).
}

${ }^{16}$ This information can be substantiated through the Aleut Foundation, Alaska state archives, and US federal government sources. Among the sources cited above, see Oliver $(1988: 16,56)$-- a U.S. schoolteacher assigned by the government to the village of Atka after the repatriation of the Aleuts at the conclusion of that war -who mentions the villagers' own reconstruction of their church which had been destroyed by the armed forces, causing the loss of a valuable icon and a 19th century cast iron bell. Also see the account by Alex. Prosoff [Prokoff] in ibid. (pp. 241-248). An Attu Aleut leader who was taken captive by the Japanese in 1942 and deported from the western Aleutian Islands with his fellow villagers, Prosoff managed to keep the village church funds, a sum of over two hundred US dollars, hidden during the incarceration in Japan throughout the war. Also see the account of the Head of Red Cross Repatriation of Prisoners of War in the Pacific, Monroe M. Sweetland (ms.), to whom Prosoff entrusted the money -- and who proved worthy of this trust -- because the bank notes had become soaked in a typhoon and had to be exposed to the sunlight, and thus exposed to theft, to avoid their ruin by the damp. 
a skeleton was discovered in a cave, and the Alutiiq leaders called the priest to provide these ancestral bones with a blessing and burial. ${ }^{17}$ Or on the Alaska Peninsula in September 1991 when scores of skeletons and bodies were returned by the Smithsonian Institution to the Alutiiq nation, after a long legal battle by the latter to regain possession of these remains that had been exhumed from their graves and shipped away by an archaeologist early this century, the Alutiiq people had the priests come from Kodiak to rebury these ancestors. ${ }^{18}$ Rather than presenting such material myself, I have chosen to cite material that is available through library research, thus to demonstrate that social anthropologists, ethnographers, a sociologist, government agents, even a botanłist, have since the mid-19th century with very few exceptions (and those exceptions are self-contradictory as I have indicated) themselves consistently recognized Russian Orthodox Christianity as the Aleut and Alutiiq peoples' religion.

\section{(4) Summary Chronology.}

A summary chronology, provided for an expedient orientation to the history of the transition from shamanism to Russian Orthodoxy in Alaska, can clarify a reason for my focus upon the Native Alaskan peoples themselves. The chronology will indicate

\footnotetext{
${ }^{17}$ Personal communication, Luke Kontgas, priest of the Greek Orthodox Church of the Tranfiguration, Anchorage, August 1990. He took part. I recall this information and that in the following note from private conversations, not formal interviews. As I was not conducting research, I did not make a note of the exact date within that month. It can be traced through the local newspapers where the event was reported, and also through the Alutiiq associations. For a similar event from the same region collected in 1933, see Birket-Smith (1953:2).
}

${ }^{18}$ Personal communication, Joseph Kreta, priest and dean of St. Herman's Pastoral School, Kodiak, September 1991. He took part in the reburial. I understood that the archaeologist who had the bodies exhumed and who took them away was A. Hrdlicka. 
that they have comprised the mainstay while ecclesiastical suprastructures and political suprastructures have been in flux. The data derive from primary and scholarly analytical sources until $1867 .{ }^{19}$ Subsequent dates, which do not bear upon my study, derive mostly from a history attributed to a present bishop in Alaska. ${ }^{20}$ Scholarly attention would be given to them with recourse directly to the primary sources if the later phases of the history were to be developed.

1741: Bering's Expedition proceeds from Kamchatka eastward to the Gulf of Alaska.

1745: The first commercial fur hunting enterprise from Kamchatka arrives at the Aleutian Islands, specifically the Near Islands.

1747: A young Aleutian Islander travels to Kamchatka on that enteprise's return, and is baptized as Pavel.

1762: Initial contacts have taken place across the length of the Aleutian chain; and a number of young men have been baptized, some through alliances of their elder kinsmen with, particularly, Kamchadals who came to the Aleutians for the sea hunt.

post-1766: New commercial enterprises begin on the eastern Aleutian Islands.

1784: A company of entrepreneurs "pacify" and "colonize" Kodiak Island.

The ecclesiastical suprastructures begin to wax.

1794: A religious mission arrives at the commercial colony, but is reduced within four years from ten members to only four, all in the Kodiak area.

1796: The leader of the religious mission returns to Irkutsk to be elevated to the "bishop of Kodiak".

19 For these sources, see section 4 (iii) in this Introduction: "Method of Study: History".

${ }^{20}$ Afonsky $(1977 ; 1990)$. 
1799: The newly elevated bishop drowns in a shipwreck on his return voyage to Kodiak. The same year, the Russian-American Company is formed by imperial decree with a renewable charter for monopoly rights.

1804-7: The surviving mission is reinforced by a hieromonk.

1820s: A renewed charter period begins for the Russian-American Company in 1821. Subsequently, four vast parishes, each with a parish priest, are designated for the Russian-American Pacific coast territories and Kurile islands. These parishes are: the Kodiak parish (where the religious mission had been sent), the Unalaska parish, and the Atka parish, and the Novo Arkhangel'sk parish. The latter in this list had its priest assigned earlier, in 1816.

1840: Bishop lnnokentii (Veniaminov) of a newly created diocese of "Kamchatka, the Kurile Islands, and the Aleutians Islands", arrives at his see at Novo Arkhangel'sk, company headquarters. ${ }^{21}$

1840s: Innokentii conducts an indefatigable series of pastoral journeys through this immense diocese; establishes missions in Russian-America -- at Ikogmiut on the western Alaska mainland; at Kenai on the Pacific coast; and in the southeastern archipelago; and creates a new parish at Nushagak on the southwest mainland. He himself spends most of this decade not in RussianAmerica however, but in Kamchatka.

c.1852: The diocese is incorporated into an archdiocese, Innokentii is elevated to archbishop with his see is Asia, initially at Aian, ultimately at Iakutsk, from where he administers the auxiliary parishes (those not specified in the

${ }^{21}$ Notice that this site on the American northwest coast is located more than a thousand miles farther east than the closest location designated in the diocesan title. 
diocesan title) and the missions in Russian-America. An auxiliary bishop, Petr, is placed at Novo Arkhangel'sk.

1867: Petr is transfered to Iakutsk. Russian-America including the Aleutian Islands are sold.

The ecclesiastical suprastructures wane.

1872: The bishopric at Novo Arkhangel'sk is transfered into the United States (to be distinguished from "the federal possession", later "the federal territory", of Alaska). Although they will retain the designation "Aleutians and Alaska" in their titles, bishops will not, through the next one hundred years, be resident in those locations; and the see will be vacant intermittently: 1876-1879, 1882-1888.

1989: The see is retitled the "Archdiocese of the Aleutians and North America".

1903: Three "vicar bishops of Alaska" succeed one another from 1903 to 1917, but they, also, are located in the United States proper.

1917: Due to the revolution, the "vicar bishop of Alaska" returns to Russia from the eastern seaboard of the United States. As factions emerge in the Russian diaspora with the political confusion, the diocese of Alaska remains vacated or jurisdiction is confused (careful research is needed here due to factional claims and counterclaims). One faction which organizes itself is designated the "Metropolia" as it recognizes the Patriarchate of Moscow, newly reconstituted under the government of the U.S.S.R.

1959: The territory of Alaska becomes the 49th state among the United States. An ecclesiastical suprastructure waxes new.

1970: By unilateral act from the U.S.S.R. (without reference to the other Orthodox Churches), the "Metropolia", is designated "The Orthodox Church of America". 
1972: The "O.C.A." establishes a seminary in Alaska and places/bishop here, who has remained to this day. ${ }^{22}$

As the chronology indicates, "allogenous" ecclesiastical suprastructures ("allogenous" will be my antonym in contrast to "indigenous") have been in flux, waxing initially in the 1790 s with the Russian-American Company, then waning with the selling of the possession, and waxing anew with Alaskan statehood. Throughout this flux, the Russian Orthodox communities consisting almost entirely of Native Alaskan peoples have been the mainstay, as the following additional data integrated into part of the chronology (to be repeated below) should further indicate.

Between 1858 and 1972, no ecclesiastical seminary existed in Alaska. At the earlier date the original seminary (a small school established in 1841) was transferred outside Russian-America to lakutsk, Asia. In 1972, the present theological school was opened in Alaska. In the meantime, the nearest seminary was thousands of miles away, initially in lakutsk, and then also in San Francisco; and, from 1876, bishops were rarely present in Alaska (despite their titles). During this long waning of ecclesiastical suprastructures, Alaskan church leaders were prepared within village infrastructures. Ordinands to the priesthood were trained in the major parishes, particularly at Unalaska and also at Sitka; ${ }^{23}$ they were then ordained during the few

${ }^{22}$ My research indicates that this is probably a watershed date, the significance of which I can only note now. My findings regarding the Orthodox Church as a Native Alaskan institution derive before this date or involve the generation that spans it. Future research should take this date carefully into consideration. What will the effects of this new Church jurisdiction and its practices be upon the next generations of Alaskans? Will they consider it their own? It seems to me that the nature of ecclesiarchs and their intentions must be taken into consideration, not merely their presence.

${ }^{23}$ I am aware that these processes could be misinterpreted as implying an insularity; but to the contrary, anyone who is familiar with Alaskan history and geography would recognize that: (i) Unalaska and Sitka had already become centres of Orthodox culture, as will be established for Unalaska in my Chapter 1; and (ii) the distance traveled by ordinards from newly converted peoples, particularly the Yupiit, 
episcopal visits to Alaska. Yet during this time, the number of indigenous clergy remained stable, and the number of churches and chapels increased. ${ }^{24}$ In 1858 , nine priests served forty-four Orthodox churches and chapels in Russian-America. ${ }^{25}$ ln

during this time was equivalent to the distance between Greece and England. Yupiit men being trained at Unalaska or Sitka would be like Englishmen being trained in Thessalonika or Moscow before returning to their native land to minister. And they returned multilingual (see, e.g., Oswalt 1963a:132). These indigenous processes were manifestly cross-cultural, not insular.

${ }^{24}$ For an example of some of the operative processes during this period, see a study of the Yup'ik village of Napaskiak, conducted by a U.S. field researcher (Oswalt 1963a:131-146). He found that the conversion of this village had taken place in 1905 and 1906, due to the village's own interactions and inter-relationships with other Yupiit villages who had themselves already become Russian Orthodox. Choosing to be baptized, the village of Napaskiak invited the priests to perform the sacrament: these priests were Native Alaskans themselves. For these men's derivations, see Michael Oleksa, "Aleut and Creole Churchmen in Alaska: Nineteenth and Early Twentieth Centuries", Appendix in Oleksa, ed. (1987:377-386). "Fr. Nichafor" in Oswalt (1963:132) is Fr. Nikifor Amkan; the "songleader Matthew Berezkin" is Bereskin. Four Napaskiak village elder men became psalomshchiks. A psalomshchik is a layman who cooperates essentially with the clergy to effect the church services, and who will, in the absence of priests, lead the corporate worship himself according to role assigned to laymen in the rubrics of the Orthodox Church.

The village subsequently constructed their own church building. Significantly a "driving force" within the Napaskiak church was an Aleut who had been educated within the parish seminary at Unalaska. In 1957 (the time of the fieldwork) the village was being visited on occasion by two priests from nearby major villages: both men were Yupiik. One was Fr. Zachary Guest.

25 Veniaminov (1975:28-29). But the source counts each altar as a church. The number can therefore be reduced to eighty-four chapels and church buildings; as two buildings contained two altars each. This source requires further clarification, because, while addressing the shareholders of the Russian-American Company in Petersburg on 17 December 1857, published in the Company's annual report for 1858 (Lada-Mocarski 1969:413; see the translation (Veniaminov 1975), as cited above), he assigns undue credit for this number to them. He specifies that the Russian-American Company was responsible for the construction of churches at only the company's main sites. Yet he extends to them credit for the promotion of Christianity throughout this vast region in general. But the Company had sometimes impeded the missionaries' work, and opposed the functioning of churches. For a local chapel being appropriated by the Company's chief manager, P. E. Chistiakov, who rendered it a warehouse in 1826, then had it destroyed when the stores were depleted, see Black (1984:98, ftnt. 30). For the axing of the dwelling of the last surviving missionary by order of the Company district manager (assisted by a priest) in the Kodiak area at about the same time, see Fr. Petr Kashevarov, "Information about Fr. Herman", 7 
1972 , the number of priests was the same, while the number of churches and chapels had increased to as many as eighty-six..$^{26}$ Even if the later figure is a high estimate, there was an increase in the number of churches and chapels between 1858 and 1972. The credit for the stability and increase must be assigned to the indigenous mainstay; and the causes for this stability and increase must be sought within indigenous processes.

(5) Method of Study.

Three fields of study have been involved in this research: (i) theology, especially patristics; (ii) social/cultural anthropology; and (iii) history. My method of study in each of these fields will be described subsequent to a brief description of the overall approach. Findings from this research which began effectively in 1983, have been given in various conferences since 1987 (the conferences and publications will be noted). By bringing them into academic conferences, 1 have put my concepts and vocabulary to the test prior to their consolidation here. The concepts themselves have not changed through this process; to the contrary they were made public only after

Sept. 1866, in Valaam, ed. (1894:185-186; 1978:111); also see Semen Ivanovich Ianovskii, Letter to Damascene, 22 Nov. 1865, in ibid. (1894:142; 1978:87). Earlier, for another Company district manager, 1. 1. Banner, attempting to impede a gifted young man from being prepared for church service, see Cathedral Hieromonk Gideon to the Kodiak Office, 11 March 1805, in Gideon (1989:85); also see Gideon to Metropolitan Amvrosii [no date], in ibid., p. 82. For yet earlier instances of antipathy and impedement, see Chapter 1 , sec. 6 , below. And for further information regarding Veniaminov in this context, see that chapter at notes 121-122.

${ }^{26}$ Kodiak (anon.). (1985:6). The source might have confused this date with later figures, as Afonsky (1990:294) specifies eighty-six for 1987. At the later date, there were twenty-seven priests (ibid.) due to the new seminary. Is it possible that while so many priests had been ordained the number of churches and chapels had, in contrast, increased by only two? About the sources: Kodiak (anon.) is a booklet produced by the seminary; Afonsky is a bishop presently in Alaska. 
considerable prior thought and discussions. They have remained constant. But the vocabulary has been refined as it has either become more attuned to the concepts (as noted in Chapter 5, section 2), or become more attuned to audiences who span disciplines (as explained later in this Introduction). The referencing has also been refined here, so that the present work supersedes all publications to date in this respect as well.

(i) Patristic Theology. My references to patristic texts are to the most recent critical editions whenever possible, and otherwise to the most recent publications, as specified in the Clavis Pat rum Graecorum corrected and kept updated by the Bodleian Library catalogues, and also as specified in the third edition of the Thesaurus Linguae Graecae. Due to the volume of texts being published in theology presently, it is possible that a critical edition has not come to my attention. Yet even with this possibility, the bibliography should be current to 1990 and in almost all cases to 1992. This concern is bibliographic. It does not have effect upon my argument.

A patristic writer's authority as a saint within Greek Orthodoxy will be specifed in the initial references to an author within each chapter of my text. The dates for patristic and other religious writers will be given according to the dates in the Oxford Dictionary of the Christian Church.

My selection of patristic texts is straightforward. They begin in Chapter 2 with St. Justin the Martyr, because he was specified by a key historical source to be described in Chapters 1 with regard precisely to the focus of this study. This key source from the history in Chapter 1 will thus provide the starting point for the patristics in Chapter 2. But this reference is not the only cause for my study to begin with him. Justin (c.100-c.165) was among the first Christian writers; and he was 
involved with concerns that parallel the theme of this study: the relationship of Christianity with aspects of the non-Christian culture (or now retrospectively, the pre-Christian culture) in which he lived. From Justin, the study proceeds to other Apologists who followed him in the second and early third centuries, and who also were involved with the same concern, regarding relationships of Christianity within the ancient Graeco-Roman world.

Subsequent to the initial development with the Apologists, I shall refer to later patristic writers who concerned themselves with the types of themes that my chapters will be addressing. For example when "ecstasy" becomes a theme in Chapter 4, a concern that the Apologists did not address further than an occasional reference to it, then the study will proceed to St. Epiphanius of Constantia and also to Didymus of Alexandria, both of whom wrote on this theme in the fourth century. When the meaning of icons is considered in Chapter 3 , then the reference will be made to St. John of Damascus, St. Nicephorus of Constantinople, and St. Theodore the Studite who articulated the theology of iconography clearly during the eighth and ninth centuries. Thus my focus on patrisic writers is thematic.

1 have striven to bring the thematic patristic focus into the regional focus throughout my writing, as with Justin at the start. When the meaning is considered of the Divine Liturgy, my reference will be to ninth century commentary by St. Germanus of Constantinople because his text in translation was incorporated into Slavonic church books that would most probably have been read by liturgists in my region of study. Also the Divine Liturgy as he wrote about it would have been virtually the same as that celebrated in Alaska in the 19th century. Similarly when in my last chapter, the patristic focus on the desert fathers in ' $\mathrm{H} \kappa \alpha \tau^{\prime}$ Alyustov $\tau \bar{\omega} \mathrm{V}$

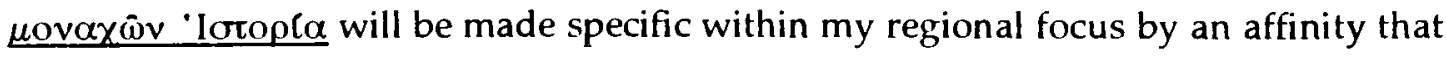
was expressed in the mid-19th century between the Egyptian Thebaid and the 
"Russian Thebaid" (as the latter was known by analogy), and the latter will be linked thematically to Russian-America, that is Alaska. The thematic patristic focus is brought into the regional focus, and vice versa. There is an apparent exception to this method: St. Athanasius of Alexandria has been selected to provide examples from patristics in Chapter 3, and Blos 'Oolov 'Avtuviou has been selected in Chapter 4, when other patristic writers and lives were possible. By chosing Athanasius and Anthony, I have striven to strengthen the thematic link between northern Eurasia and the patristic Greek-speaking world, between the "Russian Thebaid" and the Egyptian Thebaid, between Alaska and Egypt. The significance of that affinity will be highlighted in my final chapter.

My patristic research has thus involved a breadth of texts and history. My own preparation for incorporating such scope was provided by studies for the Masters of Divinity at Holy Cross Greek Orthodox School of Theology, preceded by the Bachelor of Arts from the affiliated Hellenic College.

(ii) Social/Cultural Anthropology. Research in this field has combined library research with field experience. The library research was conducted into ethnographies and other descriptions contemporary or nearly contemporary with the conversions of Alaskan peoples to Russian Orthodoxy; and the material in these sources were then compared.

Certain problems with the comparative method were explained by E. E. Evans-Pritchard in particular, whose constructive criticism was retrdpfective as well as current. ${ }^{2}$ Insights gained from him have been applied by me to a recent critique

\footnotetext{
${ }^{27}$ Evans-Pritchard (1963).
} 
of that method by L. Lévy-Bruhl; ${ }^{2 s}$ and I have attempted to avoid the weakness in this method myself while building upon its strengths. The method is strong when the sources can be ascertained as credible, and when the material they contain is incorporated with integrity into further analyses.

I have ascertained the credibility of sources according to the authors' familiarity with the peoples and with their languages. The latter criterion could be met by an author's cooperation with a good translator. lndeed 1 have experienced this process of communication through an interpreter, and have gained some primary knowledge of the possibilities, as communication occurs through more than an exchange of words alone. It occurs within a social context that can be called "participatory", as the participation and willingness of one party to learn is combined with the ability and willingness of another party to impart. When a good translator is added who has rapport with all the people involved, then the possibilities for real communication become greatly potential. And it could well be argued that, for the purpose of ethnography, this combination of factors is most important, while the author's own proficiency in the language can be a desirable further addition. Would proficiency in the language alone, without these social and personal factors, enhance communication or inhibit it? Let one be an accomplished linguist, his fieldwork would be hardly accomplished if he were unable himself to participate; and his liability would increase where a people valued warmth of heart and/or proper social discourse as much they valued a meeting of minds. When research requires that precise terms be ascertained, or that specifically analytical field research be conducted, then proficiency in the language would (in my opinion) become the primary consideration. Otherwise the criterion for a credible ethnography can be met

${ }^{28}$ Mousalimas (1990a:40). 
through a competent translator; and I have allowed this criterion in my consideration of the sources. My reasons for an exclusion of a description include: immaturity of a source such as G. I. Davydov who was merely a teenager, albeit a prolific one, when he compiled his ethnographic notes; ${ }^{29}$ or gross bias such as that of G. I. von Langsdorff, who would have hid himself away in his chamber rather than have prolonged contact with the "savages": those were the Russian hunters. He had very little contact with Aleuts or Alutiiqs whom he observed occasionally from a distance. $^{30}$

${ }^{29}$ Davydov (1977). Born in 1784, Gavriil Ivanovich Davydov was a cadet at the imperial naval academy in his youth, then entered into service with the Russian-American Company, remaining in Russian-America until June 1803, and again from June 1805 until July 1806, with two-and-a-half months in California during the later phase (see Pierce 1990:113-114). During his service, he kept himself personally occupied by writing. While the material is topical and interesting, the author was no more than a teenager during the initial phase and only three years older during the second phase of his stay. Following his untimely death by drowning in the Neva one night in 1809 , the material was published by the patronage of a influential friend of his family. The publication was evidently meant to redeem the young man's reputation from the embrace of that icy river, as the patron authored a warm preface to the impressive volume himself. Thus endorsed and beautifully bound, the volume can belie the author's age. It has value as a historical source; but it can not be received as a credible ethnography.

${ }^{30}$ Langsdorff $(1812 ; 1814$; see e.g. 1812:14-15; 1814:12-13). Born in 1774 of a baronial family in Rheinhessen (see Pierce 1990:288), he had never been into Russia until his excursion into Russian-America for a year, from June 1805 until June 1806. He had come to Russian-America from Kamchatka, where he had arrived by way of Cape Horn on the circumnavigational voyage of the Nadezhda, Petersburg's first round-the-world voyage. He was in the company of N. P. Rezanov (who will be described in Chapter 1), and remained in his company as Rezanov toured the Company operations in North America. During this time, they journeyed also to California with Davydov and others. Langsdorff did not speak Russian or any of the languages of the various peoples of Russian-America. He conversed in German, French and English. He was aghast at his situation here, and did not conceal his reaction. It was worse towards the Russians with whom he had, of necessity, to come into proximity, than towards the Alaskans whom he could observe from a distance. About the latter he wrote statements such as this: "An Aleutian [Kodiak Alutiiq] whom 1 questioned upon the subject, answered me with perfect indifference that his nation, in this regard [sexual behaviour], followed the example of sea-dogs and sea-otters" (1814:64; see 1812:58). And regarding the Unalaska Aleuts, he wrote: 
Once compiled from credible sources contemporary or nearly with the conversions, the information was compared to establish corroborative facts, in other words information that was ascertained from more than one credible source. For the purpose of this comparison, I organized the material geographically as if the region consisted of two concentric circles -- or rather two arcs, a smaller one contained within a larger one, according roughly to the actual geography. Material from the outer arc was employed to substantiate further the material from the inner arc. The inner, or primary, arc is comprised of the specific focus of study: the Aleutian Islands, Kodiak Area, and Chugach Bay Area encompassing the Aleut and Alutiiq peoples. The outer arc encompasses the immediately neighbouring people: the Yupiit, the Ingalik Athapascans, the Kolchan Athapascans, and the Dena'ina Athapascans directly north of the inner arc; and the Eyak and Tlingit due east. The cultures of the Kamchatka Peninsula to the west were not brought into this comparative study because evidence of sufficient proto-historic contact was lacking. Kamchatka becomes important in my study during the early historic period, as will be explained in my Chapter 1. Pre-historic and proto-historic contact between northeast Asia and Alaska took place mostly farther north, across the Bering Strait and earlier yet across the Bering Land Bridge.

Thus established, the corroborative facts were used inductively to give rise to regionally specific concepts. And these concepts were then compared with recent scholarly analyses. Most remarkable among the latter is the work regarding Aleut Christianity by L. T. Black, and the more recent work regarding Yup'ik Christianity

"Their religion consists like that of most uncivilized nations, in superstitions and a belief in charms" (1814:47; see 1812:42). Yet his work appeared in no less than two languages, nicely bound for posterity, readily accessible, and interesting in many respects - but not as credible work with regard to these peoples' beliefs. 
by A. Fienup-Riordan. ${ }^{31}$ Somewhat outside the focus of the present study, but noteworthy nonetheless, is an article produced by E. Turner from a study among the Inupiat at Point Hope, Alaska. ${ }^{32}$ Also significant in the field of Alaska religion are the contributors in the symposium on "Iconography and Symbolism" at the International Conference for Inuit Studies (at Fairbanks in 1990). ${ }^{33}$

Soviet analyses were sorely deficient due to the Marxist bias against Christianity and the Marxist-Leninist bias against religion. Sources for the study of religion in the Far North were themselves inaccessible until very recently, as became clear to me in Iakutsk in July 1991 when I was able to see some of the wealth of archival and library material that had been storehoused, and thus hidden from militant atheists who would have destroyed them (or so I was told). A work published in lakutia at the end of the Soviet dictatorship has yet maintained Marxism as its interpretive model but only to a degree; and this work has, signficantly, sought to affirm a value in Christianity. ${ }^{34}$

Field Experience. Because my study is retrospective, direct field research was not an option. Nonetheless field experience has comprised a vital aspect for the formation of my perceptions. I first visited Kodiak Island in 1978, then lived in Barrow on the North Slope and Juneau in the southeast from winter 1981 until autumn 1982. I have returned for visits to various locations throughout the state since 1983. This experience has provided the personal relationships that have created

${ }^{31}$ Fienup-Riordan (1990a), Part 2: "Negotiated Meaning: the Yup'ik Encounter with Christianity", pp. 71-122.

${ }^{32}$ E. Turner (1989).

${ }^{33}$ See 'Études/INUIT/Studies 14 (1-2), 1990, which contains papers from this symposium.

${ }^{34}$ Shishigin (1991). 
the motivation and the theoretical foundation for my writing. However these personal relationships were never entered into for the sake of research, and will not be cited as such. There is a single exception: in Anchorage in March 1988, followed by Kodiak and Spruce Islands in April 1988 (before and after the First Kodiak Area Heritage Conference), I sought information and identified my intent. I have since kept my sources informed as I have made use of their information, either publishing it or including it here (in Chapter 1: "Kodiak Area").

Experience that contributed to the formation of my concepts took place also in Greece intermittently from 1966 until the present. This experience comprised a necessary aspect for the present study as it provided insights into the cultural dynamics of Orthodox Christianity within traditional village and monastic settings, cultural dynamics that have yet to be expressed thematically in theological literature. My references to Arcadia in Chapter 3 and in the Conclusions are actual, not figurative. They derive from these experiences directly. I myself am Arcadian: while born and raised in America, I have had the opportunity to return to those villages and learn. I have also visited monastics at Mount Athos, and have stayed in the Monastery of $\Pi \alpha v \alpha \gamma\langle\alpha$ T $\alpha \tau \alpha \rho v \eta 5$ near Carpenision in Eurytania, the latter from 1976

September/through the Advent Lent to Theophany in 1977.

Recent visits to Iakutia and to Egypt, at the invitation from the Ministry of Culture for a week in July 1991 in the first instance, and as a guest of the Copts' Patristic Centre at Cairo for a week in December of the same year in the second instance, have made my references to these locations existentially specific.

Finally, experience both within southern England and to a lesser extent at Geneva through the last decade has provided cultural contrasts that have proved to be essential for this type of work. Without the contrasts, many cultural patterns 
would have probably remained conceptually dormant, because they might otherwise have seemed to me to be universals.

This range of international experience has combined with library research to create the concepts within the social anthropological aspect of this work.

(iii) History. The primary sources for this history are late 18th and early 19 th century manuscripts contained in various archives in Russia, America, and Finland. A number of these regarding the political history of Russian-America (as the possessions in North America were known) are published in editions, to which I have had recourse, by $\mathrm{P}$. A. Tikhmenev in 1863 , by A. 1 . Andreev in 1948 , and by $N$. N. Bashkina et al. in 1980.

I have had access to transcripts of some manuscripts from my field of study in the United States Library of Congress Manuscript Division, filed "Russian Reproductions, Holy Ruling Synod". The manuscripts themselves are located in catalog $\tilde{U}^{e}$ numbers 643 and 564 in the Archive of the Holy Governing Synod in the Central State Historical Archive. ${ }^{35}$ An inventory of the manuscript catalog archive was published by F. Golder who made the transcriptions, ${ }^{36}$ and the list indicates a ripe field for study in Russian archives.

The same year that Golder compiled this inventory and made these transcriptions by invitation from the imperial government, in 1914, he published a book in the United States on the history of Russian expansion to the Pacific. In 1917, he returned to conduct more research. Furthermore he reproduced four drawings from the Valaam Monastery archives that are also relevant to this study; they are

${ }^{35}$ Golder (1917:9). The same location is cited in "Russian Reproductions", Library of Congress Manuscript Division catalog/list, p. 6.

${ }^{36}$ Id. (1917). 
filed in the Library of Congress as "Russian Reproductions, Valaam Monastery", and have been published with Valaam sources in the Limestone Press Alaska History Series. ${ }^{37}$ Returning to the United States from Valaam, he produced a readable booklet, meant for distribution to his own friends, about one of the original missionaries to Kodiak, the monastic Herman (who is the subject of my Chapter 6). In 1921, Golder became professor of history at Stanford University, where he died in 1929. I have established my own archival research upon his transcriptions as authentic. $^{38}$

I have also had access to the documents collected by G. V. ludin (or "Yudin"), stored on microfilm in the Library of Congress Manuscript Division. Among them, a single document is most relevant to this study: the letter from Kodiak by Archimandrite Ioasaph to Grigorii Shelikov, dated 18 May 1795. It is the second item, first reel, first container, in the "Yudin Collection" at shelf number 18, 292-2N-2P.

Translations into English of Russian primary sources have been provided with substantial introductions, appendices, notes, and reproductions, in the Limestone Press Alaska History Series (LPAH). Some of these materials are published for the first time in any language. This valuable series is edited by Richard Pierce, professor emeritus in history from Queens College in Ontario, presently continuing as professor of history at the University of Alaska at Fairbanks. A characteristic of this series is its on-going effort for ever greater accuracy. For example, an important source in my study, the letters by cathe dral hieromonk Gideon, dated between 1805 and 1807 , were published in translation in this series initially in 1978 , and have been

${ }^{37}$ In Valaam (1978). Three were published in ibid. (1894).

${ }^{38}$ For Golder's biographical data, see the "Introductory Note" by J. Franklin Jameson to Part 1 in Golder (1917); also see the Preface to Part 2 in ibid. The latter part was issued in 1937, but is bound with the first part as volume no. 37, dated 1917. 
reissued in 1990 in a revised translation from a critical study of the manuscripts and publications accomplished by L. T. Black. Another source important to my study, a collection of materials and a commentary pertaining to the religious mission to Kodiak, published by Valaam Monastery in 1894, was issued in translation by the Limestone Press in 1978, and will soon be reissued in a revised translation. In addition to translations of Russian primary sources, this series also includes American primary sources. And the series furthermore includes Russian analytical studies in translation as well as American analytical studies in first editions. I have used LPAH throughout my work, as 1 have recognized its accuracy. ${ }^{39}$

In some publications, the Limestone Press has appended supplementary material from an unrelated translation project known as "Documents Relative to the History of Alaska" (DRHA). This voluminous early project is different from the Limestone Press Alaska History Series, and the standard of accuracy is not the same. Copies of DRHA are available on microfilm in the University of Alaska Library system, and also in the Alaska State Historical Library at Juneau. Another copy exists on microfilm in the Library of Congress Manuscript Division, filed under "Alaska University: Alaska History Research Project", at shelf number 10,612, serviced through the library's Microfilm Reading Room. The value of this pioneering project can be found in the effort to make Russian language primary sources available in English for Alaskan history. While I refer to the appendices from DRHA, no detail in my study has been based on them. Nor have quotations been incorporated from them into my text. My few references to them are in each case to the entire appendix in $\mathrm{LPAH}$, and refer in each case to the general content of that appendix.

\footnotetext{
${ }^{39}$ My statement is not naive. I am aware that sources are selected by the editor for translation and publication in this, as in any, series. But within the LPAH series, accuracy has been achieved in the treatment of those texts selected for publication.
} 
Whenever 1 cite a translation appended in LPAH, be it from DRHA or from another source, I provide the appendix's own reference to its own source by direct quotation (in quotation marks within brackets in my note). I also provide my own reference directly to the published Russian primary source: except in one instance where the original has not been published, and then I specify this circumstance in the note, and qualify the material by explaining my reason for including it.

Analysed data from North American and Russian scholars have been incorporated into my study, principally for the details of dates and for the analyses of population figures. These sources are: L. T. Black and R. A. Pierce of North America; S. G. Fedorova, R. G. Liapunova and R. V. Makarova of Russia. I have also had recourse to the work by L. A. Sitnikov.

Excluded from this paper is any primary source about which there is a question of authenticity, and any analytical source about which there is a question of credibility -- except when the credibility is itself the matter of concern, and then that concern is expressed in my text.

Among the dubious material 1 have counted the volumes of primary source material edited by I. Barsukov and the additional volume of biography by him, all published in the 1880 s. These volumes may be accurate; but their credibility has not yet been established authoritatively. They relate to the important churchman I. Veniaminov who arrived in Russian-America in 1824, and who later strongly influenced the history of northeast Asia. Interest in Veniaminov has revived, or rather resurfaced, in Russia where a conference devoted solely to Veniaminov's life and work was held at Vladivostock in 1990, involving scholars in various disciplines. Assessments of Barsukov's edition and biography will probably be forthcoming from such conferences. There has been no need for me to risk involving myself in any spurious material, erroneously edited data, or other contentious matters, that 
Barsukov's volumes might contain. Setting them aside, I have had access to first editions of Veniaminov's published works. I have also had recourse to direct archival research by $\mathrm{L}$. T. Black and by the Rasmusen Library at the University of Alaska at Fairbanks. My exclusion of Barsukov, and the attention I have brought to it, is meant to strengthen the basis for sources 1 have included for my argument.

Entirely excluded from my text is the three volume series of Russian documents loosely rendered into English by B. Dmytryshyn, E.A.P. Crownhart-Vaughan, and T. Vaughan, published by the Oregon Historical Society between 1985 and 1989 . I have listed this series in my bibliography only to signify my knowledge of it. ${ }^{40}$ Impressive by bulk and artly format, it was funded by U.S. national endowments and other grants; but its scholarship, as I have found, can hardly be considered commensurate with such funding. For example, baidara is repeatedly mistranslated as baidarka. ${ }^{41}$ Where the original document refers to an opened skin boat that could carry as many as twenty men, the "translation" has rendered the boat repeatedly as a kayak. A baidarka is a kayak. A similar error is made in geography in another document. ${ }^{42}$ The neighbouring islands Unalaska and Umnak, locations of men with entrepreneur S. G. Glotov and cossack S. T. Ponomarev from 1759 to 1762 , have repeatedly been rendered as Unalaska and "Unimak". Glotov and Ponomarev had camped on Umnak Island, then dispatched hunters northeast along the Bering Sea coast of neighbouring Unalaska Island. "Unimak" is farther away along the island chain, separated from Unmak and Unalaska by three other major islands. The error would bear directly upon the study

\footnotetext{
${ }^{40}$ Dmytryshyn, Crownhart-Vaughan, and Vaughan $(1985 ; 1988 ; 1989)$.

${ }^{41}$ Dmytryshyn, et al. (1988:380-381).

${ }^{42}$ Ibid., pp. 215-216.
} 
at hand; because this document contains a report regarding an Umnak leader named Shashuk entrusting a young kinsman to Glotov who baptized the youth. But the erroneous rendition would place this event in an altogether different location.

The problems with another document that is important to this study are indicated by the title attached to its rendition: "A Report from leromonk Makarii, head of the Russian Orthodox mission in Alaska ... detailing the treatment of natives by Russians"..$^{3}$ Firstly, Makarii was not the "head of the mission". It was Archimandrite Ioasaph. This is an uncontested fact, readily available in any publication: primary, secondary and tertiary sources, and analytical studies alike. Furthermore, the term "native" never occurs in this report; ${ }^{44}$ in fact this term rarely occurs in 18 th century Russian reports from the Aleutians and Kodiak. But the highly connotative term is used in the rendition of this document for terms as diverse as the "Aleuts" and the "voiceless people" (the latter emphasizes Makarii's appeal on their behalf). Finally these "natives" are pitted against "the Russians", although Makarii's protest was against a specific enterprise that he very clearly named and emphasized in his report: the Shelihov-Golikov enterprises. Just as the Aleuts become "natives" and the hieromonk's title is changed, so the culprit is effectively hidden under the loosely rendered title.

Were a point of merit to be found in that series, it would be that the "translators" and editors recognize in an introduction that no history has yet interpreted the initial contact periods before the mid-1760s, across the Aleutian Island archipelago. ${ }^{45}$ But overlooking this period, they then embark upon a treatment of

\footnotetext{
${ }^{43}$ Ibid., p. 497.

${ }^{44}$ Hieromonk Makarii, Report to the Holy Synod, 5 Oct. 1797, HRS/RR/LCM
} 643:13-23.

${ }^{45}$ Dmytryshyn, et al. (1988:xl). 
events after the 1770 s as if that were the totality nonetheless. Yet their brief statement remains insightful itself: no work has concentrated on the early contact periods.

An understanding of the early contact periods may be provided by the present study, as the first baptisms took place across the length of the Aleutian Island chain then. I have attempted to analyse the interactions in those early periods, and also to compare them with interactions in a later period, from the 1770 s into the $1820 \mathrm{~s}$.

Regarding subsequent periods in the religious history, from the 1820s, scholarly work has been accomplished by L. T. Black, and is contained in her substantial introductions, appendices and notes in published translations into English of Russian primary source materials. ${ }^{46} \mathrm{Her}$ analytical work is very important. It could be consolidated.

Otherwise, the only noteworthy published work is a readable biography of the churchman I. Veniaminov written by P. Garrett. ${ }^{47}$ This biography does not pose as scholarly work, and needs to be considered as it presents itself, as a readable work produced mostly from Barsukov's biography and editions, and perhaps as an inspirational work published as it is from a seminary press. It makes few pretensions -- although it does allow itself a peculiar latitude in its title when it elevates its subject to "The Apostle to America". An "apostle" to northeast Asia and the Aleutians could be more accurate.

Dates in the Russian-American history sources are according to the Julian Calendar.

${ }^{46}$ In: Gideon (1989); Netsvetov (1980; 1984); Veniaminov (1984).

${ }^{47}$ Garrett (1979). Compare the title in Hale (1888), a churchman of a reputable organization who was contemporary with Veniaminov, indeed who knew him. 
(6) Transliteration, including Personal and Place Names.

Aleut, Alutiiq, Tlingit and Yup'ik words have been spelled in Roman script according to the current usage at the Native Language Center, University of Alaska at Fairbanks, and for Tlingit at the Sealaska Heritage Foundation.

The Library of Congress system has been used as a basis for transliteration of Russian words from the Cyrillic alphabet, but has been modified as I have omitted the "soft-sign" and "hard-sign" when they occur at the ends of transliterated words. For proper names, I have deferred to popular usage when a name is well known, such as "Dostoyevsky". Similarly "Herman" is allowed instead of the direct transliteration German, "Gideon" instead of Gedeon, "Peter" for Peter 1, and "Catherine" for Catherine II, as the transliteration in instances such as these might cause confusion and can be unsightly.

For place names, I have transliterated the historic Russian designations, and have underscored them: for example, Pavlovskaia gavan for today's Kodiak town, Novo Arkhangel'sk for today's Sitka. When the historic Russian and modern American designations are very similar -- for example Unalashka and Unalaska, Atkha and Atka, Kad'iak and Kodiak -- 1 have opted for the modern as it allows fluency while yet conveying the historic sense. But I have broken these rules at the Pribylof Islands: they have been spelled "the Pribylovs" to accord with the transliteration of other Russian surnames, because the " $f$ " appeared incongruous among so many resonant "v"'s.

An unusual problem was posed by/imperial capital. Its name, Санктпетербургъ, ، was coined as a euphonic composite evidently from the Latin sanctus and the Germanic Peterburg; therefore, I have desisted from using the normal English term "St. Petersburg", that would be a translation of the Russian CB. 
Петрограпъ; and that imputes a meaning of sanctity not necessarily found in the actual name. A sense of splendơ might be conveyed by the euphonic composite, but not necessarily saintliness. Care should be given to desist from imputing a meaning of holiness where that meaning does not necessarily exist in the original sources, should it not? -- particularly in a study that involves theology. I shall write the my

normal English term into bibliography, while writing "Petersburg" in my text and notes. An alternative would be "S.-Peterburg", the transliteration of the thencontemporary abbreviation С.-Петербургъ. This is not an idiosyncrasy on my part: in 18 th century primary sources for this study, Петербургъ and С.-Петербургъ were written, not Санктпетербургъ. ${ }^{48} \mathrm{I}$ am conforming my terminology to these primary sources.

For Greek patristic names, I have opted for the normal English usage, as written in the Oxford Dictionary of the Christian Church, the Encyclopedia Britannica and the post-1920 Bodleian Library catalogues; because it approximates the immediacy of the Greek. For example, "Cyril of Jerusalem" is the translation from the original, with the name "Cyril" equivalent to the Greek; if the transliteration "Kyrillos" or its Latin equivalent, "Cyrillus", were inserted instead, the name might appear too remote: "Cyrillus Hierosolymitanus" might as well be a palaeontological specimen. Whenever the English maintains the Latin, so shall I: I shall not transliterate the Greek name directly into English; because, while transliterations such as "Athanasios" would be recognizable, would "Klementios" and "Sokrates" be clear? Furthermore, it seems to me that the direct transliteration passes by the original Greek and Latin affinities, or Graeco-Roman as I shall refer to them. The direct transliteration ( -ios: instead of -ius, for instance) can serve to indicate that a

\footnotetext{
${ }^{48}$ See, e.g., Valaam (1894a:45), and Valaam, ed. (1894:131, 141); but translated as
} "St. Petersburg" in Valaam (1978:28), and Valaam, ed. (1978:80, 87). 
divergence has occurred of the medieval Latin systems from the original Greek sources; and this is a vital indication. However, it effects a separation also from the earlier Latin churches. The major theological divergence, as I understand it, is between patristic Christianity, that includes the early Latin churches, on the one hand, and on the other hand, the medieval systems written in the Latin language. Precision about this divergence is vital for this study (and, indeed, for any study of Christian missions), as I shall indicate in Chapter 2. Thus shall I incorporate Latin for the Greek names in my referencing in the Roman script, to highlight an original affinity; while at the same time, I employ the English versions of these names in my text to convey the immediacy of the original Greek. The result may seem incongruous, as the reader turns from text to references. But the incongruity is purposeful.

Having expressed the affirmative aspect of this purpose -- to convey the immediacy and affinity -- I should finish my Introduction by underscoring the other aspect. The discrepancy in the mode of referencing, deliberately included, can signify that the disjunction exists: patristic theology does not continue directly into the medieval Western experience, as I shall indicate in Chapter 2, where two contrasting outlooks on pre-Christian Alaskan cultures will be described: the one is patristic, and it is optimistic without being naive or sentimental; the other is pessimistic, involving an attitude which remained minor during the first centuries of patristic writing, but then came to predominance in the Middle Ages in specific locations. The divergence is important to this study; and my manner of referencing, by translitering the Greek names into a form that renders them obscure, may serve as a reminder of the divergence, the ramifications of which will be expressed in the Epilogue to my ultimate chapter and in my final Conclusions. 


\section{CHAPTER 1}

\section{INITIAL CONTACTS, FIRST BAPTISMS}

The purpose of the first chapter is to indicate that the transition was indigenous and corporate: it involved indigenous spiritual and social processes; and it involved the whole bodies of peoples' societies, or kinship-based polities. The opening sections of this chapter will concentrate on the Aleutian Islands, the concluding sections on the Kodiak area. In the latter location, the historical circumstances differed about the intial contacts and first baptisms; yet the characteristics of the transition were very much the same: indigenous and corporate. ${ }^{1}$

\section{The Aleutian Islands}

When the first parish priest assigned to the eastern Aleutian Islands arrived in 1824, the Aleut laity of his parish were already conducting Orthodox services that did not require clergy. Throughout his ministry from 1824 to 1834 , whenever Fr. Ivan Veniaminov made pastoral visits to the villages that comprised this parish, he conducted those sacraments that require an ordained minister: chrismation, confession, and communion. This is evident in his journals where he recorded the sacraments he

\footnotetext{
' Sections of this chapter are to be published, in expanded forms, as follows: Mousalimas (n.d.a; n.d.c; 1991). Research for this chapter resulted in more material than the information included in this study, and some of this material has already been developed into articles, accepted for publication in scholarly journals (id. n.d.c; $1990 \mathrm{e})$. The research has also resulted in a presentation, by invitation, at the centennial of the Iakut Museum, in the city of lakutsk, 2 July 1991.
} 
had ministered. ${ }^{2}$ To marry, he "sacramentally blessed" the couple (a phrase from his journals): in other words, he performed the marriage ceremony for a couple who had already been bonded through local customs. Rarely did he baptize: he would chrismate those who had been newly baptized by others. Very rarely did he bury: he would sometimes lead a memorial service. Only at the harbour village on Unalaska Island where he himself remained most of the year, did he conduct baptisms and funerals regularly. Elsewhere the village laity were ministering these sacraments themselves, throughout the vast parish.

The parish was vast indeed. Known as the Unalaska parish, it extended from Unalaska Island eastward along the Aleutian archipelago to Unga Island and to the tip of the Alaska Peninsula, westward to Uthmak Island, and northward across the Bering Sea to encompass the Pribilov Islands. Veniaminov made pastoral visits to various locations through this parish during the summer and spring months of each year of this decade. During autumns and winters, he remained mostly in Unalaska's harbour village (near today's Dutch Harbor).

The same type of ministry is evident in the journals of the priest of the neighbouring Atka parish, Fr. Iakov Netsvetov, who arrived in 1828, soon after Veniaminov, and ministered for sixteen years. ${ }^{3}$ The Atka parish encompassed the central and western Aleutians and extended farther westward to the Kurile Islands; so that this parish together with the Unalaska parish encompassed the Aleutian archipelago and locations beyond.

\footnotetext{
${ }^{2}$ Veniaminov (n.d.).

${ }^{3}$ Netsuetov (1980).
} 
How had these parishes come into being? Their formation was a development by the laity, beginning three generations prior to the arrival of the first parish priest. The process can be explained with reference to:

(1) a chronology of the clergy prior to Veniaminov;

(2) social dynamics that brought forth Russian Orthodox leadership: (2.1) intermarriage, and earlier (2.2) alliances;

(3) an indigenous social process in the upbringing of baptized men who succeeded their elder kinsmen as leaders known as toions;

(4) evidence for the merging of faith and polity.

(1) Chronology of clergy prior to Veniaminov. No clergyman had been assigned as a missionary to the Aleutian lslands before Fr. Ivan Veniaminov arrived as the parish priest in 1824, except one missionary who had served for approximately a year, from summer 1795 to summer 1796: the hieromonk (monastic-priest) Makarii whose ministry was located mainly in the vicinity of the harbour settlement on Unalaska Island. ${ }^{4}$

Other clergy in transit had made brief landfalls at Unalaska Island, the port-of-call for east-west voyages between Okhotsk/Kamchatka and Kodiak/Sitka, and for north-south voyages between the north Pacific and the Bering Sea. Their combined total of time amounted to less than a year. A chronology is provided below:

${ }^{4}$ For Makarii see section 4, below. He was without an antimins; and therefore, although ordagined, would have been unable to celebrate the Liturgy. Not every monastic is ordained: hence the qualification in his title, hieromonk, "monastic-priest". The monastic Herman, also a member of this mission, who will comprise the subject of Chapter 6, remained unordained. 
(a) Briefly in 1790: Fr. Vasilii Sivtsov, chaplain to the Slava Rossii,

Billings/Sarychev expedition, performed baptisms and marriages. ${ }^{s}$

(b) Two days in September 1794: missionaries in transit from Okhotsk to

Kodiak Island stopped at Unalaska. They also harboured through inclement

weather at a remote bay on the same island. They performed baptisms. ${ }^{6}$

${ }^{5}$ Sarychev (1802:26; 1807:13). Research in Russian archives would consult the following document as described by Golder (1917:2): "Archive of the Holy Ruling Synod ... 1768, May 12 [the opening date of this catalogue]. No. 297. The priest Vasili [sic] Sivtsov reports, June 4, 1792, that when he was in America with Billings many natives desired to be baptized and married by the church; list. $20 \mathrm{ff}$."

I should note that the surname "Sivtsev" occurs among the lakut. One of the most significant people I met in lakutsk in July 1991, a tradition bearer with knowledge of the history of Orthodoxy in Iakutia, had this surname. Also, the following spring, April 1992, while hosting at my home two members of the faculty from the University of Iakutia, and a young businessman, Iakuts all, I mentioned the surname of the first priest to the Aleutians, and my visitors remarked themselves that his was a Iakut surname.

"Archimandrite Ioasaph [head of the mission] to"Vladika", 19 May 1795, HRS/RR/LCM 643:47. Monastic Herman to hegumen Nazarii of Valaam Monastery,19 May 1795, HRS/RR/LCM 643:54; for the latter, also see trans. in Oleksa, ed. (1987:40). This is the first note in which HRS/RR/LCM occurs. As explained in my list of abbreviations, HRS/RR/LCM indicates the transcripts which are catalogued as "Holy Ruling Synod, Russian Reproductions" in the Library of Congress Manuscript Division [LCM]. The catalogue and page numbers follow the abbreviation.

The name "Herman" is a softening of Германъ, a name deriving from $\Gamma \varepsilon \rho \mu \alpha$ vós. Some dialects of Russian normally soften the pronunication of " $\mathrm{g}$ " to " $\mathrm{h}$ ", Гавриил for instance being pronounced as "Havriil" while yet spelled with an initial $\Gamma$. This softening occurs among the Carpatho-Russians, for example. It may be possible that the softening was assimilated in Alaska. In any case, it occurs there in English usage today; and my spelling of this name will conform to that usage.

The term hegumen is transliterated from игумен, a word deriving from

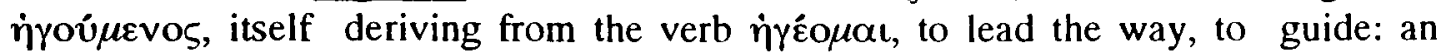
hegumen is the leader of monastics, someone who leads the way, one who guides. I have chosen to transliterate the Russian but with the initial vowel adapted to the conform to aspirated Greek, so that the relationship between the words can be readily

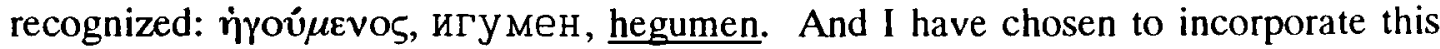
adapted Russian transliteration into my text for congruity with the men's Slavicized Christian names: hegumen being congruous with Damascene, as hegoumenos would be with Damaskenos, and (perhaps) hegoumenus with Damascenus. 
(c) A week in July 1807: hieromonk Gideon in transit from Kodiak to Okhotsk performed baptisms, chrismations, and marriages at Unalaska.'

(d) Briefly during a period in June 1820 , at the end of August 1820 , and mid-June 1821: Fr. Mikhail Ivanov chaplain to the Vasil'ev/Shishmarev circumnavigational expedition, on the Blagonamerennii, might have landed while that vessel was anchored in the Unalaska harbour. ${ }^{8}$

In August 1824, Veniaminov arrived as the parish priest and recorded nearly the same list of clergy in the region before him, but without the chronological details.'

In summary, prior to Veniaminov's arrival a single missionary had been assigned who had served for approximately a year. Otherwise, chaplains and missionaries in transit had made landfalls at Unalaska Island, for a combined total of less than a year. Thus the combined time of all clergymen was less than two years prior to Veniaminov's arrival; and their presence was located mainly on a single island, Unalaska, and more specifically at the harbour settlement.

Yet when Veniaminov arrived, sacraments were already being performed by laity on the islands throughout the region; and he was assigned as the parish priest who ministered within an existing parish -- a parish comprised of Aleut villages, or kinship-based polities.

The history in the neighbơring Atka parish is even more impressive in this respect. Encompassing the central and western Aleutian Islands, this parish had known

${ }^{7}$ Gideon (1989:131-143). Also see Pierce (1990:161).

${ }^{8}$ lvashintsov (1980:141).

${ }^{9}$ Veniaminov (1840b:160-161; 1984:238). He overlooked only point (b) in the chronology: the missionaries in transit to Kodiak. 
its first baptism by 1747. Four generations later in 1828 lakov Netsvetov was assigned as the parish priest. Yet never had a clergyman been in these regions prior to him; and he had roots here himself, as his mother, Maria, was an Atkan Aleut.

(2) Social Dynamics that brought forth Russian Orthodox Leadership. How had such

Orthodox leadership developed prior to the arrival of parish priests? (2.1) Intermarriage was one social dynamic that brought it forth. An example is provided by the parents of Fr. lakov Netsvetov. His mother Maria Alekseeva from Atka married his father Egor Vasil'evich from Tobolsk, a man of particular piety. ${ }^{10} \mathrm{He}$ had arrived in 1794 within the second generation following the first baptisms in this region that later came to comprise the Atka parish. The couple was married according to local customs; and their first child Iakov was born in 1804 . In July 1807 , they had their marriage blessed sacramentally by hieromonk Gideon; the only priest in this region since 1796 , he had landed at Unalaska for a week while journeying from Kodiak to Okhotsk. It is significant that the couple sought him. They received an anointing with blessed oil from him, as well. At that date, Egor was 34 years old and Maria was in her 20s, according to Gideon's records." They raised a family of six children on St. George, Pribilov Islands, a location that eventually became part of the Unalaska parish. All their children distinguished themselves: one son as a master ship-

\footnotetext{
${ }^{10}$ Appendix 3, Inscription on the Gravestone of Egor Vasil'evich Netsvetov, in Netsvetov (1980:271).

"Gideon (1989:137-138, 141). Gideon administered chrismation instead of Holy Communion, because he was without an antimins: see sec. 2.1 above. For Maria's age, cf. ibid. where she is listed as twenty, with ibid., p. 132, where she is listed as twenty-five. Notice in the latter that Maria is recorded among the "children born to Russian promyshelennye". Was she a Russian-Aleut herself? An intermarriage in her parents' generation would be very early indeed.
} 
wright; another as a navigator; one daughter as the wife of a company manager at Sitka; another as the wife of a Russian-Aleut educated at Petersburg; and the eldest son Iakov as a graduate of the lrkutsk seminary, then as the first priest of the Atka parish (1828-1844). Later, Iakov became the first clergy missionary to the Yukon and Kuskokwim River regions (1844-1863).

The leadership this marriage brought forth was bilingual. Netsvetov translated into Atkan Aleut and cooperated with Veniaminov in creating an alphabet based on the Cyrillic for the Aleut languages. Netsvetov instructed the next generation of parish priests for both the Atka and Unalaska parishes: Fr. Lavrentii Salamatov and Fr. Innokentii Shaiashnikov. These men who also derived from intermarriages were fluently bilingual: they translated scriptures and authored original work in Atkan and Unalaskan Aleut respectively.

A fact has been indicated that deserves attention. From the beginning the priests had kinship ties within the parishes. Netsvetov, Salamatov, and Shaiashnikov were raised and were kindred on islands where they served. A foreigner intervened in the Unalaska parish between Shaiashnikov and Veniaminov: Fr. Golovin, who may have been a Kamchadal. As for Veniaminov who had come from Irkutsk, he became competently bilingual and he developed kinship ties through the marriage of a brother to an Aleut woman and the marriage of a daughter to a Russian-Aleut man. The combination of dual kinship and dual language (Russian-Aleut) must have been instrumental to the communication and indigenization of this faith, instrumental to its implanting from Asia and engrafting in the Aleutians. ${ }^{12}$

${ }^{12}$ Veniaminov's brother Stepan had accompanied him and later became a missionary priest to Chukchs; Veniaminov's son-in-law Petelin became the priest of Nushagak and subsquently of Kodiak, then a missionary priest in northern Asia 
The combination of dual kinship and language should be emphasized to avoid any misinterpretation of this dynamic of intermarriage. While intermarriages in other historic and modern contexts can result in monolingualism and monoculturalism, the dynamic here resulted in multilingualism, and thus a blending of cultures or rather an ingrafting of Russian elements into Aleut culture(s). ${ }^{13}$

(2.2) While intermarriage was thus a vital social dynamic for the development of Orthodox leadership, this dynamic occurred rather later. An earlier social dynamic began with the intial contacts, as it occurred within alliances formed between hunters across the Aleutian Islands. ${ }^{14}$

In 1762, Shashuk a toion of Umnak entered into alliance with Stepan Glotov a hunter who had come from northeastern Asia and who remained in the Umnak region from 1758 to 1762 . Shashuk entrusted a nephew to him, and the ally baptized the youth. This was the first baptism, or among the first, in Unalaska region. Names were given and shared: the godson received the baptismal name Ivan and he assumed his godfather's names as his own patronymic and surname; thus the youth Mushkal

(Pierce 1990:527). See Appendix, Aleut and Creole Churchmen in Alaska: Nineteenth and Early Twentieth Centuries, in Oleksa, ed. (1987:377-386).

${ }^{13}$ This emphasis can be heightened with reference to occurences in Iakutia (eastern Siberia) where initial contacts with Russian cossacks took place in the early 1600 s. Yet as late at the 1890 s, according to my own research, the Russian settlers in lakutia were being assimilated to the lakut language, so that a primary concern of the Orthodox Brotherhood in thit town of lakutsk at that time was to teach Russian and to reinforce the use of this language among the Russian population (Iakutsk Church Brotherhood 1897:3). The town of Iakutsk itself was a eastern centre in the Russian empire, probably next in importance to the city of lrkutsk, located to lakutsk's southwest.

${ }^{14}$ For an indicative analysis of types of Aleut-Russian contacts, see Sardy (1985/86:43-58). For a summary historical analysis, see Black (1981b:117-121). And for a summary description of social interactions, see Black (1989:46-57). 
(Mushkalyax) became the Aleut Ivan Stepanovich Glotov. ${ }^{15}$ He remained alongside his godfather for the next three years. Together they departed Umnak aboard the Sv. $\underline{\text { Iulian }}$ and traveled to Kamchatka where they stayed from August until October 1762. They then journeyed aboard the Sv. Andreian i Natalia to Kodiak Island where they spent the winter of $1762-63$, before returning along the eastern Aleutian Islands to Umnak, Ivan's home island, in spring of 1764.

Eventually succeeding his uncle Shashuk as the primary toion of Umnak, the Aleut Ivan Stepanovich Glotov exercised mature political and spiritual leadership into the next century, including the conducting of Orthodox services in a chapel he himself had had constructed, as reported in $1808 .^{16}$

Another example of this social dynamic is evident concurrently at the other side of the island chain, on the western Aleutians. On Attu in 1761 a toion named Makuzhan had his young kinsman baptized by men who had come there from northeast Asia for the hunt. The toion's young kinsman received the baptismal name Leontii and also assumed his godfather's names as his own patronymic and surname, becoming the Aleut Leontii Vasil'evich Popov. ${ }^{17}$

Entrusted thus to his godfather, he journeyed alongside him, departing that

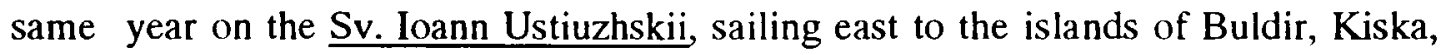
Segula, Awadax, Little Stikin, and Amchitka; then turning westward to hunt on Shemya (a Near Island) in summer 1763, before continuing to Kamchatka. In September of the following year, the merchant Popov funded the same vessel for a

\footnotetext{
${ }^{15}$ See Pierce (1990:169).

${ }^{16}$ Gideon (1989:122).

${ }^{17}$ Stepan Cherepanov, 3 August 1762, in Andreev, ed. (1948:117-118).
} 
voyage that spent nearly a year on Bering Island before returning to the Near Islands in summer 1765 . This would be the voyage that brought Leontii home. ${ }^{18}$ By then, he would have had four years in his godfather's company, hunting, exploring, and learning the ways of these men who had come from northeastern Asia.

(3) An indigenous social process. A process occurred in these parallel, concurrent examples that corresponded to an indigenous social process guiding the successions of toions. Three key elements were involved. Firstly, succession occurred among "customary lineage chiefs" on the eastern Aleutians, and within a "hereditary kin group" on the central and western Aleutians. ${ }^{19}$ Hence among the examples, on the eastern Islands the Aleut Ivan Stepanovich Glotov succeeded his own uncle Shashuk as toion of Umnak. A further example derives before 1786 when the Aleut Sergei Dmitrievich Pan'kov succeeded his own brother as toion: ${ }^{20}$ the successor's names clearly indicate baptism, for Sergei is a baptismal name, and also indicate an alliance with the Russian Dmitrii Pan'kov who had made a number of voyages into this region and had evidently entered into a number of lasting alliances. ${ }^{21}$

\footnotetext{
63).

${ }^{18}$ For these voyages, see Black $(1984: 67,83)$; also see Makarova (1975:60-61,
}

${ }^{19}$ Veniaminov (1840b:171; 1984:244); Netsvetov (1840:12-13; 1984b:370). For the toions' patriarchal, or conciliar, manner of leadership, see Veniaminov (1840b:165; 1984:240-241) and Netsvetov (1840:12-13; 1984b:370). Aleutian Island societies comprised several regional groups. See map in Unangam Ungiikangin (1990:xviii). Compare map in Black (1980:83); reprinted in id. (1984:x). For analyses see: Black (1984:41-71; 1980:82-84); Bergsland (1990:2-5).

\footnotetext{
${ }^{20}$ Black (1984:94, 187-188).

${ }^{21} \underline{\text { Ibid. }}$ (1984:83-84); id. (1977a:99).
} 
The second component in the social process was the fostering of children. Parents permitted their children to be raised by kinsmen or even by non-consanguine affines: $:^{22}$ the latter would be friends and allies. Hence the young men were entrusted to their godfathers by elder kinsmen. The Aleut lvan Stepanovich Glotov's godfather and the Aleut Leontii Vasil'evich Popov's godfather clearly honoured the trust by returning the youngsters to their elders after years of traveling, exploring, and hunting.

Succession depended also on skill and on valour. A successor was expected to have distinguished himself by mastering techniques of seafaring and of hunting. He was expected also to have completed expeditions to foreign lands and thus to have gained experience of wider geography and of other peoples. ${ }^{23}$ This was the third component. Hence the successor journeyed alongside his godfather for a series of years in each example: exploring, hunting, and learning the ways of these men who had come from northeast Asia.

In each example the godson went to Kamchatka. What would he have seen? By the early 1740s, the Kamchadals were Eastern Orthodox; churches (with priests) or chapels (without priests) existed in the major settlements where Kamchadal men exercised leadership. ${ }^{24}$ The first clergy had been assigned in 1705 , from Tobolsk. ${ }^{25}$

${ }^{22}$ Netsvetov (1840:10-11; 1984b: 369); Veniaminov (1840b:72; 1984:191).

${ }^{23}$ See Veniaminov (1840b:58, 72, 99-100, 143; 1984:184, 191, 206, 229).

${ }^{24}$ Krasheninnikov (1764:180, 205, 263-267). Compare Krasheninnikov with Gideon (1989:124-126): the former's contemporary obsvervation in the early 1840s, deriving from successive years there, reports four churches/chapels at that time; while the latter's retrospective history, deriving from a brief tour, reports two churches/chapels from the 1740 s and others from the $1760 \mathrm{~s}$ to $1790 \mathrm{~s}$. With regard to the Kamchadals' religion, also see King (1784:303-304, 367, 368). But in Beaglehole (1967) King's journals have been presented piecemeal, so that the 
A priest was described at Petropavlovsk in 1779, an embarkation site for the Aleutians since 1741: the "benevolent and hospitable pastor" was "native on his mother's side". ${ }^{26}$

The Kamchadals themselves comprised up to 50 per cent of the men who came to the Aleutians for the sea hunts during the initial contact period, between 1745 and the 1760 s. Later during the 1770 s when the purpose of enterprises and the nature of contacts changed, the percentage of Kamchadals involved decreased. ${ }^{27}$

(4) The merging of faith and polity. This merging is evident through: (4.1) the successful exercise of leadership by Aleut Orthodox on behalf of their people in the $1780 \mathrm{~s}$ and $1790 \mathrm{~s} ;(4.2)$ a continuity in this leadership from the $1760 \mathrm{~s}$; and (4.3) specific examples of this leadership from the 1760 s into the time of Veniaminov's ministry.

(4.1) The merging is evident in the exercise of leadership by Aleut Orthodox in the 1780 s and the 1790 s in protests against an influx of enterprises and imperial interests into the Unalaska region during the later 1700 s. The following is a chronological summary of these protests. Before June 1787, a toion's kinsman named Izosim Polutov dispatched a written protest from the central Aleutian lslands to the

descriptions of religion have been omitted by the editor. Readers must refer to the original publication. Also see my note 73 to this chapter, below.

${ }^{25}$ Glazik (1954:92); Smirnoff (1903:12).

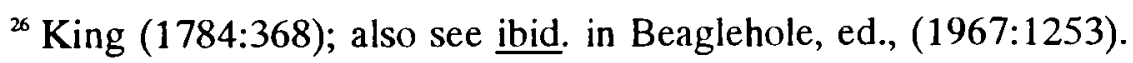

${ }^{27}$ Black (1984:77; 1980:92). For the composition of Russian hunters during later decades, see my note 174 to this chapter, below. 
Okhotsk district commander. ${ }^{28}$ At the same time, Tukulan Aiugnin dispatched a report from the "third Fox Island" (an eastern Island: Akutan, possibly Akun, or even Unalaska) also to the Okhotsk office. ${ }^{29}$ Before 1791, a toion Algamalinag named in baptism Mikhail and bilingual Saguakh named Ivan Chuloshnikov spoke out in person to the naval captain G. Sarychev who had anchored at Unalaska, whose expedition for the government had been charged in part to collect such testimony..$^{30} \ln 1796$, toion Ivan Stepanovich Glotov of Umnak led twenty-two other toions of his region in a protest directed to the imperial capital Petersburg. ${ }^{31}$ In 1797 , a toion Ielisei Popachev traveled with the Aleuts Nikolai Lukanin and Nikifor Svin'in and with the missionary hieromonk Makarii toward Petersburg. ${ }^{32}$

The key to the chronology exists in the men's names. Only one lacked a baptismal name. Aleut Orthodox leaders were in place, stood firmly, and acted on behalf of their people through the influx.

\footnotetext{
${ }^{28}$ Kozlov-Ugrenin, 15 June 1787, Okhotsk, in Tikhmenev, ed. (1863:20; 1979:16). Also see Liapunova (1987:116).

${ }^{29}$ Kozlov-Ugrenin in Tikhmenev, ed. (1863:20; 1979:16); Liapunova (1987:116).

${ }^{30}$ Testimony from the Aleuts Ivan Chuloshnikov and Mikhail Algamalinag from Unalaska Island, 7 June 1789, in Appendix 6 ["LCM, Yudin collection, Box 2, folder 23; trans. DRAH, vol. 2, pp. 237-240"] in Shelikhov (1981:128). As explained in my Introduction, the sources for the appendices in the Limestone Press Alaska History Series [LPHA] will be quoted from LPHA in my notes within brackets and within quotation marks. The first instance of such a quotation has occurred in this note.

${ }^{31}$ Liapunova (1987:124).

${ }^{32}$ Hieromonk Makarii, Report to Holy Synod, 5 Oct. 1797, received 20 Dec. 1797 (no. 3056), HRS/RR/LCM 643:13-23. Also see ibid., trans. Lydia T. Black in Oleksa, ed. (1987:288-290).
} 
An extended example is found in the toion Sergei Dmitrievich Pan'kov. By 1791, he had visited Kamchatka and had made at least two journeys to Okhotsk, ${ }^{33}$ whence in response to protests received, offical communications had been dispatched that clearly articulated the Aleutian Island peoples' civil rights as Russian subjects. ${ }^{34}$ In that year of 1791 , this toion had traveled to Unimak Island (in the Unalaska region) where he consulted with kinsmen. Then he journeyed to Unalaska to meet with naval captain Sarychev whose governmental expedition was charged, in part, to investigate. Pan'kov came with twenty-five Aleut men: fourteen with him in a baidara (an umiak), another eleven alongside in single-hatch baidarkas (kayaks). ${ }^{35}$ At the meeting, other toions were present as well, among whom Pan'kov presided. Addressing Sarychev in Russian, this primary toion wore a headcovering and a over-garment of light red cloth and of velvet with gold or golden trim, presented to him by a government office in northeastern Asia. Outstanding in colour, unusual in texture, they distinguished him from the other toions in the council and from Sarychev: for the clothing was unlike a European uniform. Dressed as an Aleut of high status, the primary toion stood and spoke.

Through leadership such as this, the Aleuts maintained remarkable autonomy on the Aleutian Islands and achieved an unusual degree of independence. As observed by Veniaminov in the 1830 s, they were more independent than the Kamchadals and were freer than some Asians: "in their own locale, the Aleuty are more independent

\footnotetext{
${ }^{33}$ Black (1984:94).
}

${ }^{34}$ Kozlov-Ugrenin in Tikhmenev, ed. (1863:19-20; 1979:15- 16); Liapunova (1987:116).

${ }^{35}$ Black (1984:95). 
and free than the people of Kamchatka and even baptized Asians." ${ }^{136}$ Autonomy was reflected in the moral qualities described for them consistently by Veniaminov; ${ }^{37}$ it was reflected as well in their intellectual pursuits in their own language, evident in these journals and also in the work of subsquent generations on the Islands. With autonomy and with the language, the culture prevailed. ${ }^{38}$ The leadership was successful.

(4.2) These leaders were empowered legally and morally: legally through information received from northeast Asia where an articulated prerequisite for trade on the islands was humane conduct; and morally through the ethics intrinsic in Orthodox Christianity. Especially those leaders who had succeeded their kinsmen as toions through native social processes of upbringing and succession, ${ }^{39}$ would have known themselves to be empowered in these ways, by having traveled to Kamchatka

${ }^{36}$ Veniaminov (1840a:30; 1972:47). Veniamionv's primary knowledge was of the Unalaska district (eastern Aleutian Islands). For autonomy in the Atka district (central and western Aleutians), see Netsvetov (1980:12); for specifically Atka Island and Amchitka Island (central Aleutians) see ibid., pp. 18-19, 30; and for specifically the Near Islands (western Aleutians), with adaptation to a commercial economy, see Appendix 1, "Notes on the Western Aleutians and the Commander Islands by Navigator Vasil'ev (1811-1812)", in Black (1984:151-170 passim, esp. pp. 160-161).

${ }^{37}$ Veniaminov (1840a:42-48; 1840b:19-66, 319-321, 326-327; 1972:50-52; 1984:166-188, 319-320, 323). But not for company dependents at Sitka: id. (1840a:30; 1972:47).

${ }^{38}$ See Unangam Ungiikangin (1990) photographs as well various texts. Also see the artifact collections from the Aleutians e.g.: under Etholen and Wrangell 1820s-1830s; by Voznesenskii, 1840s; by Pinart, 1870-1872. The Voznesenskii collection is described in part in Blomkvist (1972); also see Alekseev (1987:105).

${ }^{39}$ See sec. 3, above. 
and moreover having had Christianity imparted to them through alliances with men like themselves. They exercised this power.

Their leadership on behalf of polity was a continuation of leadership in the previous generation. Earlier in the mid-1760s, toions in the Unalaska region had created a militant alliance to counter the escalating influx. The alliance was formed by polities on major islands in the Unalaska region (later the parish): it was led by the polities of the islands of Tigalda and Akun and included Unimak, Unalaska, and Umnak. ${ }^{40}$ The successors continued, employing new tactics now, including reports directly to Petersburg and petitions for the governmental enforcement of legality.

When one reads of the Russian Orthodox Church defending native people during this time of trouble, one should therefore recognize the Aleut Orthodox toions. They were already leading when they were joined by the missionary hieromonk Makarii. While thus widened, the perception would also become clearer: for Makarii was reprimanded by authorities in the imperial city for his unauthorized activity.

Who was Makarii? A hieromonk (monastic-priest) from the Konevskii Monastery in Karelia, he was a member of the spiritual mission to Kodiak Island, that initially consisted of ten monastics. Arriving at Kodiak in September 1794, he was dispatched with an interpreter to the Unalaska region in summer 1795 , where he traveled to a very few islands, including Unga and Akun, on the route to the harbour settlement at Unalaska Island. Remaining in the latter vicinity, he joined Aleut toions against the escalating commercial enterprises of the Shelikhov-Golikov Company; and the

\footnotetext{
${ }^{40}$ Black (1977a:97); Pierce (1990:391).
} 
following June, with six Aleut men he journeyed towards Petersburg, carrying a petition of protest from regional toions.

The dimensions of the task become clear when one considers the purpose and circumstances of the journey: they were traveling to protest against a commercial power which had representatives in the towns of Okhotsk and Irkutsk and which was gaining influence over the northeast Asian coast, the North Pacific archipelagos, and the southern Alaskan coast. The men had to arrange transportation through those regions and had to travel through those towns. Makarii himself was a monastic without title, and would have had few if any sources of financial support. Furthermore he lacked authority to travel: he had departed without authorization. He journeyed resourcefully and (one may well imagine) cleverly. Of the original group of seven men, three survived to arrive at Petersburg in spring 1798: hieromonk Makarii, Nikolai Lukanin and Nikifor Svin'in were granted an audience with the Emperor. Makarii was reprimanded for unauthorized activity. Intercessions by the Aleut men spared him from punishment. ${ }^{41}$ On their return journey eastward, all three died: Lukanin and Svin'in on the overland route across Siberia; Makarii on the sea crossing, off the Aleutians, towards Kodiak. This was the only Russian missionary to the Aleutians: the conscientious and resourceful Makarii who gave his life with these Aleut leaders.

(4.3) Orthodoxy thus merged with the people's own leadership, with their own struggle, with their destiny. This merging of faith and polity is reflected particularly in a person who recurs in Veniaminov's journals: Ivan Pan'kov the toion of the

\footnotetext{
${ }^{41}$ Pierce (1990:325).
} 
islands of Tigalda and Akun. The same islands had provided the leadership for the Aleut wars in Pan'kov's grandparents' generation during the mid-1760s; and in his parents' generation in 1791 , the toion Sergei Dmitreivich who presided at the council at Unalaska had had the same surname. ${ }^{42}$ Yet, prior to Veniaminov's arrival, Ivan Pan'kov was providing instruction in the faith within his polity himself; ${ }^{43}$ and when Veniaminov arrived, Ivan Pan'kov donated money for the reception and settlement of the priest and family: indeed he donated more than the average sum..$^{44}$ Elder in age to the priest, Pan'kov accompanied him on pastoral visits to Tigalda and Akun where the priest was warmly received. ${ }^{45}$ This toion co-translated the catechism and the Gospel; and after Veniaminov's transfer, Pan'kov had chapels constructed in 1842 and 1843 on both those islands for his own people. ${ }^{46}$

An earlier example of the merging of faith and polity is provided by Ivan Stepanovich Glotov the Aleut toion of Umnak. It was he who had led twenty-two men of the Unalaska region in a protest written directly to the imperial capital in 1796. Yet when hieromonk Gideon landed briefly at Unalaska in 1807 , the toion came to receive an anointing from him. ${ }^{47}$ This toion constructed a chapel for his polity (Recheshnoe in the journals; near today's Nikolski). Baptized in 1762 through his

${ }^{42}$ For possible kinship between these toions, see Black (1978:32-33).

${ }^{43}$ Veniaminov (n.d.), Comment, 24 April 1828.

${ }^{44}$ Black (1977a:97).

${ }^{45}$ Veniaminov (n.d.), 13 April and 24 April 1828, 16 September 1829. In 1824, Pan'kov was forty-six years old (Black 1977a:96), Veniaminov was twenty-seven years old, born in 1797 .

${ }^{46}$ Black (1978:29-32; 1977a:98); Pierce (1990:392). See sec. 4 below.

${ }^{47}$ Gideon (1989:142). 
uncle's alliance, journeying to northeast Asia, having become literate and bilingual, he also became proficient in Orthodox rubrics: in his mature years the same toion was conducting daily services in that chapel himself. ${ }^{48}$ Indeed, "he may have substantially assisted in spreading Christianity among the Aleuts. ${ }^{149}$

Section summary. How had the Aleutian Island parishes come into being? They were a development by the people beginning three generations prior to the arrival of the first parish priest on the eastern Aleutian Islands, and four generations prior on the central and western Aleutian Islands. When the priests Veniaminov and Netsvetov arrived in 1824 and 1828 respectively, the Aleuts were Orthodox; and these clergymen were assigned as parish priests, who ministered within existing parishes. lndeed Veniaminov described his parishoners as "exemplary Christians". so

${ }^{48}$ Ibid., p. 122.

${ }^{49}$ Veniaminov (1984:233). See ibid. (1840b:151).

${ }^{\text {so }}$ Veniaminov (1984:229); see ibid. (1840b:144). Also see id. (1840a:44; 1972:51). While these statements were retrospective, published originally in 1840, subsequent to Veniaminov's ministry as the parish priest, the following statement is an example of those he wrote during his actual ministry. This one is specifically from his first pastoral visit to the village of "Recheshnoi" on Umnak Island (where Ivan Glotov had been toion: see my text at notes 44-46, above): it is a note to his journal entry dated 4 May 1825 in Veniaminov (n.d.);

It is impossible to remain silent about the zeal, devotion, and affectionate manner of all the local Aleuts. They have only to catch sight of the baidara, and all -- from the small to the great, and even those on crutches -- come to receive us, to greet us, and to receive the blessing with great joy.

Also see hieromonk Gideon who had landed at the habour village at Unalaska Island on 30 June or 1 July 1804 and departed the island on 7 July, according to his own records (Gideon 1989:121-122). Thus ministering from the first to the sixth of July, twenty years prior to Veniaminov's arrival, Gideon (1989:131-143) reported, evidently from his own observations and also from reports he must have heard from others, that: 
The transition on the Aleutian lslands was thus an indigenous movement, involving indigenous social and spiritual processes, such as intermarriages, and earlier the process of alliances in which baptisms occurred and through which Aleut Orthodox leadership was generated.

(5) Insights into these processes within the alliances. Before proceeding to the next major section of this chapter that will concentrate upon the Kodiak area, the study should provide descriptions of the process of diffusion of the religion as this process was taking place on the Aleutian Islands within alliances that had formed among hunters. Descriptions derive from two hunters" camps: (5.1) one on the western Aleutian lslands between 1759 and 1762; (5.2) another on the eastern Aleutian Islands in 1778 .

(5.1) The report from the western lslands, specifically the Near Islands, was written by Stepan Cherepanov, a leader among Russian hunters with the small vessel Sv. Zakharii i Elizaveta. He had earlier spent two winters on Agattu Island (a Near Island); and he would make at least one other voyage, between 1768 and 1773, farther east to the Andreanov Islands (central Aleutians). ${ }^{51}$ Observing propriety, distributing gifts, sharing meals, cooperating, Cherepanov and his men found themselves in a "special position of friendship" with the Near Islanders, and also

The inhabitants of the Unalashka Island, as well as of the entire Aleutian Chain, are strongly devoted to the faith. They know and reverently observe all major Feasts, lovingly, and very willingly listen to the teachings offered, and follow these in real life.

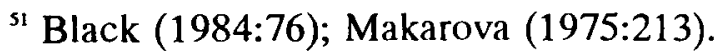


found themselves to be "kinsmen by affinity" with the Andreanov lslanders, according to contemporary accounts. ${ }^{52}$ The reported relationships are substantiated by the tone and content of Cherepanov's own report, as he referred to the Aleuts virtually as his equals. Nowhere does he refer to them as "savages" or "heathens", appellations that are found in abundance in later reports by other men. ${ }^{53}$ Instead, he referred to the Near lslanders as "these foreigners", indeed at one point he stated that they are "like ourselves". .4

Among other information, Cherepanov's report includes an account of the baptism of Leontii Vasil'evich Popov who was one of the primary examples in section 2, above. Cherepanov provides the circumstances about this baptism and describes a healing that took place. ${ }^{\text {ss }}$ An Aleut toion named Makuzhan had brought the youngster, his own kinsman, into the Russian hunters' camp for baptism. (Baptisms were already known on the Near lslands, the first having occurred in the later 1740 s.) $)^{56}$ The youngster had requested to be brought himself because, badly injured

${ }^{52}$ Quoted respectively in Liapunova (1987:110) and in Black (1977a:99). See Liapunova, for the Near Island stay; see Black, for the Andreanov Island stay. For the former, also see the original statement by Cherepanov in Andreev, ed. (1948:117).

${ }^{53}$ E.g. Shelikhov (1981).

${ }^{54}$ Cherepanov in Andreev, ed. (1948:117).

ss In Stepan Cherepanov of Tot'ma, An Account of his stay on the Aleutian Islands (1759/60-1762), 3 August 1762, in Andreev, ed. (1948:117-118). The translation is by Lydia T. Black, provided to me by personal communication at the outset of my research into this topic.

${ }^{56}$ The first known to have been baptized was the youth Temnak (his name) who visited Kamchatka with $M$. Nevodchikov from the latters' voyage to the Near Islands (Liapunova 1987:111), as cited also in my introduction. A subsequent reported baptism was that of a boy taken to Kamchatka from the Near Islands on the 1756-1758 voyage of the Petr $i$ Pavel, and baptized there, who later became a cossack known as lvan Cherepanov (ibid.). The coincidence of Ivan's surname with Stepan 
with a compound fracture (mauled by a sea lion), he was suffering nearly to the point of death, and he believed, according to Cherepanov, that when he was baptized he would be cured. The baptism was performed by the Orthodox hunters, a practice among laity when clergy are at a distance. He recovered. This healing was a "special incident", as Cherepanov explained it, "an evident blessing by God" that made these foreigners "very understanding of the Orthodox Christian faith": ${ }^{57}$

They are very understanding of the Orthodox Christian faith and do not think that there is untruth (in our faith), because there was a special incident which was an evident blessing by God. To whit: the foreigner Leontii Vasil'evich Popov who traveled hither in the year '761, suffered at home cruelly in his arm which was wounded; the bone could be seen, and all despaired that he would survive. He could not even raise from his place of repose unless others lifted him. The father, whose name is Makuzhan came to our ship and said that his son wanted to be baptized to see if he might get better. We responded that he should have hope, as our God is great and merciful and is quick to be compassionate to those who call upon him with faith. Makuzhan answered: If your God is good, my son will recover. The son in that year 1761 was baptized with holy baptism by the company of other vessel that was at the island, that of Vasilii Popov, merchant of Lal'sk. As soon as he was baptized, he showed immediately better and eventually recovered. Then Leontii's father Makuzhan in his joy was saying: your God is very good, that means great.

Very significant in this description is that both the Russians and the Aleuts perceived the miracle that occurred among the hunters. Evidently, these men lived alike within

Cherepanov's surname may be significant, as the latter had spent two winters on the Near Islands before 1759. Was Stepan Ivan's godfather?

${ }^{57}$ In Andreev, ed. (1948:117-118). 
a sacred cosmos that embraced the miraculous; and a further indication is forthcoming in Cherepanov's report when he stated: $:^{58}$

We did not observe among them any special faith, except what is proper to any kind of faith. They live and act in everything very simply.

"No special faith, except what is proper to any kind of faith," he wrote. What might this phrase have meant? Today, it would probably indicate a quasi-agnostic theism; but what did the statement mean there, then, as written by Stepan Cherepanov, a leader among far northern hunters? An answer derives from lakov Netsvetov, the first priest of this greater region (the central and western Aleutians), himself the son of an Aleut and Russian marriage: ${ }^{59}$

while acknowledging the Creator of the universe, they also believed in spirits who ruled the world. ... The supreme being they called the Creator of Heaven, and the Creator of the nether regions or the base of the world. ... The lore on spirits ... was extensive. They believed in birds, fish and other living things; and in the sun, the sky, and other inanimate beings, thinking that spirits dwelt in them.

This was the "faith" that seemed to Cherepanov not particularly "special": this cosmos imbued with the spiritual seemed to him "proper to any kind faith". Indeed was it not universal in his own Eurasia? Moreover, numerous prescriptions and just as many prohibitions applied within Aleut traditions, including: prayers; fasts; seclusions; community and public rites; offerings at sacred places or at sacred times. ${ }^{60}$ All

${ }^{58}$ Ibid., p. 117.

${ }^{59}$ Netsvetov (1984b:365); see $\underline{\text { ibid. }}$ (1840:2).

${ }^{60}$ Ibid. (1840:1-14; 1984b:365-371). Also see Veniaminov (1984:222) for the Unalaska Aleuts: "Every activity or undertaking and almost every step required its own elaborate signs and talismans." 
seemed to be not "special" but "proper" to Cherepanov, as these men lived alike within a sacred cosmos; ${ }^{61}$ and thus together they perceived the miracle at baptism.

The Aleut hunters furthermore had spiritual traditions similar to the Russian hunters, as described by Cherepanov who compared their spiritual preparations for the hunt. ${ }^{62}$ Beginning with a generality about his own men, he wrote that before any endeavour "we Russians invoke the name of the Lord God to aid us and to bless". He was referring to a widespread element in Orthodox cultures, and his generalization is correct. ${ }^{63} \mathrm{He}$ then became specific, referring to the preparations before the sea hunts from these islands. Before setting out in the baidaras, (open skin boats), "we Russians" would observe a moment of silence and would pray, "God come to our aid". Turning to the Aleuts he noted a similar practice: "In the same way these foreign peoples, leaving for the hunt say the prayer: "Lord bless". Moreover, the Aleut hunters would join the Russian hunters in prayer as they set out together in the same baidaras: "like us they say "God come to our aid". Cherepanov's comparison follows: ${ }^{64}$

As we Russians when we set out on any endeavour and invoke the name of the Lord God to aid us and to bless, or when we proceed on any sea hunt in the baidaras

${ }^{61}$ Compare the phrase "sacralized cosmos" in Eliade (1959:17).

${ }^{62}$ In Andreev, ed. (1948:117).

${ }^{63}$ To substantiate my statement, see e.g. the following easily accessible source: Pascal (1976:19-20). But Pascal stresses a dichotomy between laity and clergy unrealistically in my opinion. The contrast exists where the clergy are unrelated to the people and non-dependent upon them. Otherwise, close inter-relationships and a mutual dependence usually exist in my experience.

${ }^{64}$ In Andreev, ed. (1948:117). 
observe a moment of silence by all, calling on God to aid us and expecting his mercies, say "God come to our aid", in the same way these foreign peoples, leaving for the hunt say the prayer: "Lord bless". Also, when traveling in the baidaras, like us they say "God come to our aid".

The Aleuts had corresponding traditions and corresponding perceptions within the sacralized cosmos of the far northern hunters. While this theme will be developed to greater depth in subsequent chapters of my thesis, it should be indicated at this point to indicate a process of communication of the religion as this process was taking place within alliances that had formed among hunters on the Aleutian Islands. As the hunters themselves had thus merged in the camp and in the baidaras for the sea hunt, so their faithful practices had meshed; and in this way, Orthodoxy was communicated from far northern hunters to far northern hunters within personal alliances.

(5.2) This merging of men and their traditions and this communicating of religion is evident in another report, this one from the other side of the Aleutian archipelago, from Unalaska Island (among the eastern Aleutians) in $1778 .^{65}$ In this instance, the observer was John Ledyard, a corporal of marines on James Cook's third voyage. Dispatched by the captain to accompany an "Indian" who had made contact with them, Ledyard became most probably the first of his own kind ever to enter a hunters' camp in the eastern regions of Russia, and certainly the first of Cook's voyage.

He was literally carried by "Indians" a distance through the night (the month was October) to the hunters' camp: transported within a two-man kayak as he himself

\footnotetext{
${ }^{65}$ Ledyard (1963:92-100).
} 
lay inside the thin hull between the two kayakers. He remained inside to feel the kayak strike the beach, then feel it being lifted and being carried. Finally as he was pulled up and out by his arms, he found himself in the hunter's camp, and immediately he was taken, still by the arms, into a iurta aglow with oil lamps within. (A iurta is a semi-subterranean dwelling then-typical of the Aleutians and also of regions of northern Asia.)

Later, having enjoyed the men's hospitality despite the language barrier (he did not speak Russian or any of the local languages), ${ }^{66}$ he was made comfortable so that he might sleep, and from this bed he observed the hunters at evening prayer. The "Indians" (as he referred to them) particularly impressed him among these men, as they prayed together "after the manner of the Greek church":67

I could not but observe with what particular satisfaction the Indians performed their devoirs to God through the medium of their little crucifixes, and with what pleasure they went through the multitude of ceremonies attendant on that sort of worship.

The "multitude of ceremonies" that he observed would have been ritual acts including the making of the sign the cross, bowing, sometimes kneeling to make obeisance by bringing the forehead to the ground, that these men would have repeated, as they were oriented eastwards together "after the manner of the Greek church", while the prayers were being chanted or recited.

Who were these "Indians"? They remained undifferentiated in the corporal's account except in contradistinction to the "Russians", or those men who appeared to

${ }^{66}$ Nor did any of the officers of this voyage speak any of these languages. See Capt. Cook, Capt. Clerke, and Lt. King in Beaglehole (1967:449, 1335, 1445).

${ }^{67}$ Ledyard (1963:95). 
him to be "European, fair"; and thus they remained undifferentiated until the following morning when he collected only a few vocabulary items from only some of the "Indians". He then discovered two languages: one was "Kamchadal", the other "American". ${ }^{68}$ It was Aleut. ${ }^{69}$ The "Indians" became either "Kamchadal lndians" or "American Indians" subsequently in his account, particularly when he presumed to estimate the number of "Indians" in contrast to "Russians", as he observed these men in the larger camp, consisting of thirty iurtas, on this snowy day in October (he would have been counting men who were clothed for this weather): ${ }^{70}$

The number of Russians were about 30, and they had with them about 70 Kamchadales, or Indians from Kamchatka[;] these with some American Indians whom they had entered into friendship with occupied the village, enjoyed every benefit in common with the Russians, and were converts to their Religion.

As the corporal's collection of vocabulary was sparse and cursory -- he collected only a few numerals from some of the men and made no further collections during his brief stay of merely the previous night and part of this day -- it can not be considered inclusive of all "Indians" there. Others may have been there also; for by this time, 1778, the Russian hunters included -- in addition to the Kamchadals -- other northeast Asians as well as Evenks, Iakuts and men from northwestern Russia. ${ }^{71}$ The latter

${ }^{68}$ Ibid., p. 97.

${ }^{69}$ The "American" numerals are Unalaskan Aleut cardinal numbers with the Atkan Aleut "one" and "ten". But Ledyard's transcription is nonsequential: compare sec. 58 in Veniaminov (1944:30).

${ }^{70}$ Ledyard (1963:98).

${ }^{71}$ Black (1984:77). The proportion of Kamchadals has been mentioned in my text, at note 27 to this chapter, above. From the 1740 s into the 1760 s, prior to Ledyard's experience, the Kamchadals had comprised the major proportion among the Russian hunters on the Aleutian Islands. Their relative proportion here decreased from the 1770 s. 
derived from approximately the latitude of Vologda northwards to the White and Pechora Seas, and included the Komi, a people who had been likened in physical appearance to the Kamchadals at the initial contact on the Kamchatka Peninsula. ${ }^{72}$ Any of these men who were Asian or Eurasian in appearance would have been subsumed under Ledyard's categories as the "Indians".

Many of the nations from which these men derived were already, or were well in the process of becoming, Orthodox. The Kamchadals had already been identified as Orthodox by this time. ${ }^{73}$ The Christianization of the Iakuts had begun in the

The term "Kamchadal" in this context should be understood as signifying the original population known in their own language as Itel'men. See, e.g., part 3, chapter 1 in Krasheninnikov (1764:170) where "Kamchadal" clearly designates the original population. Subsequent to the initial contacts, intermarriages occurred, and the term "Kamchadal" came to signify the offspring of these marriages as well, within a social context that was bicultural. The culture at Kamchatka combined Russian and Itel'men language, leadership, and customs, including dances and foods. For the biculturalism: see King (1784:189, 214, 218, 367). Today in academic usage, the term "Kamchadals" sometimes designates the Russian-Itel'mens, an "ethnographic group of Russians", as distinct from the Itel'mens (Arutiunov 1988:34). But in popular usage, the term "Kamchadals" is a geographical designation that includes both these groups and also the descendents of the Russian cossacks who settled on the peninsula in the 17th century (Levin and Potapov 1964:876). The modern academic and the popular usages should be not be confused with the use of the term "Kamchadal" in the 17th century source cited in this note or in the 17th and 18th century sources cited in the notes below.

${ }^{72}$ Lantzeff and Pierce (1973:197), citing Report by Vladimir Atlasov at Moscow, $10 \mathrm{Feb} .1701$, in $\mathrm{Al}^{\prime}$ kor and Drezen, eds. (1935:29-33). Atlasov was himself from Komi-land.

${ }^{73}$ The Kamchadals were described as (Russian) Orthodox by Krasheninnikov (1764:180, 205, 263-267), an educated Russian affiliated with Vitus Bering's expedition who remained on the peninsula for a number of years in 1740s; he also recorded a church with a priest or a chapel without a priest in each of the major villages and towns by that date (see my note 24 to this chapter, above). The Kamchadals were again described as (Russian) Orthodox in 1779, this time by King (1784:303-304, 367, 368 ), an educated Englishman who was a lieutenant with Cook's third voyage. These two unrelated, independent sources agree about the Kamchadals' religion. The first hunters embarked from Kamchatka for the Aleutians in 1745, between the dates of these reports.

It should be noted that Cook's voyage had proceeded from Unalaska to Hawaii for the winter, 1778/79. The following season, the voyage proceeded northwestward 
mid-17th century. ${ }^{74}$ The Komi had been Christianized as a nation by 14 th century. ${ }^{75}$ Therefore when Ledyard presumed that these "Indians" in general were "converts", and was impressed with them performing "their devoirs [sic] to God after the manner of the Greek church", he was actually observing men who had derived from Orthodox peoples themselves. In other words, Orthodox men were virtually indistinguishable from the Aleuts in the corporal's unaccustomed sight, especially as these hunters prayed together.

to Kamchatka under the command of Capt. Clerke. He died during a subsequent, more northern exploration of the Bering Sea and Strait. Having requested that his body be returned to Petropavlovsk for burial, instead of being deposited at sea, Clerke was interred with the assistance of the Orthodox priest there who had earlier provided him with pastoral care during the captain's illness (between the voyage's initial landing and the subsequent more northern exploration) and who was himself "native on his mother side" (King 1784:368). The burial is reported in all the journals: see Beaglehole (1966).

${ }^{74}$ Shishigin (1991:32-35, 80-81).

${ }^{75}$ This is generally accepted as a fact: see "Komi", Encyclopedia Britannica, 15th ed. A major figure in Komi history was St. Stefan of Perm (c.1340-1396): see Ware (1963:93). My reference to the Komi and "Orthodoxy" should be understood as including the Old Believers, those groups that resisted the reforms imposed by the imperial government in the 17th century. The White Sea regions were Old Believer strongholds, and many Komi comprised their members. Indeed, the Komi Old Believers continue as important element among the Komi people and in Komi culture today; an ethnographic video of Komi Old Believers today was shown at the the International Association for the History of Religion (IAHR), Regional Conference on Circumpolar and Northern Religions, Helsinki, 13-19 May 1990. For Karelian Old Believers, see Pentikäinen (1989:124-130). Continued research into the Alaska Church history, and into the relationships between Alaska and the White Sea regions would take the Old Believers into consideration.

Komi intellectuals are aware of the historic bonds between Komi men and Alaskans, as I was informed by Komi intellectuals at the IA HR Conference, Helsinki, 13-19 May 1990. 
As the far northern hunters lived and prayed together, they themselves merged in the iurta, and their faithful practices meshed. In this way, Orthodoxy was initially communicated on the Aleutian Islands from northern hunters to northern hunters: from like to like.

\section{The Kodiak Area}

In the Kodiak area however, the historical circumstances differed. The alliances that had comprised a significant dynamic during the initial contact periods on the Aleutian jh

Islands, were eclipsed in the Kodiak area by a invasion and colonization during the initial contact period here. The circumstances differed furthermore as a religious mission was dis patched to the Kodiak area within this setting.

The invasion was spearheaded by commercial interests that had, since the 1770s, escalated to deluge the eastern Aleutian Islands. But the earlier alliances in the Aleutian archipelago (from 1745 into the early 1760s) had resulted in the emergence of baptized Aleut leaders who withstood, and who provided leadership against, the deluge (as has been explained in the preceding sections of this chapter). It is possible that alliances of this sort were initially forged in Kodiak area also, as Stepan Glotov and his Aleut godson Ivan (the future leader of the Uminak Aleuts) had wintered here during their travels to gether in $1762 / 63$. The type of contact that would allow this possibility was sparse in the Kodiak area however, and was abruptly eclipsed by the colonization that took place in 1784 .

Yet, nonetheless, the characteristics of the transition to Russian Orthodoxy in the Kodiak area were very much the same as those on the Aleutian lslands. Here also 
the transition was indigenous and corporate. It involved indigenous spiritual and social processes, and it involved the whole bodies of peoples' societies, or kinship-based polities. To perceive these characteristics, the study must delve deeper into the sources than the reports written by the colonizers, because they attempted to usurp the credit for the Christianization for themselves. Their attempt was highly effective indeed, as their claims have been repeated from their own generation to the present day, as will be explained in the following section of this chapter.

(6) Grigorii Ivanovich Shelikhov: In his own Words, the First Missionary.

The invasion was spearheaded by Grigorii Ivanovich Shelikhov. Born in 1748 at Ryl'sk, Kursk gubernia, southwest Russia, he had moved to Irkutsk, Siberia, where he entered into the employ of a compatriot, from Kursk, Ivan Larionovich Golikov. In 1775, Grigorii married Natal'ia Alekseevna, "probably the daughter or widow of some rich merchant, and thus an initial source of Shelikhov's capital". ${ }^{76}$ The following year, he financed the first of his ventures in the north Pacific maritime fur trade; then funded ships, mostly in partnership with Golikov, in rapid succession for overlapping enterprises that extended progressively across the Aleutian Islands, into the Kodiak area, and eventually to the American northwest coast: $1777-81,1777-82$, $1779-85,1780-86,1783-86,1783-89,1783-93,1790,1790-92,1795$, (again) 1795, 1797, and (again) 1797. The latter were dispatched from a permanent base the partnership had, in 1784 , established on Kodiak lsland. ${ }^{7}$

\footnotetext{
${ }^{76}$ Pierce (1990:454). For detail in Shelikhov's biography, see Sitnikov (1990).

${ }^{77}$ For the dates of these enterprises, see Makarova (1975:213-216). Finer detail
} 
The fur trade along the Aleutian Islands had been inaugurated earlier, between the mid-1740s and the mid-1760s. This was the initial contact period, during which personal alliances were forged along the chain, and the first baptisms of Aleuts took place (as established in the preceding sections of this chapter). The next phase began in the 1770 s, when a proliferation of companies began coming increasingly more frequently along routes that were known now, and were less risky. Passing the western Aleutian Islands, a very few stopped at the central islands, while almost all concentrated on the eastern Aleutians. It was during this phase, into these predatory waters, that the Shelikhov-Golikov partnership entered in 1777 , and gained advantage by forging yet farther east than their rivals, to establish the base on Kodiak Island in '84.

The establishment was daring, absorbing the personal interest of not only of Grigorii Ivanovich Shelikhov, Ivan Larionovich Golikov, and lvan's nephew, but also of Natal'ia Alekseevna Shelikhova who ventured to Kodiak alongside her husband, and was thus at the helm from the start.

Their daring was profitable; for with this advantage, and with subsequent astute political management, their enterprises prevailed over others, until at last the major shareholders gained the monopoly rights over the entire north Pacific archipelagos and coast, and formed the Russian-American Company by imperial charter in 1799.

Grigorii lvanovich did not achieve this consolidation, however; because four years earlier, the active forty-seven year old died very suddenly at home. Nor did the

work with regard to the chronology of Russian voyages from northeast Asia to the Aleutians and eastward, from 1745 to 1799 , is being accomplished by Dominique Desson, University of Alaska, Fairbanks. Also see Pierce (1990:454): "In eight years [from 1776], he participated in at least ten voyages." 
partner Ivan Larionovich enjoy the consolidation; because soon after the untimely death, the widow Natal'ia Alekseevna Shelikhova, through her connections in the capital city, had overtaken the partner's interests in the company; so that her family, and those connections, became the major shareholders in the monopoly.

From the Aleutians, as in a single voice. Earlier, the Shelikhov enterprises were implicated or explicitly identified in the deeds of violence and gross exploitation that had been reported from the Aleutian lslands to the imperial government. (These reports have been mentioned in the context of Aleutian Island history in section 3 , above, and will be repeated here with reference now to Shelikhov's involvement.) Prior to June 1787, the Aleut toion's kinsman named Izosim Polutov, dispatched a protest from the central Aleutian Islands. ${ }^{78}$ During the decade prior to that date, two ships in this region belonged to Shelikhov enterprises, one of which had remained in this region exclusively for a period of four years. ${ }^{79}$ In 1797 , a decade after the Polutov protest, the Shelikhov-Golikov partner ship was accused from the eastern Aleutian lslands in the report carried towards Petersburg by the missionary priest-monk Makarii and the six Aleut men including Ielisei Popachev, Nikolai Lukanin, and Nikifor Svin'in. ${ }^{80}$ This report was carried the entire distance across northern Eurasia. It explicitly identified the Shelikhov-Golikhov company in deeds

${ }^{78}$ See Colonel Grigorii Kozlov-Ugrenin, Commandant of the Okhotsk oblast, "Document, to the Toions and Peoples inhabiting the Northeastern Ocean and Aleutian Islands who are subjects of the Russian state", 15 June 1787, in Tikhmenev, ed. (1863:20; 1979:16). Also see Liapunova (1987:116).

${ }^{79}$ See the chronological tables in Makarova $(1968: 185-186 ; 1975: 214)$.

${ }^{80}$ Hieromonk Makarii, Report to Holy Synod, 5 Oct. 1797, HRS/RR/LCM 643:13-23. See my note 31 to this chapter, above. 
of horrific violence. Indeed, Shelikhov-Golikov company hirelings were accused solely. Referring to events in 1795/96, it was dated in December 1797 by which time all except a rival had been merged with this company or had been otherwise eliminated through the intense competition. Deeds of gross brutality were described, for instance $:^{81}$

The Shelikhov-Golikov company men act like barbarians toward the people. They exhibit no humanity whatsoever. They forcibly take women and children as concubines. They beat people to death. Beginning in early spring they send both the heathy and sick to hunt sea otter against their will. The sick often die on the way. They force them to continue hunting until autumn so that they have no time to attend to their own subsistence activities, to store food for themselves, or to take animals to make winter parkas.

The report was recapitulated in a sentence: "The newly-enlightened people [-- the Aleuts recently baptized --] cry not tears but blood". ${ }^{82}$

While the Shelikhov enterprises would later laud themselves for implanting the Orthodox faith in Alaska, the reality was more clearly the inverse: Orthodox Christian leaders were already in place on the Aleutian Islands, and were speaking out, indeed crying out, as in a single voice against those enterprises.

Despite a decade of such reports, the controlling interests in these enterprises were nonetheless awarded a monopoly by imperial decree in 1799. Part of the articulated rationale was that a monopoly would control the "harsh treatment of the natives by the traders"; ${ }^{83}$ but those "traders" were the hirelings of the monopoly's

${ }^{81}$ lbid., trans. Lydia T. Black in Oleksa, ed. (1987:288).

${ }^{82}$ Ibid., p. 289.

${ }^{83}$ For example, the history commissioned by the company asserted that "this event [the granting of the monopoly] was significant not only in consolidating the 
progenitors, and the "harsh treatment" was itself the condition through which the progenitors had prevailed, and in which the monopoly had been spawned.

Nearly twenty years subsequent to the granting of the monopoly, a plea was written from the Kodiak area that sounded strikingly like the earlier one carried to Petersburg from the Aleutian Islands. Written by a monastic missionary Herman in 1818 , it was addressed to the company's new on-site chief manager: ${ }^{84}$

I the most humble servant of the local people and their nursemaid, stand before you with bloody tears and write my request: be a father and protector to us. We, of course, know no eloquence, but we say, with the halting tongue of children, wipe away the tears of our defenseless orphans, soothe the sorrows of aching hearts, let us know what joy is like.

This plea came from area where Grigorii Ivanovich Shelikhov and Natal'ia Alekseevna Shelikhova had established their company's permanent base, which (after a relocation in the same area) became the monopoly's initial on-site headquarters. How had the permanent base first been established?

The establishment of the Kodiak base: Three independent, corroborative reports. Aware that the people of the Kodiak area had earlier repelled other companies' attempts to locate even temporary camps, the Shelikhov-Golikov partnership went prepared to establish a permanent base, not in one but in three ships,

company's position, but also because it enabled the company to introduce proper government" (Tikhmenev 1978:53).

${ }^{84}$ Herman to Semen Ivanovich lanvoskii, 28 Dec. 1818 [transcript in Valaam Monastery archives] in Valaam, ed. (1978:92); reprinted in Oleksa, ed. (1987:310). [ftnt. continued] See ibid. (1894:151). 
equipped not only with arms but with two-pound cannons. ${ }^{85}$ Their little fleet was a small armada. Regarding the events subsequent to the landing, three independent eyewitness accounts corroborate each other:

(i) one by a Kodiak elder;

(ii) another by an assistant surgeon with the company; and

(iii) yet another by a navigator, also with the company.

Shelikhov's own report reflects basically the same events, that is, once his euphemisms are decoded.

(i) In the early 1850 s, seventy years subsequent to the events, Arsenii Aminak, ${ }^{86}$ a Kodiak elder who had been a boy at the time, related his eyewitness account to a Finnish scholar. ${ }^{87}$ An ultimatum had been sent from the ships to Sitkalidak ("Sakhliadak"), a populous stronghold, to warn of the danger if the people did not capitulate by relinquishing children as hostages. Twice it was sent, twice these people refused; then they were attacked:

This happened in April. When our people revisited the place in summer the stench of the corpses lying on the shore polluted the air so badly that none could stay there, and since then the island has been uninhabited. After this every chief had to surrender his children as

${ }^{85}$ Pierce (1981a:12). Two ships landed at Kodiak in summer 1784; the third, separated from the others and then repeatedly delayed, arrived much later, in spring 1786 (ibid, pp. 10, 16). Nonetheless, the three were constructed near Okhotsk for the purpose of this voyage; they were equipped and departed together for Kodiak.

${ }^{86}$ Aminak's name, written as "Arsentii" by the Finnish scholar (see the reference to H. J. Holmberg, below) but the name is actually Arsenii from the Greek 'Apóévios.

${ }^{87}$ In H. J. Holmberg (1855:137; 1856:416-417; 1985:59): originally published in 1855 , reprinted as as abstract in 1856, translated in 1985 . 
hostages; I was saved only by my father's begging and -- many sea otter pelts. ${ }^{88}$

(ii) Aminak's account is corroborated by testimony to the Billings/Sarychev Expedition, an imperial government expedition, four years after the event, submitted by the assistant surgeon Miron Britiukov who had been aboard with Shelikhov. ${ }^{89}$ Britiukov presented the same sequence of events: the armed assault; many casualties -- 300 fatalities according to Aminak; over 500 according to Britiukov -- the subsequent capitulation with the relinquishing of children as forced hostages.

This was only the initial attack, described alike by unrelated eyewitnesses. The one witnessed it from among the Kodiak Islanders, the other from among Shelikhov's men. The one account was collected by a Finnish ethnographer on Kodiak Island in the 1850 s, the other account was collected by a Russian naval officer in northeastern Asia in 1788. The two independent accounts are fundamentally the same.

Subsequent attacks elsewhere on the island were described by Britiukov, ${ }^{90}$ who also reported that a number of adult captives were executed as public examples, and on one occasion when kinsmen came to ransom child hostages, these kinsmen were $\not x$ tortured for information, then executed on Shelikhov's order by an employee, namely the navigator Izmailov.

${ }^{88}$ Aminak in H. J. Holmberg (1985:59).

${ }^{89}$ Testimony by "pod-lekar" (поплекарь, assistant surgeon) Miron Stepanovich Britiukov to navy captain Joseph Billings 2 Nov. 1788, Appendix 5.2 [ "LCM, Golder collection, Box 3, from Russian State Archives, Petersburg, 1789, vol. 7, no. 2742; also in Pamiatniki novoi russkoi istorii, Sbornik istoricheskikh statei i materialov, vol. 3 (Petersburg, 1873), pp. 373-383, trans. in DRAH, vol. 2, pp. 332-336" ], in Shelikhov (1981:123-126).

${ }^{90}$ Ibid. Also, during the prior year, 1787, Britiukov submitted a report of assaults to the governor-general of Siberia (Pierce 1990:70). 
(iii) When Izmailov himself was questioned by the Billings-Sarychev expedition, he admitted that he had shot two individual men on Shelikhov's orders, although in a context different from that described by Britiukov (according to Izmailov, Shelikhov had eventually freed all surviving captives without further harassment of their relatives who had come for them). ${ }^{91}$ The navigator moreover reported instances of executions of small groups of men (not by Izmailov himself), each execution by Shelikhov's orders; and he emphasized that he had reported this to the government office at Okhotsk earlier, in 1787 . The executions had included the spearing of six to ten old men selected specially for this purpose from among the initial captives, who themselves numbered from two to three hundred people. Regarding the initial attack, Izmailov described the same pattern of violence which had been described by Britiukov and Aminak, so that the three independent eyewitness accounts corroborate each other. ${ }^{22}$

And Shelikhov's own account reflects the same information when he himself mentions the establishment of forts and the subjugation of the populace during the pacification of Kodiak. ${ }^{93}$ Once decoded, these euphemisms are deadly accurate: for

${ }^{91}$ estimony of navigator Gerasim Grigor'evich Izmailov to naval captain Joseph Billings, 1 July 1790, Appendix 6.3 ["LCM, Yudin collection, Box 2, folder 23; trans. DRHA, vol. 2, pp. 237- 240"], in Shelikhov (1981:1-30-131). Hence Shelikhov's retort: "Britiukov, who sent a false report concerning me last year, will be punished by law after the investigation. He is a hundred times sorry, but nobody will help him, because his report reached the high realm where justice reigns supreme" (G. I. Selikhov to E. 1. Delarov, 30 Aug. 1789, in Tikhmenev, ed. (1979:21).) (1992).

${ }^{92}$ A correlation has been noticed also by Pierce (1981a:12-13) and by Black

${ }^{93}$ Petition, I. I. Shelikhov and G. I. Golikov to Catherine II, [13] Feb. 1788, in Andreev, ed. (1948:266); also in Bashkina et al., eds. (1980:166): the words укрепление and крепость аге used; they are fortifications. Also see Grigorii 1. Shelikhov, Report to Irkutsk governor-general Ivan V. Iakobii, after 18 Nov. 1786, 
why are forts established; and how would such numbers be so quickly pacified, indeed pacified to "obedience"? Reaching either a height of triumphant pretenśde, or a crescendo of subtle humour, in a petition to the empress, he himself proclaimed 50,000 savages obedient to a single Shelikhov. ${ }^{94}$

The distinguished citizen. The euphemisms were linked to an articulated motive which together created a self-justifying circle enclosing and submerging those deeds. Shelikhov wrote to Empress Catherine Il: "Through innumerable labors and dangers, we have had no object in view except love for our country and zeal for the public good; these have been the main motives in our enterprises". ${ }^{95}$ Such noble motives ringed such brutal deeds.

published as G. I. Shelikhov, Россійскаго Купца Григорья Шелехова Странстівовніе в 1873 гопу (St. Petersburg, 1791; 2nd ed. 1792; 3rd. ed. rev. 1793), trans. Shelikhov (1981:36-48). For the contents of and circumstances about the pubfications of the Russian editions of 1791 to 1793), see Pierce (1981a:32-35).

${ }^{94}$ Petition, Shelikhov and Golikov to Catherine, [13] Feb. 1788, in Andreev, ed. (1948:266); also in Bashkina et al., eds. (1980:166). "пятидесяти тыся ч человек" in the Andreev edition; "50 тыс. человек" in the edition by Bashkina et al. See Appendix 4 ["LCM, Golder collection [box ?], photostat of ms. copy, Soviet archives, Vorontsov collection, File 476, no. 416- 419; DRHA, vol. 2, pp. 330-331"], in Shelikhov (1981:121): "up to 50,000 in all". Also see Grigorii's statement immediately subsequent: "по пятисот [sic (пятьсот)] детей в аманаты принял" (Andreev, ed. 1948:266); "500 детей в аманаты" (Bashkina et al. 1980:166). An аманат was a hostage: "about 500 children were taken as hostages".

After Grigorii's death, Natalia Shelikhova asserted a number higher than Grigorii's own, "120,000 people" subjugated by "my husband, the late Shelikhov", in her Notes concerning "The duties and the success of the American company", written not before 3 Aug. 1798, in Bashkina et al. eds. (1980:208).

${ }^{95}$ Petition, Shelikhov and Golikov to Catherine, [13] Feb. 1788, trans. in Appendix 4, Shelikhov (1981:121). See ibid., in Andreev, ed. (1948:266-267); and in Bashkina et al., eds. (1980:166). 
The motive was reflected in Shelikhov's own portrait. ${ }^{96}$ Looking squarely

ahead, he holds a telescope in his hand, while behind him a masted ship sails out of harbor: signs of his vision and his ventures. He wears a large medallion given to him by imperial decree in 1788 for noble activities on behalf of civilized society. ${ }^{97} \mathrm{~A}$ distinguished citizen of the empire, he has his sight set on the expanding horizon: he is an empire builder (similar to Cecil Rhodes, for example) expanding the sphere of "civilization" and the sceptre of the "anointed" monarch. Having donned a short wig worn by men of that class and of that era in Western Europe and in the United States,

${ }^{96}$ See the portraits reproduced in Shelikhov (1981). Also see the portrait reproductions of numerous colonial figures in Bashkina et al. eds. (1980) and in Pierce (1990). Differences in bodily features in various portraits of Shelikhov are noted by Sitnikov $(1990: 378$, n. 2.) who considers the portrait reproduced in Tikhmenev (1861) frontispiece, to have been "most probably the official representation". See the frontispiece replicated in Tikhmenev (1978). Within the various portraits reproduced in Shelikhov (1981), including the one from Tikhmenev (frontispiece), the bodily differences are slight, and all the portraits contain the same symbols in the clothing and in the background. These symbols are the key. The theme expressed by these symbols was expressed literally in then-contemporary written sources, and the theme could be developed at length with reference to those written sources: see, e.g., the ukaz granting nobility to the Shelikhov family for Grigorii's extending of empire (cited in my note 110 to this chapter, below). The portrait's symbolism is meant to suffice to illustrate the theme as vividly and succinctly as possible.

Shelikhov's portrait can be contrasted to another merchant's portrait painted in 1840. The latter was exhibited at Costumes Historique Russes du Musée de l'Hermitage de Leningrad, Musée Jacquemart-André, Paris, 1-31 May 1989. A merchant of the town of Rzhev on the upper Volga, Petr Vassilievich Filatov was affluent enough to commission a portrait of himself and another of his wife. Yet he posed for his own in the traditional appearance of a Russian Eurasian merchant, in a caftan and with a beard. His wife posed in regional custom with flowered embroidery and flowered headdress. They remained attached to these traditions.

${ }^{97}$ This medallion and other rewards he received are minor in comparison to the recognition and patronage he requested from the Crown (for these requests, see Pierce (1981a:20-21). But they are honours nonetheless. Whether he was shunned by Petersburg society, as the limit of the patronage would suggest, is inconse quential for the argument. Regardless of how he might be perceived by them, he is advancing their interests in this way and he is being rewarded. 
and having shaved his face according to the same fashion, Shelikhov wears a contemporary tail-coat and a vest, replete with a slight belly visibly extending the vest: signs of his modernity and of his affluence in the new society. These are also signs of this merchant's break with Russia's own past. Gone are the Eurasian merchants' caftan and beard.

The new society he was intent on extending was that inaugurated by Peter 1 , the first emperor. ${ }^{98}$ Just as this emperor had shed the Moscow tsars' symbolic oriental robes for a military uniform, so this merchant shed the caftan for a suit. Shelikhov was a minor image of Peter I, his object for the colony a minor image of Peter's for the empire.

The intent was two directional: while reaching out for new territories and resources, Grigorii's enterprises would bring in new subjects, and would bring them to "innumerable advantages", particularly to the benefits of "security and prosperity". While the benefit of security is ironic, that of prosperity is rather interesting. A type of prosperity was envisioned: warehouses bustling with productive workers on busy docks; fields and pastures in the countryside; offices, houses, a school along proper streets in the town. Kodiak town (Pavlovskaia gavan) was to be a proper colony..$^{100}$ Kodiak remained mostly Alaskan, however. Alutiiq maritime

\footnotetext{
${ }^{98}$ Peter I was the first Russian ruler to adopt the term "emperor". "Tsar" remained the popular term, maintained from the prior era, that of the Moscovite rulềs.

99 "безчисленные выгопы, безопінность и благоденствие": Petition, Shelikhov and Golikov to Catherine Il, [13] Feb. 1788, in Andreev, ed. (1948:266); also in Bashkina et al., eds. (1980:165-166). See trans. in Appendix 4 ["DRHA"], in Shelikhov (1981:121).
}

${ }^{100}$ For indications of the colony envisioned, see Letter, G. I. Shelikhov and A. E. Polevoi, 9 Aug. 1794, in Tikhmenev, ed. (1863:71-73; 1979:54-56); Governor-General Ivan A. Pil' to G. I. Shelikhov, no. 991, Irkutsk, 12 May 1794, 
technology prevailed, so did the Alutiiq language. The richly artistic culture was not supplanted. ${ }^{101}$ Indeed the Alutiiq people were never entirely "subjected" during the occupation which itself was localized, or geographically limited: ${ }^{102}$ to the contrary, while personally allied with some Russians, ${ }^{103}$ they remained opposed to and defiant of others, and according to Aminak, "did them harm in many ways". ${ }^{104}$

The colony Shelikhov envisioned was to have its church. Shelikhov himself had boasted of baptizing a number of Kodiak people: ${ }^{105}$ the same writer who had also boasted of subjugating the fifty thousand, and of bringing them to obedience to himself; and he requested from the Crown the assignment of "two priests and a

points 2 - 7, in Appendix 7 ["LCM, Yudin collection, Box 1, folder 4; trans. DRHA, vol. 2, pp. 161-163"], in Shelikhov (1981:132-134).

${ }^{101}$ See e.g.: the Pinart collections from $1871-72$ in the Bancroft Library, University of California, Berkeley, and in the Château-Musée, Bologne-sur-mer; the Fisher collections from the 1880 s in the Smithonsian, Washington, D.C. For an accessible published source see Huggins (1981:3-7, 14, 23-24, 29-30, 33). All these sources are subsequent to the Russian occupation, all are within the initial phases of the U.S. occupation, during the first three decades after the selling/buying of the territory. Huggins, 1868-70, reflected the complement of traditional culture, language, dwellings, artifacts, dress; Pinart, 1871-72, collected oral traditions, tales, ornamentation, masks, and carvings; Fisher, 1880s, collected numerous artifacts including emboidered clothing, intricately carved sea hunting equipment, symbolic ornamentations of many kinds. The latter's rich and varied collection derived (according to Alan Crowell, Smithsonian Institution, 1st Kodiak Area Culture Conference, Kodiak, AK, 28-30 March 1988) from various locations in the Kodiak area: both near to and far from Kodiak town: including Woody Island, Three Saints Bay, Karluk, and the Alaska Peninsula.

${ }^{102}$ The approximate average was 500 Russians through the extent of Russian-America per year: Fedorova (1971:117, 136-147; 1973:124, 147-159).

${ }^{103}$ According to observations in 1794 from areas of Kodiak other than the company settlement and from Kenai Bay (Cook Inlet), in Vancouver (1984:1241, 1308-1309).

${ }^{104}$ Aminak in H. J. Holmberg (1985:59). See $\underline{\text { ibid. }}$ (1856:415).

${ }^{105}$ Shelikhov (1981:43-44). 
deacon". This request was specifically distinct from a petition for missionary priest-monks. Priests would be married men, who could be envisioned as cooperative colonial clergy indeed, isolated as they would be across the "Eastern Sea" (the Pacific), dependent as they would be on the company for necessities as basic as transportation and communication, not for themselves alone but for their families. "Two priests and a deacon" were specifically requested to propógate "the Greek-Catholic faith". ${ }^{106}$ However, a score of missionary monastics were sent instead, most from the monastery of Valaam: and they were far northern men from the taiga of vast Ladoga in Karelia themselves, strangers neither to the far northern climate nor to far northern subsistence.

They were received with remarkable alacrity by Shelikhov at Irkutsk, who transported them to Kodiak. But when they arrived in September 1794, they found no

${ }^{106}$ G. I. Shelikhov regarding privileges for his company, May-Nov. 1787, in Andreev, ed. (1948:224):

Да сверх сих чинов [military personnel and artisans] нужны к просвешению пришепших народов в греко-кафолическое исповедание и впредь пожелавших, в чем ни малейшего нет затрупнения, 2 священника и диакон.

Also see Report of the governor-general at Irkutsk, I. Iakobii, regarding the activities of I. I. Golikov and G. I. Shelikhov's company on the Pacific Ocean islands, 30 November 1787, in Andreev, ed. (1948:264): "послать туда пля проповепывания христианской веры хотя пвух из ученых священников [two from among the educated priests to propogate the Christian faith]. 
provisions there for themselves. ${ }^{107}$ Among them was hieromonk Makarii, assigned to the eastern Aleutian Islands the following year.

Laudations in stone, echoed to the present. The year after the mission arrived at Kodiak, Grigorii died very suddenly at home in lrkutsk. He and Natalia had just married their daughter, or the widow Shelikhova herself would soon arrange the marriage (the date of the wedding is unclear), to Nikolai Rezanov, a thirty-one year old ascendent courtier, then in Irkutsk. The daughter, half his age, was wed with a

${ }^{107}$ Archimandrite Ioasaph [Bolotov, head of the monastic mission] to G. I. Shelikhov, from Kodiak, 18 May 1795, microfilm reel no. 1 [pages unnumbered], Iudin [Yudin] collection of Russian-American Co. papers, LCM [henceforth: RAC/ludin/LCM]. See ibid., trans. Lydia T. Black in Oleksa, ed. (1987:58-59, 61). Also see this source in Tikhmenev, ed. (1863:101-104; 1979:77-79, 80).

The publications of this source pose a problem which require explanation. It was published in Tikhmenev, ed. (1863), an edition of collected sources which was meant to supplement a history that had been commissioned by the Russian-American Company to influence opinion favourably for the renewal of the monopoly's charter (see the translators' and editors' Preface in Tikhmenev 1978:vi). Many segments of Ioasaph's letter which were particularly damaging to the on-site company manager were omitted in this publication. The omissions were indicated by the editor with ellipsis points. When this publication was translated into English (Tikhmenev, ed. 1979:77-85), the omissions were reinserted but by quotation from an earlier translation project known as "Documents Relevant to the History of Alaska" (DRHA), while the segments of the document published in the 1863 edition were translated anew. The insertions from DRHA were indicated by underscoring by the editors as the two translations were thus merged in Tikhmenev, ed. (1979). A congruent translation has been accomplished more recently by Black from a copy of the original document, and has been published in the volume of translated primary sources edited by Oleksa, ed. (1987:58-63); however only the initial two-thirds of the document has been included there. 
dowry of company shares. ${ }^{108}$ Her sister had been married, or was soon to be married, to a merchant with eastern involvements, Mikhail Buldakov.

Within five years, a series of events took place through which the social and financial standing of Shelikhova and family was consolidated. In 1797 , the widow and associates merged with Grigorii's partner lvan Golikov and with most remaining rivals to coordinate the far eastern and north Pacific enterprises. ${ }^{109}$ The next year, Shelikhova and progeny, including Buldakova and Rezanova, were "ennobled" by imperial decree through patronage at Court. ${ }^{110}$ In 1799 , the merger was reorganized to form the Russian-American Company with monopoly rights by imperial decree and with controlling interests secured for the Buldakov, Rezanov, and Shelikhov family members and their financial and social connections.

The extended family erected monuments immediately prior to the granting of the monopoly. They had an obelisk constructed in 1800 at Grigorii's gravesite on cathedral grounds at Irkutsk, the imperial administrative center for the Far East including the north Pacific. It was constructed against the will of the local bishop who complained: "it is higher than the altar"."' An imperial decree silenced him.

\footnotetext{
${ }^{108}$ Having moved to Petersburg, young Anna died in 1802, after her second childbirth. Within the next year, Rezanov (then a major shareholder and a primary influence behind the Russian-American Company) became Court Chamberlain, was assigned as Petersburg's first ambassador to Japan, and commenced upon a tour of the north Pacific which combined the embassy with a subsequent inspection of the company's on-site operations.
}

${ }^{109}$ For the merger, see Partners of the United Company to Aleksandr Baranov, 19 July 1797, in Tikhmenev, ed. (1863:114-115; 1979:90-91).

${ }^{110}$ Ukaz, granting Madam Shelikhova and her descendęnts nobility, 15 Feb. 1798, in Tikhmenev, ed. $(1863: 116 ; 1979: 91)$.

III Veniamin bishop of lrkutsk to Amvrosii metropolitan of Petersburg quoted in Radchenko (1979:349), citing: "f. 859, k. 33, no. 12, Shil'der collection, Otdel 
Erected tall on cathedral grounds, the stone would itself express laudations such as these: ${ }^{112}$

\author{
He Proclaimed \\ Among the Uncivilized People \\ The Name of God Unknown to Them, \\ And in the Name of the Life-Giving Trinity, \\ Implanted the Orthodox Christian Faith \\ in the year 1794.
}

That was the year Grigorii Shelikhov had, with alacrity, transported the monastics whom he had not requested, and for whom he had not made provisions. As for the monastics, their mission had included protests against the company management on Kodiak $^{113}$ and also against the company activities on the Aleutians; ${ }^{114}$ and would

rukopisei Gos. publichnoi biblioteki SSSR". See Radchenko, trans. in Appendix 9 in Shelikhov (1981:143).

${ }^{112}$ Drafts for the inscriptions, Appendix 8 ["LCM, Yudin collection, Box 1, folder 5; trans. DRHA, vol. 2, pp. 164-166"], in Shelikhov (1981:136).

${ }^{113}$ Archimandrite Ioasaph [head of the religious mission] to Shelikhov, from Kodiak, 18 May 1795, in RAC/ludin/LCM. (see my note 107 to this chapter, above); see ibid. partly trans. Black in Oleksa, ed. (1987:58-63). Also see this source partly in Tikhmenev, ed. (1863:101-107; 1979:77-85). Also see the following source reporting the same types of misdeeds seven years later: Complaint by the monastic missionaries Athanasii, Nektarii, Herman, and loasaph from Kodiak to the Holy Synod against Aleksandr Baranov, 31 July 1802 .[filed 1 August 1804], HRS/RR/LCM 564. "loasaph" in this instance is not the archimandrite but another monastic.

But while critical of the on-site management at Kodiak, and in this sense an advocate for the Alutiiq people, what was Archimandrite loasaph's attitude towards Shelikhov who was in Irkutsk and towards the Shelikhov-Golikov wider view and enterprises? The answer may not be as important as the question itself: What should a missionaries' leader's attitude and response be in a situation such as this? An insight by Florovsky (1979:121) regarding Russia in general can be significant to the response here in specific: "The upper realm of clergy maintained an ambiguous silence".

${ }^{114}$ Report of Makarii to Holy Synod, HRS/RR/LCM 643:13-23. 
continue to involve protests, ${ }^{115}$ indeed no less than a plea, ${ }^{116}$ against the monopoly's management.

The commendation of Grigorii Shelikhov would apply by extension to the Shelikhov family name and enterprises. The extension had been articulated clearly in the ennobling of the Shelikhov family when the ukaz, bearing the signature of the emperor, proclaimed:

Our attention has been drawn to the services of the late citizen Shelikhov, who gave his life and property in annexing to our Sceptre the peoples inhabiting North America. He laid the foundation there for the Greek-Catholic [sic] Christian Faith and for various trades useful to the State. Most graciously we bestow upon his widow ... and to their children, the merit of nobility ... [etc.]. ${ }^{117}$

The laudation was then repeated, indeed it has been echoed from those times to the present day. Praise for Grigorii's "Christian mission" was voiced, for example, by an imperial naval officer V. N. Berkh [Berg] in 1817, in a history of the company's circumnavigational frigate the Neva: ${ }^{118}$

${ }^{115}$ Secret report of hieromonk Gideon from Kodiak, to Metro politan Amvrosii, 2 June 1805, critical ed. and trans. Lydia T. Black in Gideon (1989:75-79). Gideon to Holy Synod, 1-2 June 1805, trans. Black in Oleksa, ed. (1987:290-292).

${ }^{116}$ Monastic Herman to Semen lanovksii, 28 Dec. 1818, in Valaam, ed. (1894:150-152; 1978:92-93); trans. reprinted in Oleksa, ed. (1987:309-310).

${ }^{117}$ Ukaz, 15 Feb. 1798, in Tikhmenev, ed. (1863:116; 1979:91). Also see the claim by Natalia Shelikhova dated 3 Aug. 1798 in Bashkina et al., eds. (1980:208) that Grigorii himself had requested these Orthodox missionaries who, upon their arrival, baptized "more than 8,000 souls", a number that exceeds the missionaries' leader's report by 2,000. For the latter, see: Archimandrite loasaph to Archbishop, 19 May 1795, and Ioasaph from northeastern [sic] America, same date, HRS/RR/LCM 643:41 and 643:25.

${ }^{118}$ Berkh (1979:42). But research would probably bring to light a critical view on Shelikhov from the reports by naval officer Vasilii Mikhailovich Golovnin who examined the Russian-American Company officially on site in 1818, and who then, 
The well-known Grigorii Ivanovich Shelikhov was the first of all the Russian Argonauts, who, upon conquering the island of Kad'iak, founded upon it a regular colony, and after settling more than two hundred Russians there, took to America the Religious Mission, built a church and started to convert the savages to the Christian faith.

(Very significant in this source is the explicit coupling of Christianity with conquest, and explicit confusion of nobility with barbarity: which had been implicit in the ukaz.) A footnote was added:119

The reader should know that for these exploits $\mathrm{Mr}$. Shelekhov was raised to the dignity of a nobleman and wore the insignia of the favors of the Most Wise Empress Catherine of Blessed Memory.

(The empress, however, had not bestowed the rank of nobleman upon Grigorii, but had recognized him as a distinguished citizen; her successor Paul had decreed the nobility upon the widow and descende̊nts.)

The laudation for Grigorii's "Christian mission" was repeated predictably in a history commissioned by the company directors in preparation for a renewal of the monopoly charter: ${ }^{120}$

everything Shelikhov did was done much more from zeal for the good of the country than for his own personal advantage. The way he made savage and hostile peoples see the advantage of dealing peacefully with visitors to their shores was truly amazing. After they had shown clear hostility toward Shelikhov and his men, he not only pacified them to the point where they entrusted themselves to his leadership and defended his interests against other natives, but he persuaded them to give him their children as voluntary hostages. When

according to (Pierce 1990:177), became "major general", and eventually "head of the Naval Ministry".

${ }^{119}$ Ibid.

${ }^{120}$ Tikhmenev (1861:19-20; 1978:21). 
Shelikhov taught these children reading, writing, and Christian doctrine, their fathers were favourably impressed ...

Less predictably, it was echoed by Ivan Veniaminov: mentioned in the preceding sections regarding Aleutian Island history, he was the first parish priest to the eastern Aleutians (1824-1834) who became bilingual and literate in Aleut; he then became the first bishop, named Innokentii, of Russia's newly created easternmost diocese of Kamchatka, the Kurile Islands, and the Aleutian Islands, was finally elevated to the Metropolitan of Moscow, and recently in 1977, was canonized a saint by/ Moscow Patriarchate. He made a mistake: ${ }^{121}$

Mr. Shelikhov, the founder of the present company, in his plans and designs for the benefit of this land, had the main aim the wider and wider spread of Christianity and the establishment of churches. For this reason, on his return from Kadiak in 1787 , before everything else, he presented the idea to the Government and asked for the appointment of a spiritual mission.

The mistake is understandable. Veniaminov had been born in a village in the Irkutsk region in 1797 , during the consolidation by the Shelikhov enterprises. He had been schooled during the monopoly's initial charter period: schooled at seminary in Irtkusk, under a shadow cast by the obelisk, cast by persons distinguished and ennobled by the anointed monarch. His statement was a repetition of verses he would have heard from his youth, a paraphrase of the claims the distinguished citizen had made for himself, a recitation of the claims the family and company continued to make for themselves. ${ }^{122}$

${ }^{121}$ Veniaminov (1984:234). See ibid. (1840b:153).

${ }^{122}$ Or did Veniaminov himself write this? The book Записки [Notes] was published by the Russian-American Company. Did they edit it and insert the claim? He probably was the author himself, because a reference in a footnote to this text 
Another bishop associated with Alaska repeated the commendation, in this instance in 1896 , after the centennial celebration of the arrival of the mission to Kodiak. He wrote imperatively in a "proclamation": 123

I on my part hold it my duty to remind the Orthodox Christians of Alaska of their moral obligation to show their gratitude to G. I. Shelekhof for the good he did them while he lived.

Evidently, Shelikhov had been ignored at the centennial, so that this "duty" was felt to remind them of their "moral obligation". The bishop further instructed them to collect funds for a monument to express "their gratitude" to the distinguished citizen "for the good he did them". No monument was built here.

In 1943, Shelikhov was again commended as "pious", now in a history of religious missions written by an ecclesiastic, as follows: ${ }^{124}$

Shelekhov, accompanied by his companions, the brothers Golikov [sic], landed on Kadyak Island, on July 22nd, 1784, and founded the first Russian settlement in America. Within three years Shelekhov subjected to his rule the neighbouring natives and returned to Russia. The Empress Catherine II recognized Shelekhov's conquests and decorated him, granting him also a reward of 20,000 . Shelekhov continued his fur trade very successfully, but being a pious man, he grew uneasy at the harsh treatment of the natives by Russian traders. He decided to do everything possible to protect them. In 1793 he requested the Holy Synod to send a mission to Alaska.

cites the biography of the initial on-site company manager, a biography which had been written by a company official, Kiril Timofeevich Khlebnikov. But compare Veniaminov (1840b:313-327; 1984:317-323), where he questions the wisdom and practicality of aspects of the colonial aim.

${ }^{123}$ Nicholas, bishop of the Aleutians and Alaska in The Russian Orthodox American Messenger, no. 9 (13 Jan. 1897), p. 157.

${ }^{124}$ Bolshakoff (1943:84-85). Ivan L. Golikov and nephew did not travel to Kodiak Island with Shelikhov. 
Surely the author must not have intended to couple Christianity with such "conquests", as he did.

In 1970 , the commendation was repeated by yet another bishop who described Shelikhov as "a staunch member of the Church". ${ }^{125}$ The actual deeds, encircled as they were by euphemisms, covered as they were by decorations for "nobility", indeed by the decoration of a cross, remained (evidently) hidden from this source. And yet again: $:^{126}$

Shelikov also became the first missionary to the native people. In his own words: "I exhorted them to keep the Orthodox faith which they had accepted according to law."

Thus "in his own words", Shelikhov was the first missionary; and in the words of his widow, family, their companions, he was the patron of the mission from Valaam to Kodiak.

A Sounder Voice. Gavriil the Metropolitan of Novgorod (or Novgorod and St. Petersburg), who had himself been instrumental in dispatching the score of monastic missionaries in 1794 , did not assign any credit for this mission to Grigorii Shelikhov however. The metropolitan assigned the credit to Shelikhov's partner, Ivan L. Golikov: "Golikov ... sought to send the missionaries [and] ... the Archimandrite and monastics are maintained at Golikov's expense". ${ }^{127}$ Metropolitan Gavriil mentioned Shelikhov very briefly only as having "organized the commer cial enterprise in America"; and

${ }^{125}$ Afonsky (1977:32).

${ }^{126}$ Ibid., p. 12.

${ }^{127}$ Letter, Metropolitan Gavriil to Prince Platon Zubov, 18 Feb. 1796, HRS/RR/LCM 643:30-32. 
the metropolitan subordinated him: "Golikov had initially recruited Shelikhov from the lower ranks and then elevated him to a full partner". ${ }^{128}$

Metropolitan Gavriil provided this information in a letter to Prince Platon Zubov, dated three months after a letter by Natalia Shelikhova to the same influential person. ${ }^{129}$ Natalia was appealing for support in the struggle for company control that had ensued with Grigorii's untimely death, a few months prior. Metropolitan Gavriil, on the other hand, was championing Golikov.

Gavriil's sounder voice from that very time, prior to the prevalence of company propoganda, should itself clearly indicate that the subsequent laudations of Shelikhov were at first pretentious, and then naive. To reach an understanding of the Christianization of the Kodiak Alutiiq, the study must therefore delve more deeply into the history than the company's claims.

\section{(7) The Account from Old Harbor}

regarding the Baptism of the Kodiak Alutiig, 1794/95.

This history can be fathomed by complementing the more credible written historical sources with oral historical sources, the latter's crebibility ascertained by corroborative evidence; and through this method the following account has been substantiated regarding the baptism of the Kodiak Alutiiq, as recounted today by a toyuk of

${ }^{128}$ See ibid., 643: 31 .

${ }^{129}$ Natalia Shelikhova, Letter to Count [Prince] Platon Zubov, Adjutant-General, General-Feldtseikhmeister, and Representative of the Empress in the Crimea, 22 Nov. 1795, in Tikhmenev, ed. (1863:108-113; 1978:1979:85-89). 
longstanding, Simeon Haakanson, in the village of Old Harbor on Kodiak Island. ${ }^{130}$ (Toyuk is the Alutiiq rendering of the word toion.) He is a tradition bearer of particular stature and particular abilities. His account relates to Kodiak Island and also to the Alutiiq regions of the Alaska Peninsula where the sequence of events was fundamentally the same. Three leaders, all originally from the village of Belkovsky on the Alaska Peninsula, were cited by him by name as having received the same account and having communicated it themselves. They also were leaders and tradition bearers of particular stature, and of particular abilities, themselves. ${ }^{131}$

Old Harbor is the village nearest the site of the initial settlement founded by Shelikhov in 1784 . The settlement was subsequently relocated to Pavlovskaia gavan (today's Kodiak town); and it was to the latter location that the missionaries arrived in September 1794.

The missionaries' own reports merit attention before the account from Old Harbor is presented, as merely nine months after their arrival the missionaries' leader, Archimandrite Ioasaph, reported that they had baptized more than six thousand people: ${ }^{132}$

${ }^{130}$ Personal communication, Simeon Haakanson (Sven Sr.), Old Harbor, Kodiak, 26 April 1988, written into this study with his permission. Among other official and local governmental titles, he had been the "Council President" for ten years (or eleven?) until spring 1987, and had become the vice president by April 1988 to nurture the development of younger leadership.

${ }^{131}$ Their names, contained in my fieldnotes, will be withheld because I have not maintained communication with these men to request permission to make their names public. The specification of their derivation, and the indication of their social status, should be sufficient for the argument, and will be significant for anyone familiar with the Kodiak area.

${ }^{132}$ Archimandrite Ioasaph to hegumen Nazarii of Valaam, 19 May 1795, HRS/RR/LCM 643:50. The number is given also in: Report, Archimandrite Ioasaph to "Vladika", 19 May 1795 HRS/RR/LCM 643:41, where it is specified as indicating 
we baptized more than 6,000 people through the winter on Kodiak, who were so willingly baptized that they destroyed and burnt all their shamanistic array.

If attention is focused squarely upon the more definite aspect within this statement -that is the number of baptized that the source himself would have ascertained from the records he was keeping -- the reader encounters an extraordinary number representative of whole lineages or of an entire population. ${ }^{133}$ Such a number could not have been achieved by the missionaries themselves within the nine months

virtually the entire population. The number is conveyed by Veniamin bishop of Irkutsk [and Nerchinsk] to Archbishop, 22 Nov. 1795, HRS/RR/LCM 643:33; and by Gavriil Metropolitan of Novgorod [and St. Petersburg] to Platon Zubov, 18 Feb. 1796, HRS/RR/LCM 643:30. The rounded number of "slightly less than 7,000" is given in: Letter, Monastic Herman to hegumen Nazarii of Valaam, 19 May 1795, HRS/RR/LCM 643:54. But the number in Ioasaph's letter to Nazarii is given as "more than 6,000" in Valaam, ed. $(1894: 68 ; 1978: 42)$, reprinted in Oleksa, ed. (1987:38); instead of the figure "more than 6,000" that is written in the HRS/RR/LCM transcript.

${ }^{133}$ As mentioned in the preceding note, Ioasaph to "Vladika" (HRS/RR/LCM 643:41) reported that the number indicated virtually the entire population of Kodiak Island. The number also included some people who had sought baptism at Kodiak from locations farther afield: the Alaska Peninsula, the Kenai Bay area, and the Chugach Bay area, according to Ioasaph to Shelikhov (18 May 1795, RAC/Iudin/LCM, p. 1; in Tikhmenev, ed. 1863:101, trans. in Tikhmenev, ed. 1979:77; also see trans. in Oleksa, ed. 1987:58). The population for Kodiak Island for winter $1795 / 96$, the year subsequent to Ioasaph's report, was specified as "more than $6,200 "$ in a Russian-American Company publication originally published, volume 1, in 1861 (Tikhmenev 1978:47). This population count corresponds approximately to loasaph's number of baptized.

The entire extended Alutiiq population, including the Chugach area, has been recently estimated to have been at least 9,000 (Clark 1984:187), or at least 10,000 (Crowell 1988:134), at the time of first contact which should be the first major contact of 1784 . Hence, the number baptized in 1794/95 would represent a sizeable proportion of the extended Alutiiq population.

We may therefore refer with certain'ty to the baptism of whole lineages, and quite likely of the entire population, of the Kodiak area in 1794/95. One of the missionaries, Iuvenalii, traveled to the Chugach area later in 1795, and baptized many people there. From that later date, it should be possible to speak of the baptism of the Alutiiq nation ( $\varepsilon$ vo , нароп). Access to Russian archives would allow a more detailed analyses of dates, numbers, and locations (and may yield names as well). 
between their arrival at Kodiak in September 1794 and the date of this report in May 1795; therefore, reasons for the baptisms must be sought within processes preceding, or immediately contemporaneous with, the missionaries' arrival. These processes are related within the account from Old Harbor.

According to the account from Old Harbor, the Alutiiq people continued to resist the invaders, and were selective in their contacts. Yet when the missionaries arrived, the Alutiiq people welcomed them, and willingly received baptism, because the Alutiiqs' own leading "shamans" had had visions and had given advice. Whole villages accepted baptism with these receptive leaders; and while a few dissenting shamans went to live apart, village membership coalesced around baptism.

Each element in the account -- (a) the Alutiiqs' continued resistance; (b) their reception of the missionaries; (c) the exile of the few dissenting shamans; and (d) the receptivity by leading visionaries -- is consistent with the historical sources and furthermore substantiated by parallel events elsewhere in Alaska.

(a) Continued resistance. While the invaders of Kodiak pretended otherwise in public statements, ${ }^{134}$ the Alutiiq were never actually conquered. To the contrary, the Kodiak Alutiiq had been "pacified" in terms of resistance by direct warfare only. Otherwise they remained actively defiant and continued to resist, indeed they counted fatalities among the invaders. According to a retrospective statement by a Kodiak eyewitness to the initial events of ' 84 , yet long afterwards "we did them harm"; and he provided a specific instance as follows: ${ }^{135}$

\footnotetext{
${ }^{134}$ E.g., Shelikhov (1981:42-45).

135 "The Account of the Kodiak Elder Arsentii Aminak" in H. J. Holmberg
} 
The lake contained sea hedgehogs (sea urchins), which are poisonous. We knew of this but smartly kept it to ourselves. We never ate them; not even gulls touched them. Many Russians died upon eating them. But in other ways, too, we did them harm.

The same message is contained, understated, in the account from Old Harbor, and the message is corroborated by information in letters written from the 1790 s into the 1800 s by the on-site company manager who reported the danger from Kodiak Alutiiq and other Native Alaskans ${ }^{136}$-- a danger that reached the proportion of a possible large scale revolt. ${ }^{137}$

Continued resistance is evident in another manner through the 1830 s, when a source, Fr. Ivan Veniaminov, asserted too hastily yet very significantly that the Kodiak Alutiiq refused to be submissive to "Church duties": ${ }^{138}$

All who have been to Kad'iak unanimously agree that the Aleuts there [the Alutiiqs] almost never go to church. Secretly and openly, they adhere to their own shamanism; and very few fulfill their duties with regard to the Church, usually only those living in the main settlement.

$(1856: 415 ; 1985: 58-59)$. For Aminak, see my section 6 in this chapter, above.

${ }^{136}$ Letter, Aleksandr Baranov to Shelikhov and Polevoi, 20 May 1795; Letter, Baranov to Malakhov, 11 June 1800; Letter, Baranov to Larionov, 22 March 1801: in Tikhmenev, ed. (1979:68, 105, 126-127). Also see the uprisings in the Kenai and Chugach regions in Letter, Aleksandr Baranov to Shelikhov and Polevoi, 20 May 1795; Letter, Baranov to Polomoshnoi, 28 April 1798; Letter, Baranov to Radionov, 14 May 1800; Letter, Baranov to Larionov, 24 July 1800: in Tikhmenev, ed. (1979:76, 92, 107, 115).

${ }^{137}$ Letters, Baranov to Larionov, 24 July 1800, and 22 March 1801, in Tikhmenev, ed. $(1979: 115,126-127)$.

${ }^{138}$ Veniaminov (1840b:39). Also see ibid. (1977:49). 
"All who have been to Kodiak unanimously agree": the source was conveying an opinion which had been expressed by certain others, but the assertion of "unanimity" is mitigated by different sources.

These different and mitigating sources, themselves contemporary with or prior to the asssertion, state that "Aleuts" - (as the contemporary term "Aleut" is unqualified by a geographical designation, it signif ies, or includes, Kodiak Alutiiqs) - would gather on Sundays and feastdays at a distance from Pavlovskaia gavan, the company settlement. They were worshiphing at Elovoi island (today's Spruce Island) with the last surviving missionary. ${ }^{139}$

He was the monastic Herman who had acted alongside Alutiiq leaders against the on-site company management at the turn of the century, ${ }^{140}$ and had since removed himself from Pavlovskaia gavan to isolated forested Elovoi island (some time after 1807 and before 1819) where he resumed the anchoretic life that he had known in the forests of Karelia at the Monastery of Valaam. ${ }^{141}$ From this forest hermitage

${ }^{139}$ Letter, Sem'en Ianovskii to hegumen Damascene of Valaam, 22 Nov. 1865, in Valaam, ed. (1894:134; 1978:82). Also see Letter, Ianovskii to Damascene, 3 Sept. 1866 , in ibid. (1894:153; 1978:93). About the source: naval officer lanovksii was the acting chief manager of the Russian-American Company from 1818 to 1820 , knew the monastic Herman personally, and wrote in retrospect about him to Damascene at Valaam Monastery. For the rendering of the name Германъ as "Herman", see note 6 to this chapter, above.

${ }^{140}$ Baranov, letter to Larionov, 24 July 1800, in Tikhmenev, ed. (1979:121); Hieromonk Gideon, Secret report from Kodiak to Metropolitan Amvrosii, 2 June 1805, critical ed. and trans. Lydia T. Black in Gideon (1989:77); Ianovksii, letter to Damascene, 22 Nov. 1865, in Valaam, ed. (1894:134; 1978:82).

${ }^{141}$ It is important to note that this anchorite was living within a tradition in which he had been well steeped, and he was recognized by the Monastery of Valaam as being securely within this tradition. After numerous years of monastic life, he was sent to Kodiak by Nazarii, the hegumen of Valaam (an hegumen is a monastic leader: see note 10 in Chapter 6 , below). Herman then corresponded by letter with the subsequent hegumen of Valaam, loafan. After Herman's repose $(+1836)$, a further 
at Elovoi, he extended his mission to the colonial administration: ${ }^{142}$ a direction

inverse to the more usual thrust of missionary work.

Some "Aleuts" and "Creoles" (Alutiiqs and Russian-Alutiiqs) had settled at

Elovoi to live in proximity to him; ${ }^{143}$ and they would then be joined by others on

Sundays and feastdays. This activity on the small island was reflected in the

hegumen, Damscene, recognized his achievements, and collected information about him in the 1860s. When the collection was published (Valaam 1894a), the Monastery of Valaam described Herman as Сватой Старець [sic], "Holy Elder" (Valaam 1894a:53; 1978:33). For the term "elder", see my Chapter 6 at note 10 , below. The same year as this publication, the monastery also published his vita (Valaam 1894b). It is important to note these facts to differentiate him clearly from merely anyone who might don monastic garb and chose to live in a forest.

${ }^{142}$ Ianovskii to Damascene, 22 Nov. 1865, in Valaam, ed. (1894:138-139; 1978:84-85). Also see, Konstantin Larionov, "Information about Father Herman", [dated in a postscript] 7 Sept. 1866, in ibid. (1894:174-175; 1978:104). About the sources: for Ianovskii, see my note 139 to this chapter (above). Konstantin Larionov, of Alaskan and Russian parentage himself, had known the monastic Herman during Larionov's own childhood in the Kodiak area in the 1820 s and particularly the 1830 s. As an adult, while holding the position of староста of the Kodiak church, Larionov wrote about him in retrospect. Larionov also collected accounts from Alutiiq and Alutiiq-Russian older people who had also known Herman.

Herman converted naval officer Ianovskii, according to the latter's own account to hegumen Damascene, 22 Nov. 1865, in Valaam, ed. (1894:135-136; 1978:83). According to the same source (p. 85), he also converted a certain naval "captain G.", whom the editor of the translation (Pierce 1978:177) has assumed to be Leontii Andreianovich Gagemeister, also spelled Ludwig von Hagemeister. A Baltic German of landed gentry who had been sent to England as a youth to be trained with the British fleet, Gagemeister assumed the position of chief manager of the colonies, briefly from January 1818 until April of that same year, at the summary retirement of the first chief manager of the Russian-American Company, Aleksandr Baranov. In his communications in this position, Gagemeister referred to Herman as the старец (in Pierce, trans. and ed. 1984:20), meaning "elder" it is a term of respect that is applied to monastic spiritual fathers.

${ }^{143}$ Letter, Herman to hegumen Ionafan of Valaam, 13 Dec. 1819; Letter, Herman to Ianovskii, 20 June 1820; Narrative of the Pilgrim Lazarev [inscription at Valaam dated Oct. 1864]; Larionov, Information [postscript at Novo Arkhangel'sk dated 21 May 1867): in Valaam, ed. (1894:193, 147-148, 122-123, 179; 1978:115, 91, 76, 107, respectively). About the sources: for Larionov, see note 142 to this chapter, above. Lazarev had made a pilgrimage to Elovoi where he collected reminiscences from people who still lived there about Herman who had reposed in 1836. 
designation assigned to the location officially in 1831: "New Valaam", ${ }^{144}$ named for the Monastery of Valaam in Karelia from where the missionary himself had derived.

The evidence from "New Valaam" into the 1830s thus mitigates Veniaminov's hasty yet very significant assertion published in 1840 . Instead of remiss in "their duties to the Church", the Kodiak Alutiiq were selective. ${ }^{145}$

Why would Veniaminov have written the assertion? He had been the priest of the parish of Unalaska from 1824 until 1834 (as explained in previous sections of this chapter), and then became the priest of the Sitka parish from 1834 until 1838. These parishes were separated from Kodiak Island by many hundreds of miles: Unalaska to the west, Sitka to the east. Ministering within those parishes, Veniaminov had never been in the Kodiak area prior to the publication of his statement about the

${ }^{144}$ Communication of the Chief Manager, F. P. Vrangel [Wrangell], 18 June 1831, Communications of the governors no. 345, cited by Pierce (1978:178). But the name had been attached to this place earlier: see Letter, Herman to Ianovksii, 20 June 1820; Letter, Herman to Ianovskii, 10 August 1821; and Letter, Herman to hegumen Ioafan of Valaam, 13 Dec. 1819, in Valaam, ed. $(1894: 149,168,193 ; 1978: 92,100,115$, respectively); also see Letter, Ianovksii to Damascene, 22 Nov. 1865, in ibid. (1894:133; 1978:82).

${ }^{145}$ The assertion is further mitigated by evidence which derives twenty-eight years subsequent to Veniaminov's report. On Afognak lsland, away from the (now former) company settlement, Alutiiq and Russian-Alutiiq villagers were constructing a new church building for themselves through their own labor and with their own resources, to replace their prior building that had become too small for their needs. See Huggins (1981:28-29). 
Alutiiq. ${ }^{146}$ Only subsequently did he visit the Kodiak area, specifically in the year 1842 for eighteen days, a visit that was meaningful but brief. ${ }^{147}$

Thus without immediate experience in the Kodiak area prior to publication, Veniaminov had relied on information for the assertion from "all who had been to Kodiak", as he himself admitted forthrightly. ${ }^{148}$ They were unanimous in their opinion. He was conveying their opinion.

In contrast, he had personal insights within the Unalaska region where he had had extensive experience, ${ }^{149}$ so that he remains a key source in some respects there, particularly with respect to pastoral care, linguistics, and some aspects of ethnography.

${ }^{146}$ No record of a visit to the Kodiak area is contained in Veniaminov's journals from the date of his initial arrival in Russian-America until the eve of his intial departure: from October 1823 into the year 1837 (Veniaminov n.d.). He departed for Petersburg in November 1838 from Novo Akhangel'sk (Sitka) southward around Cape Horn; and he returned in 1840, the same year as the publication. That same year, Veniaminov's comprehensive notes were published as book, and they also contain the assertion about Kodiak (Veniaminov 1840b:147; 1984:231): "Of the Kad'iak people only about a hundreth part fulfill the obligations of Religion [обязанности Религіи] to any extent and very few of them may be acknowledged as diligent in it."

${ }^{147}$ He came as the bishop of a newly created diocese of Kamchatka, the Kuriles, and the Aleutians, a position to which he had been elevated, with monastic name Innokentii, in 1840. For a incident during his visit to Kodiak in 1842, see his retrospective account: Archbishop Innokentii (the bishop had subsequently become an archbishop) to Damascene hegumen of Valaam, in .Valaam, ed. (1894:169-170; 1978:101). Although brief his visit was meaningful and was remembered: see an account from Afognak Island, Kodiak area, recorded by Huggins (1981:29). For a summary chronology of Veniaminov's movements, see Pierce (1990:524). I am assuming that the vessel Okhotsk, trans porting Veniaminov from the town of Okhotsk to Novo Arkhangel'sk between 19 August and 26 September 1841, did not stop at Kodiak on the way; but if it happened to harbour there, the fact would remain that he had not been to Kodiak prior to 1840 , and subsequent to that date he had visited only briefly.

\footnotetext{
${ }^{148}$ Veniaminov (1840a:39).

${ }^{149}$ See Veniaminov (1840b:1-327; 1984:157-323).
} 
His credibility there can not be extended to the Kodiak area, however. For example, he had taken the initiative to meet an elder who was referred to as a "shaman" by the local populace on Akun Island in the Unalaska region, and had discovered that this baptized man differed from shamans. Having met him, and having gained personal insights, Veniaminov differentiated the content of this man's experience. ${ }^{150}$ Veniaminov had entered into no such personal relationships in the Kodiak area however, and he exercised no such immediate insights prior to the publication of the assertion about Kodiak "shamanizing".

Yet his assertion about Kodiak is very relevant nonetheless, as it indicates that the Kodiak Alutiiq were refusing to submit to the "duties [obiazannosti]" required of them. "Usually only those in the main settlement" were complying. ${ }^{151}$ In other words, a few in the company's main settlement who were thus probably conformed to the foreign occupation and to the imperial designs, were conformed visibly to such "duties". ${ }^{152}$

But otherwise, non-conformity was observed by "all who had been to Kodiak". It was noticeable enough to elicit the "unanimous" opinion, and disconcerting enough to be reported. Instead of conformity to the occupying authority, there was resistance.

(b) The reception of a missionary. An otherwise resistant people welcomed the missionaries, and received baptism.

${ }^{150}$ See Veniaminov (1977), developed as a theme in Chapter 5 of my study, above.

\footnotetext{
${ }^{151}$ Veniaminov (1840a:39).

${ }^{152}$ lbid.
} 
Two missionaries had traveled to Kodiak area villages within the initial nine months in $1794 / 95$, each singly with an interpreter; ${ }^{153}$ and both returned alive, although either missionary could easily have met with an "accident", as these are coastal villages, joined not by land routes over the interior mountains which are glaciated, but by sea routes navigated by baidarka and baidara (kayak and open skin-boat), along which fatal accidents by drowning occurred. Yet both returned, indeed well enough to be enthusiastic about journeys to locations farther afield the next season, ${ }^{154}$ and each commenced on his subsequent journey singly again: the one to the eastern Aleutian Islands, ${ }^{155}$ the other to the southwest mainland..$^{156}$

The account from Old Harbor about the missionaries' reception is corroborated by similar occurrences elsewhere in Alaska. On the eastern Aleutian Islands, the missionaries were received when they were compelled by inclement weather to harbour while on their way to Kodiak in 1794 , as recounted with some detail by the monastic Herman: ${ }^{157}$

${ }^{153}$ Archimandrite Ioasaph to Archbishop, 19 May 1795, HRS/RR/LCM 643:39-40; Herman to Nazarii, 19 May 1795, HRS/RR/LCM 643:55. According to Ioasaph to Archbishop, the two missionaries who traveled around the island had sent a report to Veniamin, bishop of Irkutsk and Nerchinsk. Research into Russian archives is needed to locate these reports.

${ }^{154}$ See Herman to Nazarii, 19 May 1795, HRS/RR/LCM 643:56-57.

${ }^{15 s}$ For Makarii who joined Unalaska Aleut leaders against the company, see section 4.1 to this chapter, above.

${ }^{156}$ For Iuvenalii who was subsequently killed on the southwest Alaskan mainland, see Oleksa, ed. (1990:340-341, cf. pp. 336- 337). Also see Black (1981a:33-58).

${ }^{157}$ Herman to Nazarii, 19 May 1795, trans. in Oleksa, ed. (1987:40); see ibid. HRS/RR/LCM 643:54. Also see Ioasaph to Nazarii, 19 May 1795, HRS/RR/LCM 643:50: "We spent two days at Unalaska and baptized more than 100 people". 
during our journey through the Aleutian Islands, we were driven against our will into one bay by unfavorable winds, and the Aleuts there caused us great amazement by their kindness to us in distress and their willingness to be baptized.

Receptivity and readiness were likewise reported by Russian-Aleut priest Iakov Netsvetov among the Yupiit and Athapascans of the Kuskokwim and lower Yukon Rivers region in the 1840 s and ' 50 s when whole lineages, or kinship based populations, sought him and invited him for baptism. ${ }^{158}$ Subsequent to his ministry in the Atka parish, encompassing the central and western Aleutians (as explained in previous sections of this chapter), Netsvetov was assigned as a missionary in the Kuskokwim and lower Yukon River regions where he served from 1845 until 1863.

(c) Exile of dissenters. While the reception by the Alutiiq villages was thus deliberate and selective, a few shamans dissented however, and went to live apart, away from the villages. Whether the dissenters chose to go or whether they were banished, the effect would have been the same: they went into exile.

Exile was a traditional method for the maintenance of social cohesion and identity among the ancestral Alutiiqs in the Kodiak area. ${ }^{159}$ With the exile of the

${ }^{158}$ Netsvetov (1984a:47-50, 250-253 [esp. 25 and 30. May 1851], 349-350).

${ }^{159}$ KANA (1987:56-66). It is noteworthy that Veniaminov (n.d.: journal entry 29 Dec. 1827) mentioned Aleut men who lived a secretive existence apart from the villages:

All Aleuts are unanimous in affirming that on the Alaska Peninsula there live Aleuts who have fled from this island arc [Aleutian archipelago] or from Kodiak Island, and that they travel along the entire arc in secret.

While roaming, they did "nothing greatly offensive", and "rarely took young men off with their group" (ibid.). These "Aleuts" could be Alutiiq as well as Aleutian Islands Aleuts, as the writer did not predicate the contemporary Russian term with a 
dissenting shamans, the villages followed the receptive leaders into baptism, and thus membership and mutual identity within the kinship-based communities, or the villages, would coalesce around baptism and Russian Orthodoxy.

(d) The receptivity by leading visionaries. Just as the dissenters were referred to as "shamans" in the account, so were the receptive visionaries. It is possible to refer to the latter as leaders with exceptional prophetic gifts, and thus render a difference in terminology equivalent to the difference in response.

Those who were receptive among the Alutiiq had had visions; and visions heralded the conversions of other Alaskan peoples, also. Among the Tlingit in the Juneau area in the 1890 s the following took place, precipitating Orthodox baptisms: ${ }^{160}$

A young Indian man had a vision. A venerable old man came to him and advised him to go to Sitka and to be baptized. The young man followed the advice. A few years later he became sick, and on his deathbed he

geographical designation that would have specified the group, such as the Kodiak Aleuts, or Unalaska Aleuts, or Atka Aleuts. Indeed, Veniaminov himself stated that some had derived from Kodiak. He also mentioned that the Russian-American Company office seemed to deny their existence. The following year during a pastoral visit to the village of Recheshnoi on Umnak Island, eastern Aleutians, Veniaminov told the village: anyone who sees "nomadic Aleuts" should "greet them and tell them that I feel sorry for them and desire that they should settle some place permanently and that they are pardoned" (ibid., journal entry 19 Aug. 1828).

I have noted this information, instead of placing in my text, because the information is secondary while very significant: it is Veniaminov relaying, and responsing to, a concern that he had received from the eastern Aleuts, and that he himself had accepted. The concern relates directly to the Old Harbor account regarding exiles; and in turn, the more substantial Kodiak Island data supports the eastern Aleuts' perceptions and Veniaminov's concern.

${ }^{160}$ Helen A. Shenitz, "The Legend that Built a Church", Capital City Weekly [Juneau, AK] (9 June 1967), pp. 1-2, quoted in Stamey (1979:74). Shenitz and Stamey were associated with this parish. 
called for the elders of his tribe and told them that the same venerable old man came to see him again and told him to advise the other Indians to be baptized. The young man died, but his message did not die with him. Other Indians started having the same vision and the urge to be baptized spread like wildfire.

Although this account from the Juneau area refrained from referring to the prophetic Tlingit young man as a "shaman", another account regarding the baptism of Unalaska Aleuts makes the reference explicitly, and the reference clearly corroborates the Old Harbor account: ${ }^{161}$

It seems proper to remember the predictions of the Shamans. It is probable that they much facilitated the work of the missionaries.

The source was Ivan Veniaminov, who remains credible for the Unalaska Aleuts with whom he had lived for a decade and whose language he spoke. He was himself informed about some aspects of the workings of Unalaska Aleut shamans from an older era: neither did he dismiss them off-handedly, nor did he embrace them naively in his retrospective considerations. ${ }^{162}$ And in his actual pastoral practice, he demonstrated an ability (deriving from regional knowledge and from patristic guidelines alike) to discern true prophecy from other phenomena. ${ }^{163}$ Furthermore, he himself was a Russian-Siberian from the Lake Baikal area, in proximity to the

${ }^{161}$ Veniaminov (1840b:148 ftnt.; 1984:231 ftnt.)

${ }^{162}$ (1840b:123-126; 1984:219-220). But Veniaminov's ethnographic notes pale, as should be expected, in light of the specific research by Shirokogoroff (1935). Can two sources be complementary? -- Shirokogoroff applying specific indepth fieldstudy and psychiatric training to the context of far northern shamanism, Veniaminov applying Greek Orthodox theological discernment within the content of the phenomenon.

${ }^{163}$ See Chapter 5 in my study. 
Evenk, or "Tungus", from whose language the very word "shaman" originated. ${ }^{164}$ Thus it was with particular knowledge that Veniaminov considered the account entrusted to him by the Unalaska Aleut elders.

He arrived at the following conclusion. Having considered whether the prediction was "truly the words of the shamans", or whether this account derived from "the fictions of old men" (in other words, from the old Aleuts who had related it to him their parental and grandparental generations), he decided: ${ }^{165}$

I leave it anyone to judge for himself, but I, for the most part, am on the side of the former because the Aleuts all suddenly and without the slightest compulsion accepted the Christian faith.

He accepted the account entrusted to him - "I, for the most part, am on the side of the former" - because the Aleuts "all suddenly and without the slightest compulsion accepted the Christian faith", as he said. ${ }^{166}$

In the Kodiak area, the final proof may also be found in the acceptance of this faith by the Alutiiq, and moreover in the ingrafting of this religion into their own community life and identity.

${ }^{164}$ Shirokogoroff (1935:268); Eliade (1964:4; 1987:202). Also see Tugolukov (1970:147).

${ }^{165}$ Veniaminov (1940b:124; 1984:219).

${ }^{166}$ Ibid. 
The account from Old Harbor is thus corroborated throughout by historic sources, including finally the reference to Veniaminov; and Haakanson himself is a leader of longstanding and of particular stature within a community in a significant location.

According to the account from Old Harbor regarding the baptism of the Kodiak Alutiiq, 1794/95, Kodiak Alutiiq identity, village membership and leadership became identified with baptism through indigenous spiritual and social processes involving direction by the Alutiiq people's own spiritual leaders: the conversion was thus an indigenous and corporate movement.

(8) Affinities and Attachments.

Once the processes intrinsic within the Old Harbor account are highlighted, then scholarly interpretations could begin to emphasize the meeting of, and synergy between, spiritually gifted indigenous people (Alutiiq) and spiritually gifted allogenous people. Among the latter was, specifically and most notably, the forest-dwelling monastic of Valaam, monakh Herman. ${ }^{167}$ And the interpretations would describe the lines of personal attachments along which the communication of this faith and its practices took place. These attachments in general, as well as certain affinities that engendered them, will be indicated next.

The transition occurred within the Alutiiqs' far northern hunting culture, as these people continued to exercise many of their own traditions confidently. Their confidence remains evident by the many intricate hand-crafts in museum collections,

\footnotetext{
${ }^{167}$ For Herman (venerated today as St. Herman of Alaska), see Chapter 6 in this study.
} 
as mentioned in section 6 to this chapter. ${ }^{168}$ Their confidence is evident also in the immediately preceding section by the rather hasty yet very indicative statement written in the 1830 s by Veniaminov, published in 1840 : "they openly adhere to their own shamanism". ${ }^{169}$ The statement was hasty as Veniaminov himself had never been to Kodiak to meet or observe any of these "shamans", as he had taken the initiative to meet the (so-called) "shaman" on Akun Island in the eastern Aleutians. Yet the statement indicates that traditional functionaries were practicing openly among a people who were visibly attached to them. This statement by Veniaminov prompts a question regarding the nature of this "shamanizing" that continued among these baptized people; and an answer begins to emerge in light of Archimandrite Ioasaph's report about the numbers of people baptized in 1794/95 (as quoted in the preceding section): they "were so willingly baptized that they destroyed and burnt all their shamanistic array". ${ }^{170}$ The term "array [наряди]" is indefinite, and may well have been non-inclusive in this context as signified by the statement written by Veniaminov a generation later. Not everything had been destroyed, or not all practices had been abandoned. Some phenomena had been maintained that elicited the "unanimous opinion" among "all who had been to Kodiak", probably foreigners (non-Alutiiq), that this constituted "shamanism".

A two-fold reality is thus yielded by Ioasaph's and by Veniaminov's statements: (i) the discarding of a type of "shamanistic array"; but also (ii) the continuity of some kind of "shamanizing", or rather of phenomena that appeared to

\footnotetext{
${ }^{168}$ See note 38 to this chapter, above.

${ }^{169}$ своихъ шаманствъ: Veniaminov (1840a:39). See ibid. (1972:49).

${ }^{170}$ шамаск iе наряпи: loasaph to Nazarii, 19 May 1795, HRS/RR/LCM 643:50.
} 
certain observers to constitute shamanizing. The challenge is to discern between these realities, and thus to achieve a perspective into the nature of the "shamanizing" maintained, and the nature of the "array" discarded, by a people who had been decisively baptized. This challenge will be accepted in Chapter 5 of my study, while presently my focus will remain upon the social and spiritual processes at the baptism of the Kodiak Alutiiq, 1794/95.

I identified these processes as indigenous (involving Kodiak Alutiiq spiritual and social dynamics) and as corporate (involving virtually whole lineages, or kinship-based polities). Now I shall place these processes within a description of the then-contemporary far northern hunters' culture, so that the initial communication of Russian Orthodoxy may be understood to have taken place from hunters to hunters along lines of personal attachments, engendered by certain affinities that existed between these people.

The Source for the Description. The primary source for this description of the affinities and attachements is George Vancouver who explored some regions relevant to this study during May and June 1794, immediately prior to the missionaries' arrival in September of that year. The regions that he explored more extensively were the Kenai Bay and the Chugach Bay areas. These were the very regions from where people would come to Kodiak to be baptized the following winter. He also explored along eastern and northern coasts of the Kodiak archipelago, from Sitkalidak to Shugak Islands, before voyaging eastward to the Kenai and Chugach Bay areas.

Although his explorations of the Kodiak archipelago were less intensive that those of the Kenai and Chugach Bay areas, yet his generalizations may be extended 
to the Kodiak archipelago, inasmuch as he observed Kodiak people in those bay areas, and as he included Kodiak people in his statements (quoted and cited below).

Were a qualification to be placed upon his observations, it would be that he most probably had interacted mainly with men attached to a merchant of lakutsk, surnamed Lebedev-Lastochkin, and had not had contact with the company of Golikov and Shelikhov. Vancouver did not enter the settlement at Pavlovskaia gavan on Kodiak Island, where the missionaries would arrive; nor did he visit the Golikhov and Shelikhov company's outpost at the tip of the Kenai Peninsula, but instead proceeded farther into Kenai Bay where the Lededev-Lastochkin company was located.

Vancouver's observations were predicated upon greater experience than one might expect from transient explorers. He had had prior experience in these same regions when he had been midshipman on Cook's third voyage which had explored here in 1778 , sixteen years earlier. ${ }^{171}$ Vancouver moreover had had extensive global experience, as he had taken part not only in Cook's third circumnavigational voyage but earlier yet in the second also; and most recently prior to the circumnavigational voyage that he himself was now commanding (1791-1794), he had had nine years in Dutch service in the East Indies. He thus had considerable experience in various parts of the world, both in Dutch and British service, on which to predicate his observations of the "Russians and Indians". Finally as a consideration regarding the credibility of his observations, he was in fact an explorer: an outside observer without an invested interest here; and he developed his perceptions regarding social life in

${ }^{171}$ Cook's third voyage explored here prior to Unalaska Island (it was at the later location that corporal Ledyard was dispatched into the hunters" camp, as described in section 7 of this chapter, above). Kenai Bay where Vancouver would write the observations relevant to this study, is also known today as Cook Inlet due to the earlier, and lesser, exploration by Cook. 
these regions to a greater length than one might expect from explorers whose observations were usually comparatively cursory. He developed his perceptions with detail for a combined total of twenty pages, from which the quotations below have been selected.

Affinities. Vancouver was impressed that Russians "appeared to be perfectly content to live after the manner of native Indians": ${ }^{172}$

They appear to be perfectly content to live after the manner of native Indians of the country; partaking with equal relish and appetite their ... food adopting the same fashion, and using the same materials for their apparel, and differing from them in their exterior appearance only by the want of paint on their faces, and by not wearing any of the Indian ornaments.

They were living within a similar culture. Wearing the same clothing, sharing the same food, they differed only slightly from each other in this explorer's eyes. He recorded the affinity yet again, while remarking on a mutual assimilation that he observed: ${ }^{173}$

Without deviating much from the habits and practices of their earliest infancy, the Russians can readily adopt many of the lndian customs, by which means the manners of the two people become much assimilated. This is greatly furthered by their partaking of the same sort of food, and wearing the same sort of clothing. Their external appearance differs little from the natives.

Vancouver's perceptions in 1794 are consistent with the actual origins of the men at this time. The majority of the Russian hunters into the 1780 s derived from

\footnotetext{
${ }^{172}$ Vancouver (1984:1241).

${ }^{173}$ Ibid., p. 1309.
} 
Russia's far east and northwest (as mentioned also earlier in my chapter). ${ }^{174}$ By 1799, the majority derived from the towns of Siberia. ${ }^{175}$ Ancestral cultures indigenous to all these regions were more-or-less far northern hunters' cultures, in contradistinction to the agrarian cultures in Russia's west-central and southwestern regions, the latter including Little Russia, also known as the Ukraine. ${ }^{176}$

Hunters' culture(s) might not be expected in Russia's northwest, which extends from approximately the latitude of Vologda northward to the White and Pechora Seas and includes Karelia as well as Komi-land. But these too were regions of ancient hunters' cultures. Karelia for example was the cradle of runes that came to comprise that great saga of Arctic hunters, the Finnish Kalevala. These runes were collected between 1824 and 1845 , contemporaneous with Russian-America. ${ }^{17}$ The regions of the northwest, more over, had fostered Arctic maritime hunting and exploration recorded since the 16 th century: $:^{178}$ hence these men's ability for the sea hunt in the north Pacific, and also their ability to construct seaworthy vessels from local materials

${ }^{174}$ Fedorova (1971:155; 1973:168-169). For the composition of Russian hunters from the 1740 s into the 1760 s, see my note 27 to this chapter, above.

${ }^{175}$ Fedorova (1971:158-159; 1973:172-173).

${ }^{176}$ Also see Fedorova $(1971: 156 ; 1973: 169)$ : "It is a characteristic that among the northern gubernias of Russia most of the departing peasants and tradesmen came ... specifically from those uezds where agriculture and cattle breeding were weakly developed ... and the chief regional occupations were crafts (hunting, forestry, salt-boiling and others)."

${ }^{17}$ See Pentikäinen (1989:229). It is noteworthy that all the major sources but one for these runes were Orthodox and Old Believer Karelians: ibid, pp. 99-115, 124-130. (See my note 75 to this chapter, above, for comments regarding the Komi Old Believers.) These runes will be mentioned again in this study: see the Epilogue to Chapter 6.

${ }^{178}$ Lantzeff and Pierce (1978:20, 127). 
for the open sea crossings from Kamchatka. The indigenous far northern culture(s) might not be expected in Siberian towns either; however, in the town of Iakutsk where the merchant Lebedev-Lastochin was registered -- (a town that had developed from a fort founded by Cossacks in the early 1600s) -- the settlers had become "Iakutized", as they had assimilated the Iakut language to the demise of the Russian language among them as late as the 1890 s, a century later than Vancouver's observations. ${ }^{179}$ Vancouver's perceptions regarding affinities and mutual assimilation are thus supported by analytical and other historical data.

Attachments. Affinities can engender personal attachments; and certain attachments were also perceived by Vancouver, as the "the Russians seemed to live upon the most intimate terms of friendship with the Indians of all descriptions; "180 and as "the Indians" had an interest in these Russians' "success and welfare". ${ }^{181}$ Certain "principles of attachments", as Vancouver expressed it, had formed which were evidently interpersonal alliances: ${ }^{182}$

The interest the Indians seem to take in the success and welfare of the Russians, originates in principles of attachment which do not appear likely to be easily removed by the influence of strangers to the prejudice of the Russian commercial interest, and which from the

\footnotetext{
${ }^{179}$ Iakutsk Church Brotherhood (1897:3). One of the primary aims of this organization in 1895-96 was to teach the Russian language to Iakuts and Russians alike, because Iakut was the predominant language among the latter as well. This fact has been emphasized also in my note 13 to chapter, above.

${ }^{180}$ Vancouver (1984:1241).

${ }^{181} \underline{\text { Ibid., }}$ p. 1309.

${ }^{182}$ Ibid.
} 
practice of the present day may probably be strengthened in the succeeding generations.

These men lived closely and comfortably together, as these Russians had found a way the

to heart and secured "an affectionate regard" among the "Indians": ${ }^{183}$

Although we could not gratify our curiosity to the extent I could have wished respecting the situation of the Russians, yet I could not avoid feeling a degree of satisfaction in observing the comfortable manner in which they seem to live amongst these untutored children of nature; having gained them over to be obedient to their wishes, they appear to maintain their influence not by fear, as their conquerors, but by having found the way to their hearts, and by securing an affectionate regard.

These "Indians" were particularly Alutiiqs ("people of the Kodiak") and Dena'ina Athapascans ("people of the Cook Inlet"); they spoke of their "attachment" with "praise": ${ }^{184}$

This was manifested in all their [these Russians'] transactions, though more especially in their intercourse with the people of Cook's inlet and the Kodiak; many of whom, the women as well as the men, are retained in the service of the Russians, who speak of their attachment and fidelity in the highest terms of praise and approbation, and indiscriminately employ them with their own parties on business of the most confidential importance.

These observations by Vancouver describe people living intimately and comfortably with each other in relationships of affection, confidence and trust.

${ }^{183} \underline{\text { lbid., }}$ p. 1308.

${ }^{184}$ Ibid. 
A glimpse into the initial Kodiak settlement. While Vancouver's perceptions in 1794 were predicated upon numerous experiences in this region, another explorer, Gonzalo Lopez de Haro offers an interesting glimpse, if fleeting from a sojourn of a single morning, into the initial camp on Kodiak Island in 1788 where affinities again become evident, and the practice of religion is evident as well. ${ }^{185}$

The intial camp was Tri Sviatitelia gavan (at today's Three Saints' Bay), the establishment founded by Shelikhov on Kodiak Island four years prior to Lopez de Haro's exploration of this site. Four years subsequent to his exploration, the settlement would be moved to Pavlovskaia gavan (today's Kodiak town) by a new on-site chief manager, Aleksandr Baranov.

The "officers [oficiales]" whom Lopez de Haro met at Tri Sviatitelia gavan were from "Siberia. ${ }^{186}$ One of the men from eastern Russia who was active in the Kodiak enterprise at this time was Gerasim Grigor'evich Izmailov who had studied navigation at Irkutsk and had distinguished himself as a navigator and explorer in the north Pacific; indeed, he had corrected the maps carried by Cook when Izmailov made contact with the Enterprise and the Discovery at Unalaska in 1778. Journals from Cook's third voyage describe him as a "native of lakutsk" and also as "leader among the Russians". ${ }^{187}$ A child at the relocated establishment on Kodiak Island was his own godchild whom he took away from the company camp in $1795 .{ }^{188}$ When Lopez

\footnotetext{
${ }^{185}$ Lopez de Haro (ms.), trans. and ed. Moore (1979:67-69).

${ }^{186}$ Lopez de Haro (ms.: 104).

${ }^{187}$ Cook, Clerke and King in Beaglehole (1967:450, 1335, 1446, 1450).

${ }^{188}$ Aleksandr A. Baranov to Grigorii I. Shelikhov and Aleksei E. Polevoi, 20 May 1795, in Tikhmenev, ed. (1863:91; 1979:69).
} 
de Haro visited the original camp in 1788 , Izmailov was away exploring the Chugach Bay area. The unnamed "officers" whom Lopez de Haro met here at this time were yet other men from "Siberia".

An "officer" had a wife here who appeared to be "white [blanca]" to this explorer who himself had been born in, and had journed northward from, Mexico. She was dressed in oriental fashion: "very modestly in the manner of Chinese women with very good clothes of this kind". ${ }^{189}$ Two other women, whose beauty he also admired, were dressed in similar fashion, and were themselves "daughters of Siberia [Hijas de la Civeria $(\underline{\text { sic) }}]^{1 .} .{ }^{190}$

The "captain" was "del Aro", as Lopez de Haro transliterated the name. ${ }^{191}$ Actually the company's chief manager Delarov, Evstratii Ivanovich, he had begun his career more than twenty years earlier on the Aleutian lslands. ${ }^{192}$ Delarov had not been present at the founding of the Kodiak settlement in 1784 , but had been subsequently hired by Shelikhov in 1787 , a year prior to Lopez de Haro's visit, when Shelikhov returned from Kodiak to Okhotsk. Delarov would remain in this position until 1791. This "captain" was originally from the Peloponesse. ${ }^{193}$ He was a Greek.

${ }^{189}$ Moore (1979:69). See Lopez de Haro (ms.:107). For Lopez de Haro's birthplace see: "Lopez de Haro (Gonzalo)" in Enciclopedia Universal Ilustrada, vol. 31, pp. 146-147 (n.d.): photocopy and citation provided by the Manuscripts Division, Huntington Library, San Marino, CA.

${ }^{190}$ Lopez de Haro (ms.:107).

${ }^{191}$ Ibid., p. 104.

${ }^{192}$ For Delarov, see Pierce (1990:115-117).

${ }^{193}$ But Lopez de Haro (ms.:104) writes: "navida [sic] en Constantinopola". 
The "Indians [Indios]", of whom there were many in the establishment, remained undifferentiated from each other in Lopez de Haro's account as some were attending to pelts valued for sale in China and in Europe; others were preparing whale oil, others a catch of fish; and yet others were "attending school [tenian una Escuela] to learn the Russian language. ${ }^{194}$

"Doctrine [la Doctrina $]$ " was also being taught. ${ }^{195}$ Religion was furthermore evident when Lopez de Haro observerd "many pictures of saints well painted [muchos quadros de Santos de superior pintura]" in the captain's and officers' rooms. ${ }^{196} \mathrm{He}$ mentioned the presence of a "chaplain [capellán]", 197 who would not have been a priest as there were no clergyman here or in proxmity at this time. He would have

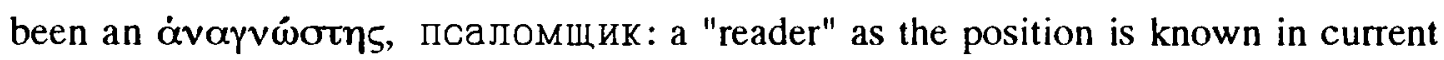
English usage in Alaska. Proficient in chant and ritual for the daily, weekly, and seasonal cycles of prayers, and for life-crisis rites, he would conduct the services performed by the laity without a priest. A beached galliot served as a "chapel [capilla $]^{\prime \prime} \cdot{ }^{198}$

Thus Lopez de Haro's account regarding the initial settlement at Kodiak in 1788, in which affinities with "Indians" were evident among the Russians, reflects some of the dynamics described by Vancouver in other locations in 1794 . The practice of religion is also evident in Lopez de Haro's account.

\footnotetext{
${ }^{194}$ Ibid., p. 106.

195 Ibid.

${ }^{196}$ Ibid., p. 107.

${ }^{197}$ Ibid., p. 106.

${ }^{198}$ Ibid.
} 


\section{(9) Chapter Summary and Conclusions.}

The purpose of this first chapter has been to indicate that the transition was indigenous and corporate: it involved indigenous spiritual and social processes, and involved the whole body of peoples' societies, or kinship-based polities.

Even in the Kodiak area where the historical circumstances at the initial contacts differed from those on the Aleutian Islands, the characteristics of the transition were fundamentally the same: indigenous and corporate. These characteristics became clear in the account from Old Harbor by Haakanson; and they were evident in the observations in the Kodiak, Kenai Bay and Chugach Bay areas by Vancouver. They were also evident in the more cursory yet informative report by Lopez de Haro. Haakanson's account and the explorers' reports are substantiated by analytical studies and by other historical sources (as cited).

The affinities described repeatedly by Vancouver in 1794 are reminiscent of those observed by Ledyard in 1778. In the hunters' camp on Unalaska Island, eastern Aleutians, Ledyard could not easily distinguish "Indians" from "Russians", although unlike Vancouver he was unaware of his own confusion. Moreover, the repeated descriptions by Vancouver regarding the positive personal attachments and the affinities, are reminiscent of the report by Cherepanov regarding the similiar customs, the baptism, and the perception of the healing among the hunters on the western Aleutian Islands, 1759-1763.

On the Aleutian Islands, insights were forthcoming into the process of the initial communication of this faith and its practices, especially as Aleut toions entrusted their young kinsmen to Russian godfathers, and the godsons later assumed 
the leadership in their own communities. The history of the godfather Stepan Glotov and his godson Ivan Glotov was particularly indicative in this respect, as the latter built the first chapel on the eastern Aleutian Islands, and as he himself conducted the lay services there as the bilingual and literate toion of Umnak. In subsequent generations, the Aleut people were conducting baptisms and prayers themselves within their own villages, so that in the 1820 s the priests Veniaminov and Netsvetov were assigned not as missionaries but as parish priests. Netsvetov was himself Russian-Aleut. Veniaminov derived from a village in the Irkutsk region, Asia.

This chapter should signify that the communication of this faith and its practices took place from like to like: that is to say, from northeast Asians and far northern Eurasians to Aleuts and Alutiiqs within the Far Northerners' own culture(s). ${ }^{199}$ Therefore to comprehend this history, Christianity must not be identified a priori with any other peoples or culture(s). Orthodox Christianity existed, and the communication of this faith and its practices occurred, within the Far Northern hunters' own culture(s). This perception will be developed in subsequent chapters and emphasized in the final conclusions in this study; yet the perception should be highlighted now, as it leads to the questions that will guide the next chapter.

${ }^{199}$ I have written "culture(s)" because these men derived from different nations ( $\check{\theta} \theta \eta$, наропы) which in contrast to each other would be considered different cultures; but together the affinities between them could be described as a general type of culture. 



\section{CHAPTER 2}

\section{CORRESPONDENCE}

For the transition to have been indigenous and corporate -- involving these peoples' social and spiritual processes, and occurring through the whole body of their societies, or kinship polities -- there must have been vital characteristics within their own ancient cultures that corresponded to, and could engage, the Orthodox Christian faith and practices. In this chapter, a theoretical basis for the existence of this correspondence will be established. Correspondence means similarity, or agreement in significant ways, not necessarily equivalence.

The first section will address the following questions: Are there precedents within patristic theology that would support a theory of correspondence? If so, were areas of correspondence recognized and expressed in historic sources with specific reference to the ancient Aleut and Kodiak Alutiiq cultures, the primary focus of this study? Affirmative answers will establish a basis for a theory of correspondence.

In the final section, the theory will be tested with reference to the ancient Yup'ik Eskimo culture before the theory is applied to the ancient Aleut and Alutiiq cultures (in Chapter 3). The "test case" will involve the Aleut-Russian priest, lakov Egorovich Netsvetov, as he ministered among the Yupiit.'

${ }^{1}$ The part of the material in sections 1 and 2 of this chapter was presented as a paper at the First [International] Kodiak Island Culture Heritage Conference, sponsored by the Kodiak Area Native Association, Kodiak, Alaska, 28-30 March 1988; published as Mousalimas (1989b). Material in section 3 was presented as a paper at the Conference on the Cosmologies of Polar Peoples, University of Edinburgh, 26 Nov. 1988; published as id. (1988c). The present work supercedes these publications in referencing as well as in textual details. The overall themes remain the same. 


\section{(1) Precedents within Patristics.}

Are there precedents within patristic theology that would support a theory of correspondence? An appropriate starting-point is St. Justin the Martyr (c.100-c.165): not only because he considered ancient Greek culture within the Graeco-Roman world, and may thus provide a theological prototype for the consideration of an ancient pre-Christian culture; but also because he was quoted and cited by Valaam Monastery in a publication on the mission to Kodiak, at the centennial of that mission. ${ }^{2}$ Valaam cited the following passage from Justin that contains a theological kernel that would engender an affirmative, or positive, outlook upon elements in pre-Christian cultures: "[God] is not a name, but glory inexplicable implanted in the nature of humanity." ${ }^{\prime 3}$ The phrase "God is not a name" signifies that the divine is not merely a concept to be taught and learned, professed by one group to be understood by another. Instead, the divine glory is present within the very nature of humanity and extends beyond explication.

\footnotetext{
${ }^{2}$ Valaam (1894a:35; 1978:22). As the text continues in ibid. (1978:23), an error occurs in the translation that should be noted because it renders a universal theological principle into a narrow racist statement. The translation reads: "... originally God's Revelation was limited in all its purity to the European peoples alone." But Valaam (1894:23) wrote: наропа еврейскаго, the Hebrew people.

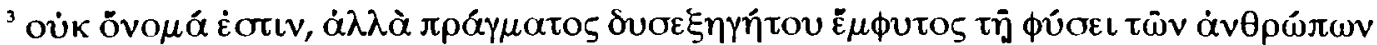

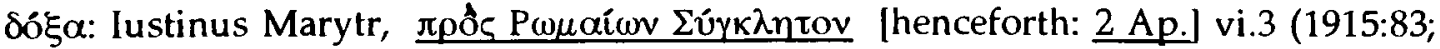
1987:204). The subject "God" inserted within brackets in the translation derives from verses 1-2, immediately precedding. The same insertion is found in Valaam (1894a:35; 1978:22). The translation in Valaam (1894a:35) is otherwise literal: Бог' не есть имя, но мысль, всажденная въ природу человьческую, о чемъ-то неизъяснимомъ.

For the word $\delta$ ó $\xi \alpha$, translated as "glory", see Liddell and Scott (1940:444): (i) expectation; (ii) notion, opinion; (iii) opinion others have of one, mostly of good repute; (iv) glory, splendor, generally magnificence. For this word for the glory of God see: Gen. 31:16, Ex. 16:10, 24:17, 40:34, John 1:14, Acts 7:55, 22:11, 2 Cor. 3:18.
} 
The Positive Outlook. This presence, or "implanting", is intrinsic within our creation, according to Justin who refers to Genesis $1: 26$, that humanity has been created in the divine image and likeness: this image is the "seed of the Logos", a "share of the divine Logos disseminated", within the very nature of humanity." Even through the Fall (the distancing of humanity from divinity), this "seed", or "share", had not altogether been destroyed, because it had been implanted within our very nature. Our contact with the divine persisted, indeed within the very nature of humanity universally. Thus despite the Fall, extraordinary people could live according to the seed of the Logos within them, and a divine likeness could thus become evident in them, according to Justin; yet their illumination and righteousness would remain partial in comparison with the fullness which was to come when, through the Incarnation of the Logos in Jesus Christ, the image of God would be fully regained and the likeness would become fully visible: ${ }^{5}$ then, the fullness could be known and received.

Justin thus affirmed two complementary realities: (1) the universal dissemination, or presence, of the divine Logos from whom no one was entirely separated, and in whom everyone partici pated to greater or lesser degrees; and (2) the fullest possibility for union with God (hence, salvation), given uniquely through the Incarnation.

These complementary realities, or the "dual complement" (as 1 shall term it), can be seen especially in his most vivid example, Socrates, who, conforming to the divine within, and living a life of truth and virtue, became highly illumined and

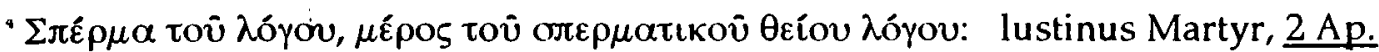

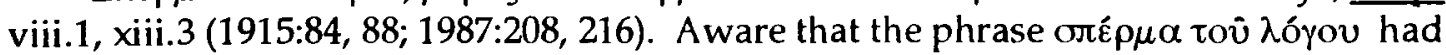
been employed by the Stoics (ibid., viii.1), he appropriated the phrase, but not necessarily the Stoics' interpretations of this phrase.

${ }^{5}$ Ibid. x.1-8; xiii.6 (1915: 85-86, 89; 1987:210, 216). 
righteous. As he heeded the divine disseminated in his very nature, Socrates was following the Logos, so that Justin boldly described him as a Christian before Christ. ${ }^{6}$ Yet even Socrates's extraordinary perfection remained incomplete in comparison with the fullness that was to be given in Christ.?

This bold statement about Socrates has caused Justin to be imagined as equating Christianity with "the best elements" in philosophy, as if Justin had considered them to be "almost identical ways of apprehending the same truth". 8 But was Justin such a relativist? The dual complement in his thought should itself preclude the possibility. It would be more accurate to state that he had recognized the godliness evident particularly in Socrates, and therefore affirmed the potential within those elements of philosophy that Socrates represented, indeed affirmed this potential in a manner superlative to any other patristic writer except perhaps Clement of Alexandria. After all, it was not to "elements of philosophy" that Justin was referring but to the person of Socrates, a teacher who had elevated his own disciples' minds towards an apprehension of virtue, a teacher who had taken the heroic stand for this virtue himself. It was this person whom Justin affirmed in the boldest terms as conformed to and thus guided by the Logos before the Incarnation of the Logos; conformed to and thus guided by Christianity before Christ, within the context of the dual complement.

As Justin perceived a presence of the Logos in Socrates, so should a theory of correspondence recognize this presence within other pre-Christians; and precisely as the dual complement precludes relativism from Justin's affirmative outlook, so

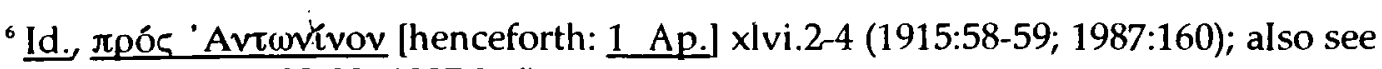
2 Ap. xiii.4-6 (1915:88-89; 1987:216).

'See my note 4 to this chapter, above.

${ }^{8}$ H. Chadwick (1966:10-11). 
would it exclude the same from a theory of correspondence predicated upon Justin's thought and upon the patristic tradition to which he belongs.

Can the dual complement in Justin's outlook be placed within a patristic tradition? He wrote two generations after Christ's Apostles.' Earlier than him, the positive, or affirmative, outlook upon human nature, so beautifully developed by Justin, was expressed in the Gospel according to John. Rather than stressing the distancing of humanity from divinity, which it clearly recognizes (John 1:10-11), the Gospel, like Justin, emphasized the positive aspect that everyone existed in, and was illumined by, the divine Logos (John 1:3,9). The Gospel then brought forth the full life and illumination now possible in Christ.

The positive outlook was expressed by mainstream theologians who immediately followed Justin in the late second century: Theophilus of Antioch, ${ }^{10}$ Irenaeus of Lyons, ${ }^{11}$ and Clement of Alexandria; ${ }^{12}$ and it was expressed by

\footnotetext{
${ }^{9} 1$ Ap. was written about the year A.D. $155 ; 2$ Ap. followed, after the succession of Marcus Aurelius, according to Cross and Livingstone (1983:770). Cf. Wartelle (1987:21-22) who dates the existence of both Apologies to about the year A.D. 153.

1970: 64-69;

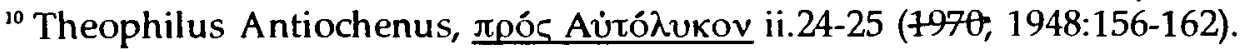

${ }^{11}$ See Williams (1927:189-199).
}

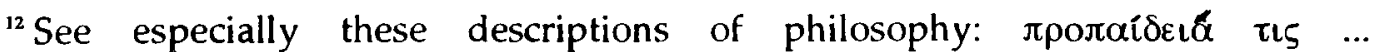

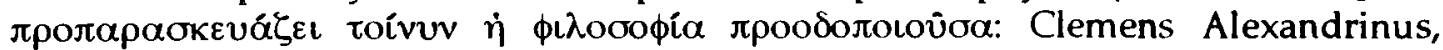
$\Sigma \tau \rho \omega \mu \alpha \tau \varepsilon i \varsigma$ I.v.28,1-3 (1985: 17-18). But notice that if these descriptions are extracted from their context, a misconception can occur, as will be explained in this note. In the $\Sigma \tau \rho \omega \mu \alpha \tau \varepsilon i c$, he likens the efforts of Greek philosophers to the efforts of the Hebrew prophets to elevate their respective peoples towards virtue; and it is in this context that he describes philosophy as "a kind of schooling ... coming beforehand, preparing the way". The perspective is more historic than current. Extracted, however, the descriptions might appear to imply a contemporary typology instead of a retrospective one: as if he were advocating the teaching of philosophical systems in preparation for a comprehension of Christian theology. This would be the misleading assumption, particularly if it were applied to the systems of logic such as the Aristotelian categories and the "Porphyrian Tree"; because elements in those systems can work away from, not towards, certain principles operative within theology (as will be explained in Chapter 3 , secs. 1 and 2). The contrary direction should be expected particularly with regard to Porphyry who authored a treatise against Christianity. The context of the Clement's descriptions within the $\underline{\Sigma} \rho \omega \mu \alpha \tau \varepsilon i \varsigma$ is 
subsequent great theologians as well. For example in the early fourth century, St. Athanasius of Alexandria stated that the Fall had not entirely annihilated the divine image in humanity. Instead, a process towards entire corruption had been precipitated by the Fall, ${ }^{13}$ until the Incar nation intervened with the fullness made possible uniquely in Christ. Just as the destruction of the divine image was not total, according to the bishop of Alexandria, neither was the separation of humanity from God. To the contrary, the divine Logos exists in the cosmos, "giving light and movement by His providence to all things in it".14 In his other writings, those against the Arians, Athanasius emphasized the uncreated divine nature of the animating and vivifying Logos. Athanasius thus expressed the dual complement, and moreover emphasized the divine presence within the cosmos.

The latter perception -- of the divine presence, itself an integral aspect of the dual complement that engenders and supports the positive outlook --was expressed in the same century as Athanasius by St. Basil of Caesarea (Basil the Great, c. 329-379) in particular. Just as the bishop of Alexandria had earlier confronted the Arian heterodoxy which would diminish the divinity of the Logos, so this bishop of Caesarea confronted a heterodoxy which would diminish the divinity of the Holy Spirit: ${ }^{15}$ both bishops in both generations thus affirmed, indeed defended, the operation of undiminished divinity within the cosmos. And just as Athanasi $u$ s had

therefore important; and my quotations will imply this context, as interpreted in this note.

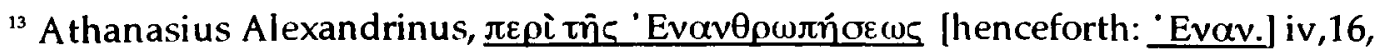
vi,2-4 (1971:142, 146); also see ibid. lines 19 and 4-5 (1973:276, 282). Notice the verb tenses in the original: $\delta \varepsilon \phi \theta \varepsilon\{\rho \circ \tau \tau$, , $\phi \alpha v i \zeta \varepsilon \tau o, \pi \alpha \rho \alpha \pi \omega \lambda \lambda v \tau o$.

${ }^{14}$ lbid. xlvi,24-25 (1971:236); also see ibid., line 27 (1973:414).

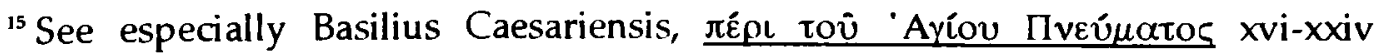
(1892:77-113). 
stated that uncreated divinity was itself illuminating and animating "all things", 16 so Basil stated that divinity is itself immediately present in creation through the divine "energies", or operations."

The same fundamental perception of the divine presence in the cosmos remained consistent, although terms varied, among early patristic writers. In the next generation, St. John Chrysostom (c.347-407) articulated this perception in terms of

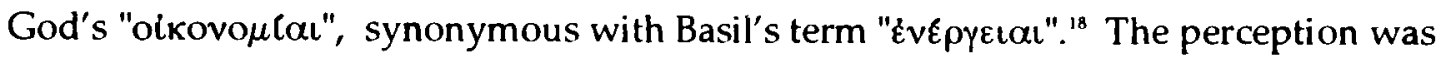
subsequently articulated in writing to a degree further than any predecessor by St. Maximus the Confessor (C.580-662) who preferred the term $\lambda \sigma \gamma o t$-- reminiscent of Justin's own expression -- to signify the divine presence that sustains all creation; and the articulation was advanced yet further by St. Gregory Palamas (1296-1359) with

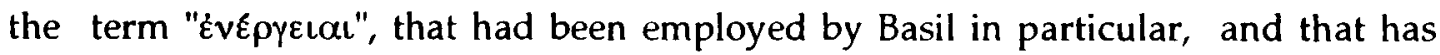
become standard since.

Therefore, Justin's perception of divine presence in the cosmos --a vital aspect within the dual complement that engenders the positive outlook --exists firmly within this patristic tradition; and when Valaam quoted and cited Justin in the publication regarding the mission to Kodiak, the monastery was, in effect, referring to this tradition.

\footnotetext{
${ }^{16}$ As cited in note 14, above: Athanasius Alexandrinus, Enan. xlvi,24-25 (1971:236); also see ibid., line 27 (1973:414).

${ }^{17} \dot{\varepsilon} v \varepsilon ́ \rho \gamma \varepsilon \iota \alpha$ : Basilius Caesariensis, Ep. 234 [to Amphilochius] (1966:41-42); also see ibid. (1857a:869C-870B).

${ }^{18}$ Ioannes Chrysostomus, $\pi \varepsilon \rho i{ }^{\prime}$ Ak $\alpha \tau \alpha \lambda$ úлtov i.280-281 (1970:124). Also see ibid., ii.359-361, ii.370-371, iv.113-115 (1970::170, 172, 238). For the theological relationship between Chrysostom 'and the Cappadocians in this respect, see Christou (1973). But notice the differing effect when oikovo $\mu$ i $\alpha /$ oikovo $\mu$ i $\alpha$ is rendered as "le gouvernement de l'universe", and "les desseins de Dieu", in loannes Chrysostomus $(1970: 125,171,173,239)$. Renderings such as those allow a conceptual separation of the divine from nature according to the dictates of theism. For "theism", see Chapter 3 , sec. 1 .
} 
When the quotation from Justin is explained within a particular context in this tradition, the meaning may increase in significance. The context involves Basil's and Chrysostom's polemic against Eunomianism, a heresy which had interpreted the phrase $\sigma \pi \varepsilon \rho \mu \alpha \tau \iota \kappa o i ~ \lambda \sigma \gamma o l$ as if the $\lambda \sigma$ yol were in fact words, or names, disseminated by divine providence to indicate the essences of phenomena. A real, or revealed, name was supposed by the Eunomians to indicate a reality in its essential self, and thus rational creation was supposed to be able to comprehend and profess essential reality through dialectic and reflective exercises of the intellect upon a name. No less than the essence of divinity was expected to be grasped and professed in this way, through the names revealed for the Trinity. Against this misinterpretation of the

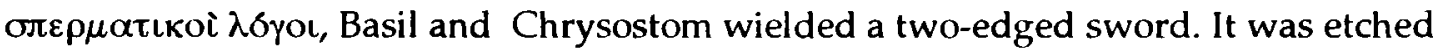
on one fine edge with the "incomprehensibility of the divine essence", to severe the presumption that the intellect could encompass the divine. And it was emblazed on the other fine edge with the "energies", or "economies", to defend the presence of undiminished divinity that actually, not nominally, sustains and illumines all things. This presence was itself "implanted", as Justin would state, and as Valaam would cite: ${ }^{19}$

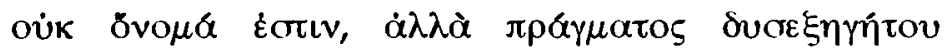

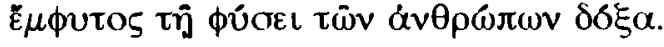

It is not a name, but glory [the energy] implanted within the nature of mankind, about something [the incomprehensible essencel that can not be explained.

Valaam cited Justin whose outlook exists firmly within this patristic tradition.

In accord with this patristic tradition, a theory would avoid relativism because of the one aspect of the dual complement -- that the fullest possibilities are given uniquely through the Incarnation. At the same time, because of the other aspect --

\footnotetext{
${ }^{19}$ Iustinus martyr, 2 Ap. vi.3 (1915:83; 1987:204). Cf. Valaam (1894a:35; 1978:22).
} 
that a highly potential contact of humanity with divinity endures within the very nature of humanity -- the theory would recognize relative righteousness and illumination among pre-Christians and non-Christians. The latter must be expected when the presence of the divine Logos is affirmed as a universal: that is to say, it must be expected more-or-less depending upon the relative degrees of people's participation in the divine; and this participation may reach extraordinary degrees as in Socrates's case.

\section{(2) A Negative Outlook}

There was another attitude however, an opposite one. It derived from a conviction that evil had prevailed over humanity's primal goodness, so that the very nature of mankind had become utterly corrupt. The major proponents of this theology in the early church were Tertullian (c. 160 - c. 225) and St. Augustine of Hippo (354 - 430).

Accordingly, the depravity of fallen humanity was thorough, progenitive, and inherited. Wholly ruined, humanity was "marked" with "a sentence of transgression". ${ }^{20}$ Sinful at its root, it was a "stock condemned". ${ }^{21}$ No one was exempt, not even children. Corrupted essentially, and belonging by nature to this

${ }^{20}$ Tertullianus, de Resurrectione carnis 34 (1960:92, lines 5-6): "totum hominem elogio transgressionis inscripsit". See ibid. (1870:272): "it has marked the whole man"; but cf. (1960:93): "[it] has involved the whole man".

${ }^{21}$ Augustinus Hipponensis, Enchridion xxiii.92 (1969:98; 1953:80): "perditionis massa". Also see id. ad Laurentium, Ep. ccxiv.3 (1911:382 [repr. 1930:408]; 1930:409): "massa illius perditionis", "that mass of perdition"; but cf. (1956:59): "clay of perdition". Also see id. "De peccato originali" xxxviii.43 (1902:200-201): "Ubi ni hil deus fecit, nisi quod hominem voluntate peccantem iusto iudicio cum stirpe damnauit, et ideo ibi quicquid etiam nondum erat natum merito est in praevaricatrice radice damnatum, in qua stirpe damnata tenet hominem generatio carnalis". See ibid. [43 (xxxviii)] (1887:252): "Where God did nothing else than by a just sentence to condemn the man who willfully sins [Adam], together with his stock; there also, as a matter of course, whatsoever was even not yet born is justly condemned in its sinful root. In this condemned stock carnal generation holds every man". 
"massa damnata", and "massa perditionis", they too were eternally damned unless saved through baptism. ${ }^{22}$

This line of thought was highly legalistic. For example, Tertullian (trained as a lawyer himself) asserted that a soul remained "unclean" (immunda) unless "recounted" (recenseatur) in Christ, ${ }^{23}$ as if salvation were a census in which

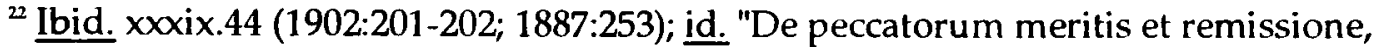
et de Baptismo" 1.xii.15, I.xv.20- I.xx.28, II.xxvii.43, III.iv.7 (1913:15-16, 20-27, 114-115, 133-134); see ibid. (1887:20, 22-25, 62, 71). Also see H. Chadwick (1986: 111). Also see Cross and Livingstone (1983:109): "At times Augustine shows himself to be frankly Predestinarian. The whole human race is one mass of sin (massa peccati), out of which God has elected some souls to receive His unmerited mercy. There is no other explanation of the elect and non-elect than the inscrutable wisdom of God, and babies who die unbaptized go into everlasting perdition."

Compare Tertullianus de Anima xxxix (1947:55-56; 1950:270- 271), who assigned this condemnation to children of pagan parents and attributed the corruption to these parents' invocations of pagan gods during gestations and births.

${ }^{23}$ Tertullianus, de Anima Ix (1947:56, lines 15-16). Also see Cross and Livingstone (1983:1352): " 'De anima' ... prepared the way for that pessimistic doctrine of the Fall and Original Sin which came through Augustine to dominate Latin theology."

Compare Tertullian in Latin (as cited) with the renditions into English (Tertullian $1950: 271 ; 1870: 504)$ : the original "recenseatur" is rendered, respectively, into the phrases "reborn" and "born again". The following note will explain the reason for "recounted" as the translation in my text. Tertullian was obviously alluding to the verse (known today as) 1 Pet. 1:23. In that verse, the word $\dot{\alpha} v \alpha \gamma \varepsilon \gamma \varepsilon v v \eta \mu \varepsilon$ vo properly translated as "born anew" and "born again" in the RSV and the KJV (AV), respectively: the RSV is equivalent to the rendition of Tertullian in English translation ibid. (1950:271), and the KJV is identical with that in ibid. (1870:504). Evidently the Biblical phrases were placed into Tertullian's text when it was rendered in English. But Tertullian did not use $\dot{\alpha} v \alpha \gamma \varepsilon \gamma \varepsilon v \vee \eta \mu \varepsilon ́ v o \iota$ or its Latin translation himself. The Latin translation in 1 Pet. 1:23 is renati, as found in the critical edition of the Vulgate (Wordsworth and White 1949), and in Stephanus's (Robert Estienne's) editions of the Latin Bible printed at Paris and Lausanne during the first half of the 16th century.

Tertullian's term is different, deriving not from this verb renasci (renascor) but from the verb recensere (recenseo). The latter is found, very significantly, in Old Testament verses such as Exod. 30:12, where the saved are described as numbered against impending doom:

When thou takest the sum of the children of Israel after their number, then shall they give every man a ransom for his soul unto the Lord, when thou numberest them; that there be no plague among them, when thou numberest them.

Tertullian's term is found similarly in Num. 1:18,22, 24, 29, 30, where the people of God, who are being led towards the promised land, are described as counted by Moses and Aaron. For other verses, see "recenseo" in Fischer (1977:4361). This is the term, and the meaning, that Tertullian imputed into the allusion to Peter's first 
individuals were enrolled, having passed through the baptismal font as through a laver.

Salvation in this type of thought was indeed a kind of census, in which particular individuals only were counted. They were an elect, chosen and predestined by God, according to Augustine; while the rest of humanity remained depraved, therefore justly damned, and eternally alienated from the divine. ${ }^{24}$

Among the non-elect, there could be very little, if any, possibility for illumination and righteousness. This was true even of the ancient philosophers. Their partial revelation of morality and of divine existence had, according to Tertullian, come not from within themselves but from the ancient Jewish prophets. The ancient Greeks had received inspiration from the ancient Jews, albeit indirectly through the Egyptians. This notion was not too unreasonable; for eastern Mediterranean cultures were in proximity and had long been in contact. In addition to Tertullian, others had expressed this notion of a borrowing. Justin and Clement had done so. But in Tertullian's mind, it assumed a particular importance. For him, the prophets became the philosophers' primary source of revelation. Thus, truth and virtue had come to the latter from outside themselves, and had to, because within the non-Christian soul, the "primeval good" which "lingered" had been entirely eclipsed by evil due to the Fall. Goodness could merely struggle through as a "stray beam" by "accidental

epistle. To place into his work the word proper to the Biblical passage itself instead, is to gloss over his own meaning. He wrote "recenseatur", which means "recounted".

${ }^{24}$ See Brown (1967:350, 398-407); H. Chadwick (1986:115- 117). I am presenting a literal interpretation of Augustine's thought. Another interpretation is possible: one that would emphasize his educational limitations, and his own "Retractions", and that would accept him as speculative, not definitive (see note 28 , below). But would such an approach to him not skirt around the thrust of his "speculations"? Speculations they may have been; but they are hardly neutral in their effect as he expresied them with vigour. 
outlet", as for instance when someone exclaimed Deo commendo (good-God, good-bye). ${ }^{25}$

Thus, a wide wedge was thrust between Christian and non-Christian cultures, and Tertullian posed his rhetorical question: "What has Athens to do with Jerusalem?" Athens was a centre of philosophy of the time. The gulf between them was ontological from the negative outlook. Difference existed in the very natures of the elect and the non-elect, so that the redemption of the latter would require a radical change of nature, personal and cultural.

This outlook remained a local, minor current in the early church. It developed especially in the Roman province of Africa in particular (present-day Tunisia and northeasternmost Algeria), where Tertullian and Augustine of Hippo lived. Coming into conflict with predominate attitudes, Tertullian separated himself from mainstream Christianity to become a leading member of a rigorist sect, the Montanists. As for Augustine, his overall thought may have been more complex than his pessimism in these matters. In his own generation, this negativity was strongly criticized by St. John Cassian (c.360-435), who had established two monasteries near Marseilles. ${ }^{26}$ Even a local council held in Augustine's region during his own

${ }^{25}$ Tertullianus, de Anima xli.3 (1947:57; 1950:273).

${ }^{26}$ See especially Cassianus, Conlatio XIII.v.2: "primum philosophos nequaquam credendum est talem animi castitatem qualis a nobis exigitur ... habuerunt autem illi

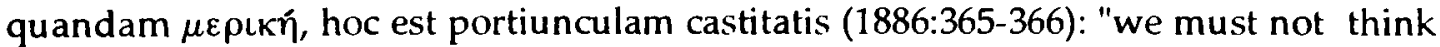
that the philosophers attained such chastity as is required of us ... But they had a sort of $\mu \varepsilon \rho \iota n^{\prime}$, i.e. some particle of chastity" (1894:424). Compare Justin in note 4 to this chapter, above. Also see, e.g., Cassianus, Conlatio XIll.viii.3: "adest igitur inseparabiliter nobis semper diuina [sic] protectio tantaque est erga creaturam suam pietas creatoris, ut non solum comitetur eam, sed etiam praecedat iugiter prouidentia" (1886:371); "The Divine protection then is inseparably present with us,

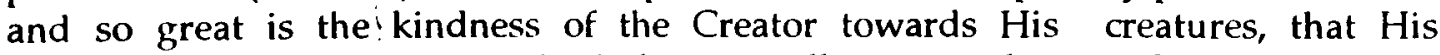
providence not only accompanies it, but actually constantly precedes it" (1894:426). And Conglatio XIII.xii.1: "Nec enim talem deus hominem fecisse credendus est" (1886:378); "For we should never hold that God made man such that he can never will or be capable of what is good" (1894:428). For Cassian, also see O. Chadwick (1968). 
lifetime, the Council of Carthage in 418 A.D., did not entirely express the bishop of Hippo's pessimism in these matters. ${ }^{D}$ A century later, the Second Council of Orange in 529 A.D., endorsed more of this pessimism than the Carthaginian council but still remained less severe than Augustine and Tertullian; and this was the only important conciliar pronouncement of this sort in the early church. ${ }^{2 s}$ The pessimism was thus surpassed by the greater optimism of the patristic outlook within the early church.

\footnotetext{
${ }^{27}$ Concilium Carthaginense, A.D. 418, in Munier (1974:69- 77). Also see the main phrases in Latin in the "Canons of the Carth giginian Council of A.D. 418 dealing with the Fall and Original Sin", in Williams (1927:391).

${ }^{28}$ Concilium Arausicanum, A.D. 529 [Second Council of Arausio (Orange, France)] in Clerq (1963:53-76); also in Bright (1880:384-392). For translations of the main clauses, see Bettenson (1963:86-87). For this council, see Cross and Livingstone (1983:1001). AIso see Bettenson (1963:84-85): "The decisions of Carthage were not popular throughout the Church, and the full Augustinian doctrine did not win wide acceptance." Also see Williams (1927:389):
}

[Augustine's doctrine] can not be said to have ever attained to acceptance in a literal sense ubique et $a b$ omnibus. Not even in a modified and secondary sense of the term, therefore can it claim to be the 'ecclesiastical doctine' par excellence.

It may be useful to note that Augustine never gained such importance within the Greek Orthodox ecumene where (as I understand it) his "Retractions" are taken more literally than his earlier speculations; and where his value is found, not in those speculations specifically, but more generally in his attempts to stand in virtual isolation against various heterodox movements, as he was located remote from the patristic centres. There is no special commemoration for him: he is mentioned among other saints on a single day, June 15, while the hymns of the day attend to the Prophet Amos instead; and in the abbreviated synaxarion in the Mnvaiov printed in Rome in 1900, and in the new edition printed by $\Phi \bar{\omega} s$ in Athens (not dated), his name is not found.

Why should his speculations have assumed the stature of theology "par excellence" during the Middle Ages in the West? They must have meshed with corresponding presuppositions, or a corresponding worldview, during the structuring of estates, then states, ultimately empires, by Visigoths and Ostrogoths initially, then the Lombards, Franks, and Normans, who conquered the Western Roman world, and who appropriated the Latin language for themselves (a language in which Augustine was the most prolific of early Christian writers). For a correlation of this sort, but regarding the influence of Leviticus Numbers and Deuteronomy upon the warsome Gothic mind, see Toynbee (1935:212). Compare my note 107 in Chapter 6, below. 
The negativity surfaced with vigour later. By the 16 th century, a thousand years after the Second Council of Orange, it was being propounded in Western European political and historical theories written by churchmen whose theories can be directly correlated with elements in Augustine's thoughts. ${ }^{29}$ During that same century, it received its full expression in specifically religious terms in two important works: the Institutes of the Christian Religion and Formula of Concord . The latter was written by a number of Lutheran theologians in 1577, but not by Luther himself from whose view it deviated, according to Gustaf Aulén who argues convincingly that Luther's own view, in contrast, was patristic. ${ }^{30}$ The Formula had limited acceptance: the book in which it was published, The Book of Concord, was rejected by the Danes and by others. ${ }^{31}$

As for the Institutes of the Christian Religion, its author, John Calvin (1509-1564), referred his opinions mainly to Augustine of Hippo, as if Augustine's

${ }^{29}$ For instances of correlation see Padgen $(1982: 19,71,115,133,178,193)$. The argument could well be developed that it was the long focus, from the 600s, upon Augustine's Predestinarianism as if it were the Christian "doctrine par excellence" (cf. Williams in the preceding note) which was providing a theological justification for the violence against the heathen in the colonialization of the Americas and Africa. If this argument were to be developed retrospectively, it could be shown that the same outlook had previously justified the violence of the Crusades - for the Crusaders' attacks against, specifically, Orthodox Christians from the First Crusade in the 1090s to the Fourth in the early 1200s, and furthermore to the crusading Teutonic Knights in the north, see Runciman (1952:365, 387; 1954:107-131; 1969a:281-282, 285; 1969b:318, 337, 340; 1951:15, 128, 156); Duncalf (1969:260, 269); E. Johnson (1975:575); Krey (1921:49, 63, 64-65). If long a primary focus, then should Predestinarianism not be sought as an ingrained pattern with various outward manifestations? -- that is to say, with manifold correlations.

${ }^{30}$ Aulén (1931). This translation is an abridged version of his Olaus Petri Lectures for 1930 when he was bishop of Lund. In 1913, he had become professor of systematic theology at the university in that city. See Cross and Livingstone (1983:112).

${ }^{31}$ Cross and Livingstone (1983:327). 
outlook on these matters represented early Christian thought. ${ }^{32}$ Calvin also interpreted the Gospel along the same lines; for instance, he wrote: ${ }^{33}$

For a heavenly Judge, even our Saviour declares that all are by birth vicious and depraved, when he says that "that which is born of the flesh is flesh" (Jn. 3:6), and that therefore the gate of life is closed against all until they have been regenerated.

Calvin, following Augustine, extended this indictment even to infants. They brought "condemnation with them from their mother's womb", their nature was "a seed-bed of $\sin "$, and they were "odious and abominable to God." ${ }^{134}$

As unbaptized infants were odious and adominable, what might heathens be? By "natural instinct", heathens had "some sense of deity", ${ }^{35}$ that God had allowed universally, or nearly universally. However, rather than a highly potential point of participation in, and sanctification by, the divine, it had been given as a judgement:

${ }^{32}$ E.g., Institutionis [henceforth: Inst.] 2.2.4, in Calvin (1962: 245, lines 18-25). See ibid. (1845:304 [1949:226]). Among the patristic writers, John Chrysostom was cited most conspicuously in the Institutionis; but precedence was taken even over Chrysostom by Augustine in Calvin's thought (e.g., ibid.). Calvin's view of himself in relation to Augustine, and of Augustine in relation to the "early Church", was clearly expressed in the following

summary passage (Calvin 1552:886; also in 1870:265):

Sed quia odiose nobis ingeritur veteris ecclesiae autoritas, breviter etiam praefari operae pretium est, quam iniuste hac partim falsa, partim frivola invidia, prematur Christi veritas. Augustini tamen verbis potius quam meis, hoc quidquid est crimina tionis diluere malo.

See ibid. (1961:62):

But since the authority of the ancient Church is offensively brought against me, it is perhaps worthwhile to say at the outset how unjustly the truth of Christ is smothered by this enmity, partly in error and partly in frivolity. But I would rather disperse this accusation, such as it is, with the words of Augustine than with my own.

${ }^{33}$ Inst. 2.1.6, in Calvin (1845:290 [1949:216]). See ibid. (1962:235, lines 30-34).

${ }^{34}$ Inst. 2.1.8, in Calvin (1962:237, lines 24-26). See ibid. (1845:293 [1949: 217-218]).

${ }^{35}$ Inst. 1.3.1, in Calvin (1962:37-38). See ibid. (1845:55 [1949:43-44]). 
God himself, to prevent any man from pretending ignorance, has embued all men with some idea of his Godhead, the memory of which he constantly renews and occasionally enlarges, that all to a man, being aware that there is a God, and that he is their Maker, may be condemned by their own conscience when they neither worship him nor consecrate their lives to his service. ${ }^{36}$

These severe words may be studied in context. In their own cultures, Calvin, Augustine, and Tertullian might have incited their own people by such harsh admonitions to vigorous pursuits of virtue, and the last quotation from Calvin could be reviewed in this manner. In their own cultures, such preachers might comfort their own people with the emphasis on election, a surety of redemption; but preaching of this sort could incite "the elect" against others. Applied to other people in other cultures, this severity could have destructive effects.

This application took place in Alaska beginning in the last two decades of the 19th century when theology of this type influenced policies, particularly education, under the territorial Agent of Education, Sheldon Jackson, a Presbyterian minister. An "unbending Calvinist", as described by his biographer, ${ }^{37}$ Jackson instituted a strictly monolingual educational policy that would accord with an unbending Calvinistic stance towards other cultures. Alaskan languages, along with other aspects of Native Alaskan cultures, were devalued. ${ }^{38}$ Schoolchildren who spoke any language other than English had their mouths washed with soap by United States territorial schoolteachers across the breadth of southern Alaska during the first half

${ }^{36}$ Ibid.

${ }^{37}$ Hinckley (1961:256).

${ }^{38}$ See M. Krause (1980:13-25, 92-99; 1988:149), and R. Dauenhauer (1980), for the educational policy and its affects on Alaskan languages. Also see Toynbee (1935:221-227): "The Protestant Background and our Modern Western Race Feeling", especially pp. 221-215. 
of the twentieth century. ${ }^{39}$ The wide wedge was driven. Unilinear assimilation was demanded.

The example provided by Jackson can pose a challenging reflection for churchmen who may be forging similar wedges but on different anvils. And these anvils need not be overtly theological themselves: sharp wedges can be worked also upon harsh social principles. The forging upon a metal of political theory, and the driving of the resultant wedges violently against Native American peoples by Roman Catholics is clearly identifiable. ${ }^{40}$

A similar wedge, if smaller, was wielded visibly about the memory of Grigorii Shelikhov by the naval officer Berkh when he coupled the Cross with the battleax in his account of Russian-American history;" and when this coupling was repeated by Bolshakoff, an Orthodox church historian of sorts, in his own uncritical reflections upon the Kodiak mission (as explained earlier). ${ }^{42}$ The same combination was relfected by a chaplain to Petersburg's embassy at London who assumed the assimilation of certain Finnic tribes to the Russian nation (in other words, their

${ }^{39}$ Personal communications by people who are now over sixty years old in Juneau and at Kodiak about incidents at those locations, and in Anchorage about incidents at Unalaska. Also see: Worl (1988:320); Pullar (1991:14-19). For further published substantiation see the transcribed autobiographies in McClanahan (1986), where the multilingualism that had been maintained into the mid-20th century throughout southern Alaska is contrasted in almost every account 'with the monolingualism prevalent by the 1980 s.

${ }^{40}$ Padgen (1982). Also see the film "Tununeremiut: the People of Tununak", by Sarah Elders and Leonard Kamerling, Alaska Native Film Project, University of Alaska Fairbanks (c. 1977), for the supression of Yup'ik Eskimo dancing by Catholic missionaries at Tununak, southwestern Alaska, during the first half of the twentieth century, and the revival of traditional dancing by the Christian people themselves. The documentary was shown during the 7th International Inuit Studies Conference, University of Alaska, Fairbanks, 19-24 August 1990.

${ }^{41}$ Berkh (1979:42). See above, Chapter 1 at note 118.

${ }^{42}$ Bolshakoff (1943:84-85). See above, Chapter 1 at note 124. 
cultural annihilation) to have been a commendable result of early Russian missionary work $^{43}$

While working their hands in negative principles such as these, the smiths may be speaking ostensibly purely in patristic terms as is evident currently in America, including Alaska, where some churchmen are attempting to forge an "Orthodox Church" for themselves by promoting monolingualism, English only, ${ }^{44}$ thus effectively co-operating to displace Alaskan and other American cultures within that church group's limited sphere of influence (they are a relatively small group whose designs are not endorsed by the ancient patriarchates). In these last decades of the 20th century, these smiths have in effect joined hands with Jackson in their social manipulations although they would never join him in theological articulations.

Therefore while Calvinism is a readily recognizable construct for the negative outlook, and presents a vivid contrast with the positive one, the wedge can be driven by other legions -- legions which are, it should be underscored in conclusion to this section, hardly confined to Christianity: the destruction wrought by the negativity within Mohammedanism in its fundamentalist forms, by Judaism in its Zionist form, by Marxism as a militant ideology, could be described. It is against legions on all these sides that the patristic outlook can guide, indeed it has guided, along an affirmative, creative way.

${ }^{43}$ Smirnoff (1903:4). The key phrase in my criticism is "complete assimilation". A considerable degree of assimilation is to be expected, and promoted, which should rather be termed "integration" or "éngrafting". It would involve the transformation of an ethnos ( $\varepsilon \theta \vee o \varsigma)$, not its annihilation.

44 Although the catalogue issued by their seminary in Alaska claims that Native languages are taught, and lists these languages, they are not taught; evidence for which can be found, beyond my observations, in the faculty listings. Has a faculty member ever been proficient in any of these languages? Has a faculty member ever been a Native Alaskan? To my knowledge, there has been one, briefly at the inception of this seminary, and now recently reappointed, in 1992, curiously closely in advance of the bicentennial of the arrival of the mission, to be commemorated in 1994 . 
A Summary Contrast. Different outlooks upon, or broad currents regarding, the same pre-Christian cultures can be identified through the course of Christian history. The positive outlook perceives an enduring, highly potential point implanted within human nature where humanity meets divinity. Relative righteousness and illumination are seen among pre-Christian peoples and their cultures. The negative, in contrast, focuses on the separation between humanity and divinity, and posits a gulf so wide that the good which is evident among non-Christians is seen as but an epiphenomenon overlaying the reality of an essentially depraved nature.

The positive current has greater historical depth, and in the ancient church it had a much wider distribution. It provides the precedents within patristic theology to support a theory of correspondence between Orthodox Christianity and the ancient, pre-Christian Aleut and Alutiiq peoples and their cultures.

\section{(3) The Positive Outlook Applied.}

As precedents for a theory of correspondence exist, the next question arises: Were areas of correspondence recognized and expressed in historic sources with regard specifically to the ancient Aleut and Alutiiq cultures?

Correspondence was expressed in a commentary by Valaam Monastery, and also in an ethnography by Ivan Veniaminov. The commentary was published in 1894, for the centennial anniversary of the mission to Kodiak, as most of the members of this mission had belonged to Valaam. The commentary's author remained anony mous as he spoke not for himself but for the monastery. He drew information from two sources: an ethnography of the Kodiak Islanders compiled between 1804 and 1807 by Hieromonk Gideon, who had been sent by the Holy Synod to boost and 
examine the mission; ${ }^{45}$ and the ethnographies of the Aleutian Islanders and of the Tlingits compiled between 1824 and 1838 by Ivan Veniaminov. ${ }^{46}$

Veniaminov -- who was introduced in the preceding chapter where most of the information in this paragraph was provided (it will be repeated in the present context) -- served as the priest of the Unalaska parish, 1824-1834, where he became bilingual. Subsequently until 1838, he served as the priest of the Sitka parish, in the Alexander Archipelago, southeastern Alaska, where he became familiar with the Tlingit people and studied their language and culture (the parish itself was predominantly Aleut, Alutiiq, and Russian). In 1840, he became the first bishop of the newly created diocese of Kamchatka, the Kurile lslands, and the Aleutian Islands, was then elevated to archbishop over Russia's northeast Asian territories, including the Alaska parishes, with his see in Asia, and in his old age became the Metropolitan of Moscow.

Many of the ancient Aleut and Alutiiq moral traits -- including patience, loyalty, hospitality, truthfulness, charity, humility, sensitivity toward others, respect for parents, and care for children ${ }^{47}$-- were described in the Valaam commentary, and Valaam recognized "more good features and traits than bad". ${ }^{8}$ Finding their charity especially impressive, "their complete readiness to share their last crust with anyone in need", 49 Valaam saw that the hand of God had touched their heart. "To us, at least, this seems the appearance of an inner moral law, inscribed in the hearts

\footnotetext{
${ }^{45}$ Gideon(1989:33-680); also in Black (1977b).

${ }^{46}$ Veniaminov (1840b; 1984).

${ }^{47}$ Valaam (1894a:20-37; 1978:13-23).

${ }^{48}$ lbid. (1978:14). See ibid. (1894a:22).

${ }^{49}$ Ibid. (1978:15). See ibid. (1894a:23).
} 
of men by the Creator of the universe": The "spark of God's truth" was "visibie"..5

Considering the ancient Kodiak "religious concepts", the monastery arrived at the conclusion that "in general the pure and elevated moral ideas of the Aleuts and Kodiaks [Alutiigs] and their religious views" were "in essence similar to the Bible stories", and that "in accordance with God's Holy Revelations", the Aleut and Alutiiq people were not "bereft of God's Grace". 51

From this perspective, virtue and truth existed among these peoples and their cultures. Divine presence was evident. The spark of God's truth was visible. Valaam referred this positive perspective directly to St. Justin the Martyr, when it quoted and cited him. ${ }^{52}$ Yet as Justin said, Valaam reaffirmed: "the fullness" was with Christ. ${ }^{53}$

This positive outlook was expressed also in Veniaminov's ethnographies. He recognized "good qualities" in the ancient Aleut character. ${ }^{54}$ In fact, he had such admiration for the Aleuts specifically that he considered them to be "excellent", so that with them almost nothing was impossible. ${ }^{55}$ Thus Veniaminov perceived these peoples and their cultures, particularly the Aleut, as essentially good and highly potential.

\footnotetext{
${ }^{50} \underline{\text { Ibid. }}$ (1978:15). See ibid. (1894a:24).

${ }^{51} \underline{\text { Ibid. }}$ (1978:22-23). See ibid. (1894a:36).

${ }^{52}$ Ibid. $(1894 a: 35 ; 1978: 22)$. See my note 3 to this chapter, above.

${ }^{53}$ lbid.

${ }^{54}$ Veniaminov (1840b:148; 1984:231).

${ }^{55}$ lbid. (1840b:319; 1984:320).
} 


\section{(4) A Concluding Word about the Positive Outlook.}

Was the positive outlook sentimental or naive? To the contrary, it was informed and discerning. Valaam and Veniaminov considered moral and spiritual qualities in detail before coming to the positive conclusions about the Aleut and Alutiiq peoples. Furthermore while perceiving goodness as the essential aspect among these people, Veniaminov criticized, and Valaam did not endorse, those rites which induced ecstasies, involved paraphernalia such as animated dolls, and occasioned peculiar spirit manifestations. ${ }^{56}$

Similarly, Justin in particular was discerning as he refused to compromise with the philosophers through an inappropriate syncretism: to the contrary, he was martyred. Neither sentimental nor naive, his response was unlike the untoward syncretism of some Gnostic sects contemporary with him in the second century. Those sects espoused a very broadly encompassing, essential synthesis of philosophies, religions, and mythologies. In contrast, Justin's positive outlook was discerning and informed: discerning, he bravely resisted an inappropriate syncretism while, informed, he affirmed the positive aspects within ancient philosophy.

But was he as precise with regard to the then-contemporary rites and religions? The question needs to be addressed before the next section to this chapter commences.

A Clarification. Justin, and Clement of Alexandria as well, rejected the then-contemporary rites and religions; yet nonetheless, these men were "prepared to

\footnotetext{
${ }^{56}$ See ibid. (1840b:124-125; 1984:219-220); also see ㅁ․ $\left.1840 \mathrm{a}: 39 ; 1972: 49\right)$.
} 
retain some culture traits", according to Daniélou. ${ }^{57}$ But were they actually "prepared"?

Justin and Clement did not speak against the festivities interspersed among the seasonal ceremonials in the ancient pre-Christian world (they can be termed ceremonial festivities) or against ritual acts such as votive offerings, pilgrimages, and processions. However neither did they explicitly affirm them. These Apologists were generally silent in this regard; and silence can not be assumed to be an affirmation. The general silence was broken against a specific set of rites: those of communion in the popular Graeco-Roman and Oriental religions, the so-called "Mystery Religions". Justin and Clement rejected them bluntly as deceitful and demonic. ${ }^{58}$ The rejection

${ }^{57}$ Daniélou (1973:20).

58 Iustinus Martyr, 1 Ap. Ixiv.1-6 (1915:73-74; 1987:188); Clemens Alexandrinus,

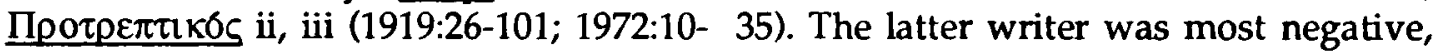
proceeding at length against the ancient religions, and particularly against their use of idols: ibid. iv (1919:101-144; 1972:35-48).

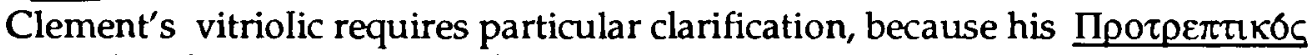
has been cited to develop a theory of correspondence, and the theory will be applied to images in the next chapter. Harsh criticisms similar to Clement's regarding pagan religions, and specifically against their images, can be found in other patristic writers from the earliest Christian centuries, when the pagan gods were yet prevalent. For example also in the 2 nd century A.D., St. Athenagoras of Athens pointedly criticized the then-contemporary pagan religions as misleading, and he emphasized particularly

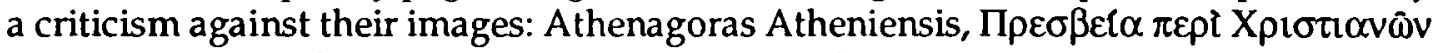
xv.1-4, xvii.3-5 (1972:30, 34-36; 1990:50, 54-55), a criticism he expressed while explaining the Christians' reasons for refusing to sacrifice at them. Precisely this context constitutes a basic element for an interpretation of his criticism, as Christians were being compelled, by social pressure including sometimes legal pressure, to make those sacrifices; and the key term for the interpretation is the very term he applied to those images in that context: $\varepsilon £ \delta \omega \lambda \alpha$. The same term was applied by Clement (as cited). These men did not use the word $\varepsilon \kappa \omega \omega$ in their criticisms. The difference in terms signifies a difference in types of representations. As Athenagoras explained particularly clearly, the $\varepsilon[\delta \omega \lambda \alpha$ represented $\delta \alpha$ oves: sacrifices to the idols comprised sacrifices to the demons (ibid., xxiv.3-xxvi.5, in 1972:58- 66; [xxiv.2-xxvi.2] 1990:79-88). The problem was, thus, with the represented. For the relationship between the represented and a representation, see Chapter 3 , sect. 4 .

The criticism was not necessarily against representations in general. To the contrary, the same criticism was affirmed by St. John of Damascus and St. Theodorus the Studite, in the eighth and ninth centuries respectively, to defend icons against the 
can be compared with a response by Athanasius of Alexandria to manifestations of the ancient Greek and Egyptian gods which he considered to be demonic guises. ${ }^{59}$ The similarity is only apparent however: there is a difference. Athanasius referred to perceptible manifestations, while Justin and Clement were referring to symbolic ritual acts that did not necessarily involve such manifestations. They were referring to the rites. I shall indicate in a moment, and explain further in Chapter 4 of this study, that there was an implicit reason in the Apologists' criticisms as those rites would induce certain types of ecstasy; but the reason was not made explicit by these Apologists.

Nor did they explicitly admit that some of the dynamics in the Mystery Religions could be prefigurations and preparations in a manner analogous to the dynamics in then-contemporary philosophy. Where was the magnanimity that characterized Justin and Clement in relation to ancient philosophy? Is it possible that they were driving a wedge in this direction, distancing themselves from affinities here while emphasizing instead those affinities with philosophy to ingratiate Christianity to their erudite readers? If so, the affectation involved a paradox, because among their readers were imperial rulers who were themselves philosophers, the prime example being Marcus Aurelius (121-180). Ruling from the 140s, he was contemporary with Justin who was martyred in Rome in the year 165, midway during this reign, and with Clement of Alexandria who was born in the year 150 and lived for thirty years

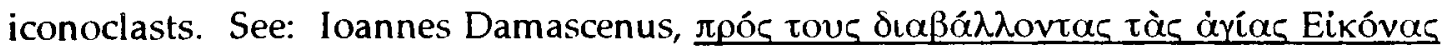
[henceforth: Eikóv.] I.xxiv-xvii, Il.xvii-xviii (1975:114-118); and Theodorus Studita,

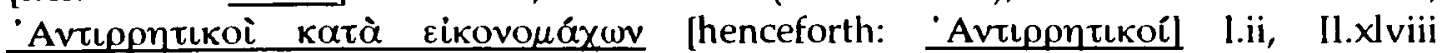
(1860:329C-332A, 388B-D). This clarification has been provided in the present context in this note in anticipation of the subsequent chapter of this study.

${ }^{59}$ Athanasius Alexandrinus, Evav. xlvii (1971:252-254); also see ibid. (1973:436-440). Is it possible that there was a lessening of the severity of criticism as the ancient gods went into manifest decline; so that the general criticism by Justin, Athenagoras, and particularly Clement in the 2nd century, became more focused in this way by Athanasius in the 4 th century? 
under this philosopher-emperor's rule. But Marcus Aurelius was never baptized. He chose to be initiated into the Mysteries at Eleusis during the last decade of his life. ${ }^{.0}$

If the Apologists' outlook was, thus, somewhat blurred in the direction of the Mystery Religions, it must be studied along three distinct planes with regard to:

(1) their distancing from, or wedge-driving against, the symbolic and ritual elements within the Graeco-Roman and Oriental religions;

(2) an implicit, more specific rejection of those rites which claimed to make gods manifest: a rejection that is defensible particularly with regard to the rites that induced ecstasy (as will be explained in my fourth chapter);

(3) their positive view of philosophy, a view that was unsurpassed by any other patristic writers.

Of these three planes, the second and third remain firm. Even upon the third, the extent to which Justin and Clement were affirmative of philosophy can withstand criticism, as I shall indicate briefly as follows with reference to Justin in particular. Writing before the threshold of the imperial conversions, he was attempting to construct a way for unconverted philosophers to enter into Christianity; and he was emphasizing areas of affinities, indeed to an extent uncharacteristic of most of his patristic successors. They, in contrast, would be writing on the other side of that threshold, and would stress Christianity's superiority over philosophy in order to exhort the nominally converted. The homilies by John Chrysostom provide a comparison with Justin's apologies in this respect; ${ }^{61}$ the types of writing could

${ }^{60}$ Generally accepted: see Encyclopedia Britannica: Macropaedia, 15th ed. Among the references cited in that entry, see the treatment by Farquharson (1951) who develops the biography only to the year 161 (pp. 13-88), and then concentrates at length upon Macrus: Aurelius's earlier Stoic and rationalistic views upon death, among other topics (pp. 76-141). Where is the conversion to the Mysteries?

"See the use of the term "philosophy" by Chrysostom as listed in Lampe (1961:1482-1483): three references by Chrysostom are to ancient philosophy, and those are criticisms. In contrast, 26 references by him, from 24 of his homilies, are to the 
themselves indicate the nature of the comparison: apologies by Justin, then homilies by Chrysostom. The fundamental differences between these two patristic writers can be found in their relative purposes and audiences, not in theological outlooks. Thus even the third plane remains firm.

But the initial plane becomes feeble against the strength of subsequent Christian history. Dynamics in the ancient religions were retained transformed, as they were imbued with Christian meanings, and were oriented towards Christian realities. Pilgrimages became directed to saints: votive offerings became purely supplications and thanksgivings. ${ }^{62}$ The very word "mysteries" from the ancient Greek rites was retained transformed, as it became the word for the Christian sacraments: $\tau \grave{\alpha} \mu v \sigma \tau \eta \dot{\rho} \rho \alpha$. Yet this retention and transformation must have taken place quite apart from the Apologists if they did project unduely negative attitudes along that

"philosophy" and "philosophers" of the Christian life, and specifically of the Christian

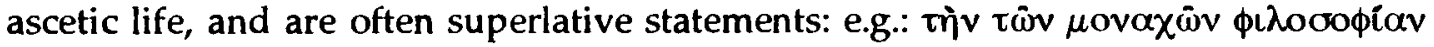

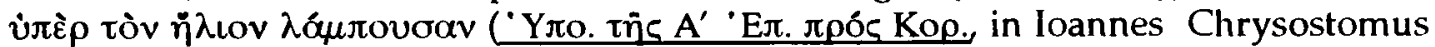

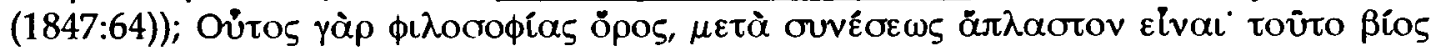

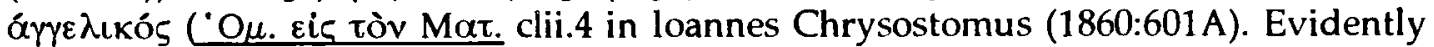
he was not inimical to philosophy per se, as $\phi \iota \lambda_{0}$ - ooфi $\alpha$ signifies a "befriending of wisdom"; but he was very critical of pretentious forms. Thus Chrysostom was like Justin. As Chrysostom said during the 4th century that in Christ one saw "true

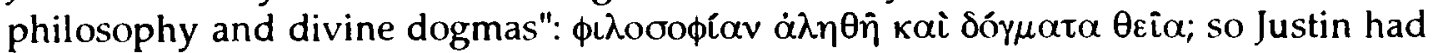
said during the 2 nd century that "only by taking the words of Christ into account

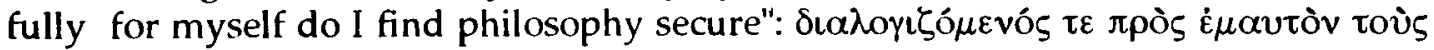

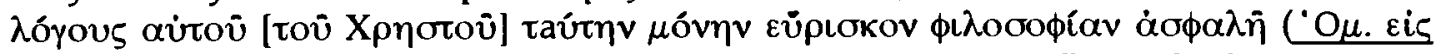

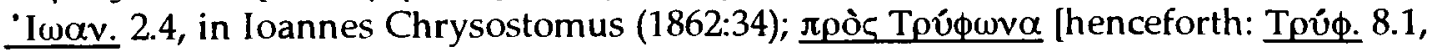
in lustinus martyr (1915:99)).

Instead of being contrasted, Chrysostom and Justin could together be compared with Aristotle who, without their clarity of direction, nonetheless admonished his own disciples likewise to pursue philosophy as the highest pursuit in life: "we ought therefore to pursue philosophy or to say farewell to life and depart hence, since all

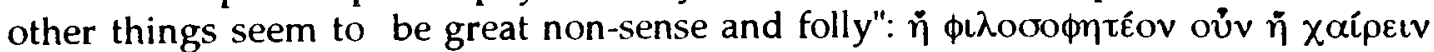

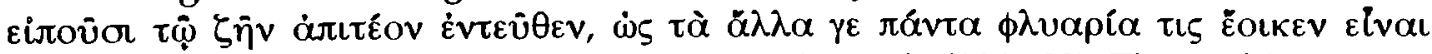

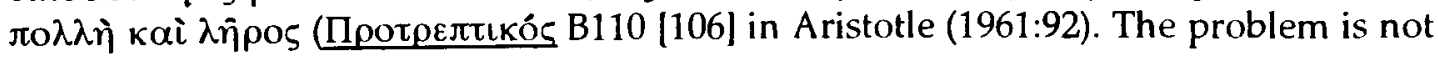
with that pursuit itself.

${ }^{62}$ An interesting collection of votive offerings that beseech Artemis to curse the people named on them for various transgressions, are displayed in the Roman Baths Museum, Bath, Britain (and against these ancient displays the Lord's Prayer assumes a fresh meaning). 
plane. The retention and transformation must, then, have occurred within processes that were far wider than the limits of these writers' influence.

The Apologists could well have interpreted those dynamics explicitly without wholly endorsing them as "a kind of preparation" for, or prefiguration of, Christianity, just as ancient philosophy, itself a culture complex, was interpreted without being entirely endorsed. ${ }^{63}$ Certainly there were elements within those ancient religions which were contrary to Christianity, but contrary elements existed within philosophy also. And as Justin's outlook in particular was not naive or sentimental with regard to the latter, neither would the positive outlook upon the ancient religions and rites be characterized by naivety and sentimentality. Informed discernment in this field has already been indicated with reference to Veniaminov and Valaam; and instances of more precise discernment will become evident later (Chapter 4). Certainly there was resistance to Christianity within some of those religions and rites. But so was there resistance within schools of philosophy, yet the latter became a challenge for Justin, and occasioned his creative thought and bold affirmations.

Therefore, dynamics in ancient religions and rites can be interpreted within the positive, or affirmative, outlook although the Apologists themselves seem to have remained either reticent or reluctant in this field. And the interpretation has been expressed indeed. The ancient Mystery Religions were included within a "vast preparatio evangelia" as "foreshadowings" of the "ideal and supreme Mystery

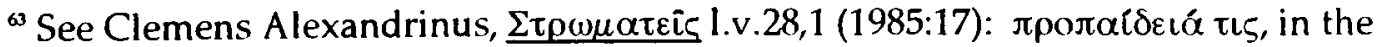
historical perspective explained above, at note 12 to this chapter.
} 
Religion" by N. P. Williams ${ }^{64}$ who thus extended the positive outlook by stating that: ${ }^{\text {s5 }}$

[the objective observer] would see no reason why the "Creed of creeds" should not include, side by side with an ethic loftier than that of Socrates, and a theology richer and grander than that of Aristotle, "Mysteries" more pure and ennobling than those of which Sophocles wrote ...

It is hardly coincidental that the same author developed the contrast between the patristic tradition and the Augustinian-Calvinist divergence as his theme for the Bampton Lectures. ${ }^{66}$

More specific to this study, the interpretation has been applied within the field of contemporary missions by Anastasius, bishop of Androussa and professor of theology at the University of Athens. With regard to cultures in Kenya, he has expressed his theological foundation, or guiding principle, as follows: ${ }^{67}$

the "ancient religions should not be considered on the one sided basis of demonic domination in the sense of Romans 1:21: '... [they] became vain in their imaginations, and their foolish heart was darkened'; ... but also in light of Acts 14:17: "he left not himself without witness".

Anastasius's conclusions are of particular importance to my study as he assesses those peoples' ancient religious concepts and practices as being already "on a high level". ${ }^{68}$ His assessment is analogous to the ones by Veniaminov and by Valaam

${ }^{64}$ Williams (1950:396-397). 1st ed., 1926. The author was the Lady Margaret Professor of Divinity at the University of Oxford, and Canon of Christ Church Cathedral, when he wrote this article.

${ }^{65}$ lbid., p. 397.

${ }^{66}$ Williams (1927)!

${ }^{67}$ Yannoulatos (1983:222-223); cf. English summary, p. 267. For his consideration of the ancient rites and religion of these peoples, see pp. 71-73, 108-119, 194-216.

${ }^{68}$ lbid., p. 221; cf. English summary p. 267. 
regarding the Aleuts' and Alutiiqs' moral qualities; and the assessment by Anastasius is applied directly to the field of ancient rites and religions.

It is into this field that the next section of my chapter will proceed, to develop a "test case" in Alaska for a theory of correspondence.

\section{(5) A Test Case for the Theory of Correspondence.}

In the preceding section of this chapter, precedents were identified that support a theory of correspondence. Now in the following section, the theory will be tested with reference to the ancient Yup'ik Eskimo culture that neighbours the Aleut and the Alutiiq. The introduction of a neighbouring group at this point in the study will serve to provide a case peripheral to the primary focus of the study before the theory is applied more definitively within that focus (Chapters 3,4 and 5). There is another consideration as well: while the study remains focused upon the Aleuts and Alutiigs, the theory generated by this study should apply to peoples and cultures who are similar to them, particularly to those from whom corroborative material will be drawn in my subsequent chapters; and this application should be demonstrated clearly within the body of this text.

The test case will involve a comparison between a view of the cosmos proper to the ancient Yup'ik culture, and a view of the cosmos proper to Orthodox Christian culture. The comparison will be developed between symbols within rituals, as these symbols reflect the cosmos; and for this purpose, major rituals have been chosen proper to each culture: for the ancient Yup'ik culture, the hunters' major ritual festivals; for the Orthodox, the Divine Liturgy. A comparison of this sort, involving cosmology, was indicated earlier in this study with reference to the report by the leader among hunters Stepan Cherepanov, on the western Aleutian Islands, 
1759-1763 (Chapter 1, section 3), when Russian and Aleut hunters together performing similar rituals, perceived the miraculous. A comparison of this sort can be developed further now, supported by the precedents that would allow a theory of correspondence.

The comparison will begin by describing the Divine Liturgy with minimal definitions and minimal technical language, so that the comparison shall be balanced, because the primary sources for the ancient Yupiit material do not contain many definitions or technical terms. It is expected, of course, that theological readers will be familiar with those academic terms and concepts that have been deliberately omitted.

For congruence, the test case will involve the Aleut-Russian priest who ministered among the Yupiit. In 1845, Fr. lakov Netsvetov, earlier the first priest of the Akta (central and western Aleutian Island) parish, was assigned as the sole priest of the newly established Mikhailovskii-Kvikhpak (Yukon) Mission where he served until 1863. He lived among the Yupiit on the Yukon River at lkogmiut (towards the Bering Sea), and he traveled among the Yupiit and Athabascans in the lower Yukon and the Kuskokwim River regions. He made icons, and he carved an iconosstasis of ivory at Ikogmiut. He healed and he became known as a healer.

A View into the Orthodox Cosmos. A view of the Orthodox cosmos can be gained through the symbols within the major ritual, the Divine Liturgy, celebrated by Fr. Iakov at Ikogmiut and elsewhere during his journeys through the Mikhailovskii-Kvikhpak Mission; and also through the symbolic structure of the place where the Liturgy is celebrated, be it a church building or a church tent. Netsvetov would celebrate the Liturgy in a church tent if a church buifing or chapel 
had not yet been constructed in a location. ${ }^{69}$

The interior structure of the building is itself a symbolic representation. It is divided into the sanctuary and the nave by an iconostasis, a screen of icons, a division that symbolizes the separation of the human from the divine. In the middle of the iconostasis are doors that open inward into the sanctuary, symbolizing the opening of the way to the Kingdom of Heaven and to union with the divine. The union of humanity with divinity is seen in the icons on the iconostasis, with the icon of Christ, in whom the divine is uniquely human, predominant on one side of the Royal Doors, and the icon of the Mother of God, Mary, on the other side (thus balancing the masculine by the feminine). This symbolic structure -- sanctuary, iconostasis, nave -- is always reproduced for the celebration of the Liturgy. Even in a church tent, icons will be placed on stands and arranged in a line as an iconostasis to mark the division, with openings left between them as open doors.

Procession is highly symbolic, also. For example, at an early point in the Divine Liturgy, the celebrants robed in liturgical garments make a procession into the nave. While others carry lighted candles, the main celebrant in the center of their

\footnotetext{
${ }^{69}$ The form of the Liturgy in the following description is virtually standard throughout the Greek Orthodox ecumene today. This will be emphasized again later, in the text itself.

For the use of a church tent for the Liturgy, see e.g. Netsvetov (1984a:5): at Ikogmiut in October 1845, he conducted Matins and the Hours in his iurta because of the intense cold, then went out into the tent to celebrate the Liturgy. Only in more intense cold did he refrain from using the tent: see Remark, 12 March 1849 (ibid., p. 133). The church building at lkogmiut was constructed in 1851. A chapel had already been constructed at Kalmakovskii, a redoubt on the Kuskokwim River, prior to his arrival in the region, and the people were "continually holding prayers" there themselves (ibid., pp. 6-7). It was the practice also in Atka and Unalaska parishes to use a church tent wherever a church chapel or chapel had yet to be constructed: see, e.g., pastoral visits to Bering Island in 1830 and 1832, in Netsvetov (1980); also see pastoral visits in the Unalaska parish, dated 8-10 July 1827, 3 May 1829, 26 July 1829, 17 April 1830, 10 and 14 August 1830, 20 April 1832, in Veniaminov (n.d.). At locations where a church tent was pitched during pastoral visits, the tent would be replaced on the space where it had earlier been pitched (for examples, see the references cited for Veniaminov in this note). Especially sacred space was thus defined.
} 
line carries the Gospel high, and enters the sanctuary through the Royal Gates. In

Netsvetov's case, he would himself have been the main celebrant, assisted initially by a deacon and a sacristan. ${ }^{70}$

Later in the Liturgy, a similar procession is made, this time to offer the bread and wine for the Eucharist. These gifts are carried by the main celebrant, again in the middle of the procession, who will bring them through the Royal Gates and place them on the Holy Table. During the procession, the gifts are censed by another of the processionists. Yet another who leads the procession, carries a tall cross with figures of the Resurrection on it as well as of the Crucifixion. Others carry lighted candles. A few carry fans, actually fan-like circles on poles (slightly taller than the height of a man). Known as $\tau \grave{\alpha} \varepsilon \xi \alpha \pi \tau \varepsilon \rho \gamma \alpha$-- "the six-winged" -- these fans are embossed or

${ }^{70}$ From 1848, Netsvetov was assisted by the sacristan and by Netsvetov's own nephew, each of whom had become a rank of deacon. All of these assistants were were themselves of Alaskan and Russian parentage, as was Nestvetov. The original deacon was Innokentii Shaiashnikov, an Aleut-Russian. He was ordained to the priesthood by bishop Innokentii (Veniaminov) at Mikhailovskii in 1848, while the bishop was on a northern pastoral tour; and the new priest was transferred that same year from the mission to the Unalaska parish. The original servitor, Konstantin Lukin, derived from a Alaskan-Russian family from Kalmakovskii on the Kuskokwim River. For the Lukin family, see the Appendix by Lydia T. Black in Netsvetov (1984a:469-479). Konstantin Lukin became the deacon, or a rank of deacon, also by Innokentii in 1848, and remained Netsvetov's mainstay. It is very important to note in this context, and to emphasize, that this man was a renown hunter in the region. Netsvetov's nephew Vasilii, became a rank of deacon also in 1848 , but the young man died sometime in the mid- or later 1850 s. In addition to these men who were in the ranks of deacons, there would normally be other people who chant and participate in the Divine Liturgy according to the roles of the laity.

Four priests were assigned to the mission in succession, each to assist Netsvetov, and each from Russia (ibid., pp. 482- 484); but the first of them, hieromonk Filaret, who arrived in the summer of 1848, returned to Novoarkhangel'sk the following summer; the second, hieromonk Gavriil, who arrived in 1853, was mentally unbalanced and had to be suspended in 1856; the third, hieromonk Theoktist, who had been transferred repeatedly for a prior decade (and sent farther eastward or northward in each instance), was unruly, and remained at the mission for merely three years, from 1858. In 1861 an assistant with a balanced character was finally assigned: hieromonk Illarion who remained until 1869. Until the latter's arrival, Netsvetov was virtually the only priest and thus the main celebrant, by virtue of his stability as well as his authority. Subsequent to Illarion's arrival, Netsvetov would (it should be expected) have had seniority by relative status. 
carved with figures of the seraphim, whom they represent. The procession is accompanied by the Cherubic Hymn that begins: "Let us who mystically represent the Cherubim".

These symbols of the seraphim and the cherubim provide a good point for comparison and contrast with the ancient Yup'ik view of the cosmos. They are explained in a commentary written in the eighth century by St. Germanus of Constantinople regarding the Divine Liturgy. He explains that by means of the fans in the likeness of the seraphim, and by means of the chanting of Cherubic Hymn, the spiritual powers (the seraphim and cherubim) "run invisibly before the great king, Christ, who is coming to the mystical sacrifice, born aloft [as he is] upon material hands"."

The fans ... manifest the six-winged seraphim, and are the likeness of the many- eyed cherubim; and thus the earthly imitates the heavenly, other-worldly, noetic order. $^{72}$

The earthly and heavenly celebrants exclaim "alleluia" together.

Germanus then carries this imagery from the vision in Isaiah $(6: 1-3)$-- where the Lord "enthroned, high and lifted up, his train filling the temple", is surrounded by and hymned by the seraphim -- to the symbolism in Revelation $(4: 7-8):^{73}$

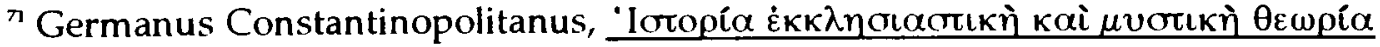
xxxvii (1984:86).

${ }^{72}$ Ibid. xli (1984:94).

${ }^{73}$ Ibid. The word $\zeta \hat{\omega} \alpha$ is used in Revelation and by Germanus. Translated literally as "animals" here, it is rendered as "creatures" in the KJV, as the one is a man. The scriptural references are clearly evident in Germanus's commentary. Either the figures from Revelation or the seraphim from Isaiah are often depicted in the pendentives of the central dome in churches, with Christ himself depicted inside the dome, thus "lifted up", surrounded, and hymned. The figures from Revelation are symbols of the four Evangelists, one in each of the four pendentives, each figure with the appropriate Gospel; or they are sometimes depicted in sections of the Royal Gates that open into the Altar. Iconography and architecture thus represent the Biblical images.
} 
And the four-formed animals antiphonally giving to, receiving from each other: the first, a likeness of a lion exclaims, HOLY: the second, a likeness of a calf exclaims, HOLY: and the third, a likeness of a man exclaims, HOLY; and the fourth, a likeness of an eagle exclaims, LORD OF SABBAOTH.

According to this commentary by Germanus, and according to words in the Cherubic Hymn, these spiritual powers are not only represented figuratively but are actually present. They participate in the ceremonial, indeed in a liturgical setting where the earthly and the heavenly are open to each other.

The eighth century commentary exercised influence in Russia where, beginning in the thirteenth century, it was incorporated into Slavonic service books; ${ }^{74}$ and this commentary remains standard within, and is typical of, the instruction given in Orthodox seminaries to the present day: therefore either this instruction in specific or this tradition in general would have been imparted at the theological school at Irkustk where Netsvetov studied. The Divine Liturgy that Germanus described is virtually the same as that celebrated by Netsvetov at Ikogmiut (indeed, it is virtually the same as that celebrated today), complete with the prayers and hymns, the processions, the proces sional fans, and the other characteristics described above.

A View into the ancient Yup'ik Cosmos. While this was the new view of the cosmos, what was the ancient Yup'ik view? A view can again be gained through major ceremonials. They involved the same general sorts of elements as the Orthodox Liturgy -- including visual representations, processions, offerings -- but within a somewhat differing constellation, or orientation.

The ceremonials took place in winter in the gasgiq or according $\left.\right|_{0} ^{t_{0}}$ Russian

${ }^{74}$ Meyendorff (1984:9), citing Taft (1980/81:46 [ftnt. 10]). 
usage the kazhim: a communal house that was itself a representation of the cosmos. Its tunnel entrance was an image of the birth passage. The smokehole at the roof was an image of the passage to the spirit world.$^{75}$ The latter symbolism was evident at a point during Nakaciug an annual ceremonial festival, primarily honouring the spirits of sea mammals, especially seals, which were vital to Yup'ik subsistence. At the festival's ritual climax, the spirits of the animals that had been caught during the year were escorted on their way from the hunters' world to their own world. These spirits (known as the animals' yua) were associated with certain internal organs which had been preserved from the animals throughout the year and were now being returned ceremoniously to the water by the celebrants, but first the celebrants would raise them through the qasgiq's smokehole, thus representing the spirits' return from this world to their own. ${ }^{26}$

At particular times during Nakaciug shamans would travel to the animals' yua world to make sure the spirits were pleased by the honour shown to them. ${ }^{\pi}$ If they were, the animals would come again to the hunters, for a successful hunt was as much an act of giving by the animals' yua as it was an act of taking by the human Yupiit. ${ }^{78}$

The animals' yua as well as the shamans' spirits and other similar spirits were represented by ritual masks during ceremonial festivals, especially during Kelek which followed Nakaciuq. Made in many sizes (as large as a man; as small as a finger) and in many forms (human, animal, surreal), the masks represented the

\footnotetext{
${ }^{75}$ Oleksa (1985:117); Fienup-Riordan (1988:266, 264, 268). But Fienup-Riordan (ibid., p. 260) associates the birth imagery with the women's houses, the enet.

${ }^{76}$ Fienup-Riordan (1988:264, 267-268); Morrow (1984:123- 127); Oleksa (1985:117).

" Fienup-Riordan (1983:234-235); Lantis (1946:145).

${ }^{78}$ See Fienup-Riordan (1988:256-260; 1983:175-187, 202-208); Morrow (1984:124).
} 
various spirits active in the cosmos and affecting existence."

Memorial ceremonies, on the other hand, primarily honoured the deceased ancestors, and supplied their needs. Clothes, food, and water were provided to them ritually. For example, bits of food and drops of water would be cast into the gasgig fire or dropped to the ground, transfered in this way to kinsfolks' spirits. The action was personal; it was directed to particular deceased kin who were addressed:

Return, our father;

We wait for you;

Come back to us;

And we, who are lonely,

Will give you food. ${ }^{\text {so }}$

The [deceased's] namesake would take [a bowl of water provided by the host], dip his fingers, and shaking drops of water three times to the side into a crevice in the floor, would say quietly: "Drink, our dead." Then when he was given another bowl of food, he would take small bits of each food, and likewise throw them into the firepit, with the words: "Accept, dead ones, from our supplies, and help us secretly next summer." ${ }^{\prime 1}$

Receiving the offerings, the spirits of deceased kinsfolk participated in the event. Divisions which normally separated the worlds became permeable.

A procession that took place during a memorial for ancestors at Ikogmiut was described by Netsvetov. ${ }^{82}$ "Dressed in their best garments which had been prepared beforehand especially for this occasion", the processionists emerged from the qasgiq,

${ }^{79}$ Fienup-Riordan (1988:269; 1986:52); Morrow (1984:137-138); Nelson (1899:358-359, 395); Ray 1981:27. Also see Chapter 3, section 1, of this thesis. Masks were a predominate feature of Kelek, but not of Nakaciug: information from the village of Old Kashunak emphasized that masks were not used during the latter ceremonial festival there at all (Morrow 1984:126).

${ }^{80}$ Nelson (1899:369).

${ }^{81}$ Zagoskin (1967:123).

${ }^{82}$ Netsvetov (1984a:56). 
made a round of the cemetery, then returned to the qasgiq. A drummer led. ${ }^{83}$ The men who were offering the memorial ceremony followed slowly. Next came their wives. Carrying thin rods which were decorated with feathers, the women swayed from side to side to the solemn drum beat and the chant.

The ancient Yup'ik ceremonials were also social events: occasions for feasting, gift-giving, myth- and story-telling, pantomime, and dancing, as well as for the trading of goods and the exchanging of ideas. Some participants traveled great distances to attend and could be of different linguistic groups: for example, Athapascans from the lower-middle Yukon River, Inupiat from the Norton Sound area, and central Yup'ik from lower Kuskokwim River, all participated in ceremonial festivities at Ikogmiut. ${ }^{84}$ Indeed, Ikogmiut was a center for these festivities -- and this was where the Aleut-Russian priest lived.

A Comparison. Certain correspondences become evident in the comparison. ${ }^{85}$ In the new and the ancient Yup'ik cultures alike, indeed within the "sacralized cosmos" in general, the ceremonials occur in sacred time and space: a time-space, or dimension, where the mythic and historic, the eternal and temporal intersect. Similarly in both cultures, spirits participate with human beings in the ceremonials, and the manner of this participation is alike with regard to the visual symbols that make the unseen manifest. In these ways the cosmologies overlap and naturally merge.

* The drum would have been normally the large tambourine-shaped drum, held in one hand and beat with a drumstick. The beat could have been solemn. Yup'ik song and dance is very controlled.

s4 Netsvetov (1984a:67).

${ }^{25}$ As defined in the introduction to this chapter, correspondence means similarity, or agreement in significant ways, not necessarily equivalence. 
In yet other ways, they differ; for example, in the ancient ceremonial festivals, the central ritual acts were directed to the participating spirits who, particularly in

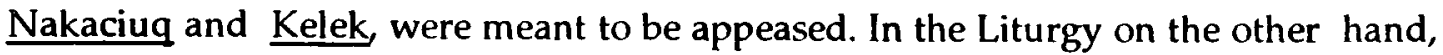
the spirits are present as co-celebrants who join in the worship of something greater, encompassing them and all.

The comparison should suffice to demonstrate that a theory of correspondence can be developed systematically within the fields of religion and cosmology with reference to a far northern hunters' culture. Dissimilarities nothwithstanding, signficant areas of correspondence existed beween this ancient far northern hunters' culture and Orthodox Christianity; and the corresponding characteristics within the ancient can be interpreted to an appropriate extent according to precedents within patristics as prefigurations of, preparing the way for, the new.

\section{(6) The Usefulness of the Theory.}

An indication of the usefulness of the theory can be indicated in conclusion to this chapter, with reference to the test case, and more specifically with reference to Fr. Iakov's response to the ancient Yup'ik ceremonial festivities at Ikogmiut.

How did he respond to them? Insightfully he differentiated between activities, by distinguishing the central ritual acts directed toward the spirits on the one hand, from the gift-giving along with feasting and dancing, on the other hand. He considered the former to be superstitious acts, and advised against them as he refrained from participating in those acts himself. He was not adverse to the other activities, however.

It can be stated therefore with regard to this Aleut-Russian priest in particular

\footnotetext{
${ }^{86}$ Netsvetov $(1984 a: 56,227)$.
} 
that he manifested the very characteristics that have been identified as necessary to the positive outlook: he was discerning and he was informed. Informed, he remained non-adverse to the seasonal festivities as whole. Discerning, he advised those people who were attached to him, not to conform themselves to areas of essential non-correspondence within the central ritual acts, just as he himself did not conform to them.

The discernment is vividly evident in his use of a church tent, chapel, or church building, instead of a qasgig or a iurta or any other structure, for the Divine Liturgy. The practice would serve clearly to minimize relativism by marking a difference between the new and the old. He did not place the new Liturgy in old structures: "Neither do men put new wine into old wineskins ... but they put new wine into new wineskins and both are preserved" (Matt. 9:17).

He was prepared to preserve qualities of the old, or in other words to "retain some cultural elements", ${ }^{8}$ and to allow an appropriate synthesis without an undue syncretism that would ruin the old and the new alike. A creative synthesis occurred indeed. Today the Yup'ik villages host generously and visit, feast, and give gifts, in a distinctly Yup'ik Christian fashion in mid-winter, from the Nativity to the Theophany. Homes are visited one after the other throughout the village by the village as a whole and by all their guests, who together "follow the star" from the church to each of the homes: it is a representation of the star of Bethlehem. The festitivies take place during the Twelve Days of Christmas in harmony with the Liturgies and other liturgical services: indeed, the activities flow with the star from the church to the homes, then again to the church; and within each house, the seasonal hymns and religious folk songs are sung in the Yup'ik and Russian languages.

These festivities, known as Selaviq, or "Starring", have been analysed from an

${ }^{87}$ Cf. Daniélou (1973:20). But see my text of this chapter at notes 56-61, above. 
anthropological viewpoint, and both the ancient Yup'ik and the Christian elements have been recognized as inseparably they create these mid-winter Yup'ik Orthodox Christian ceremonial festivities. ${ }^{88}$ It is interesting that "starring" is known also in the Carpathians, the Ukraine, and Romania; ${ }^{89}$ yet among the Yupiit, the festivities contain unique characteristics that have been retained transformed in continuity from Yup'ik antiquity. A creative synthesis has taken place.

\section{(7) Conclusions.}

The purpose of this chapter has been to develop a theory of correspondence predicated upon a patristic foundation, and demonstrated by a test case, itself from the actual field in Alaska; so that the study could proceed with solid footing further into the processes that allowed the transition to be indigenous and corporate.

This kind of transition engendered the perception inaugurating this chapter: that these ancient cultures must have contained certain vital dynamics corresponding to certain vital dynamics within Orthodox Christianity; otherwise the new could not have been engaged by the ancient through this kind of transition. The perception needed to be substantiated as a theory, before the study could proceed into those dynamics.

Now the theory established, the study can delve into them more definitively, indeed to a "point of comprehension".

${ }^{88}$ Fienup-Riordan (1990a:94-122). Also see Inouye (1990); Oleksa (1985:118). For a consideration regarding the derivation, see note 98 below.

${ }^{89}$ Did/occur as well in Kamchatka, Yakutia, the Irkutsk gubernia, and Komi-land: the locations from where the men who assumed vital roles in the Christianization of the Aleuts and other Alaskans derived? 
- 


\section{CHAPTER 3}

\section{POINT OF COMPREHENSION}

In the following chapter, evidence will be presented to identify a certain correspondence between the dynamics of divine participation within the cosmos as articulated in these hunting cultures and the dynamics articulated in Orthodox Christian cultures. It will be argued that this correspondence comprised a "point of these

comprehension" where the ancient hunting cultures could engage and retain the new faith and practices.

Commencing with divine participation within the new, the chapter will describe the concept and dynamics in Orthodoxy thematically along two planes: one with regard to the concept as defended consistently by the Ecumenical Councils; another with regard to the dynamics as evident consistently within manifold aspects of Orthodox Christian cultures. Each plane will comprise a section of the chapter. Once the centrality of divine participation is perceived within the new, then the vital "point of comprehension" within the ancient will be developed in the final section of this chapter through a comparison between icons and ritual masks. Evidence will be brought forward to state that, differences notwithstanding, icons and ritual masks correspond inasmuch as both types of phenomena involve divine participation within the cosmos through matter.

The concept of divine participation began to be explained from patristic theology in the preceding chapter where the perception of divine presence itself allowed the positive outlook, and thus allowed the theory of correspondence. Now, the same perception that allowed patristics to affirm the ancient cultures will be described as the dynamic that, reciprocally, allows them to comprehend the patristic 
faith -- to comprehend not merely in a theoretical manner, but in a profoundly existential way: for it can well be said that the divine is communicated through participation.' Concrete examples will be provided of this communication in subsequent chapters of this thesis (Chapters 4 and 5) while, now, it is the "point of comprehension" that will be identified. ${ }^{2}$

\section{(1) Cosmological Definitions.}

The following definitions of various concepts regarding relationships between the divine and the cosmos will introduce the theme, divine participation.

DEISM: Deism could well derive from the Latin preposition de although it may seem to derive from deus, as the preposition more clearly represents the deists' view: that the cosmos is "away-from-(God)", or "apart-from-(God)". Positing a separation of the divine from nature, deism will allow a natural theology but without special revelation and without divine intervention. When the 18 th century English deists were translated into French by Diderot as "théistes", the term "deism" became confused with "theism"; but the distinction can be useful, so that deism is reserved to signify a cosmology that allows a concept of God while precluding divine participation in the cosmos.

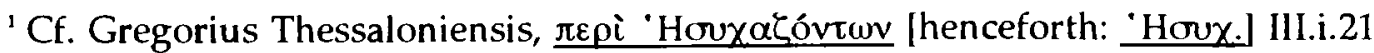
(1959:597).

${ }^{2}$ Material in the second section of this chapter was presented in Mousalimas (1990b). Material in the third section (regarding icons and ritual masks) was presented in id. (1988a), to be published in translation as id. (n.d.e). While the thesis and the general organization in these sections are the same as the publications, the details have been revised for greater definition, and greater reference to the most recent critical editions of the primary sources; the present work, thus, supersedes the previous.
} 
THEISM: Theism, on the other hand, may allow instances of special revelation and intervention by God in history. Popular usage in theology has assigned it a broader meaning also, which would encompass deistic cosmology as well: "theism" has been used against polytheism to indicate One God or One Source, and against pantheism to indicate this One existing apart from nature.

But the use of "theism" for the latter contrast can lead to a false dilemma, as if a single alternative to pantheism were the theistic and deistic separation of the divine from the cosmos. The false dilemma can be intensified by the predominance of theistic and deistic worldviews in the contemporary world. ${ }^{3}$ For this reason, another term is needed that will serve to indicate a difference from pantheism, and at the same time allow divine immanence.

PANENTHEISM. Panentheism can serve as this term, whose meaning can be found in its Greek etymology: $\pi \bar{\alpha} v$ meaning "all", $\varepsilon v$ "in", $\theta \varepsilon \zeta \varsigma$ "God": "all-in-God". It is different from pantheism, "all-(is)-God", and different, at the other extreme, from theism and deism. Implicit in the term "panentheism" is the transcendence of God from all phenomena; while equally inherent is the immanence of God in all, and reciprocally the presence of "all-in-God" The term panentheism is thus able to convey divine transcendence and divine immanence as complementary realities; indeed the term can allow no less than boundless immanence and the most radical transcendence.

TRANSCENDENCE: In its most radical sense, divine transcendence attributes to the divine the freedom beyond every constraint: ${ }^{4}$ a freedom that must be an attribute of the omnipotent God. It allows the divine an unlimited activity free from

${ }^{3}$ For the development of theism to predominance in European theology, see Williams, esp. Lecture 6 (1927:393-442). For a powerfully argued thesis regarding the development of deism into the scientific worldview, see Sherrard (1987).

'See e.g., Gregorius Thessaloniensis, 'Hovx. III.i.29, III.ii.9 (1959:612, 659). 
every categorization and every restriction that govern the cosmos. The divine is as transcendent to the cosmos in this sense as the sea is to a thimble in that sea, indeed more so. The divine transcends by being greater than, and also by being essentially different from, the cosmos without being separated from it. Rather than placing God in a dimension apart, this transcendence allows the divine to permeate the cosmos. Rather than placing God outside, this transcendence allows the divine boundless activity within: an unlimited, and potentially surprising, participation of the divine in the cosmos, and reciprocally of the cosmos in the divine.

ESSENCE AND ENERGIES: The radical sense of transcendence may clarify the perhaps obscure phrases "transcendent divine essence" and "immanent divine energies, or operations", that were introduced in the preceding chapter. While they might seem to imply a primitive paradox, as if God were entirely outside and inside simultaneously, up there and down here at the same time, they actually express a sublime and consistent logic: as the divine is essentially beyond all categorizations, the divine can be kenetic, operative, energetic fully within any category, without restriction and without diminution.

This sublime logic allows the cornerstone of the Christian faith: the Incarnation in real terms. But the cornerstone becomes a stumbling block (cf. 1 Cor. 1:23) when other rules of logic are applied instead. When, for example, the rules governing Aristotelian categories are applied to God as "the Unmoved Mover", ${ }^{5}$ then by logical necessity the divine could never be conceived as kinetic, corporeal and passible in real terms; because once these qualities were assumed as natural predicates, then according to those rules, the phenomenon they described would need to be classed as something other than the Unmoved Mover, itself predicated upon the qualities of

5 See Niarchos (1991) for a summary of this logic, and for the transformation of the Aristotelian categories in the hands of St. John of Damascus. 
incorporeality and impassibility. An example of the propensity to define the divine in this manner was presented in the preceding chapter with Eunomius who assumed that the names attributed to God indicated the divine in essence. ${ }^{6}$ Another example, now from the field of philosophy cum anthropology, will be provided at the conclusion of the present chapter.

It could well be argued that this propensity to continue defining God according to pre-Christian philosophical rules of logic, constituted the basis of many of the heterodox constructions that will be mentioned in the initial section of the present chapter. From the heterodoxy of Arius to that of Barlaam, they limited the "transcendent divine essence" by approaching God as if he were the Unmoved Mover; and therefore none could allow the quality of passibility as an actual, instead of a nominal or analogical, attribute. They thus diminished the possibilities for "immanent divine operations, or energies".

It will be argued in the conclusion to this chapter that, in contrast, more of those possibilities could be comprehended within - (suprising as it might appear, stated now in anticipation) - the Far Northern hunting cultures than within a culture infused with those heterodoxies. Prior to this argument, the divine participation within Orthodoxy must be emphasized as a central dynamic.

\section{(2) Divine Participation:}

\section{a Concept consistent throughout the Ecumenical Councils}

Panentheistic participation can be perceived as centrally important dynamic when the Ecumenical Councils are viewed through three thematic phases that follow

\footnotetext{
${ }^{6}$ For a further example from the field of theology, regarding the direct application of these types of categories by Nestorius to Christology, see Mousalimas (1987).
} 
Jesus Christ (iii) into physical nature?

(i) Within divinity. The First and Second Ecumenical Councils concentrate on coexistence and participation within the divine : the Persons of the Holy Trinity are recognized as integral realities, each fully divine in essence, who indwell perfectly to comprise the single Godhead.

The first (Nicaea, 325) expresses the Son's undiminished divine essence (one essence with the Father) against the heterodoxy of Arius who posited an ontological divide between the Father and the Son by rendering the latter a creation, albeit pre-eternal, of the former.

The second (Constantinople, 381) expresses the undiminished divine essence of the Holy Spirit against the heterodoxy of Macedonius who shifted the ontological divide by positing it instead with the Father and the Son on the one side, while the Holy Spirit was diminished on the other side, as a creation.

\footnotetext{
${ }^{7}$ The contribution of the following section is the organization of the Ecumenical Councils into the three phases to highlight the concept of divine participation. The concept itself was introduced in the preceding chapter. The data for the Councils' dates and issues are standard (cf. Ware 1963:26-51, 75-79).

Only the primary themes in the Councils will be presented to highlight the central concept; and no pretence is assumed that such expedient dimensions would encompass the breadth of the history of doctrine. Within wider dimensions, more detail would be given to the subtleties of the polemics; and the historical depth would be extended. For example, greater reference would be made to the Gnostics' dualist view of creation which was countered by Christianity prior to the First Ecumenical Council; rand (St.) Irenaeus of Lyons would figure predominantly as he affirmed Genesis 1:31: "And God saw everything He had made, and behold it was very good". For Irenaeus in this regard, see Lawson (1948:119-132). For summaries of Gnostic dualism, see Jonas (1963:250-253) and Rudolph (1983:57-60). For a comprehensive study of views of the Fall prior to and including Irenaeus, see Romanides (1957).
} 
Each of the Persons are recognized as perfectly divine and coexistent. Each participates with the Others to comprise the single, indivisible godhead.

(ii) Through Jesus Christ. The next four Councils concentrate on the union of the divine with the human in the Incarnate Second Person of the Trinity, Jesus Christ.

The third (Ephesus, 431) emphasizes the union as thoroughly pervasive (an hypostatic union) against the heterodoxy of Nestorius who kept divinity and humanity conceptually apart in a contiguous union in which qualities were exchanged only in name: for example, the divinity could be only said to have been born of Mary; the humanity could be said to be lifegiving.

The fourth (Chalcedon, 451) emphasizes the integrity of complete humanity in the union with undiminished divinity, by describing the union as unconfused while yet inseparable.

The fifth (Constantinople, 553) counters a resurgence of Nestorianism by censuring the works of Theodore of Mopsuestia that were being circulated in place of Nestorius's own; and by stressing that undiminished divinity, God the Logos Himself, became passible, suffered, died, and was resurrected.

The sixth (Constantinople, 680-681) counters the opposite extreme by emphasizing that undiminished divinity, the Logos Himself, assumed the human experience entirely, was tempted in everything as iwe are, and resisted those temptations with a human will; and thus this council censures the Monothelites, who had 
replaced the human will with solely a divine will in the theanthropic Person.

Divinity and humanity are acknowledged as completely, pervasively coinherent in Jesus Christ, so that undiminished divinity is totally participant with completely integral humanity in an unconfused, indivisible unity.

(iii) Into physical nature. The Seventh and the subsequent Constantinopolitan Councils concentrate on the participation of the divine in physical creation.

The seventh (Nicaea, 787) defends the material representations proper to the divine, particularly icons and also the relics of saints, against iconoclasts who denied that divinity could be active within created physical nature except uniquely in the elements of the Eucharist.

The defence is reiterated (Constantinople, 843) after another surge of iconoclasm.

The defence is articulated further (Constantinople, 1341 and 1351) to express the immanence of undiminished divine energy, and to express the potential for our own immediate participation in this divine presence, or energy: an articulation against the heterodoxy of Barlaam who was, one may say, an academic theist of a sort.

The immanence is affirmed of undiminished divinity in integral physical nature, and the immediate participation is thus affirmed of the Creator in creation.

The perceptions affirmed at these later councils (Constantinople, 1341 and 1351) were articulated particularly by St. Gregory Palamas who is commemorated annually on the second Sunday of Great Lent. The first Sunday is the liturgical celebration of the restoration of icons (their restoration after the iconoclastic assaults); 
and through the proximity of these annual liturgical celebrations, the theology regarding the divine particularly in material icons is joined manifestly to the theology regarding the divine immanent in creation as articulated by Palamas. Indeed just as the one Sunday follows from the other, so the theology of divine immanence articulated at Constantinople in 1351 and 1451 follows from the theology of icons articulated at Constantinople in 843 and Nicaea in 787. Together they comprise the third phase And the later councils have a doctrinal authority "scarely inferior to the Seven General Councils themselves".

The three phases follow one from the other: from (i) participation among the divine Persons within the Trinity, to (ii) participation of divinity with humanity in the Incarnated Second Person of the Trinity, Jesus Christ, to (iii) participation of the divine in created matter. And they follow in particular direction: the divine participating in creation.

The reciprocal direction. The reciprocal direction - creation participating in the divine - begins to be expressed explicitly during the third phase, yet it is inherent throughout, from the beginning. It may have been the very reason for controversies, the Councils maintaining this dynamic against heterodox constructs which would separate the divine from nature, and which would thus diminish the possibility of creation's participation in the divine.

(i) In the first phase, the indwelling of the Divine Persons has an effect upon the reciprocal movement of creation in the divine. When God the Father creates through the Son in the Holy Spirit, divinity is no way diminished in the act. Divinity

\footnotetext{
${ }^{8}$ Ware (1963:76).
} 
is fully present in the act of creation, because each of the Persons is fully divine by essence. Creation implies no lessening, neither through emanation nor through a demiurge.

In contrast Arius and Macedonius both posited a demiurge, by rendering the Logos in the one instance, the Holy Spirit in the other instance, as a lesser divinity than God the Father. Such constructions may meet the demand in some philosophical systems that uncreated divinity be categorized exclusively apart from creation: the demiurge acting as the intermediary; but the conceptual construct precludes the participation by creation in the fullness of divine Life. An intermediate separates. The demiurge stands between.

Countering these heterodox constructions, the Councils during the first phase affirmed that creation derives from, and is sustained by, no less than complete divinity. Therefore it is with undiminished divinity that we are immediately in contact.

(ii) In the second phase, the same relationship was at risk. Any division posited conceptually between the divinity and the humanity in the Person of Jesus Christ would (again) separate the fullness of uncreated divinity from the creation. Consequences would ensue affecting our reconciliation to God in Christ, because the processes of salvation would then have to be interpreted in terms other than dynamic participation. Concepts of election or merit would beçome dominant, while the dynamics of participatory theosis would be either confined to ethical development or altogether lost.'

\footnotetext{
'For Nestorius, see e.g. Mousalimas (1987:284):

Consequently, Nestorius denies humanity's deification by any but ethical means: a nominal equality with God by virtue of a perfect adherence of humanity to divinity; and he denies God's communication of himself to us by any but created means: allogenous prosopa or, in the unique case of
} 
At the other extreme during this second phase were the heterodox confusions which diminished Christ's humanity. By compromising the integrity of creation, they would radically circumscribe or preclude our participation within the divine. They would radically circumscribe or preclude the possibility of a sanctification of our whole being. So vital were these dynamics of the participation of integral humanity with complete divinity that the controversy continued against the two extremes to the end of the seventh century. ${ }^{10}$

(iii) The third phase follows, as the Incarnation imbues creation with divinity. This phase began with the relationship between image and prototype in iconography. Here, participation is predicated upon the nature of the image in relation to the archetype; and, here, any confusion of substance was rejected, so that natures remain integral, unconfused: particularly because here participation is not the same as the pervasive union in Christ (the hypostatic union). The icon is not the same as the prototype, instead representing it by participating in the prototype's existence. The reciprocal movement involves the sanctification of created nature through that participation, so that St. John of Damascus could declare: "Divine grace is conferred

Jesus Christ, the prosopon of the union.

These consequences of Nestorius' metaphysics are riddled with irony. Attempting to maintain the divine nature uncompromised, he limits the transcendent by allowing it natural unions with consubstantials only; and striving to preserve the integrity of human nature, he diminishes humanity's capacity for deification. He binds the uncreated to the limitations which circumscribe creation, and he reduces creation's potential for participation in the divine.

For the consequences of his heterodoxy for the Eucharist, see Bebis (1964:316-330) and

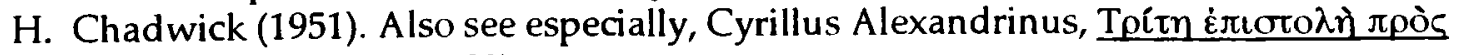

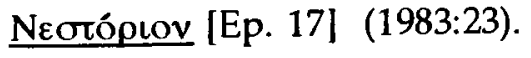

${ }^{10}$ Mousalimas (1980). 
on material icons, by virtue of the persons whom they depict"." While icons were the primary focus of attention, the implications for the veneration of saints' relics, and also for direct interaction with the saints themselves, would be of concern at the same time.

The later councils during this phase defend, and clearly articulate, the potentiality of humanity to participate in divinity, indeed in the undiminished immanent in creation. The defence is pastoral. Simple monastics came under attack from philosophers and theologians of a particular sort, because these monastics claimed to have had an immediate experience of the divine, one they would not explain as being of anything other than of God. Their perception was as of pervasive, divine light, the same as that perceived by the Apostles on Mount Tabor at the Transfiguration of Christ. But their experience was rejected by those philosophers and academic theologians recapitulated by the antagonist Barlaam who felt that these men were coarsely imputing a material, sensible quality to the immaterial divine. Like Nestorius, Macedonius, and Arius before him, Barlaam insisted on a radical conceptual divide between the divine and the created, and the consequences were the same: the separation of creation from immediate participation within the divine.

In defence, St. Gregory Palamas, bishop of Thessalonika, differentiates between the divine essence and the divine energy, or operation. ${ }^{12}$ He explains that creation is sustained and pervaded by the divine energy, while the divine essence remains

\footnotetext{
"Ioannes Damascenus, Eikóv. I.xxxvi (1975:148).

${ }^{12}$ This terminology was explained among the definitions in this chapter; and it was introduced earlier (in Chapter 2, above) with reference also to: St. Basil the Great who used the same terms; St. John Chrysostom who used very similar terms; and St. Maximus the Confessor who developed much the same theme in terms of $\lambda$ ó influence of Maximus in particular has been great in this field: see Thurnberg (1965; 1985).
} 
radically transcendent from, and utterly unknowable by, created nature. ${ }^{13}$ Neither is there confusion, as the Creator is other than creation; yet nor is there division, as the divine energy is fully present, so that undiminished divinity herself creates and sustains creation, and therefore can be experienced within creation.

A simile may be useful for the distinction. The divine essence and energy is in relation to creation like the sun and sunlight is in relation to the earth. While the sunlight vivifies us, and is perceived by us, we are utterly incapable of perceiving the source, the sun itself, not only because of its intensity, which is beyond our capacity, but furthermore because we are constantly in a position relative to the sun that will never allow us the perception of the source itself: by the time the sunlight infuses our world, the source is already in a different location relative to us. We always perceive the sunlight, never the source, even when we are focused directly on the orb itself. The analogy however is insufficient: unlike the sun, the divine essence remains immutable; unlike sunlight, the divine energy is undiminished in intensity from the fullness of the source. Yet the analogy is useful, for it is the sun itself that vivifies us, nothing other than the sun, in its energies or its operations. And it is the sun itself that we perceive, however never the self-same source, never the essence.

Some of the implications inherent at the councils in 325 and 381 were thus rearticulated a millenium later, in 1341 and 1351; for at the earlier councils, creation was affirmed as occurring through the operation of undiminished divinity; and a millenium later the same was affirmed, that creation occurs through the operation of undiminished divinity. The implications for the human experience of undiminished divinity were then articulated (at the later councils), because this

\footnotetext{
${ }^{13}$ E.g., Gregorius Thessaloniensis, 'Houx. Ill.ii.5-15 (1959:651-671).
} 
experience had to be defended, or rather because the way had be maintained obstructed for this experience.

Rather than assumed to have been convened for the sake of defining, the Ecumenical Councils can be understood as having been convened to defend against limiting definitions. These councils set boundaries to guard against diminution. They set boundaries on one hand against any division between the divine and creation, and on the other hand against any confusion of integral realities. Boundaries were set and reset against a chasm on the right, and against confusions on the left, particularly against the chasm - while the way ahead was maintained open, unobstructed, for the boundlessness of divine manifestation, and for the limitlessness of divine-human participation. Can there be a more rational approach to the divine than this? - an approach that defines against limitations of the divine.

A simile for this approach is that of a thimble in the sea. ${ }^{14} \mathrm{~A}$ thimble is like the created cosmos, and more specifically the created consciousness of human nature. The sea is like uncreated divinity. A thimble in the sea is filled and keeps being filled. Supremely rational is a stance that would allow the thimble to be so filled, and to continue to be, through the operations of the uncontained sea, according to the sea's own nature. Irrationality would occur as soon as the thimble supposed itself capable of containing the expanse, or supposed itself capable of categorizing all the possibilities of the sea's movements.

${ }^{14}$ The simile has been assimilated from patristic literature: cf. Athanasius Alexandrinus, 'Evav. liv (1971:268). Also see Basilius Caesariensis, Eis tòv $\rho \varepsilon^{\prime}$ $\Psi_{\alpha \lambda \mu o ́ v}$ ii (1857b:105D): but listed among "dubia" in Clauis Patrum Graecorum, vol. 2 (Geerard 1974:166). 


\section{(3) Panentheistic Participation:}

\section{Articulated within Orthodox Christian Cultures}

The concept of panentheistic participation defended by the Ecumenical Councils is articulated through manifold cultural dynamics as evinced by the following examples from: (i) patristic literature; (ii) iconography; (iii) popular literature; (iv) folk traditions; and (v) liturgical traditions.

(i) Patristic Literature. A few typical examples from among the material presented previously, will be reiterated here, with fresh quotations, for congruence within this section.

Developing ideas already expressed in the Logos theology of Justin in the early 2nd century, St. Athanasius of Alexandria, in the early 4th century, expresses a threefold reality to explain the Incarnation of the divine in Jesus Christ: (a) the divine transcendence; (b) the divine immanence; and (c) this immanence made specific in the Incarnation of Jesus Christ: ${ }^{15}$

Being in a human body, and vivifying it himself, he [the divine Logos] is also vivifying all, and existing in everything: yet is he outside all. And known through the works in his body, he is not imperceptible also through activities in all.

"Yet outside ${ }$ all" - this is: (a) the transcendence. "Vivifying all, and existing in every thing" - this is: (b) the immanence. "Being in a human body, and vivifying it himself" - this is: (c) the immanence made specific in the Incarnation in Jesus Christ. Athanasius continues, clearly expressing this threefold dynamic again: ${ }^{16}$

\footnotetext{
${ }^{15}$ Athanasius Alexandrinus, Evav. xvii (1971:174); also see $\underline{i b i d}$. (1973:326).

${ }^{16}$ Ibid.
} 
He was not bound by the body, but rather he held it, so that he was in it and in every thing, and yet outside, resting with the Father alone. And this is the wonder: that as man he was living the human life; and as Logos, engendering the life of all; and as Son, existing with the Father.

The same threefold dynamic is expressed in The Gospel according to John 1:1-14, where (a) the transcendence is articulated:

In the beginning was the Word [the Logos], and the Word was with God, and the Word was God. The same was in the beginning with God.

(b) The immanence is expressed:

And all things were made by him; and without him was not anything that was made. In him was life; and the life was the light of men. And the light shineth in the darkness; and the darkness comprehended it not. ... That was the true Light, which lighteth every man that cometh into the world. He was in the world, and the world was made by him, and the world knew him not. $\ldots$

(c) The immanence is made specific in the Incarnation:

And the Word was made flesh, and dwelt among us (and we beheld his glory as of the only begotten of the Father, full of grace and truth).

(ii) Iconography. The same dynamic is expressed through icons of Christ. In

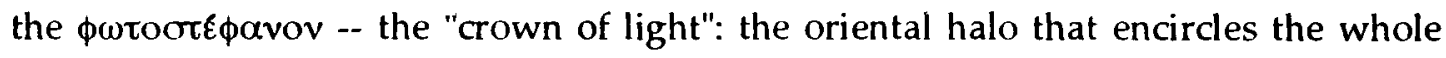
face -- there are normally three Greek letters around Jesus. Christ uniquely, not found

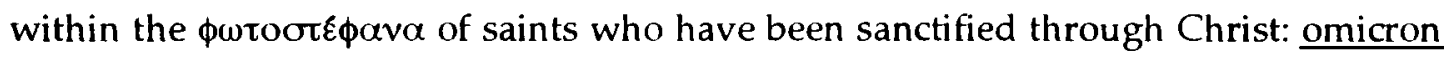
at one side; omega at the zenith; and nu at the other side. Together they spell the participle with its masculine article: o $\dot{\omega} v$, "the Being", or "the Existing". This is the name that God pronounces for Himself to Moses in Exodus 3:14 in the Septuagint, translated between the 3rd and 1st centuries B.C. God speaks from the "burning bush", itself a prefiguration - according to an understanding within patristics - of 
the human nature in the Incarnation, aflame with the divine without being consumed. At the same time, the name refers directly to the existent principle permeating and vivifying the cosmos, that was known to the pre-Christian Greek world. The icon communicates that this immanent principle has become Incarnate uniquely in Jesus Christ.

Both Athanasius of Alexandria and The Gospel according to John communicated the same in writing with reference to the Logos (as we have just read); and both men then explained that this immanent principle is personal, not an impersonal force as conceived by the philosophers. So, iconography through painting communicates the same dynamics that theology communicates through writing. The divine incarnate in Jesus Christ is the divine immanent in the cosmos.

(iii) Popular Literature. "God and nature are one and the same thing," says Dostoyevsky in The Possessed through the voice of a humble character named Maria. ${ }^{17}$ An innocent crushed by her sufferings, she articulates this suddenly, emphatically, in the presence of an important abbess who, tending toward theism and moral legalism, balks. The wise woman flounders foolishly when the simple fool states the full breadth and implication of the divine immanence.

Without the slightest qualification from the mouth of this humble woman, the unmitigated articulation that is meant to contrast most boldly with the abbess's narrowly rigid worldview, might seem pantheistic; but the articulation derives from the fluid pen of Dostoyevsky who describes the dynamics of panentheism with detail through another character, the saintly starets Zossima, whom the author insightfully develops at length in The Brothers Karamazov. Expressing the difference of God in

\footnotetext{
${ }^{17}$ Dostoyevsky (1971:154).
} 
relation to "God's work" that "strives towards the Lord", Zossima in coversation with a young peasant expresses the divine transcendence: ${ }^{18}$

"But," asked the lad, "can Christ really be with them?" "How could it be otherwise," I said to him, "since the Word is for all; all creation, all creatures, every leaf are striving towards the Lord, glorify the Lord, weep to Christ, and unknown to them accomplish this ... And I told him how a bear once came to a great saint, who was seeking salvation in a little hut in a forest. And the great saint was filled with tenderness for it, went up to it fearlessly and gave it a piece of bread: "Get along with you," he said to the bear, "Christ be with you." And the ferocious beast went away obediently and meekly, without doing him any harm. And the lad was deeply moved that the bear had gone away and that Christ was with him [the bear], too. "Oh, how good that is," he said, "how all God's work is good and beautiful."

The transcendence thus expressed, the immanence is also described by Zossima in conversation with the same peasant, whom he tells that "Christ has been with them [- the birds of air, the beasts of the field, the leaves, and the blades of grass - ] even before us". ${ }^{19}$

And an implication of this immanence for the dynamics of panentheisic participation is drawn out by the starets as he describes even the minute creatures partaking "in the mystery of God":20

Every blade of grass, every small insect, ant, golden bee, all of them knew so marvellously their path, and without possessing the faculty of reason, bore witness to the mystery of God, constantly partaking in it themselves.

${ }^{18} \underline{1 d}$. (1982:346). Compare the following sources quoted in Chapter 6 at notes 72 and 74 , below: Valaam, ed. $(1894: 140,182 ; 1978: 86,109)$ regarding bears, a mink, and the anchorite Herman of Alaska; also compare 'Ioropí ŁHistoria (anon.)] xxi.15 (1961:127), regarding a hyena and the anchorite Macarius of Egypt.

${ }^{19}$ Dostoyevsky (1982:346).

${ }^{20}$ Ibid. 
Further implications of the immanence are drawn out by Zossima later, within chapters of discourses, when he describes his "young brother" who "asked forgiveness of the birds". The starets' condescension to his young brother's act remains unconfused with any notion of crass animism, as the personality of the

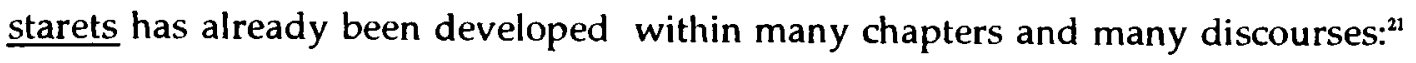

My young brother asked forgiveness of the birds: it may seem absurd, but it is right nonetheless, for everything, like the ocean, flows and comes into contact with everything else: touch it in one place and it reverberates at the other end of the world. ...

Zossima likens "everything" to "an ocean" to describe the inter-relatedness of all creation. According to the perception in patristics everything is indeed sustained by and permeated with, held together by and recapitulated within, the divine Logos; or as St. Athanasius would express the perception: the divine Logos is "the source of Life to all the universe, present in every part of it."22 Zossima continues with a repetition for emphasis, and then with advice: ${ }^{23}$

Everything is like an ocean, I tell you. Then you would pray to the birds too, consumed by a universal love, as though in a sort of ecstasy, and pray that they too, should forgive your sin. Set great store by this ecstasy, however absurd people may think it.

He repeats for emphasis later yet again: "Love all men, love everything, seek that rapture and ecstasy." ${ }^{24}$

Finally Zossima advises: "Love to fall upon the earth ceaselessly ..." He is, of course, advising . . frequent prayer with the complete prostrations that are made customarily; yet an allusion is also involved, one that rests upon the fullest

\footnotetext{
${ }^{21}$ Ibid., p. 376.

${ }^{22}$ Athanasius Alexandrinus, 'Evav. xvii (1971:174); also see ibid. (1973:326).

${ }^{23}$ Dostoyevsky (1982:376).

${ }^{24}$ Ibid., p. 379.
} 
implications of panentheism that the author allowed Maria to articulate, and that is implied as now Zossima finishes the sentence and then continues:"Love to fall upon the earth and kiss it. Kiss the earth ceaselessly and love it insatiably."25

The earth with its fecund beauty reveals the sacred to another of Dostoyevsky's insightful, however less saintly, characters in the novel with Maria: Shatov who likewise admonishes, "Kiss the earth, drench it with your tears, ask forgiveness". ${ }^{26}$

(iv) Folk Tradition. Shatov's exhortation corresponds to a folk tradition recorded in Russia. A peasant woman makes obeisance to the earth to atone. A moment earlier she made peace with the members of her family, and then with "the fair sun, the clear moon, the numberless stars, the dark nights, the soft showers, the raging wind". ${ }^{2}$ Now, she atones to the earth: Why? - because she must cut the earth with a plow to bring forth food to sustain her life. So, she brings her forehead to the earth; and sighing, she prays: $:^{28}$

One further blow, my foster-mother, I wish to touch you with my head,

To beg your blessing,

Your blessing and your pardon.

I have torn up your breast

Cutting with the iron ploughshare.

Never have I smoothed your face,

Never have I combed your locks;

I have bruised you under the harrow

With its teeth of rusty iron.

Foster-mother, pardon me,

In the name of Christ our Saviour,

Of the Holy Mother of God,

${ }^{25}$ Ibid.

${ }^{26}$ Id. $(1971: 261)$.

${ }^{27}$ Pascal (1976:12).

${ }^{28}$ Ibid. 
Of Blaise our intercessor,

Elias the wise, the prophet,

And the knightly George.

Her act is lucid. She does not confuse the divine energy immanent in the earth with the specific Incarnation in Christ; nor yet does she confuse Christ with any of the saints, all of whom she invokes integrally. She is in lucid communion with the divine in nature.

Yet while perceiving the divine in the very earth, this Orthodox Russian peasant in the North is also aware of a tragic disharmony, for her subsistence derives from her cutting that divine beauty when she plows. So, she atones. Similarly, the Orthodox Yup'ik hunter in Alaska - earlier an extended example was derived from the Yup'ik pre-Christian culture; presently this example is from the Yup'ik Christian culture - perceives the divine in the animals on whom his subsistence depends. And he atones. He restores harmony with the animals by honouring them: respectfully keeping the bones of a land animal, respectfully keeping some inner part of a sea mammal, then returning these in due season to the land or to the sea with thanksgiving, and with supplication that these animals come again as guests to this home.

The Orthodox Greek shepherd in Arcadia takes a lamb away from the sheepfold to slaughter to feed his family. The mother ewe, distressed by the separation, perhaps also by an intuition, is frantic, she butts, she bleats. And the shepherd sighs deeply: for in these harsh mountains, his small flock is part of his household; and in these harsh mountains, he too has known the death of offspring. The shepherd and his flock suffer alike. But on this day, the lamb has been cut in preparation for the feast of Pascha (Easter) when it will become an image of Christ the Lamb. In the middle of that coming night, the shepherd (like the hunter, like the peasant) will hold a candle in the darkness, and will sing: "Christ is risen from the 
dead, trampling down death by death". Then during the day of feast, while the lamb is being roasted on the open fire, the shepherd will dance in celebration of the Crucified and Resurrected Saviour who suffers with us to give life and who will restore life to all.

Among Orthodox folk early this century in traditional Romania, Mircea Eliade similarly observes that "central motif" of Pascha: "All Nature sighs, awaiting the Resurrection". The motif was expressed also by Dostoyevsky, as quoted earlier: "all creation, all creatures ... weep to Christ" as they "are striving towards the Lord". ${ }^{29}$ Eliade recognizes this motif as central in "the religious folklore of Eastern Christianity". ${ }^{30}$

(v) Liturgical Tradition. The cosmic participation in the suffering, death and resurrection of the Logos, is articulated also in liturgical traditions: indeed there is a time on Holy Saturday when the unity among liturgical, folk, iconographic, and patristic articulations becomes beautifully manifest. During that night in anticipation of the Resurrection, the people will cluster at the epitaphion, the representation of the tomb of Christ that they have beflowered within in the nave of their church (but decorated otherwise colourfully in colder climates), and have positioned where their own members' coffins have been, and will be, placed. Gathered here, the people sing hymns of lament and of faith that are so very popular, sung by virtually all and with emotion, that this liturgical tradition may also be seen a folk custom. ${ }^{31}$

\footnotetext{
${ }^{29}$ Dostoyevsky (1982:346).
}

${ }^{30}$ Eliade (1988:38).

${ }^{31}$ "Holy Saturday" has been specified; however as this liturgical event will be announced for "Good Friday evening" in contemporary parish churches, an apparent discrepancy may be noticed, and should be resolved to avoid confusion. Services that evening will be designated in the rubrics as belonging to Saturday, because the liturgical day begins at sunset. 
The participation of the cosmos in the Passion is articulated as the Logos is praised within the initial set (stasis) of these hymns: ${ }^{32}$

The whole creation was altered by thy Passion: for all things suffered with Thee, knowing, O Word, that Thou holdest all things in unity.

The cosmic lament is voiced for a few verses through Mary who recapitulates all of nature within herself, before the hymns again praise the Logos with complementary verbal images.:33

"Who will give me water and springs of tears," cried the Virgin Bride of God, "that 1 may weep for my sweet Jesus?"

"O hills and valleys, the multitude of men, and all creation weep and lament with me, the Mother of our God."

"When shall I see Thee, Saviour, Light eternal, the joy and gladness of my heart?" cried the Virgin in her bitter grief.

Thy side was pierced, O Saviour, like the rock of flint in the wilderness; but Thou has poured forth a stream of living water, for Thou art the Fount of Life.

Each set of these hymns culminates with verses such as the one above that turns sorrow into joy with the anticipation of the Resurrection. Analogously, the tomb has been turned to beauty beflowered. The tomb is expected to burst with Life, just as the winter is expected to burst into spring, just as the darkness of this night itself is turning into daylight. And on that day, all creation will join in the celebration during the Divine Liturgy when flowers (or evergreens) are brought forth from the altar and are strewn in the nave; and when the "Hymn of the Three Children" from Daniel "O all ye works of the Lord, bless ye the Lord; praise and exalt Him forever" - is

\footnotetext{
${ }^{32}$ Ware, trans. (1976:625).

${ }^{33}$ Ibid., p. 631.
} 
sung. ${ }^{34}$ But now it is the night. The time itself becomes a simile: "Thou art hidden like the setting sun beneath the earth and covered by the night of death: but, $O$ Saviour, rise in brighter dawn."135

In the next set of these hymns, the sun stands alongside the moon in mourning, through an allusion to the solar eclipse at the Crucifixion: ${ }^{36}$

The sun and the moon grew dark together, O Saviour, like faithful servants clothed in black robes of mourning.

In the third and final set, the cosmos is joined by the people in its lament: "Come, with the whole creation let us sing a funeral hymn to the creator. ${ }^{137}$

How can the cosmos be understood thus, as suffering and sighing, and, at the same time, be perceived as imbued with the divine? We may find the answer where the we began in this section of this chapter, within/theology expressed by St. Athanasius who explained that the divine Logos immanent in the cosmos is the divine Logos incarnated in Jesus Christ. Once we see the divine Logos suffering for us in Jesus Christ, we may also see the divine Logos suffering for us in nature, sighing with us even there, vulnerable to us even there, indeed communicating the divine to us even there in nature.

These people are living the theology of panentheism: the panentheism that is expressed in liturgical traditions, in folk traditions, in literature, in iconography, and in theology alike.

\footnotetext{
${ }^{34}$ See ibid., pp. 657-658.

${ }^{35}$ Ibid., p. 626.

${ }^{36}$ Ibid., p. 636.

${ }^{37}$ Ibid., p. 640.
} 
The Difference from naive pantheism. So vital and vivid is this expression, especially in folk traditions, that a question might arise, and indeed it should arise, about the principles inherent in these cultures that keep them from tending, instead, toward a naive pantheism. Two such principles are readily evident.

To begin with, cosmic disharmony is not necessarily conceived as deriving from the divine. Rain may turn to hail, rivers may flood, waters shimmering with beauty may suddenly swell: yet the Logos is always represented as lifegiving, never deadly; always rational, never irrational, not even whimsical. Neither is the disharmonious conceived as resulting from the act of creation, but instead from a marring of the cosmos by the subsequent Fall..$^{36}$

Secondly, there is the demonic which is not imputed to the divine Logos either. Instead, Christ expels the demonic. We can see this represented in icons of the Epiphany where Christ stands in the waters of the River Jordan. Ashore, John the Baptist attends to him; on the opposite shore, a company of angels are ready to receive him: the human and the angelic together around Christ. On both sides of the Jordan, the earth rises stylistically as if reaching upwards in an ecstasy of prayer; and inside the river, towards the banks, a very few figures of fish, or sometimes of tiny human beings, are almost imperceptible as they represent the nature of waters, innocent and neutral, and behold in amazement as Christ looking out from waters, and from the icon, peacefully blesses us, while beneath his feet is a humanoid or sauroid demon, rendered small, relatively insignificant, crushed underfoot.

We can hear the same theme in Alaskan folklore. The major tale among the Orthodox Dena'ina tells of holy water, the bible, and church incense expelling a

${ }^{38}$ To convey these distinctions, it could be useful to render an equivalent distinction in terminology, with "nature" indicating the harmonious and the disharmonious aspects, the latter including pests and pestilence; while "cosmos" is reserved to signify a harmony with the benevolent divine, as a meaning of harmony is instrinsic within the word "cosmos". 
deadly evil spirit-person which intruded into the village. ${ }^{39} \mathrm{~A}$ folktale among the Orthodox Alutiiq tells of an icon and church incense warding off evil spirits in the mountains. ${ }^{40}$ This recurrent theme in Alaskan folklore is recurrent also in the Gospels and in patristic writings, and constitutes one of the principles in Orthodox Christian cultures that differentiates the dynamics of their panentheism from naive pantheism.

Within these cultures the dynamics of panentheistic participation are thus articulated, as the divine is perceived in cosmos. One may therefore anticipate a certain affinity with the ancient hunting cultures, inasmuch as they also emphasized the immediate participation of the divine in nature. It is to this correspondence that the study will proceed next.

(4) Participation through Icons and Ritual Masks: A Comparison.

The previous sections of this chapter have concentrated upon the concept and the dynamics of panentheistic participation within Orthodoxy: a concept defended by the Ecumenical Councils; and dynamics articulated within Orthodox Christian cultures. The concentration has been meant to emphasize that the concept and the dynamics are centrally important.

The centrality allows the following statement: To comprehend this faith and its practices therefore, one must be able to grasp the dynamics of divine participation, if not specifically panentheistic participation. In the present section,

${ }^{39}$ Chickalusion (1982). Evidently this tale was an oral history of an actual occurrence as it is reported from Kustatan in the journal of Ioann Bortnovskii, entry dated 23 June 1896 in Townsend (1974:18).

${ }^{40}$ J. Johnson, ed. (1984:12). 
evidence will be provided that this ability existed within the ancient Aleut and Alutiiq cultures. This "point of comprehension" existed because divine participation, although articulated differently from new practices in some ways, was operative centrally within those ancient cultures also.

The "point of comprehension" will be indicated through a comparison between icons and ritual masks, a single example that has been designed to recapitulate the correspondence. Other relevant comparisons were provided earlier in this study: between ritu als in the previous chapter; and regarding the sacratized cosmos of the Aleut and Russian hunters in the first chapter. Other comparisons could be developed in the present section; for example, the nature of naming could be compared, as a name is an audible "image" analogous to the visual images of the icon and of the ritual mask." Yet other comparisons will be provided in subsequent chapters.

The Comparison. Masks were used in rituals throughout southern and western Alaska. They were used in the seasonal public ritual festivals by the ancient Aleuts of the central and eastern Islands, ${ }^{42}$ by the ancient Alutiiqs, or Koniags and Chugach, ${ }^{43}$ and by the northern and central Yupiit. ${ }^{44}$ Masks were used in shamans rites by the Dena'inas and the Tlingits. ${ }^{45}$

Icons, likewise, are essential to major ritual. This is clearly explained by two modern intellectuals in the following quotations. The first is from Phillip Sherrard, a

\footnotetext{
"Mousalimas (1990c).

${ }^{42}$ Veniaminov (1840b:87; 1984:199); Netsvetov (1840:3; 1984b:365-366).

${ }^{43}$ Black (1977b:86); Birket-Smith (1953:109-110).

${ }^{44}$ Hawkes (1913:12); Morrow (1984:136); Nelson (1899:393-394); Sonne (1988:29-30, 40-45); Zagoskin (1967:226-227).
}

${ }^{45}$ Laguna (1972:690); Osgood (1937:178); Townsend (1965:303); Veniaminov (1984:406-407). 
Britisher knowledgeable in the history of Greek Orthodoxy, and a translator of Greek monastic texts: ${ }^{46}$

The first thing that has to be said about the icon is that it is not simply a work of art similar in kind to other works of art. ... For an icon exists within the particular framework of belief and worship to which it belongs. ... An icon divorced from a place of worship is a contradiction in terms.

The framework of belief and worship to which the icon belongs is the Christian liturgy. The art of the icon is liturgical art.

The next quotation is from Leonide Uspenskii, an iconographer who was a member of the Russian emigrant community in Paris: ${ }^{47}$

Il est absolument impossible d'imaginer dans l'Église orthodoxe le moindre rite liturgique sans icone. La vie liturgique et sacramentelle de l'Eglise est inséparable de l'image. ... Objet de culte, l'icone n'est pas seulement provoquée ou inspirée par la liturgie, elle forme avec elle un tout homogéne; elle la complète et l'explique et augmente son action sur l'âme des fidèles.

Icons are, and masks were, highly visible, essential components in the respective rituals.

Icons are, and ritual masks were, made with special care as sacred objects. On the central Aleutian Islands, for instance, masks were constructed by mask-makers in a special place which was safe from all impurity. ${ }^{48}$ Before beginning, the mask-makers performed ablutions, and while constructing, they washed the masks

${ }^{46}$ Sherrard (1967:58); also in Ware (1976:58).

${ }^{47}$ Uspenskii (1960:10-11); translated by Ware (1976:5): "It is absolutely impossible to imagine any liturgical rite in the Orthodox Church without the icon. The liturgical and sacramental life: of the Church is inseparable from the image. ... As an object used in worship, the icon is not merely occasioned or inspired by the liturgy, but it forms with the liturgy a single and indivisible whole." Cf. Uspenskii (1982:461-462, 481).

${ }^{48}$ Netsvetov (1840:6; 1984b:367). 
to keep them unpolluted. Throughout southern Alaska, masks were often burned or deposited in caves after rituals. ${ }^{49}$

Icons, likewise, are made while the iconographer engages himself in asceticism for self purification. He prays, and he fasts, for the attainment of spiritual perception; so that he may acquire "spiritual eyes" and "spiritual ears", according to Photius Kontoglou, a Greek iconographer, who explains: ${ }^{50}$

No one enters uninitiated into the sea of mysteries. It is necessary that his spiritual senses be attuned, that they may grasp the spiritual tones and spiritual forms and colours.

The iconographer's task is to depict spiritual dimensions, or more precisely to depict those physical dimensions transfigured within the spiritual. The depictions themselves conform to traditional types, as the iconographer exercises his own inspiration and own ability within the inherited tradition; and thus the icons assume a timeless, otherwordly quality.

So, icons are, and masks were, sacred objects, integral to ritual, and integral to the sacralized cosmos.

More to the point, icons are, and masks were, involved in the realities represented. Ritual masks were identified with the archetypes represented; and the mutual identification could extend into a tripartite fusion that included the person wearing the mask. This has been noted by observers and commentators throughout southern Alaska:

The mask is an object made by men that, when used ritually, transforms the wearer so that he becomes, for as long as he wears the mask, a living representation or

${ }^{49}$ Black (1982a:35); Edmonds (1966:84); Hawkes (1914:17); Laguna (1956:96, 273); Nelson (1899:359); Sonne (1988:30). Also see Birket-Smith (1953:127).

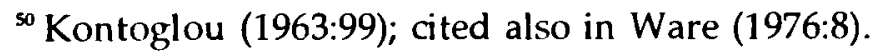


incarnation of beings outside the human sphere but with power to affect events therein. ${ }^{51}$

The painting of the wooden masks [allowed] the dancer to become visible to the spirit world and in fact to embody the spirit at the same time that his human identity was hidden from the world of men. ${ }^{52}$

[Le chaman] fixera d'eux [des esprits] des images, leur permettra de s'incarner, qu'ils l'accompagneront, troupe fidèle, dans ses pérégrinations extra-terrestres auprès des grands maîtres. ${ }^{53}$

... masks were not worn as concealment or disguise, but for visual and psychological transformation into the animal or supernatural being represented by the mask. During the wearing of the mask, the dancer or performer was suffused with its spirit. ${ }^{\text {st }}$

When worn in any ceremonial ..., the wearer lof the mask] is believed to become mysteriously and unconsciously imbued with the spirit of the being which his mask represents ...ss

... when an actor puts on the mask he is supposed to become imbued with the spirit of the being represented. ${ }^{\text {s6 }}$

The masks of the shaman represented his spirits and, when he put one on, he not only was supposed to resemble the spirit in outward appearance, but he actually became inspired by that yek [spirit], and spoke and danced as the yek. ${ }^{57}$

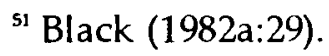

${ }^{52}$ Fienup-Riordan (1986:52).

${ }^{53}$ Lot-Falck (1957:15).

${ }^{54}$ Ray (1981:27).

${ }^{55}$ Nelson (1899:395).

${ }^{56}$ Hawkes (1941:17).

s7 Laguna (1972:690).
} 
When the shaman puts it [the mask] on, he impersonates this particular spirit and loses his own identity. ${ }^{58}$

The Koloshi [Tlingits] believe that during the shamanistic seance it is not the Shaman himself who acts but one of the Yeik [spirits] who has entered into him. ${ }^{59}$

In a similar manner, icons are associated with the realities whom they represent, and whom they make perceptible, although perhaps not to the same degree. These realities are usually known as prototypes in the theological literature about icons. The icons' association with their prototypes is relational, not substantial. In the words of St. John of Damascus (+ c. 749): ${ }^{00}$

An icon is a likeness, a similitude, a representation of someone. While showing in itself the person who is being represented, the icon is not altogether like the prototype (that is to say, the person being represented) in every way, for the icon is one thing and the person being represented is another.

The same distinction is found just as clearly in writings by, for example, St. Nicephorus of Constantinople (758-828) who explains that icons and archetypes are "different objects according to their nature", 61 and St. Theodore the Studite (759-c.826) who states that "Christ is one thing and his image is another thing by nature". ${ }^{2}$

${ }^{58}$ Emmons in Laguna (1972:692).

${ }^{59}$ Veniaminov (1984:406).

${ }^{60}$ Ioannes Damascenus, Eikóv. III.xvi (1975:125).

${ }^{61}$ Nicephorus Constantinopolitanus, 'Avríppnors I.xxx (1865:280A). Also see "Nicephorus and the Theory of Religious Images", in Alexander (1958:192).

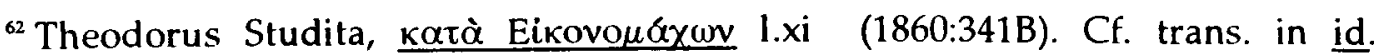
(1981:31). See Alexander (1958:192) for the operative logic, and for the similarity with Nicephorus. 
The icon thus reflects the prototype, and makes the unseen visible. This is evident particularly during liturgies, as described by Kallistos bishop of Diokleia and a don of Oxford University: ${ }^{63}$

As each local congregation prays Sunday by Sunday, surrounded by the figures of Christ, the angels, and the saints, these visible images remind the faithful unceasingly of the invisible presence of the whole company of heaven at the Liturgy. The faithful can feel that the walls of the church open out upon eternity, and they are helped to realize that their Liturgy on earth is one and the same with the great Liturgy of heaven. The multitudinous icons express visibly the sense of 'heaven on earth'.

In the preceeding chapter, the co-celebration was described in hymnography for spirits (angels) who join in the Liturgy to worship something greater that encompasses us all. Now this co-celebration is described in iconography; it includes saints as well as angels; and its dynamics extend yet further than co-celebration, because there is direct interaction between the angels and saints and the human participants.

Prayers as well as acts of respect are directed by the faithful through the icon to the reality depicted: to Christ, to the saint, or to the angel. Reciprocally, by virtue of its depiction of the sanctified reality, the icon serves as a channel of the reality's sanctified presence, or energy, as expressed very clearly, and very carefully, in theological terms, especially during the 8 th and 9 th centuries, when great thinkers were expressing the theology of icons in response to the iconoclasts. Here are some of these statements:

${ }^{63}$ Ware (1963 [1986]:277-278). Also see Uspenskii (1960:10): "L'icone est un objet cultuel dans lequel repose la grâce divine et qui fait partie intégrante de la liturgie." 
... by means of the icon we venerate the person depicted. For, as St. Basil says, "The honor given to the icon passes to the prototype."

When we honor and venerate an icon, we receive sanctification. ${ }^{65}$

Thus, if one should say there is divinity in an icon, he would not err, as it is also in the figure of the cross, among yet other divine offerings; not by a natural union [not by a union of natures] however, for they are not the deified flesh, yet by a relative participation because they share in grace and honour. ${ }^{60}$

Divine grace is conferred on material icons, by virtue of the persons whom they depict. A robe of purple silk receives no special honor in itself, but if it is worn by a king, the garment shares in the honor that is due to the wearer. So material objects are not venerated in themselves, but if the person depicted is full of grace, the material object shares in this grace to an appropriate extent. ${ }^{\circ}$

The icon is, thus, a point of interaction with the archetype represented. The icon is also a point of intersection between heaven and earth.

We have arrived at a level where now we may see at a glance the similarity between icons and ritual masks, by reading two brief quotations juxtaposed: the first from theology, the "Life of St. Stephen the Younger" (+ c.764); the second from Alaska anthropology:

${ }^{64}$ loannes Damascenus, Eikóv. III.xli (1975:143), trans. in Ware (1976:4). Also see Eikóv. I.xxxv, I.li, II.xxxi, II.xlvii, Ill.xlviii (1975:147, 154). For the quotation, see

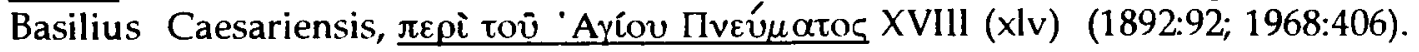

${ }^{65} 6$ th Act of the 2nd Council of Nicaea (the 7th Ecumenical Council, A.D. 787), in Mansi (1767:269), trans. in Ware (1976:6). Also see Sahas (1986:99).

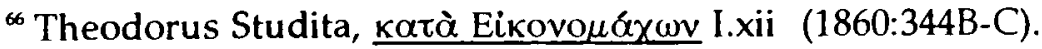

${ }^{67}$ Ioannes Damascenus, Eikov. l.xxxvi, Il.xxxii (Scholion) (1975:148), trans. Ware (1976:6). 
The icon is a door. ${ }^{68}$

[Masks are]

eyes into a world or worlds beyond the mundane. ${ }^{69}$

\section{(5) Conclusions}

The two quotations in juxtaposition recapitulate the correspondence; and they highlight "the point of comprehension" at the very centre of the ancient hunting cultures: an awareness of spiritual realities in the sacrat cosmos, including the awareness of their participation specifically through representations. Whether this awareness was expressed as a concept or remained as a less definite cognitive pattern is inconsequential. In either case, the awareness existed: the dynamics were operative.

This "point of comprehension" would allow these Far Northern hunters' societies to grasp, and to retain, the Orthodox Christian faith and practices. Remembering that the ritual masks were usually destroyed or deposited after use, and that their archetypes did not constitute a fixed pantheon, we may well envision the icons' arriving, ${ }^{\circ}$ being engaged by a people who could comprehend them, and

${ }^{68}$ Stephanus deaconus Constantinopolitanus (1860:1113A), trans. in Ware (1976:3).

${ }^{69}$ Fienup-Riordan (1986:51). Cf. id. (1988:267): "the eyes of the mask ... looked beyond this world into another."

${ }^{70}$ See Fitzhugh and Crowell (1988:81), illustrations 87 and 89 , for photographs of small portable icons: an Even wooden diptych, and a Russian metal triptych, the latter from Aleutian Islands. So that the icon could be carried, the Russian metal triptych "had a cord attached for suspension around the neck"; and the Even wooden diptych "is equipped with a belt hook and leather case" The Evens, also known in literature as the Lamut, extend from north-central and northeastern Iakutia to the northern coast of the Okhotsk Sea, opposite Kamchatka, including the region around the seaport of Okhotsk: this seaport became the main site for embarkation to the Aleutian Islands subsequent to the initial contact periods (from the 1770s); embarkation took place from the east coast of Kamchatka during those initial periods, beginning with Bering's voyage from Petropavlovsk in 1741. See King (1784:303-304) for a description of the church near Petropavlovsk in 1779, containing icons that were, according to this source, brought by the Bering expedition. As explained with 
remaining. ${ }^{n}$ With the icons, the realities represented would be engaged, and would remain, for manifest participation within the society. Icons comprise only a single example. Names could provide a further example; ${ }^{72}$ and by extension from the iconic quality of names and the participatory quality of naming, the further example could be applied to hymns and prayers as evinced already in the first and second chapters of this study.

Within the comparison between icons and ritual masks, differences are evident; just as differences were allowed within the definition of "correspondence" in the preceding chapter. It would be a misinterpretation of the argument, and of the evidence, if the correspondence were assumed to imply an equivalence between icons and ritual masks. One difference involves some of the archetypes represented. Another involves the wearing of ritual masks.

The latter merits attention because of the "tripartite fusion" (as I referred to this dynamic during the comparison) that ritual masking can engender between the "representor", the representation, and represented. An oversight would occur even here, should this obvious disparity (the wearing of ritual masks) be interpreted too quickly as if it indicated a chasm of non-correspondence. "Tripartite fusion" occurs in Orthodox ritual also: namely, in the vesting of the celebrants for the Divine Liturgy. Does the celebrant not become iconic himself through his vestments? The iconic quality of the vested presbyters and deacons is described as follows by St. Germanus

references in Chapter 1, above, significant Aleuts were traveling to and from Kamchatka beginning in the mid-1740s.

${ }^{7}$ For icons with inscriptions dated in the 1770s at Umnak, eastern Aleutians, see Lydia T. Black, ed., in Gideon (1989:162). For icons at Kodiak in 1788, see Lopez de Haro (ms.:107), trans. in Moore (1979:69).

${ }^{72}$ Mentioned also above, at note 41 to this chapter. 
of Constantinople, whose commentary on the Divine Liturgy served in the comparison in the preceding chapter: ${ }^{\text {? }}$

The presbyters by imitation of the seraphic powers are covered with stoles as if by wings; and with the two wings of their lips, they proclaim the hymn, as they take the divine, noetic coal - Christ - bringing it into the altar with the thongs of their hands. The deacons, as they go around [in procession], with the wings of their linen oraria, are types of the angelic powers who have been sent out to minister.

Vivid imagery relating to the Incarnation describes the main celebrant, the vested bishop, who becomes a symbol of Christ: ${ }^{74}$

The archpriest indicates by his stole the stole of Christ: the purple, bloody one worn by the immaterial God as porphyry adorned of the undefiled blood of the Mother of God and virgin.

An area of correspondence, thus, exists even within the dynamic of "tripartite fusion".

Yet, as this portion of the conclusions is meant to emphasize, the correspondence can not be assumed to imply an equivalence. A difference within this area also exists, in the contextualization (the liturgics) and the conceptualization (the theology) that prevents the Orthodox iconic "fusion" of distinct realities from becoming a confusion. If "fusion" is allowed as a term to signify a combining of distinct things, then "confusion" is a disorder that would render these things indistinct from each other. The presbyter's own face remains visible in the Liturgy:

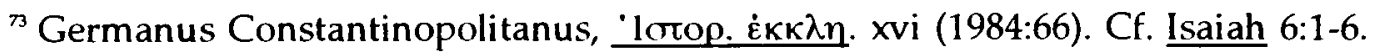

${ }^{74}$ Ibid. xxiv (1984:74). The bishop's stole, tò ómoфóptov, is very wide in comparison with the deacon's stole, tò ópóptov; worn upon the shoulders, it hangs front and back to the length of the bishop's other vestments. The possibility of correspondence becomes even more impelling when the bishop, yet unvested from his outer garments, before entering the altar, stands in the centre of the church and is vested in those garments by men of lower orders. Or, that is to say, the possibility would become impelling if evidence were brought forth to show clearly that during ancient Alaskan rituals a primary functionary was similarly dressed in symbolic paraphernalia by assistants, not by his own hands. 
his distinct personhood remains immediately manifest, and therefore remains unconfused with any symbol he represents. The "representor", the representation, and the represented are manifestly distinct realities. The relationship between them is iconic. The liturgical context furthermore prevents confusion in the tripartite dynamic by prescribing a reserved decorum for the religious celebration, and by disallowing ecstatic possession (to be explained in the next chapter), so that mental processes remain lucid. Just as the liturgical context prevents confusion, so do the theological concepts. The iconic relationship is maintained intellectually as articulated by St. John of Damascus, St. Nicephorus of Constantinople, and St. Theodore the Studite, for example, all "of whom stated that the representation is one thing, and the represented another (as quoted in this chapter). ${ }^{\pi}$ The Orthodox context and concepts become even more vital when the symbols are perceived as poetic and experiential, instead of rigidly defined and fixed; and when they become known primarily through participation, instead of by rote. An unfolding participatory experience of symbols can then occur without much risk of confusion.

Important differences notwithstanding, a correspondence within the dynamics of "participation" exists nonetheless. And it may well be argued that, for the sake of the transition, the correspondence comprises the more important factor. Although the dynamics of divine participation occurred in different ritual contexts, and were sometimes channeled toward different archetypes, the very correspondence itself is the key factor. It comprised a "point of comprehension" that would allow the transition to take place as it did: as an indigenous and corporate movement; because the ability existed in these ancient hunting cultures to comprehend the dynamics of divine participation. :

\footnotetext{
${ }^{75}$ See above, notes $60-62$ to this chapter.
} 
An antipodal hypothesis. The antithesis is implicit: where the "point of comprehension" has been diminished or denied, there divine participation would appear incomprehensible.

An example is provided by Lucien Lévy-Bruhl (1857-1939), an epistemologist who attempted a theory of "participation" from extracts from various ethnographies. Delivering a summary of his views in the Herbert Spencer Lecture at Oxford in 1934, he authored seven books on the topic beginning in 1910, including Les Carnets published posthumously in 1949; and he has been translated into English, then republished in this language throughout the course of this century, most recently by Princeton University Press in $1985 .^{76}$ Although he has paled to obsolescence in comparison with culturally-specific studies that have since been achieved, most notably by E. E. Evans-Pritchard and by G. Lienhardt," Lévy-Bruhl warrants some attention because he wrote voluminously on the subject of "participation" specifically.

In his opinion, the dynamics of participation bore no relationship whatsoever with the rules of logic and with "our mentality", as he termed it. "Ours" would be his own: that which had become prevalent in his own circles. He referred to it also as "our scientific mentality", ${ }^{78}$ a more definite term indicating the "logic" that was involved: the positivism and binary systems that governed some then-contemporary fields of science within a deistic, if not atheistic, cosmology.

But do those rules actually contradict the dynamics of participation? The principles involved in Aristotle's categories and in Porphyry's binary logic had been employed in patristic theology to explain the "relative participation" within iconic

\footnotetext{
${ }^{76}$ Lévy-Bruhl (1985). This is the third edition: first edition, 1926; second edition 1966.

${ }^{\pi}$ Evans-Pritchard (1956); Lienhardt (1961).

${ }^{78}$ See Mousalimas (1990a:35-36).
} 
relationships. ${ }^{7}$ Furthermore, Aristotelian categories and the "Porphyrian Tree" became a basis for much of the medieval Western theistic articulations that themselves hardly precluded the concept of iconic particiption: they merely diminished it. Even when those principles are applied to levels of analysis deeper than iconic relationships, in other words when they are applied to the divine nature itself, to render the transcendent divine nature theoretically subject to them, as if bound to them, thus resulting in the constructs of, for instance, Arianism and Nestorianism (as explained in sections 1 and 2 of this chapter), the potential for the divine to participate within the cosmos is limited. It is only limited. Even then it is not entirely contradicted by those rules. Why, then, would Lévy-Bruhl resolutely insist upon a radical contradiction?

His contradiction was due (in my view) not so much to those "rules of logic" as he asserted, but more specifically to the deism, if not atheism, of "our mentality" within which he was exercising them. Deism denies the existence of the divine as an objective reality itself (as explained in the initial section of the present chapter); therefore any statement that the divine is participating within other phenomena must appear as other than a logical statement, indeed as other than rational, whether it be articulated within ethnography or metaphysics or theology. The deist may recognize the internal connections that allow a coherence in some of $/$ systems of "participation", as Lévy-Bruhl admitted; ${ }^{80}$ but the deist would have to deny the rationality of any such system, because he presupposes the divine to be ultimately non-existent as an hypostatic reality within the cosmos.

\footnotetext{
${ }^{79}$ See Alexander (1958:192). Also see notes 61 and 62 to this chapter, above.

${ }^{80}$ See Mousalimas (1990a:37-38).
} 
Thus from his first book on the topic to his last notebooks, Lévy-Bruhl described the dynamics of participation as "prelogical" and "incomprehensible". They remained "non-conceptual" for him, and "deeply rebellious to intelligibility". ${ }^{82}$ The point of comprehension did not exist within his mentality, or within the society that had engendered his mentality.

In contrast, the Aleut and Alutiiq societies had developed the possibilities for divine participation, and thus in effect the possiblity for a comprehension of patristic panentheism. Whether the corresponding dynamics within their own societies were panentheistic is unknown; the evidence is insufficient to allow a conclusion of that sort. ${ }^{83}$ In any case, the very point of comprehension existed at the heart of these ancient cultures, so that they could themselves grasp, and would retain, the new faith and practices.

${ }^{81}$ See ibid. p. 43.

${ }^{82}$ Lévy-Bruhl (1975:99). See the original (1949:130): "la participation implique quelque chose de foncièrement rebelle à l'intelligibilité". Also see ibid., p. 135: "la participation n'est pas une fonction logique"; p. 138: "pour se rendre compte de la participation, il faut avoir bien soin de se tenir sur le plan affectif, et de ne pas céder à la tentation de se laisser glisser sur le plan cognitif afin de se la rendre 'intelligible'".

83 Significant studies are being conducted that articulate the permeability or flexibililty of categories within specifically Yup'ik cosmology: Fienup-Riordan (1990b); Morrow (1990). Issued in periodical volume dated 1990, but which was actually published in winter 1992, these two studies derive from a symposium at the 7th Inuit Studies Conference held in August 1990 at the University of Alaska at Fairbanks. 



\section{CHAPTER 4}

\section{ECSTASY}

Dynamics of participation were operative in southern Alaska in many ways: in masking, as explained in the previous chapter, and in ritual celebrating as mentioned earlier. Another way was shamanizing. Through shamans' ecstatic experiences the propensity for participation with spirit(s) was highly evident. It is to a consideration of shamans' practices within these Far Northern hunting cultures that the study will proceed. ${ }^{1}$

The shamans' practices were only part of greater ritual and spiritual configurations. Ritual festivals were celebrated periodically, and were officiated by tradition bearers and song leaders of other sorts, not shamans. ${ }^{2}$ Domestic rites were observed daily by elders who were not necessarily shamans: for example, eastern Aleut elders would attend each dawn with composure to greet the sun, and to "swallow the light". ${ }^{3}$ Yet while circumscribed, the shamans' own practices affected virtually the whole of the societies, as the shaman would practice at times on behalf of the society as a whole, and at other times on behalf of particular members of the society. Therefore while only part of greater ritual and spiritual configurations, the

\footnotetext{
${ }^{1}$ Material in sec. 2 of this chapter was presented as Mousalimas (1991a), to be published in the conference proceedings. Material in sec. 3 was presented as id. (1990d); but a correction is necessary in this early publication: Veniaminov was not a missionary: he was a parish priest.

${ }^{2}$ For references to the wider ritual configurations see above, Chapter 2, sec. 2; Chapter 3, sec. 4. For an exception to this regional generality see below, Chapter 5 , sec. 1 , where the shamans' characteristics are described.
}

${ }^{3}$ Veniaminov (1840b:109-110; 1984:211). Also see id. (1840b:258; 1984:290). 
shamans' own practices constituted a central phenomenon within these societies nonetheless." They were a "central societal phenomenon".

As the transition into Christianity within these societies involved them virtually in their entireties, and took place largely through indigenous social and spiritual movements, a certain continuity would be expected from this "central societal phenomenon" that would be analogous to the transformation of ritual masks into icons. However a question rises about the expectation, inasmuch as this phenomenon was ecstatic. Can a transformation of ecstatic phenomena be expected within a transition such as this?

The question will be addressed in this chapter through two subsidiary considerations. Firstly, do sound patristic criteria exist that would guide the transformation of such phenomena? Secondly if the criteria do exist, were they applied solidly within the regional focus in Alaska, thus to support a transformation?

\section{(1) Definitions.}

(i) A practicable definition of "ecstasy". A concise comprehensive definition is provided from theology by Panagiotes Christou with reference firstly to the meaning of the original word: ${ }^{5}$

'For the distinction between shamanism as a central societal phenomenon and shamanism as peripheral, see Lewis (1971). As central, the shamans' practices involved the society as a whole.

${ }^{5}$ Christou (1964:534-535). His analysis of general categories of ecstatic phenomena (ibid. pp. 535-539) is also practicable in my opinion.

(1) pathological;

(2) religious, including:

(a) frenzied, e.g. the Dionysian;

(b) philosophical, e.g. the Neo-Platonic and Zen Yoga;

(c) Christian, including:

(i) biblical and patristic;

(ii) heretical, e.g. the Montanist;

(iii) apophatic, e.g. the Aeropagitan. 
The word "ecstasy" was changed early from its primary meaning (a transposition from the familiar situation) to the metaphorical, referring to man's psychical level. The term is used particularly to indicate the condition in which the human nous, distanced from the worldly and ceasing from normal reactions to external excitement, experiences another sphere of things, be it a general experience of an other-worldly reality, or a specific comprehension of the divine mystery.

The external characteristics that typify ecstatics, vary from complete calm to frenzy. In the former instance, the body remains unmoved, while the blood circulation and breathing remain slight; while in the latter instance, observably forceful movements occur. The duration of the ecstasy also varies, depending upon its form, and upon the means through which it occurs.

Within this definition, the constant aspect of "ecstasy" remains the meaning implicit within the very word itself: $\varepsilon$ k-otaar, a transposition, implying a transposition from the commonplace to an experience of other realities. Defined in this sense, the word "ecstasy" is like the phrase "altered states of consciousness" that has become current in some anthropological literature.

Christou's definition is valuable as it allows the content of ecstatic experiences to range from "the comprehension of the divine mystery" on the one hand, to any number of manifestations of the other-worldly. The latter could either be subjective physical phenomena, such as collective representations and archetypes, or be objective hypostatic phenomena, such as actual angels or demons. This definition does not "over-define" ecstasy and thus does not become narrow and impracticable.?

For the inclusion of the latter as Christian instead of Neo-Platonic see especially the conclusions in Louth (1989:130-134).

${ }^{6}$ See Siikala (1987:31-33); Bourguignon (1973:3; 1974:235).

${ }^{7}$ Compare Lemaître [Hausherr] (1953:1863) who defines "ecstasy" as, and thus limits it to, divine union. This source warrants notation because it was recommended to me without qualification in 1986 and again in 1990 as a definition for "ecstasy", and therefore may be considered as influential.

Also compare Inge (1912:157) who allows a wider scope for the content of ecstatic experiences than does Hausherr but limits their form to pathological trance states. Inge's definition merits attention because it has remained current throughout this 
Allowing an adequate range for the content of ecstatic experiences, the definition also allows an adequate scope for their form as ecstatic experiences can vary from "complete calm", even a cataleptic-like trance on the one hand, to extreme animation on the other hand. Thus various descriptions of Far Northern shamans' practices can be encompassed by this definition whether they involve composure, ${ }^{8}$ or unconsciousness (be it momentary or prolonged), ${ }^{9}$ or role taking, ${ }^{10}$ or frenzy. ${ }^{11}$

(ii) Contrast: "Ecstasy" and "Trance". 12 An equivalence, or synonymity, between the terms "ecstasy" and "trance" has been posited in the field of comparative religions and applied to a consideration of shamanism by A. Hultkrantz of the University of Stockholm. ${ }^{13}$ Interpreting ecstasy "as a state of trance", ${ }^{14}$ he has

century, as it has been included recently in the select bibliography for "Ecstasy" in the Encyclopedia of Religion (Eliade, ed. 1987:17). This definition was originally published after he delivered the Bampton Lectures (Inge 1899), and it underwent only a minor but significant revision in his Gifford Lectures when he extricated Plotinus' ecstatic experiences, and thus any like Plotinus's own, from the otherwise definitive characteristic of psychological pathology (id. 1918:142-146). The revision may have been influenced by Underhill's work that appeared in its first edition in 1910.

${ }^{8}$ For an example from Unalaska Island in the eastern Aleutian Islands, 1791, see Sarychev (1802:141-142; 1807:64-65).

${ }^{9}$ For an example at the village of Koshiga in the eastern Aleutian Islands, 1791, see ibid. (1802:147-148; 1807:67-68). For a generality from Kodiak Island, 1804-1807, see Gideon (1989:59-60).

${ }^{10}$ For evidence of a shaman's role-taking on Unalaska Island in the eastern Aleutian Islands, 1791, see Sarychev (1802:141-142; 1807:64-65). For an extended study of shamans' role-taking from Siberian examples, see Siikala (1987).

"For a generality from Kodiak Island, 1804-1807, see Gideon (1989:59-60). For a generality from the eastern Aleutian Islands, but a secondary source in this respect, see Veniaminov (1840b:123; 1984:219).

${ }_{12}$ A contrast with "possession" need not be developed here as it has already been differentiated from "ecstasy" by Siikala (1987:37), agreeing with Bourguignon (1973:12-15).

${ }^{13}$ Hultkrantz (1973:28). The professional affiliation is current with id. (1990). He 
asserted that 'trance' is the same thing, the term 'ecstasy' being used by students of religion and ethnology, the term 'trance' by psychopathologists and parapsychologists". ${ }^{15}$ Similarly Anna Leena Siikala of Joensuu University, Finland, has allowed the equivalence while regarding Siberian shamans' practices, and has employed the same sort of justification: "As terms 'trance' and 'ecstasy' do not differ from one another except that the former is favoured primarily by anthropologists, the latter by students of comparative religion". ${ }^{16}$

These two statements - the one by Hultkrantz, the other by Siikala - could be paraphrases except that the attributions differ in each: "ecstasy" has been specified in the one statement as the term favoured primarily by anthropologists and ethnologists, but "trance" is specified in the other as the term favoured by the same groups. Confusion is evident. With respect for the writers, the confusion can be assigned to an actual overlapping of the uses of the terms in the numerous sources these writers have cited in their respective bibliographies. But an existing confusion in the sources would hardly be a justification for promoting a continuance of the

has been influential in studies of Native American "religion" (as he has termed it) since the 1950s, and has published work regarding the Far North since the 1960s: see the list of publications under his name in the "References" in id. (1978). The definition derives from the third decade of his publications, and it was not revised or contradicted in id. (1990). For Hultkrantz, also see note 16 below.

$$
\begin{aligned}
& { }^{14} \text { Id. (1973:28). } \\
& { }^{15} \underline{\text { Id. }}(1978: 41) .
\end{aligned}
$$

${ }^{16}$ Siikala (1987:39). The work cited here was written as a dissertation presented to the Finnish Academy of Sciences in 1977. It was copyrighted and published in 1978 , then reprinted in 1987, as cited. Siikala's professional affiliation specified in my text is current with the International Association for the History of Religions Regional Conference on Circumpolar and Northern Religions, in Helsinki, 13-19 May 1990, sponsored by the University of Helsinki Department of the Study of Religions and by the Finnish Society for the Study of Comparative Religions. She presented a full paper in a plenary session. Her senior from the University of Stockholm, A. Hultrkantz, presented two full papers (including Hultkrantz 1990, cited in this study). 
confusion in an analysis. Clarification is needed. Just what is meant by "ecstasy" and what by "trance"? And why have the two been confused?

The equivalence posited between these terms evidently derives from a hypothesis that "ecstasy" is a manifestation of psychopathology. This hypothesis had been articulated in the Department of Comparative Religions at the University of Sweden by Ernest Arbman in his multivolume work on the subject of ecstasy. He propounded the equivalence between "trance" and "ecstasy";: and both Hultkrantz and Siikala were influenced by him in this regard specifically, as both cited him while they were positing the synonymity between "ecstasy" and "trance" themselves. ${ }^{18}$

As soon as the hypothesis (that "ecstasy" is a manifestation of psychopathology) is challenged however, then the equivalence of "ecstasy" and "trance" begins to be sundered. Thus when Evelyn Underhill allowed psychological health in "true or sane ecstasy" (as she termed it), she began to differentiate "ecstasy" as a phenomenon distinct from "trance": she perceived trance as a physical effect unconfused with the cause and with the content of a "sane" ecstatic experience. ${ }^{19}$ If the possibility of health were advanced yet further, so that in certain kinds of ecstasy, physical health were allowed along with psychological health, then the very concept of "ecstasy" would need be sundered altogether from the concept of "trance", as a

\footnotetext{
${ }^{17}$ Arbman (1963:xv). He was professor of Comparative Religions at the University of Stockholm from 1937 to 1958.

${ }^{18}$ See Hultkrantz (1978:41); also see Siikala (1987:39).

${ }^{19}$ Underhill (1930:170, 358-361). Underhill's work has remained current throughout this century: published twenty-one times from 1910 to 1967, including twelve revised editions (the last revised edition in 1930, as cited, was reprinted in 1967), it has been included in no less than three select bibliographies, for "Ecstasy", "Mysticism", and "Mystical Union", in the Encyclopedia of Religion (Eliade, ed. 1987:17, 245, 261).
} 
separate and not necessarily related phenomenon. Ecstasy could then occur without trance.

Evidence for this possibility - that ecstasy can occur without trance, so that the ecstastic can experience physical and psychological heal th - may be forthcoming. A recognizable result of trance is the premature depletion of an ecstatics physical resources, exhausted by his straining away from the physical. ${ }^{20}$ In contrast, a recognizable effect of the absence of trance could be physical stamina well into old age. Evidence of this stamina exists in The Life of St. Anthony of Egypt. Longevity and health are described for him. ${ }^{21}$ Whether the vita was authored by a primary source who had himself actually known the Egyptian in old age or not, the very fact that the vita has been valued by so many generations should itself indicate the possibility that health in ecstasy has been expected and could occur. ${ }^{22}$

This possibility must be allowed, if the purpose of research into the field of ecstat ic experiences is to discover; and the researcher must be equipped with a flexible vocabulary that can accommodate possible discoveries.

${ }^{20}$ For examples see Underhill (1930:58-59, 362).

${ }^{21}$ Bios 'Avtôviov xciii in Athanasius Alexandrinus (1857:973). Anthony lived about a century, from c.251 until 356 (Cross and Livingstone 1983:67). For a bibliography of the scholarship that has doubted the ascription of this text to Athanasius, see Petterson (1990:33, note 69) who accepts this authorship.

${ }^{22}$ This theme will not be developed here due to the limitation of space. It could be developed as a cosmological theme. If the ecstatic or the scholar assumed a theistic cosmology, then the ecstasy or its interpretation would involve trance. Within a theistic cosmology, the ecstatic involvement with the divine must occur beyond the "confines" of physical nature because the divine itself (as explained in the preceding chapter) is posited outside the cosmos. An ecstatic would be expected to strain away from the physical to reach the divine; and ecstasy would be expected to involve rapturous trance. In contrast within a panentheistic cosmology, such a straining away from the physical would not be required; rapturous trance would not be considered necessary for ecstasy; and ecstasy (specifically divine union) could be considered nurturing of the physical body just as it would be of the soul. 
This flexibility can be achieved when "ecstasy" is separated from "trance" as follows. "Ecstasy", according the meaning intrinsic within this word itself (as identified earlier), can signify a transposition from the commonplace to some experience of other realities, and can be allowed a wide range of possible transpositions and experiences (forms and contents) as in Christou's definition. "Trance", on the other hand, can signify the psycho-physical abnormality that accompanies some but not necessarily all forms of ecstasy. The "trance" has discernable cross-cultural characteristics itself, involving an altering of the body's normal functioning probably resulting in an ultimately debilitating physical strain. ${ }^{23}$

"Trance" can thus be equated with an "ecstasy" in instances of pathology. Or "trance" can be rendered as a contingent effect of an "ecstasy" as in the instances of "sane ecstasy" described by Underhill. Or it can be rendered causal as in drug induced altered states. Finally, "trance" can be separated from "ecstasy" altogether, clearly lexically, if trance were discovered to be non-existent within an ecstatic experience.

The latter possibility is important in my view, if the transformation of ecstatic experiences is to be sought. Otherwise the valuing of ecstatic experiences would be tantamount to a valuing of pathology inasmuch as trance or "rapturous trance", ${ }^{24}$ itself pathological, is equated with "ecstasy" as in the studies I have just cited.

The word "ecstasy" having been defined -- (i) through the quotation of a practicable definition and (ii) through a contrast with "trance" -- the study can proceed to address the question: whether a transformation of ecstatic phenomena can be expected within

\footnotetext{
${ }^{23}$ Notice that the vocabulary for these characteristics avoids ethnocentricity: the physical debilitation need not be valued by the researcher while it might be valued by an ecstatic.

${ }^{24}$ Underhill (1930:170).
} 
a transition that was itself an indigenous, corporate movement. Can a transformation of shamans' practices be expected, analogous to the transformation of ritual masks into icons?

The question will be addressed through two subsidiary considerations: firstly, whether sound patristic criteria exist for the transformation of such phenomena; and secondly if the criteria do exist, whether they were actually applied within the regional focus in Alaska.

\section{(2) Patristic Criteria}

\section{for a Discernment between Ecstatic Experiences}

Do patristics provide criteria that would guide and support the transformation of shamanism as an ecstatic phenomenon: in other words, criteria that would allow a discernment between types of ecstatic experiences?

Discernment is evident among the Apologists when ecstasy represented in scripture was recognized as a means of true prophetic revelation. Referring to the book of Zechariah, Justin stated that the prophet "had not been in a normal mundane state, but in ecstasy" when he had seen Joshua, the angel, and a demon. ${ }^{25}$ Justin's disciple Athenagoras of Athens also recognized ecstasy as a means of Biblical prophecy and revelation, just as his mentor had, when Athenagoras stated that Moses, Isaiah, Jeremiah, and other prophets had been inspired by the divine spirit to speak, as a flute is inspired by the flautist to sound; so that they spoke "in ecstasy" of God. ${ }^{25}$

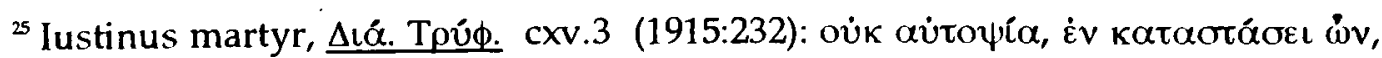

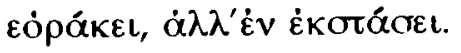

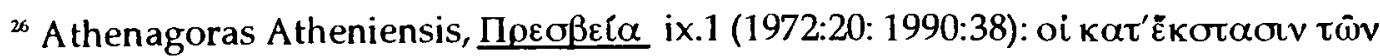

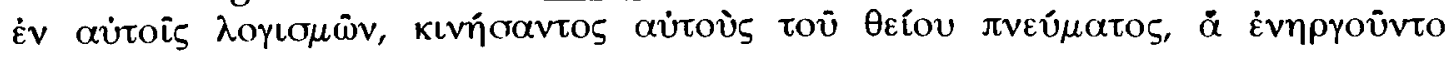


On the other hand, Athengoras and Justin -- as well as Clement of Alexandria, as I mentioned prior to my final conclusions in Chapter 2 while indicating the three planes along which the Apologists' attitudes might be studied -- criticized the contemporary rites and religions which would induce ecstasies in their adherents, for instance the rites of the Corybantes and the religion of the Eleusinian Mysteries. The Apologists criticized them harshly as deceptive and demonic. ${ }^{27}$ The criticism indicates a differentiation of the ecstasy induced in some contemporary religions and rites which was dismissed as deceptive, from the ecstasy described in the Bible that was exemplary of true prophecy.

Criteria for this differentiation remained unexplained in patristic literature, however, until they were written two centuries later. In the meantime, the very word "ecstasy" for biblical prophecy was virtually set aside, although the word itself was found in the Septuagint. In the writings of St. Irenaeus of Lyons the words "inspiration" and "prophecy" were used instead. "Ecstasy" was hardly found; and there is an evident reason for the reserve about this term: as Gnostics had involved ecstasy in their mystagogy, Irenaeus employed these other terms that would clearly mark the difference of Biblical prophecy. ${ }^{2 s}$

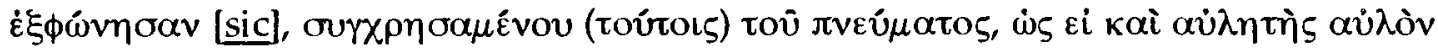
$\dot{\varepsilon} \mu \pi v \varepsilon \dot{\sigma} \sigma \alpha$.

${ }^{7}$ Iustinus martyr, 1 Ap. Ixiv.1-6 (1914:73-74; 1987:188). Athenagoras Atheniensis,

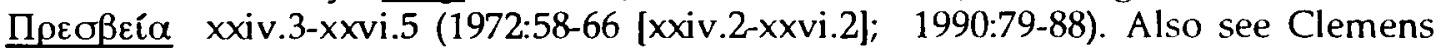

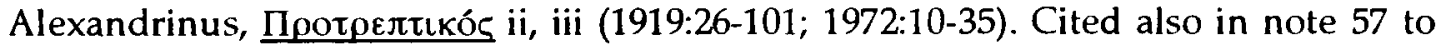
Chapter 2, above.

${ }^{28}$ Also see Lawson (1948:29):

S. Irenaeus does not, indeed, disown this theory [expressed by Athenagoras], but he most significantly does not use it. The reason for this is perhaps not far to seek. Irenaeus knows of ecstatic "prophecy" among the Gnostic followers of Marcus, and what he knows fills him with abhorrence. Impressionable women are worked up by incantations and spurious miracles into a state of violent emotion and frenzied speech, and the 
By the fourth century, Gnosticism (like the Mystery Religions prior to it) had met its demise. Yet induced ecstasies continued to a pose a problem for patristic pastors and writers due to the rise of a Christian sect referred to today as the Montanists. The founder, Montanus, in Asia Minor in the latuer second century, contemporaneous with the Gnostics himself, induced ecstasy to achieve glossolalia and visions. The movement initiated by him continued in various forms into the fourth century; and in that century in response, the criteria were written to distinguish the types of ecstatic experiences that typified the Montanists from the kinds of ecstasy that were known to the Biblical prophets.

If Montanus had once been a participant in the mysteries of Cybele or of another of the contemporary religions, who continued practicing some of those techniques of ecstasy after his baptism, then the criticisms of his practices may be related to the Apologists' earlier criticisms of the Mystery Religions. Irenaeus's criticisms of Gnostic mystagogy can be related also, as the Gnostics were involved in an undue syncretism of Hellenistic (and Judaic) elements with Christian elements. Thus the patristic discernment could be traced consistently, as in effect along a single line, from the Apologists through Irenaeus and into the fourth century when the criteria for discernment were clearly articulated in two texts.

orgy ends in sexual license. Here is one branch of Gnosticism displaying a well-known aspect of pagan religion.

The latter indefinite reference would be to, for example, the Bacchantes described vividly by Euripides. (The description could probably be applied also to the devotees of Rasputin in the capital of Christian Russia, as they can be likened to historic gnostic and modern neo-shamanistic movements; and inasmuch as Rasputin may himself have had links with various "ecstatic" sects, he may provide an instance of untoward syncretism, paralleling the Gnosticism of the second century.) For references to Gnosticism, see note 7 to Chapter 3, above. 
One of these two texts in which the criteria for discernment appear was the exposition Against Heresies by Epiphanius (c.315 - c.403), bishop of Constantia (Salamis) in Cyprus. The other text was the Exegesis on the Acts of the Apostles attributed to Didymus (c.313 - c.398), the director of the Christian catechetical school in Alexandria: the tradition that attributes the latter work to Didymus is the more important factor here.

The agreement between Epiphanius and Didymus with regard to these criteria is heightened by a contrast, a fundamental difference between these two men. The head of the catechetical school at Alexandria tended so much towards Platonism that his writings, and those attributed to him, were censured in the year 553 by the 5 th Ecumenical Council. In contrast to Didymus, Epiphanius was opposed to Platonism, particularly in its Origenistic manifestations, and Epiphanius was canonized as an Orthodox saint. Hence, the agreement becomes more significant when together they drew the initial line of discernment definitively at the type of ecstasy induced by Montanus and his followers.

Epiphanius distinguished between three types of ecstasy: an ecstasy out-of-mind, an ecstasy through extreme amazement, and an ecstasy of sleep. ${ }^{29}$ In the first, the ecstasy out-of-mind, the person literally went out of his mind, so that he lost cognizance, and sometimes even physical control. The ecstatic was unaware of the meaning of the visions and utterances, and sometimes unaware even of their occurrence. This was the type of ecstasy induced by Montanus. ${ }^{30}$

In the Biblical kinds of ecstasy, according to Epiphanius, the ecstatic's mind was neither upset nor overturned except perhaps momentarily, and then due to

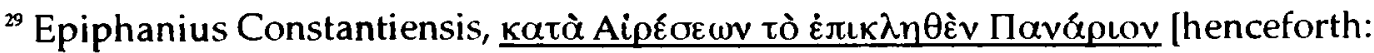

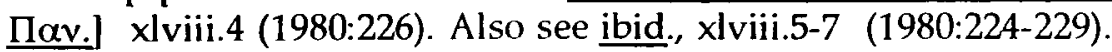

${ }^{30}$ Ibid. xlviii.4 (1980:225-226). 
astonishment in the "ecstasy through extreme amazement", or due to the natural process of sleep in the "ecstasy of sleep". Epiphanius explained that in these two types of ecstasy as represented for example in Genesis 2:21-23 and 15:12, Psalms 115:2 (116:11), and Acts 10:10-21, the ecstatic himself understood, either immediately or soon afterwards, the significance of what had been experienced. ${ }^{31}$

The bishop of Constantia devoted most attention to the ecstasy of sleep, attributed to Adam in Genesis (2:21-23), where the Septuagint states: "God had an

${ }^{31}$ Ibid. xlviii.6-48.7 (1980:227- 229). In the Septuagint, these Biblical passages include the word Ékotaors, e.g. in Ps. 115:2 (see 116:11 in KJV) where David

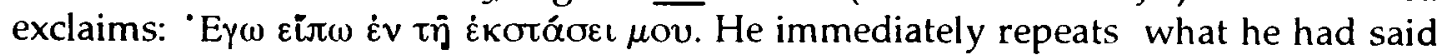

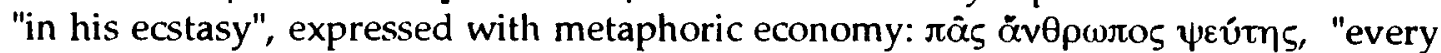
man is a liar" - see the interpretation by Epiphanius (ibid.) Other passages contain the word ह̌kotaors, e.g.: Gen. 15:12, and Gen. 27:33; and for many others see Hatch and Redpath (1897:441; 1906:203).

It is significant that the patristic tradition of the Septuagint was not translated into the KJV or RSV: the word "ecstasy" does not occur in those versions. Terms with a different meaning are found instead. Compare Hatch and Redpath's list (ibid.) from the Septuagint with equivalent verses in the KJV and RSV. For example, in Ps. 116:11, David says in his "haste" (KJV), or says in his "consternation" (RSV). The discrepancy is found also in Acts:10:10, the verse to which Epiphanius and Didymus both refer in their explanations of ecstasy: Peter does not experience "ecstasy" but falls into "a trance" in KJV and RSV; the same occurs for Peter in verse 11:5, and also for Paul in verse 22:17. :

While this note is meant for reference to the original texts cited by Epiphanius, yet the note may highlight a consideration for cross-cultural (comparative) studies where the word "ecstasy" has been disallowed in religious texts, and has been replaced by terms such as "haste" and "trance", even "madness": the latter is found in Zech. 12:4 (KJV and RSV), in place of "ecstasy". 
ecstasy seize Adam so that Adam slept". ${ }^{32}$ Montanus had evidently claimed that Adam's sleep-ecstasy was the same as his own type of ecstasy during which consciousness was lost. Epiphanius explained however that Adam had experienced natural sleep, which was correctly referred to as ecstasy in scripture because the sleeping person went from one state of activity and sensibility into another state, one of repose, as the physical senses withdrew without ceasing to exist. The eyes closed, the spirit was quieted, and so Adam became naturally insensible. But when he awoke, Adam was fully aware of what had occurred, why it had occurred, and what it meant. He was able to explain with sobriety and with understanding. Never was Adam out of his mind. ${ }^{33}$

The Biblical prophets went beyond the usual sense perceptions through ecstasies that either diminished the senses (in the "ecstasy of sleep") or expanded the senses (in the "ecstasy through extreme amazement"). Any experience of insensitivity or of confusion among them was momentary, and was superceded by increased rational awareness. Bibli $\_$cal ecstasy was thus, according to Epiphanius, a going beyond usual consciousness into greater understanding. It was not a going out of consciousness: it was not Montanus's type of ecstasy.

Referring to one of the same key texts as Epiphanius, Acts 10:19-21, Didymus, or this exegesis attributed to him, emphasized the same point. He also referred to the Montanists as "silly" and even "deranged", because they were not "cognizant of their own thoughts" in their ecstasy; and Didymus contrasted them to the Apostle Peter who was cognizant: ${ }^{34}$

${ }^{32}$ Epiphanius Constantiensis, Пㅅ․ xlviii.4 (1980:226).

${ }^{33}$ Ibid. xlviii.5 (1980:227-228).

${ }^{34}$ Didymus Alexandrinus, Expositiones in Actus Apostolorum [henceforth: in Act.] $x: 10$ (1863:1677A-B), also in Cramer, ed. (1844:176); trans. in Marriott, ed. (1851:315, ftnt. e), also in Schaff, ed. (1899:143, ftnt. 1). 
Nay Peter, in his trance, was strictly cognizant, so as to report what he had seen and heard, and to be sensible of what the things shown were symbolical.

The same was true, according to Didymus, of the Biblical prophets who had had ecstatic visions: "their consciousness kept pace with the things presented to their view. ${ }^{135}$

Summary. These sources provide the same criteria for an initial line of discernment between types of ecstatic experiences. While their agreement at the initial line has been the focus here, beyond this line where the traditions diverge, the criteria should be expected to differ $^{36}$ The initial line itself provides the criteria sufficient for the study at hand.

On one side of this line, the ecstasies induced within sects such as the Montanists, and by extension within some of the ancient religions and rites, were characterized by frenzy and by loss of consciousness to varying degrees. On the other side, the Biblical prophets were characterized differently: particularly by

${ }^{35}$ Ibid. Compare Origen, de Principiis III.iii.4 (1936:227), by whom Didymus was probably influenced:

From this we learn to discern clearly when the soul is moral by the presence of a spirit of the better kind, namely, when it suffers no mental disturbance or abberation whatsoever as a result of the immediate inspiration and does not lose the free judgement of the will. Such for example were the prophets and apostles who attended upon the divine oracles without any mental disturbance.

${ }^{36}$ See especially Louth $(1981: 194-201 ; 1989: 20-24)$ for differences between patristic and Platonic traditions. Also see, e.g., Gregorius Thessaloniensis (Palamas), 'Hovx. I.ii.14 (1959:349): a millenium after Epiphanius, St. Gregory Palamas likewise emphasized cognizance, now against the academician Barlaam: the latter evidently (from the passage cited) considered rapturous trance, that is the insensibility even to one's own self, to be the crowning experience in man's union with God. Palamas's criticism of Barlaam can therefore be interpreted as a patristic criticism against Platonic ecstasy. Thus, an example of patristic discernment extending in Orthodoxy beyond the intial line of discernment is provided by Palamas. 
cognizance as they understood the content and the significance of their types of ecstatic experiences. Theirs was an increased awareness, neither diminished nor upset, except perhaps momentarily and then with good reason - due to a momentary confusion in extreme wonder and awe; or due to a temporary insensitivity during the natural operation of sleep. The Biblical prophets understood their type of ecstatic experience and were able to explain its content. Their cognizance, indeed greater cognizance, and their composure were factors that distinguished them.

Section Conclusion. In conclusion to the first consideration, one could state that these criteria from patristics for a discernment between types of ecstatic experiences, would guide the transformation of ancient shamanism as an ecstatic phenonemon; because the problem was not with all types of ecstasy but with particular forms. The content would comprise a factor as equally important as the form of the experience; but the form has been the focus of this section.

According to the criteria from the patristic sources that have been cited, those types of ecstasy involving loss of self-control and consciousness to varying degrees would not be expected to continue into Christianity; or if they did continue they would be expected to persist in conflict with Orthodoxy, similar to the conflicts of G g'nostic mystagogy or of Montantist trance-visions. On the other hand, the composed, coherent ecstasy of Biblical, or true, prophecy would be expected to occur.

A further question that arises from these conclusions is whether true prophecy actually did occur, and whether it was associated with the ancient in such a way that it would be seen as a direct transformation of ancient shamanism. This question will remain implicit while the next consideration in this chapter about ecstasy is addressed. 


\section{(3) An Example of Discernment from the Field.}

Were patristic criteria for the discernment between forms of ecstatic experiences applied in Alaska? This is the question that follows, so that the possibility of a transformation of Far Northern shamanism as an ecstatic phenomenon can be "brought to earth": brought from the hypothetical consideration to an actual historical example inside the very regional focus itself. In the example that will be presented, patristic criteria will be shown to have been applied: those criteria for the form of the ecstasy as identified in the preceding section, and furthermore others for the content of the experience that will be identified below.

They were applied by the priest of the Unalaska parish Ivan Veniaminov who would have absorbed the patristic tradition through two sources. One would have been the seminary at Irkutsk where he had studied from 1806 until 1818 . Upon completion, he remained in the city, ordained to the cathedral, until he departed for Alaska in 1823 . The other source would have been a monastery in Irkutsk where his own uncle was a monastic at the same time young Ivan was at seminary in that town. Whether the youth had learned to locate the passages in the specific patristic texts that contain these criteria is unimportant. The relevant fact is that he had absorbed this living tradition.

Applying these criteria, he discerned prophecy of the Biblical kind in an Aleut elder of the island of Akun whose baptismal name was Ivan and Slavic surname Smirennikov. Vital facts about him that need to be emphasized at the outset are that: (a) he was a Christian who had been baptized nearly thirty-three years prior to Veniaminov's pastoral visit to the island; (b) no undue syncretism was evident in him; (c) yet he was being referred to as a "shaman" by the Akun Aleuts. The third factor will be analysed in the next chapter, while in the present chapter the very 
occurrence contained in the third point is vital: that the Akun Aleuts were themselves referring to this man as a "shaman". Thus precisely the example that is needed is provided: an example of the Biblical kind of prophetic ecstasy associated with the ancient in such a way that the prophet can be seen within the regional context as a direct transformation of an ancient shaman.

Another fact should probably be underscored at the outset as well. The elder of Akun was a generation senior to the pastor who visited him. Approximately sixty years old, Smirennikov was about thirty years older than Veniaminov, himself thirty-one years old at the time. He can also be considered spiritually elder than Veniaminov as the following description may indicate. ${ }^{37}$ But the seniority might appear reversed in this study, because the focus will be upon the priest who applied, and discerned through, the patristic criteria. The focus is systematic, to develop an example of this application and discernment. It is not symptomatic of a supremacist approach, either clerical or racist, that would a priori impute authority into the non-native priest. This priest, it may be recalled, was ministering within an existing Christian parish ${ }^{38}$ and was interacting with an elder parishioner. And this priest was a Siberian-Russian, thus not very different from Ivan Smirennikov when the two

${ }^{37}$ For Smirennikov's age, see Black (1977a:96); also see Pierce (1990:521). My use of the term "elder" indicates age, spiritual stature (including a stable moral character), and a particular quality as a counselor and healer. For this term, also see my text in Chapter 6 at note 38 .

${ }^{38}$ See above, Chapter 1, "The Aleutians", for the development of the Unalaska parish. 
met. ${ }^{39}$ This relationship between the younger Ivan and the elder Ivan is the final factor for context at the outset.

The Interaction between the two Ivans. ${ }^{40}$ In spring 1828 , Veniaminov made a pastoral visit to the island of Akun. This was his first visit to this island and he was accompanied by Pan'kov, the Aleut toion of Tigalda and Akun (with whom he would later translate the Gospel according to Matthew). ${ }^{41}$ Here Veniaminov heard of Smirennikov who had on various occasions healed, foreseen future events, and located food sources. Because he had manifested these abilities, Smirennikov had become known in the region as a "shaman";42 but this appellation had caused him to be shunned by the toion Pan'kov, who avoided contact with the "shaman". The toion "never entered into any conversation with the old man", according to the report

\footnotetext{
${ }^{39}$ Veniaminov may have been Eurasian by parentage, or grand-parentage. Photographs of him that I have seen in the museum archives in lakutsk show Eurasian features. A copy of one of these photographs was kindly provided to me, it derives from his later life in Moscow. The possibility is supported by history. Russian settlers intermarried with Siberian peoples during the 18th and 19th century; and Veniaminov derived from Russian settlers in a village in the Irkutsk gubernia. The normalcy of intermarriage as late as the second decade of the 20th century impressed Czaplicka when she visited Siberia on the "Yenesei Expedition" from the summer of 1914 until the summer of 1915, subsequent to her primary publication (Czaplicka 1914). In the memoirs she wrote on her return the Pole at Oxford described the normalcy with particular aplomb: "in no other colony in the world have ... the 'lower' and 'higher' races so happily adjusted themselves" (Czaplicka n.d.:242-243). It may be recalled from Chapter 1, above, that a cultural synthesis, or multilateral assimilation, was occurring. For example Russian settlers were being assimilated linguistically to the Iakut, and continued to be assimilated as late as the 1890s at least (see above notes 13 and 179 to Chapter 1 ). Veniaminov became the archbishop of lakutsk in the 1850s.
}

${ }^{40}$ The source is Ivan Veniaminov, Report to Archbishop Mikhail of Irkutsk, dated 5 November 1829, handwritten copy of the original "Miscellaneous Papers", Russian Church, Alaska His torical Library Archives, translated by Lydia T. Black, cited here as Veniaminov (1977).

${ }^{41}$ For the toion Pan'kov see above, Chapter 1, sec. 4.3.

${ }^{42}$ Veniaminov (1977:100, 101). Also see id. (n.d.), journal entry 24 April 1828. 
written by both Pan'kov himself and Veniaminov subsequent to this visit; moreover the toion "protested and tried to restrain others when they called on the help of Smirennikov". ${ }^{43}$

Veniaminov resolved to meet him, due to the strength of the character of the people who had described the gifts attributed to this man. These people were themselves "trustworthy informants", in other words they were people whose judgement Veniaminov respected. And so the priest decided to meet the older man, to discover for himself "how he knew the future, and what means he employed to learn it". ${ }^{44}$ Receiving the younger man and the toion, the elder related his personal history.

He told them that he had been baptized by hieromonk Makarii. As recalled from Chapter 1, Makarii had been a member of the religious mission to Kodiak, who passed briefly through these islands on his way from Kodiak Island to Unalaska Island. He spent a year, between summers 1795 and 1796, at Unalaska where he allied with Aleut leaders, and then departed with six of them for Petersburg to protest against the gross exploitation by the Shelikhov-Golikov enterprises. No other priests had been in the vicinity, or anywhere on the Aleutian Islands prior to Veniaminov's arrival, except: Gideon at Unalaska lsland for a week while in transit in 1897; and a chaplain of the Vasil'ev/Shishmarev circumnavigational expedition also at Unalaska Island briefly in transit in 1820 and again in $1821 .^{45}$ Makarii's visit in summer 1795 , therefore, most probably would have been the only one ever by a priest to Akun Island until Veniaminov's visit in spring 1828.

\footnotetext{
${ }^{43}$ Id. $(1977: 102)$.

${ }^{44}$ Ibid., p. 101.

${ }^{45}$ For the chronology of clergy prior to Veniaminov see above, Chapter 1, "The Aleutians", sec. 1.
} 
Subsequent to Smirennikov's baptism, nearly thirty-three years prior to Veniaminov's visit, "spirits" began appearing to the Aleut according to his own account as collected by Veniaminov and Pan'kov, and attested by the signature of both. Smirennikov's description of these spirits was reported as follows:46

The spirits had the appearance of humans, light of face, dressed in white robes and ... these robes resembled church vestments and were trimmed with rose bands.

These spirits had told him they had been "sent by God to instruct, teach, and preserve him"; they then "continued to appear to him for over thirty years, almost daily"."77

Veniaminov found that Smirennikov indeed knew of Biblical accounts including: the creation; the fall of the angels; the tree of good and evil; Cain and Abel, Noah, Abraham, John the Baptist, the Annunciation, and the Nativity of Christ. And "when I preached," the priest reported, "he was the first to confirm the truth of my words in the tone of a person conversant with Holy Writ". ${ }^{8}$ How had Smirennikov learned and indeed come to such authority? He could not have read these things for himself, he was illiterate. He had had only brief contact with hieromonk Makarii who had been in transit to Unalaska Island and spoken through an interpreter. The only person in the region who might have instructed him with such detail was the toion Pan'kov who had shunned him.

"Sent by God to instruct him," these spirits also "granted his requests, and through Smirennikov they granted the requests of other people, although the latter rather "seldom". Thus was he able to heal and to foresee.

Hearing of an appearance of these spirits, Veniaminov asked the elder about his internal responses to them. What did he feel when they appeared? Was it sorrow

\footnotetext{
${ }^{46}$ Veniaminov (1977:101).

${ }^{47}$ Ibid.

${ }^{48} \underline{\text { lbid. }}$.
} 
or joy? Smirennikov explained that only if he had misbehaved did he feel "a twinge of con science, otherwise he did not feel any fear".

Veniaminov accepted the account, affirmed the relationship with these spirits, and affirmed the gifts as God-given. He "did not forbid" the elder from assisting the people who came to him for aid, and furthermore "instructed" him - or, rather more probably, respectfully suggested to him, as such a response would be the more appropriate with respect to Smirennikov's age and spiritual stature - to have these people turn also directly to God themselves: ${ }^{49}$

tell those who ask your advice about the future and request your help to address themselves directly to God, as He is common Father to all. ... instruct them to pray diligently and thank the Sole God.

The pastor finally addressed the people who were there, instructing them not to call this man a shaman: "I told the other Aleuts who were present not to call him a Shaman". 50

An Analysis of the Interaction. Evident in the report, as will be explained in the following analysis, are the patristic criteria, applied implicitly by the pastor as he discerned the form and also the content of this Aleut elder's experience, so that he differentiated him from other shamans. Veniaminov emphasized the difference again when he entered this meeting in his journal: "I conversed with the elder lvan Smirennikov who is considered a shaman in these parts. I found the facts quite to the contrary."

\footnotetext{
${ }^{49}$ Ibid., p. 102.

so Ibid.

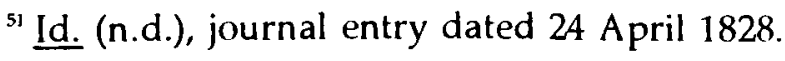


Discernment of the form. The experiences of the Aleut elder of Akun included the cognizance that typified the Biblical prophets. He was aware, his consciousness had "kept pace with the things presented", so that he spoke with an understanding of the depths that had been revealed to him of the knowledge of God, analogous to Adam and to the Apostle Peter as described by Epiphanius of Constantia and by Didymus of Alexandria. ${ }^{52}$

Cognizant, the Aleut elder of Akun was also composed. This is evident in his moral stature that had impressed Veniaminov. It was evident furthermore in the difference from other shamans that the pastor perceived and emphasized. When Veniaminov differentiated Smirennikov, he was in effect distinguishing this man's practice from the rite techniques that typified shamans. The latter would induce trance states described by Veniaminov in his ethnography as follows: "during a shamanistic seance, they [the shamans of old] leaped, grimaced, beat the drum and (entered a state of trance characterized by a loss of conscious control). ${ }^{153}$ Descriptions of actual shamanizing on the eastern Aleutian Islands prior to Veniaminov's arrival and elsewhere in southern and western Alaska contain these elements: shamans would, although not always, escalate even into frenzy; and many rite techniques would result in extreme trance states, even to comatose states. ${ }^{54}$ Veniaminov's summary ethnographic view on the eastern Aleutian Islands was broadly encompassing of these phenomena, and he likened them to practices by "shamans

${ }^{52}$ Epiphanius Constantiensis, Пav. xlviii.5 (1980:227-228); Didymus Alexandrinus, in Act. $x: 10$ (1863:1677,A-B): as cited above, in notes 29, 34-35, to this chapter.

${ }^{53}$ Veniaminov (1984:219). The parenthetical phrase has been inserted by the translator for the author's term изступленіе (1840b:123). 
everywhere", 55 wich would be a reference to his own native Siberia. Indeed he himself had derived from the very regions where the term "shaman" had originated: he was from the Irkutsk gubernia, Evenk (or "Tungus") and Buriat territory; and the term had been assimilated into the Russian language from the Evenk language. ${ }^{56}$

This contrast by Veniaminov is analogous to that between an "ecstasy out-of-mind", in Epiphanius's words, on the one hand, and Biblical ecstasy on the other hand, as expressed by both Epiphanius and Didymus. ${ }^{57}$ The contrast is analogous also to the distinction implicitly expressed by Justin and Athenagoras between the frenzied ecstasies induced in some ancient Greek religions and rites, and the ecstasy experienced by the Biblical prophets in the Greek Septuagint (as explained above).

Within this consistent discernment, the form of Aleut elder's experiences would be Biblical. He remained composed and was cognizant while "seeing other things besides those seen by people in the everyday course of events", in the words of St. Epiphanius, or seeing "not in an everyday manner", in words of St. Justin describing the prophet Zacharias who saw the angel..$^{58}$

Discernment of the content. Patristic criteria were applied moreover to discern the content of the elder's experience when Veniaminov recognized as angels the "spirits" who were appearing to Smirennikov. These criteria had been expressed clearly in patristic literature, for example in the Life of St. Anthony attributed to St.

${ }^{5 s}$ Veniaminov (1840b:123; 1984:219).

${ }^{56}$ Shirokogoroff (1935:268); Eliade (1964:4; 1987:202). Also see Tugolukov (1978:426). These sources were cited during the definition of "shamanism" in my Introduction.

57 As cited above, in notes 29 and 30 to this chapter: Epiphanius Constantiensis,

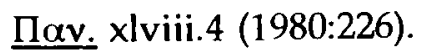

${ }^{58}$ Ibid. xlviii.5 (1980:227-228); lustinus martyr, $\underline{\Delta l \alpha \alpha \lambda . ~ T \rho u ́ \phi . ~ c x v .3 ~(1915: 232): ~ t h e ~}$ latter was cited above, in note 25 to this chapter. 
Athanasius of Alexandria. Accordingly, the discernment is "easy when God wills it", as the appearance of angels comes with tranquility and with joy. If humans are frightened at first, the angels remove fear with joy, as Gabriel did for Zacharias, as the angel did at Christ's Nativity for the shepherds, and as the angel did in the sepulchre for the myrrh-bearing women. ${ }^{59}$ The appearance of demons, however, is troubling (if not immediately then inevitably), causing terror and dejection, a "craving for evil" and "instability of character". ${ }^{\text {so }}$

The same criteria for the discernment of angels from demons were mentioned in the Epistles (1 Cor. 12:10); they were written in catechisms, such as that by St. Cyril of Jerusalem in the fourth century; ${ }^{61}$ they were given in monastic texts, including The Ladder by St. John Climacus written in the early seventh century, ${ }^{62}$ and the Philocalia compiled in the eighteenth century from fourth to fifteenth century writers. ${ }^{63}$

${ }^{59}$ Bios Avtovíov xxxv, in Athanasius Alexandrinus (1857:893-896).

${ }^{60} \underline{\text { Ibid. }}$ xxxvi, cols. 896-897. Also see ibid. xxv-xxvii, cols. 881-884.

${ }^{61}$ Cyrillus Hierosolymitanus, KaIńxnas XVI.xiii-xvi (1860:220-226; 1894:118-119).

${ }^{62}$ See Chryssavgis (1989:111-112, 171-172).

${ }^{63}$ E.g. Diadochus of Photice xxxvi-xl (1782:241-243; 1979:263-265); also see ibid. (1955:104-108). For the Philocalia see Ware (1984). The following paragraph will place some of the data in Ware (ibid.) within a context of Russian-American history. The writings in the Philocalia were compiled by St. Nicodemus of the Holy Mountain and St. Macarius of Corinth in five volumes, published in Greek in 1782. A sizeable selection was translated into Slavonic in Moldavia by the monastic Paisii Velichkovskii who had spent seventeen years on the Holy Mountain himself (17461763). In 1791, this translation was taken to the Metropolitan of St. Petersburg, Gavriil, who had the texts submitted to two select committees, one comprised of monastics, the other consisting of theology professors. Among the former group, Nazarii the hegumen of Valaam would most certainly have been found. The translation was published in Moscow in 1793, the same year the monastic missionaries were dispatched to Kodiak. The missionaries were selected, and their mission was organized, in large part by Gavriil and Nazarii. The second edition was published in 1822. Coincidentally the next year Veniaminov was assigned to the Unalaska parish. The Slavonic edition was translated into Russian partially in 1857, then completed between 1877 and 1889 (see Ware ibid., cols. 1344-1345). 
These criteria were operative when Veniaminov asked Smirennikov about the spirits who were appearing. He asked about their behaviour and their teaching, and furthermore about the elder's response to them. Then perceiving that Smirennikov was not afraid in their presence, that he was a Biblically informed and virtuous man, and that these spirits edified him, Veniaminov recognized them as angels: "as the tree of evil cannot bear the fruit of good, these spirits must be the servants sent to those who seek salvation". ${ }^{4}$ The decisive criteria were the effects of the appearance, including the nature of "instruction and teaching", as Veniaminov stated in the report. ${ }^{65}$ An insufficient criterion for discernment was merely a manifestation of a spirit in an appearance of an angel, because, as Veniaminov acknowledged, "demons may sometimes assume the image of Angels of Light".60

This discernment of the content was vital due to the importance of the human person's disassociation from demons, as Veniaminov was well aware: he understood the disassociation as an existential dynamic; and he expressed it at the start of the Indication of the Way into the Kingdom of Heaven, a work he authored in the eastern Aleut language during his ministry on the islands, when he wrote that demons had taken advantage of human suffering to gain control over human beings, but that the devil had been "conquered" and demonic power had been "crushed" by Christ for human salvation. ${ }^{67}$ This is a Biblical and patristic principle.

Aware of this principle, Veniaminov was furthermore aware of the involvement of some shamans with the demonic through induced ecstasies. He did not dwell upon the theme, but he was aware of it, and mentioned it in his

\footnotetext{
${ }^{64}$ Veniaminov (1977:102).

${ }^{65}$ Ibid.

${ }^{66}$ Ibid.

${ }^{67}$ Veniaminov, "Indication", trans. by Paul Garrett, in Oleksa, ed. (1987:83-84).
} 
ethnography as follows: "Many shamans frankly termed their profession a service of the devil and told young people that anyone who could not expect to brave the terrors should not aspire to be a shaman."6s Therefore, he would not have encouraged an actual shaman to be involved in such rites. In fact, he did require that an actual shaman promise to cease practicing when this one sought baptism from him, in July 1829, in the Nushagak region, western Alaskan mainland, outside the parish. ${ }^{69}$ The interaction with Smirennikov had occurred inside the parish the previous year, in April 1828. Veniaminov required that the actual shaman in the Nushagak region promise to cease practicing when the shaman sought baptism. But in contrast Veniaminov acknowledged - indeed acknowledged and affirmed - the spiritual gifts of the so-called "shaman" of Akun; because he had discerned the content as well as the form of Smirennikov's experience within a patristic tradition that had provided sound criteria for the discernment.

Discerning the form and the content of Ivan Smirennikov's experience, Ivan Veniaminov disallowed the term "shaman" for him. What, then, was the elder of Akun? The implication (implicit in the report) was stated explicitly three generations

${ }^{68}$ Id. (1840b:125; 1984:219-220). The same points were emphasized, unsolicited, to me in lakutsk in July 1991 by an old Yakut assistant to local shamans.

${ }^{69}$ Id. (n.d.), journal entry dated 2-3 July 1829. The promise itself was the significant factor. It alone communicated Veniaminov's direction away from the actual shaman's practices. Veniaminov had no means to supervise such a requirement. The Nushagak region was too far removed from his home location and parish ministry. He visited the redoubt twice only during his decade of ministry within the Unalaska parish. Moreover the region was too sparsely populated by Christians for social pressure to be applied: the Novo Aleksandrovskii redoubt was founded at the mouth of the Nushagak River in 1819; it was manned by a few traders in 1829; a resident priest was assigned to the region later, in 1842 .

The Russian Orthodox hunters and traders at this small redoubt might be considered part of the vast Unalaska parish, but the shaman was himself from the surrounding region. Within the parish, actual shamans' practices did not take place according to Veniaminov (1840b:144; 1984:229). For Veniaminov's assessment of the Aleuts as Christians, see above, Chapter 1, "The Aleutians", section summary. 
after the interaction between the two Ivans, and was stated appropriately by an Aleut-Russian priest who referred to Smirennikov as "an Aleut prophet".

\section{(4) Summary and Conclusions.}

The question guiding this chapter is whether a transformation of shamanism should be expected in the transition, analogous to the transformation of ritual masks into icons. Continuity and transformation would be anticipated because shamanism was a central societal phenomenon, and the transition was an indigenous, corporate movement. A central societal phenomenon would most probably continue somehow within a movement that involved a society virtually in its entirety. But this phenomeon was ecstatic, so a question arose about it.

The question was addressed through two subsidiary considerations: firstly, whether sound theological criteria existed within patristics to support the transformation of ecstatic phenomena; and secondly, whether such criteria, if they existed, were actually applied within the regional focus in Alaska.

According to the patristic criteria that were identified, a continuity of types of ecstatic experiences involving loss of self-control and loss of consciousness would not be expected in Christianity; or as mentioned earlier, if they did continue they would be expected to persist in conflict with Orthodoxy, similar to the conflicts of Gnostic mystagogy or of Montantist trance-visions. On the other hand, the kind of ecstasy described for the Biblical prophets, characterized instead by composure and

\footnotetext{
${ }^{70}$ Kashaverov (1987:346).
} 
coherence, could be expected in the transition. One could well argue that to suppress this kind of ecstasy or a propensity for it would be to thwart Biblical experience. ${ }^{11}$

These criteria for discernment were found to have been applied in the field itself. Ivan Veniaminov provided the historic example when he applied them to discern the form and the content of Ivan Smirennikov's experiences: and thus the (now canonized) saint from Siberia recognized the prophet of Akun.

${ }^{\pi}$ An example of the propensity for if not an actual occurrence of prophetic ecstasy, and its discouragement by missionaries, is evident among the Uduk "kindling the ebony", a form of folk healing that involves divining without incantation and without a loss of consciousness. See James (1988:219, 267, 329). 


$$
\text { - }
$$




\section{CHAPTER 5}

\section{TRANSFORMATION, 1}

The preceding chapter was intended to establish the possibility of a transformation of the shamans' practices by: (i) providing sound patristic criteria that would guide and support a transformation of this type of phenomena; and then (ii) providing a historical example of the application of such criteria in the very field. The present chapter will develop this theme with more detailed reference to the wider characteristics of the shamans' practices, and with reference to examples of actual transformation.

Once the requisite definitions are provided, two perspectives upon shamans-of-old will be described. A contrast between them will allow the process of the transformation to be perceived, as discontinuity is evident through an "ethnographic perspective", but continuity becomes visible through a "social perspective". The contrast will be related to the discernment between ecstatic experiences developed in the preceding chapter.

The comparative method of study that engendered these perspectives has been described in my Introduction; and the criteria for the credibility of sources was explained there as well. It should be added now that among the sources that will be cited here, a significant number are Native Alaskans themselves: Fr. lakov Netsvetov, ${ }^{1}$ Nora Marks Dauenhauer, ${ }^{2}$ and Elsie Mather. ${ }^{3}$

\footnotetext{
${ }^{1}$ Netsvetov (1984b).

${ }^{2}$ Dauenhauer and Dauenhauer are presently finishing a study of Tlingit shamanism based on oral traditions and ethnographies. This work is scheduled for publication in the same series as $\underline{\mathrm{id}}$. $(1987 ; 1990)$; a portion has already been distributed (id. 1988a, b). Also see Dauenhauer and Dauenhauer (1990:108-127).
} 
It may be useful to describe the region afresh. The primary regional focus extends west to east, like a single brush-stroke, across the length of the Aleutian Island chain, over the Alaska Peninsula, through the Kodiak archipelago, along the Gulf of Alaska, to nearly the Copper River. This expanse will be referred to as "southern Alaska". The peoples of this region (to repeat their names and locations) are from west to east:

(a) the ancient Aleuts, distinguished in this study very generally as western, central, and eastern Aleuts, the western and central encompassing the Near and Andreanov Islands that came to be included in the Atka parish; and the eastern encompassing the Fox Islands, the Shumagin Islands, and the southwestern tip of the Alaska Peninsula, that came to be included in the Unalaska parish;

(b) the ancient Alutiiqs of the Alaska Peninsula and the Kodiak area, also referred to as "Koniags" and as "Pacific Eskimos" in anthropological literature; and

(c) the ancient Alutiiqs of the Chugach Bay area, also referred to as "Chugach".

To allow sharper distinctions between the Alutiiq regions as data will be brought together from various locations in the systematic description that follows in this chapter, I shall write the term "Chugach" for (c) and the term "Koniag" for (b), each deriving from 18th and 19th century Russian usage.

Immediately neighbouring people have provided corroborative information. These people are the Dena'ina Athapascans and the Yupiit due north; the Eyak and the Tlingit directly east. This chapter's descriptions may therefore applied to them also. Encompassing all these people like a wider band, the greater territory - to be

${ }^{3}$ Mather (1985) is summarized in English by Morrow (1984). 
referred to as the "region at large" - extends from the Bering Strait in the west to the Alexander Archipelago in the east, with the eastern boundary being formed naturally by the great peaks of three mountain ranges: the Chugach Mountains, the St. Elias Mountains, and the Coast Mountains. Whenever a characteristic diverges from the general pattern within the "region at large", the divergence will be specified in this chapter.

(1) Definitions.

(i)" Shaman". The southern Alaskan terms for a shaman are: qugagie, meaning someone possessed of qugax, in central Aleut; qugagiq, someone possessed of qugag, in eastern Aleut; and kalla'alek, someone possessed of kalla'aq in Alutiiq (Koniag and Chugach). Variations of the latter term occur also in dialects of the Yupi'k language. Another term among the Yupiit, itself of a more northern Inupiaq (Inuit ) derivation, is tungalik meaning someone possessed of tungaq. All these terms are cognates in the Aleut and Eskimo languages. ${ }^{4}$

1 have employed the phrase "possessed of" to render the etymology of these cognates for "shaman", because this phrase allows both possibilities: that the shaman was possessed by the spirit(s); and that the shaman possessed, or controlled, them.

An alternative term exists in the Koniag and Yup'ik languages: an'alkuq, or angalkuq. ${ }^{5}$ While translated by a source as "someone of many tricks", 6 it can be

${ }^{4}$ For these terms, see: Bergsland (1986:127; 1980:118); Birket-Smith (1953:124); Jacobson (1984:183; 321; 380); Fienup-Riordan (1983:234); Fortesque (ms.); Geoghegan (1944:117); Hawkes (1914:17); Lantis (1946:197); Leer (ms.); Nelson (1899:428); Ray (1967:11). Dialectical and orthographic variations occur: see examples in note 7 , below.

${ }^{5}$ Fitzhugh and Kaplan (1982:188); Jacobson (1984:68); Lantis (1946:197); Morrow (1984:136); Oleksa (personal communication, 1986); Fienup-Riordan (1983:234). 
understood instead as someone who does the extraordinary. These terms together provide a definition: the shaman was someone possessed of spirit(s) who could therefore accomplish the extraordinary.

(ii) "Spirits". The terms qugag in Aleut and kalla'aq in Alutiiq signify evil spirits according to dictionaries of the modern languages, the Alutiiq being completed by J. Leer at the University of Alaska at Fairbanks. ${ }^{7}$ The Inupiaq and Inuit cognate tunraq is defined likewise in the comparative Eskimo dictionary being compiled by M. Fortesque at the Institute of Eskimology, University of Copenhagen. ${ }^{8}$ These terms were defined as "evil spirits" also by G. Marsh, a linguist who conducted fieldwork in southern Alaska in the mid-century; he identified the distribution of these cognates through Alaska and the North American Arctic, and recognized a distribution of synonyms in the Koryak and Chukch languages (in northeast Asia). ${ }^{9}$ The same meaning has been applied by ethnographers, anthropologists, and other observers with regional specificity. ${ }^{10}$

\footnotetext{
${ }^{6}$ Ray (1967:11). The source is not a linguist and makes no pretense to that affect.

${ }^{7}$ Bergsland (1986:127, "quGa-"); Geoghegan (1944:"qugaq"); Leer (ms.:"kala'aq"). Also see Veniaminov (1840b:86, 144; 1984:199, 229).

${ }^{8}$ Fortesque (ms.); personal communication, University of Alaska at Fairbanks, March 1988.

${ }^{9}$ Marsh (1954:27-28).

${ }^{10}$ See e.g. Nelson (1899:394); Sonne (1988:93-94). In the Yup'ik language according to Jacobson (1984:742), there are four terms for "shaman": kallalek, qelalek, tuunralek, and angalkuq (each term has a cognate in other Eskimo and Aleut languages); and only the term "tuunralek" is associated with an evil spirit (ibid., p. 380): this indicates that distinctions are made linguistically between types of practioneers, not by prefixing an adjective to render a "good tuunralek", which would be a contradiction in terms in the modern language, rather like positing a "good demoniac"; but by applying different terms to differing types of practione'rs. These distinctions collapse in translation into the single term "shaman"
} 
This meaning from these modern and relatively modern sources (from the 1899 to the present day) is reflected in a contrast that can be achieved with the general characteristics assigned to another set of spirits, the yua that were introduced preliminarily in Chapter 2 of my study during the description of Yup'ik rituals. As described there, the yua were "persons of animals" and "persons of the universe", or of universal phenomena; in other words, they were the spirits associated with major species such as the seals, and with great cosmic forces such as the sun, wind, and moon. They were distinguished apart from the tunraq by Nelson in the 1890s, and recently by Sonne also. ${ }^{11}$ The same distinction was made by Marsh with reference to the wider distribution of the cognates for these terms. ${ }^{12}$ The Yup'ik term yua has cognates in the other Eskimo languages and probably in Aleut as follows: yua in the Yup'ik language; sua in the Sugpiaq, or ancient Alutiiq (Koniag), language; inua in Inupiaq and Inuit; and probably "tayaruu", related to taiyaguq and tayague in Aleut. ${ }^{13}$ Yua will be the preferred term in this chapter for congruity with Chapter 2.

The meaning assigned to the qugaq, kalla'aq, and tunraq by the modern and relatively modern sources, and its difference from the general characteristics attributed to the yua, are evident in masks that survive from the pre- and proto-historic era (the "ancient" era as I shall refer to it). The yua representations were symmetric throughout the region at large, and could be sublimely beautiful. Often they were composite, so that the animal, sun or moon form would reveal its yua.

\footnotetext{
${ }^{11}$ Nelson (1899:394); Sonne (1988:94-95). But Sonne has indicated that the distinction was not as definite on Nunivak Island as on the mainland.

${ }^{12}$ Marsh (1954). Also see the entries in Leer (ms.), in Jacobsen (1984) and in Fortesque (ms.) for "sua" in Alutiiq, "yua" in Yup'ik and "inua" in Inupiaq/Inuit on the one hand, but for "kalla'aq" in Alutiiq, "tuunraq" in Yup'ik and "tunraq" lnupiaq/Inuit on the other hand.
}

\footnotetext{
${ }^{13}$ The Aleut cognate is given by Marsh (1954:24).
} 
In some composite masks, the outer form of the animal, sun or moon would open on hinges to reveal the yua within; in other composite masks, the yua would be carved as part of the outer form itself. These yua representations were often anthropomorphic, as should be expected due to the linguistic relationship in the Eskimoan languages of the words yua sua and inua with, respectively, the words Yupiit, Sugpiaq, and lnupiaq/Inuit that signify a real human person. The relationship of "tayaruu" with taiyagug and tayague in the Aleut languages may be similar. On Kodiak Island, however, the yua were perhaps not always represented anthropomorphically: anthropomorphic and zoomorphic traits might have mixed in representations there. ${ }^{14}$ On the other hand, masks that represented the qugaq (in Aleut), kalla'aq (in Alutiiq), and tunraq (in Yup'ik) could be grotesque, with assymteric faces or elongated heads, even sometimes with blood splattered mouths. ${ }^{15}$

A distinction is reflected also in the Tlingit language, outside the Eskimo and Aleut languages, between the word kwanni that signifies "persons" embodied in natural phenomena or existing in other cosmological realms (for example, teet kwáani, the "persons of the waves"), and the term yeik that indicates the "disembodied" spirits that were revealed to the $\underline{\text { xt' }}$, the shaman. ${ }^{16}$

\footnotetext{
${ }^{14}$ See Lot-Falck (1957) for the Koniag mixture of anthropomorphism and zoomorphism with reference to the masks collected by. Pinart; but Lot-Falck might have been overly interpretative in this regard. Further research is being conducted by Dominique Desson, Department of Anthropology, University of Alaska, Fairbanks.

${ }^{15}$ For Aleut masks, see the illustrations in Black (1982): compare and contrast those in figure 47. For Koniag and Yup'ik masks, see the illustrations in Fitzhugh and Crowell (1988): contrast illustration 368 of an inua with 441 of a tunraq for the Koniag; and contrast illustration 348 of an inua with 351, 353, and 436 of tunrag for the Yup'ik. For the Yup'ik, also see Sonne (1988), illustrations 19-20, 25, 29-30, 36-37, 43 and 65 of inua: contrast with illustration 55 of a tunraq and compare with illustrations 15 and 82 of "irci", another Yup'ik term for "spirit" that occurs on Nunivak Island according to Sonne (1988:78-85). For "irci", also see note 17, below.

${ }^{16}$ Dauenhauer and Dauenhauer (1990:123, 125-126).
} 
However, while evidence for the differentiation of the "tunraq set" of spirits from the yua can be found in the modern languages, and while this distinction is reflected in retrospect in the surviving ancient masks, the distinction and, more specifically, the meaning assigned to the tunraq kalla'aq and qugaq by so many knowledgeable modern and relatively modern sources, can not be imputed incisively into the ancient regional languages; because a possibility exists that the incisive definition of qugaq and kalla'aq as "evil spirit(s)" in the modern Aleut and Alutiiq languages may derive from Christianity. This does not mean that Russian Orthodox Christians classed all manifestations of qugaq (in Aleut) and kalla'aq (in Alutiiq) categorically as malevolent; but instead that those terms came to signify that sort exclusively. The possibility is indicated by the use of the term qugaq and its cognates to translate "demon" in the Gospels in the Aleut language $\mathrm{e}^{17}$ while, in contrast,

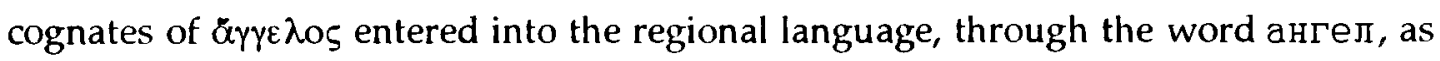
an'gilaq in Aleut and as aankilaq in Alutiiq to signify God's messengers.

An historic precedent exists for this possibility. In the ancient Greek language, $\delta \alpha(\mu \omega v$ (daimon) could be applied to various types of spirits of varying moral sorts. It was applied even to the spirit inspiring Socrates. As it could indicate intermediaries of all sorts between the mortal and the immortal - it could include various sorts of objective, or hypostatic, beings as well as various types of subjective, or affective, states (rather like the term "spirit" in modern English) - the term has been described as "vague" by E. R. Dodds, formerly Regius Professor of Greek at

\footnotetext{
${ }^{17}$ See Mark 1:32, 34, in Atkan (central) Aleut, cited by Bergsland (1980:118). See Matthew 8:31 in Fox Island (eastern) Aleut in Veniaminov, et al., trans. (1840). In the Gospel according to Matthew in the Alutiiq language, according to Leer (ms.; and personal communication, University of Alaska at Fairbanks, March 1988), the terms iiraq and $\underline{\mathrm{ii}} \mathrm{aq}$ are the translations for the "devil". Close cognates, iinraq and iinruq are found in the Yup'ik language from the same verbal root, iir-, "to hide" (Jacobson 1984:160).
} 
Oxford. ${ }^{18}$ The use of the term $\delta \alpha$ hove $\zeta$ exclusively for malevolent spirits is found

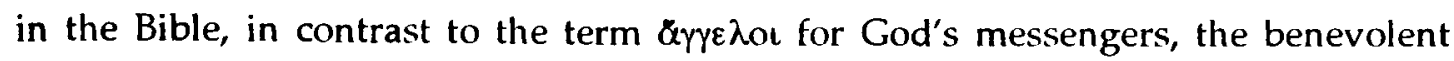
spirits. And the dichotomy was incorporated into academic writing by the second century, when it is found in texts by St. Athenagoras of Athens. ${ }^{19}$ A clearly expressed moral dichotomy was thus developed between types of spirits; yet within this moral dichotomy the terms "angels" on the one hand and "demons" on the other hand would each continue to encompass affective states as well as hypostatic realities: a range benevolent on the one hand but malevolent on the other hand ${ }^{20}$

If the ancient terms qugag in Aleut and kalla'aq in Alutiiq were "vague", or morally ambiguous, similar to the ancient term daimon in Greek, ${ }^{21}$ then we should expect that likewise the ancient shamans - whose designations qugagig and kalla'lek derive from those terms - would be morally ambiguous: neither necessarily good nor necessarily evil as a group. And we shall see that for shamans this was most probably the case. ${ }^{22}$

${ }^{18}$ Dodds (1965:37-38). Also see Rexine (1985:361), professor of classics at Colgate University: "the word had a fluidity", and the ancient "Greeks did not stop to categorize whenever they made use of the word".

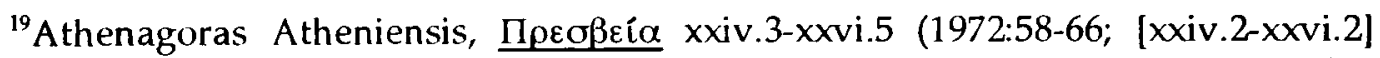
1990:79-88). See note 57 to Chapter 2, above. For an indication of the use of this terminology earlier by St. Justin the Martyr, see "Anges et Démons", Chapter 5 in Wartelle (1987:56-68).

${ }^{20}$ See Chryssavgis (1990:169-176).

${ }^{21}$ Also see Dauenhauer and Dauenhauer (1990:125) for the Tlingit: "it is our understanding that most of these yéik are not intrinsically evil, though some may be; certainly all are powerful and ambiguous at best, and not generically benevolent."

${ }^{22}$ This ambiguity about spiritual functionaries is hardly unusual; and a contrast in this regard would be spurious, as if other types of spiritual functionaries (Christian clergy for example, or Jewish rabbis) were themselves morally unambiguous. Hands that bless can damn. Healers can harm. The contrast in this chapter will not be between shamans-of-old as a group and any other group of functionaries; but instead between the characteristics typifying shamans-of-old in southern Alaska through the "ethnographic perspective" on the one hand, and on the other hand a few men visible through the "social perspective" who were also referred 


\section{(2) An Ethnographic Perspective}

\section{on Shamans-of-old in Southern Alaska. ${ }^{23}$}

Through the ethnographic perspective, shamans are seen within visible and audible characteristics that would attract the atten tion of an ethnographer, and indeed recur in ethnographies (as will be cited). These characteristics include: (i) an election by spirits which was normally disorienting and frightening; (ii) training in some cases but not in all; (iii) tasks accomplished through spirit mediation; (iv) distinctive rites with spirit manifestations; (v) particular paraphernalia; and (vi) onto logical and cosmological boundary crossings. Another recurring characteristic will be set slightly apart, because it could be a response regarding shamans; in any case it merits attention: (vii) an ambiguous moral character.

(i) The Election. Shamans were chosen by spirits. This was true throughout the region at large. In some cases, spirits normally overpowered the shamans-to-be without the latter soliciting the encounter. This occurred among the eastern Aleuts, ${ }^{24}$ and among the Yupiit on Nunivak Island. ${ }^{25}$ In these cases, the shamans-to-be did not seek the vocation: if they could not rid themselves of the spirits, they had to learn to deal with them and thus became shamans.

to as "shamans" but whose own characteristics differed significantly from that group. Among the differences were moral characteristics: a benevolent stability in contrast to the group characteristic, moral ambiguity; a difference that will be related to the nature of the operative spirits.

${ }^{23}$ This perspective was termed "cultural" in Mousalimas (1989a). The present term better reflects the types of characteristics that are involved: the highly visible and audible characteristics that would attract the attention of an ethnographer.

\footnotetext{
${ }^{24}$ Veniaminov (1940b:125-126; 1984:220).

${ }^{25}$ Lantis (1946:252).
} 
A certain Dena'ina managed to evade the vocation by fighting off the spirits as they assaulted him in dreams. ${ }^{26}$

In other cases, people sought the initial encounters and the vocation. ${ }^{20}$ Even so, the spirits took the final initiative by manifesting themselves to only some of these people. Even among the Tlingits, whose shamans came from the same matrilineal groups and normally sought the spirits, the spirits chose the shamans from those eligible: ${ }^{28}$ A person's heredity and volition determined only a propensity for the vocation, but did not necessarily secure the vocation itself.

The initial experiences that inaugurated the election were frightening and disorienting. It is difficult to differentiate between types of these initial experiences: between illnesses or traumatic accidents which precipitated a conviction of election, then were followed by encounters with spirit(s), on the one hand; and on the other hand, actual initial encounters themselves. An example is provided by the initial experience of Kalushi who become a Chugach shaman. ${ }^{29}$ When a "large fish" capsized his kayak, he was lost at sea but later was found safe atop a precipice too steep, according to the source, for him to have climbed. When asked what had happened, he said that "a mask" had carried him up there. Kalushi's experience involved typical emotions and symbols: the shaman-to-be was traumatized, cast into the depths, disoriented, caught by a mask (a spirit), and transported to a precipice. The same type of initial experience and election was reported elsewhere in the region by other sources. Here is a report from the eastern Aleutian Islands: ${ }^{30}$

\footnotetext{
${ }^{26}$ Osgood (1937:182).

${ }^{27}$ Birket-Smith (1953:126).

${ }^{28}$ E.g., Veniaminov (1984:401).

${ }^{29}$ Birket-Smith (1953:130).

${ }^{30}$ Veniaminov (1840b:125; 1984:220).
} 
While traveling at sea, for instance, suddenly in front of them there would be an inaccessible island or a horrible cliff or fearsome monsters emerging from the sea. If they were traveling on foot, different spectres would show themselves to them, or suddenly it would seem that they were standing on the brink of a precipice ready to be hurled down from it and so on.

Those chosen by the spirits were normally men, but they could be women. And on Kodiak Island, they could be transvestites whose propensity to cross ontological and cosmological boundaries as shamans would vividly be reflected in this crossing of social and gender boundaries. ${ }^{31}$

(ii) Training. After their initial experiences, the shamans-to-be might receive training from experienced shamans. Within specific areas there was variation, as indeed throughout the region at large. On the mainland among the Yupiit, and southward among the Chugach, some shamans received training, while others learned on their own. ${ }^{32}$ On Montague Island where "half the population were conjurers",a number had been trained by Apuluq, a renown shaman. ${ }^{33}$ On Kodiak Island, children might have been trained to the role. ${ }^{34}$ Eastward among the Yakutat Tlingit, the shamans received some (unspecified) training. ${ }^{35}$ On Nunivak Island, shamans claimed they had received no training, but this claim did not convince the ethnographer who wondered how they could then have learned. ${ }^{36}$ Evidently,

\footnotetext{
${ }^{31}$ Black (1977b:99). The correlation was indicated by Black (personal communication).

${ }^{32}$ Nelson (1899:428); Birket-Smith (1953:128).

${ }^{33}$ Birket-Smith (1953:128).

${ }^{34}$ Black (1977b:99).

${ }^{35}$ Laguna (1972:675).

${ }^{36}$ Lantis (1946:200).
} 
training of an apprentice or a helper occurred in some cases but not necessarily in all.

In general, the encounters with the spirits constituted the training as well as the initiation. Through these encounters, the shamans-to-be learned their spirits' names and their spirits' songs. They learned to interact with the spirits, to control them and to be controlled by them. In this way, they learned to mediate with the powers which either influenced or claimed to influence life and death, success and in this vary.

misfortune, food and famine, health and illness, and came to perform the shamans' major tasks.

(iii) Tasks. Healing was the task most frequently associated with shamans throughout the region at large. A shaman healed by identifying the spirit responsible for the malady, then either driving it away or persuading it to cease acting malevolently. On the central Aleutian Islands shamans employed herbal medicines, too. ${ }^{37}$ Where herbal remedies were less well known or used, shamans might massage, or use hand pressure. ${ }^{38}$ In the southeast, where witchcraft and sorcery were believed, according to reports, to be prevalent causes of illness, the Eyak and Tlingit shamans cured by identifying the witch or sorcerer. ${ }^{39}$

The next tasks most frequently associated with shamans were foreseeing the future and facilitating the hunt. Shamans accomplished the latter by attracting game or by locating food sources. In addition, other tasks were reported for particular

\footnotetext{
${ }^{37}$ Netsvetov (1840:5-6; 1984b:367). See my text in this chapter at notes 49-50, below.

${ }^{38}$ Lantis (1946:202).

${ }^{39}$ Birket-Smith and Laguna (1938:207, 212); Kamenskii (1985:87-9); A. Krause (1956:200-203); Laguna (1972:728); Swanton (1908:464); Veniaminov (1984:408). Also see Dauenhauer and Dauenhauer (1990:124).
} 
areas: changing the weather, identifying transgressors of norms, rescuing people at sea, learning the location or the fate of missing people, and making amulets.

Nowhere did shamans officiate at life-crisis rites, but Yup'ik shamans on Nunivak Island and Tlingit shamans, at least, performed annual village or lineage purification and perservation rites. ${ }^{40}$

Nor did shamans act as masters of ceremonies in public ritual festivals unless they did so as headmen who happened also to be shamans. These festivals were developed throughout the region at large. Shamans might participate in them. For example, shamans had specific roles at definite times during Nakaciug (the Bladder Festival), a Yup'ik hunting-related ritual festival during which sea mammal bladders were returned ceremoniously to the sea and the sea-mammals' spirits (the yua) were honoured. On the first day, the shamans sang and represented the life-death cycle. On a later day, they saw the yua to learn if they had been pleased. ${ }^{41}$ Also, for

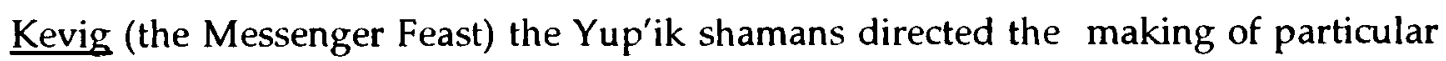
masks and the singing of particular songs associated with these masks. ${ }^{42}$ However while participating, the shamans did not preside over the festivals. Headmen and song leaders (tradition-bearers) presided.

There were exceptions. Yup'ik shamans were masters of ceremonies during Kelek (the Inviting-In Feast) which took place regularly in many places to honour the shamans' spirits as well as the yua. ${ }^{43}$ Across the Bering Sea, on the central Aleutian Islands, shamans conducted "ceremonial feasts", but whether all or only a particular

\footnotetext{
${ }^{40}$ Lantis (1946:196); Veniaminov (1984:405).

${ }^{41}$ Fienup-Riordan (1983:234-235); Lantis (1946:145).

${ }^{42}$ Lantis (1938:191).

${ }^{43}$ Morrow (1984:136-137).
} 
type the source does not say. ${ }^{44}$ If they did so at all of them, then this was a unique trait at the terminus of the island chain; but if they did so only at a particular type, then this and the Yup'ik Kelek represented a regional trait which was not recorded in other areas of southern Alaska. ${ }^{45}$

With these exceptions, the shamans did not officiate at the public ritual festivals unless they did so as headmen. The shamans' ritual function was only part of a very much larger, and more elaborate, system of public ritual activity.

(iv) Shamans' rites with spirit manifestations. Shamans had their own rites. To steady drum beats they sang songs they had learned during encounters with the spirits. They sang to make the spirits manifest. Manifestations could occur through sights and sounds apart from the shamans; alternatively, the spirits would appear through the shamans, who would represent them by masks or costumes or by mimicry. Mimicry often involved cawing like birds, leaping like fish, or growling, crawling, even mock-biting like land animals.

By differing means, shamans sought to influence the malevolent or potentially malevolent spirits which were present. These means varied from gentle persuasion to outright fights. For example, an eastern Aleutian Island shaman coaxed a spirit to cease afflicting a patient, ${ }^{46}$ while a Kodiak Island shaman battled and banished a

\footnotetext{
${ }^{44}$ Netsvetov (1840:6; 1984:367).

${ }^{45}$ Nelson (1899:494) described a ritual during which shamans presided: yu-gi-yhik' or i-t-ka-tah', referred to as the "Doll Festival" because a shaman's doll was a central feature. This ritual had limited distribution, occurring only at the northernmost rim of the Yup'ik territory along the lower Yukon River and in the neighbouring Ingalik Athapascan territory upriver. Although the information from Nelson regarding the "Doll Festival" is not corroborated by any other source from among the Yupiit Morrow (1984), summarizing the list of Yup'ik ceremonies compiled by Mather (1985), does not mention it - neither is he contradicted by information from any source in the region at large. For shamans' dolls, see notes 52-55 to this chapter, below.
}

${ }^{46}$ Sarychev (1802:141-142; 1807:64-65). 
moon-spirit. ${ }^{47}$ Another eastern Aleutian Island shaman threatened a spirit by daring to expose it as impotent if it refused to change the weather. In response the spirit knocked the shaman senseless, but finally complied. ${ }^{48}$

Shamans lost consciousness during rites throughout the region at large. In the case just cited, this was caused by the shaman being attacked by a spirit. In other cases, the shaman induced the state through rapid body movements, such as running in circles.

evidently

Drugs $\wedge$ were not normally used: drug use is not reported in the sources. A lone reference to drug use from the central Aleutian Islands was an error which occurred when "петрушка", a common word for parsley, was mistakenly allowed into the English translation as "opium". ${ }^{49}$ Petroushka is a kind of angelica widely employed today as a herbal medicine, especially in body message in the steam bath on Kodiak Island. ${ }^{50}$

(v) Paraphernalia. With regard to the shamans' appearance during their rites, two traditions existed in the region at Iarge. One, less ornate, occurred among the Chugach, eastern Aleuts, and Yupiit. The other was ornate and existed among Dena'ina, Eyak and Tlingit. Both traditions converged among the Koniag on Kodiak Island. According to the less ornate tradition, the shamans either performed in

\footnotetext{
${ }^{47}$ Pinart in Lantis (1938:146). But is a misinterpretation possible here? If the moon was a patron for males, and was invoked by whalers on Kodiak (Black personal communication), then the moon-spirit as inimical to a powerful male shaman would be incongruous. The question can be answered by the research into Pinart's notes conducted by Desson, yet to be published (also see above, note 15 to this chapter).

${ }^{48}$ Sarychev $(1802: 147-148 ; 1807: 67-68)$.

${ }^{49}$ See Netsvetov (1840:5); cf. ibid. (1984b:367).

${ }^{50}$ Black (personal communication).
} 
normal kamleikas (gut-skin parkas) or performed naked. Elaboration consisted only of the skin-pieces hung from the waist and lined with bird beaks which were worn by some Chugach shamans. In. contrast, according to the ornate tradition, the shamans wore combinations of ritual garments and talismans, including headgear, necklaces, animal furs, claws, feathers, and noise-making attachments. The shamans also used rattles and wands. Masks and costumes were changed by Tlingit and Eyak shamans as different spirits became manifest. (The Tlingit and Eyak even looked different while not performing: the Tlingit never cut their hair, the Eyak wore theirs in a distinctive style.) In both traditions, shamans wore masks during some rites only, probably the most important ones in which the most powerful spirits appeared or in which spirits received special attention.

Shamans constructed masks for their own rites and for some public ritual festivals throughout the region at large (evidence is available also from the Aleutian Islands). ${ }^{51}$ The masks made manifest the types of spirits which the shamans saw. But the shamans' masks were only one variety of masks, mask-making being well developed and varied throughout the region. Other varieties included funerary masks and story-telling or dance masks.

An item specific to the shamans alone was shamans' dolls. The northernmost Yup'ik shamans kept theirs secretly, hiding them in isolated places and consulting them as oracles. ${ }^{52}$ Central and western Aleutian Island shaman surreptitiously made human-sized dolls to carry out deeds. These large dolls were self-animating, which after doing the shamans' deeds could act of their own volition, even bringing destruction to whole lineages. They were therefore dangerous and local norms

\footnotetext{
${ }^{51}$ Netsvetov (184Q:6; 1984b:367); Veniaminov (1840b:144; 1984:229).

${ }^{52}$ Nelson (1899:494).
} 
prohibited them, but "there was always someone among the shamans willing to make one". ${ }^{53}$

Small dolls in human form and in animal forms were made by Koniag, Chugach, Dena'ina, Eyak and Tlingit shamans. These dolls were used to extract the sources of illness from patients during healing rites. During a shaman's performance, a doll might act according to its shape: a bird-form flying, a halibut-form leaping, a human-form walking. Shamans claimed they could send their spirits into such dolls at will. Apuluq (the powerful Chugach shaman from Montague Island), for example, made one for his grieving, childless wife, and when he put his power into it it could walk. $^{54}$ The dolls could be made to do deeds. They could help in the hunt; they could rescue people at sea; some could speak. Like the large dolls on the western and central Aleutian Islands, some could even act on their own. Also, they could kill. ${ }^{55}$

(vi) Boundary Crossings. Sometimes during their rites, and at other times too, shamans crossed, or claimed to cross, ontological boundaries, becoming something other than themselves. They turned into animals or into spirits, as was clearly reported everywhere in the sources that have been cited. This happened during rites through representations involving mimicry or involving the wearing of masks and costumes; but it also occurred in powerful shamans within myths whenever they willed it. ${ }^{56}$

\footnotetext{
${ }^{53}$ Nestvetov (1840:4; 1984b:366). Also see Veniaminov, ed., ftnt. in $\underline{i b i d}$.

${ }^{54}$ Birket-Smith (1953:128).

${ }^{55}$ Birket-Smith (1953:129); Birket-Smith and Laguna (1938:210).
}

${ }^{56}$ Could it have happened against their will also, analogous to the physical dislocations, or transportations, that shamans would suffer or would imagine themselves suffering (see Birket-Smith 1953:130; Nelson 1899:428; Veniaminov 1840b:125-126, 1984:220)? If spiritual or psychic power had become uncontrollable, then so would volition. 
Shamans also crossed, or claimed to cross, cosmological and geographical boundaries, by traveling up through the sky to the moon, even through star holes to upper worlds, down through the sea to the depths, far across the earth, and into the land of the dead. Whether in the body or out of the body, it is unclear:.77 ethnographies simply described the shamans as disappearing, then reappearing. FolkJore simply said the shamans flew, sometimes like birds, leaving trails of sparks in the $\mathrm{sky} .{ }^{58}$

So much prestige was attached to these crossings that some shamans practised them through dramatic acts. One shaman, for example, had his assistant kinsmen tie him up tightly, throw him in the sea, and leave him to drown. Four days later to the sound of his assistants' drumming, he walked into the village alive and well. ${ }^{59}$ Another shaman had his assistants bind him to a pyre. They then set it aflame and burned it to the ground. The next day he reappeared, coming down into the gasgig (kashim the men's house) through the smoke hole in the roof. ${ }^{60}$ Some attempts were actually fatal. ${ }^{61}$

(vii) Moral Ambiguity. Shamans in southern Alaska were morally ambiguous as a group. They could heal but they could also harm. Curing dolls could become killing dolls.

\footnotetext{
${ }^{57}$ Only two ethnographers mention soul-flight clearly: Birket-Smith (1953:127); Laguna (1972:704).

${ }^{58}$ Birket-Smith (1953:127).

${ }^{59}$ Veniaminov (1984:403).

${ }^{60}$ Nelson (1899:434).

${ }^{61}$ Ibid., pp. 430-431, 433.
} 
Even a comparatively benign shaman was treated with caution. Angauqanga, a Chugach -- he was "a good man who assisted and cured many people": an old man whose only devious work was the stealing of animals' souls, so that his own sons alone could catch them on hunts -- was "nevertheless" kept in his own dwelling, away from the home, because "his daughter was afraid to let him live in the house."62 A helpful shaman might lose control of his power. Chitna Joe, for example, although he "cured a lot of people", was unstable, "kind of goofy": he "had power too strong for him to control".63

Another became harmful in a fit of passion. In jealousy, Old Man Duke cursed his own wife. She fell ill and died. He mourned piteously, and he had to be consoled. $^{64}$ Yet another was malicious, but this time habitually: ${ }^{65}$

[The shaman Tutyiq's] spirit flew away carrying its master. Nobody ever saw the spirit, but they saw Tutyiq in their dreams when he told them he was going to make them sick. People wanted to kill him, but even Apuluq was afraid to do so.

A less formidable, dangerous shaman would have been killed or banished. Another became harmful purposely, but against her village's enemies. ${ }^{66}$

\footnotetext{
${ }^{62}$ Birket-Smith (1953:129).

${ }^{63}$ lbid., pp. 223. Throughout the region at large, people have multiple names, each name reflecting an aspect of a person's identity. (The possessing of only "one name" in this context can seem impoverished.) Readers will therefore encounter different sorts of names in various sources: ancient Alaskan names; Russian Orthodox baptismal names; Russian, Scandinavian, and English surnames; everyday American names, like Johnny; and nicknames, like the one just read, Chitna Joe, or Old Man Duke.
}

${ }^{64}$ Ibid., pp. 220-221.

${ }^{65}$ Ibid., p. 128. For Apuluq who is mentioned in the quotation, see notes 33 and 54 to this chapter, above.

${ }^{66}$ Chickalusion (1982). 
Rival shamans could battle against each other, ${ }^{67}$ and some gained power over large areas. Old Man Duke was feared by Tlingit, Eyak, and Chugach alike. ${ }^{68}$

Summary. This perspective upon shamans-of-old in Southern Alaska has viewed them through the visible and audible characteristics that would attract the attention of an ethnographer, including: (i) a disorienting and frightening election; (ii) training in some cases; (iii) tasks accomplished through spirit mediation; (iv) distinctive rites with spirit manifestations; (v) particular paraphernalia; ontological and cosmological boundary crossings; and also including (vi) an ambiguous moral character.

(3) The Social Perspective:

Two Examples of Transformation.

Two men who did not manifest this set were referred to as "shamans" nonetheless. They fulfilled the shamans' main social tasks but without fearful encounters with spirits; without typical rites and paraphernalia; and without a particularly ambiguous moral character. These men were: (i) the Aleut elder of Akun, Ivan Smirennikov, introduced in the preceding chapter; and (ii) an Alutiiq healer named Kangatyuq, who will be introduced here.

(i) The elder of Akun. The source of information for Ivan Smirrenikov was Ivan Veniaminov. ${ }^{69}$ As explained in Chapter 4, Veniaminov was informed as well

\footnotetext{
${ }^{67}$ E.g., Lantis (1938:145).

${ }^{68}$ Birket-Smith (1953:223).

${ }^{69}$ Veniaminov (1977).
} 
as discerning: he had derived from Siberia, was compiling an ethnography of the eastern Aleuts, and was becoming competent in the eastern Aleut language, indeed would soon be translating into Aleut and authoring work in that language. Furthermore he had spoken directly with the elder of Akun through a competent interpreter, the bilingual, literate toion Ivan Pan'kov. In the preceding chapter, the focus was upon the criteria evident in Veniaminov's discernment. In the present chapter, the focus will be placed upon the Aleut elder of Akun himself, within his own social context. ${ }^{70}$

He was healing ailments, foreseeing future events, and locating food supplies. ${ }^{71}$ These were the main social tasks of shamans-of-old, as evident through the ethnographic perspective. He fulfilled these tasks because he was being aided by spirits whom he described. His very vocation was inaugurated by them, when they began appearing to him nearly thirty-three years earlier than the report about him.

But his interactions with them were different from the interactions observed through the ethnographic perspective. He did not have the disorienting initial experiences or the subsequent terrifying encounters that typified other shamans. These spirits, appearing to him almost daily during those thirty- three years, had

${ }^{70}$ The contextualization is important, otherwise Smirennikov's case is liable to be misinterpreted as if it would support ad hoc communities of converts who would establish themselves as insular groups. Smirennikov can not be taken as a prototype for such marginalism. Just as he and the Aleuts have been studied here within their historical and cultural contexts, so likewise should those ad hoc communities be studied within their own; and the latter might then be recognized as a variation within a history of their own people's non-conformist religious movements. He had little possibility of entering into any other relationship of instruction than the extraordinary one reported for him. Furthermore, he belonged to the Akun Aleuts who were being converted as virtually a whole body, and who were becoming multilingual, Aleut and Russian speakers.

${ }^{71}$ Veniaminov (1977:100-101). 
never caused him anxiety, except the pang of conscious when he had done something amiss: "otherwise he did not experience any fear" in their presence. ${ }^{72}$

Nor did he employ the rites and paraphernalia that were typical of other shamans. His difference in this respect can be deduced from two factors. The first, mentioned also in the previous chapter (it needs to be repeated in the present context), is that he was encouraged in this vocation by Venia minov who was not overtly syncretistic. In another situation, Veniaminov requested that a shaman promise to cease practising, ${ }^{73}$ but in contrast he encouraged the elder of Akun not only to continue practising but to practise among the baptized Aleuts of Veniaminov's own parish. Differentiating him, Veniaminov in effect distinguished this man's practice from the rite techniques that typified shamans-of-old. Secondly and very much to the point, these spirits had not appeared in order to be propitiated or to be appeased. They came instead to instruct the elder of Akun. And they had been sent to him. He had not summoned them. .-- The very nature of the manifesting spirits therefore did not necessitate rites of summoning and propitiation.

Finally, his character was remarkably stable. Smirennikov was described as fearless and free, and as having a "clean manner of life". ${ }^{74}$ These characteristics reflected the nature of the spirits who were appearing to him: angels as discerned by Veniaminov. ${ }^{75}$

Yet despite these differences, Smirennikov was being referred to as a "shaman" by the Akun Aleuts. While the difference from shamans-of-old was articulated by Veniaminov when he advised the Aleuts not to call this man a

\footnotetext{
${ }^{72} \underline{\text { Ibid., p. } 101 .}$

${ }^{73}$ See Chapter 4 at note 69 , above.

${ }^{74}$ Veniaminov (1977:102).

${ }^{75}$ Ibid. See Chapter 4 at note 64 , above.
} 
"shaman", as explained in the preceding chapter; yet they were referring to him in just this way, and this is the key point. This man was their "shaman"

One may well hypothesize that he was referred to as such because he reflected the meaning intrinsic in the term for "shaman": he was possessed of spirits, and thus was he able to accomplish the extraordinary. If the word for spirit(s) intrinsic within the term for shaman had not yet become fixed as in the modern Aleut vocabulary - this is quite possible because the Gospel according to Matthew had yet to be translated into Aleut: Veniaminov's report was dated in April 1828; the translation would commence in September 1829 - then there would be little if any contradiction in the use of the term "shaman" for this man at that time. If, in other words, the term qugaq was fluid in popular usage, then the popular application of the term "shaman" would not be too incongruous. Once the term would become fixed, then the elder of Akun should cease being referred to as a "shaman", and should be referred to instead by another word, just as the Aleut-Russian priest referred to him in retrospect, three generations later, properly as a "prophet".76

Hypothesis aside, the reported fact remains: that these people were referring to this man as their shaman. And thus in him the transformation becomes visible; for other characteristics that typified shamans-of-old had changed, while the shamans' main, indeed vital, social tasks continued among the Aleuts through him.

(ii) The Alutiiq Healer. The next example, the Alutiiq healer named Kangatyuq, also fulfilled the primary, vital social task of healing but without the set of characteristics that can be seen through the ethnographic perspective.

\footnotetext{
${ }^{76}$ Kashevarov (1987:346). See Chapter 4 at note 70, above.
} 
The published source of information for him is the Danish ethnographer Kaj Birket-Smith who conducted fieldwork in the Chugach Bay area in 1933. ${ }^{7}$ He was aware of distinctions between shamans and other types of healers and knew various terms for them. ${ }^{78}$ However due to the nature of his fieldwork, it must remain uncertain whether he could apply the knowledge of these terms as he collected the account. He collected it among a number of accounts, and he received them through an interpreter for whom Alutiiq and Russian were primary languages, not the English language which was their language of communication, and in which BirketSmith published. The factors in the process of the collection that could inhibit the precise use of the term would thus be the volume of material collected, and the linguistic distance between the collector and the source that remained insufficiently bridged due to incomplete trilingualism. ${ }^{79}$ There is yet a further problem, involving the ethnographer's classifications. Some descriptions that contained Orthodox Christian elements were interpreted by him as "aboriginal religious ideas"; and the Alutiiq-Russian community leader who related these descriptions to him was classed as a "Chugach Eskimo". ${ }^{80}$ Therefore when this ethnographer termed the Alutiiq healer a "shaman", the term can not be taken as the indicative factor

${ }^{7}$ Birket-Smith (1953:130-132). Fieldwork was conducted with the First Danish-American Alaska Expedition. From 27 April to 22 July 1933, this ethnographer was in the Chugach area, also known as the "Prince William Sound" region; and he spent six weeks of that period with Makarii Fedorovich Chumovitskii (see note 82, below), who became the "primary informant". Chumovitskii's daughter Matrona acted as the interpreter. For this data see ibid., p. 1. For a reproduced photograph of these people, see J. Johnson, ed. (1984:iv).

${ }^{78}$ E.g. ibid., p. 116.

${ }^{79}$ These factors were initially elusive: cf. Mousalimas (1989a:313) where the process of collection by Birket-Smith was equated with that by Veniaminov.

${ }^{80}$ Birket-Smith (1953:2, 130-131). For more detail, see my final Conclusions. 
alone; because it could have been an interpretation also, according to a subjective association as follows: the Alutiiq-Russian source becomes a "Chugach Eskimo informant"; his beliefs become "aboriginal religious ideas"; and the healer in his account becomes a "shaman".

More indicative and more important is the overall content of the account as it reflects the source's own thought. The context itself places the Alutiiq healer in a context with other shamans. It then compares him with them, and emphasizes his differences from them. The shamans to whom the Alutiiq healer was contrasted include Apuluq and Kalushi. Both were seen through the ethnographic perspective. Apuluq was the powerful shaman from Montague Island who was possessed of the fearsome Copper River spirit, named Adliuq. Kalushi had had his vocation inaugurated through a capsizing at sea and the subsequent transportation "by a mask" to the cliff face. ${ }^{81}$ Interestingly the account specifies Kalushi as the Alutiiq healer's own son.

The source of the account was a leading man of stature within the community and a tradition-bearer with deep roots within the region, Makarii Fedorovich Chumovitskii. ${ }^{82}$ He had himself known Kangatyuq; and the account about him is the lengthiest and most detailed in the collection about "shamans", all of these accounts collected from the same source. ${ }^{83}$ The relative length and detail may indicate the importance of this account in particular.

\footnotetext{
${ }^{81}$ Birket-Smith (1953:2). For A puluq and Kalushi see notes 29, 33, 54 and 65 to this chapter, above.

${ }^{82}$ The surname, spelled "Chimovitski" by Birket-Smith, will be spelled Chumovitskii here because Makarii Chumovitskii was a descent of Paramon Chumovitskii according to J. Johnson (Chugach Alaska Corporation, personal communication, August 1991); and as this relationship may prove to be important for the history of the region, the transliteration of the surname should reflect this relationship here. For Paramon, see Gideon (1989:ix, 98, 110, 116, 119).

${ }^{83}$ Birket-Smith (1953:128-132).
} 
Kangatyuq was a healer. Thus the ancient shamans' most important social task of healing was thus fulfilled by him. However (similar to the elder of Akun), his vocation was not inaugurated through the disorienting initial experiences that typified shamans through the ethnographic perspective; nor did it involve the subsequent terrifying encounters with spirits. A persistent intuition alone had prompted him to discover his ability to heal. He tested this intuition during the sea otter hunt by reviving a grounded bird: he "breathed" on it; the bird strengthened and took to the wing. Yet even this discovery of the ability did not itself inaugurate the vocation.

He was encouraged to begin healing later by a man. While on another hunting expedition, this time into the Kodiak area, Kangatyuq and a cousin went into the forest to visit "a very holy man, монах Германъ [the monastic Herman]". 84 This was a member of the mission from Valaam that had arrived at Kodiak in 1794, who had since moved from Pavolovskaia gavan into the forest on islet of Elovoi, where he resumed the anchoretic life he had known in forests of Karelia. The last surviving of the initial missionaries, he reposed on this islet in 1836. According to the account, when this "very holy man" saw Kangatyuq, he recognized him as a healer ("a shaman"), and then directed him to the "priest's house" to heal the "priest's daughter" who was deathly ill. ${ }^{85}$

The parish priest at that time would have been either Frumentii Mordovskii, assigned to Kodiak (to relieve the elderly missionary monastic priest Athanasii) in

\footnotetext{
${ }^{84}$ Ibid, p. 130 (the Cyrillic is written in the source as quoted). For Herman, see Chapter 1 at notes 84, 133, 138-144, above; also see Chapter 6, below.

${ }^{85}$ Ibid., p. 131.
} 
1824 , or Aleksei Sokolov who replaced Mordovskii in 1833 , as both these married clergymen had daughters. ${ }^{86}$

As he had been "to church" the day prior, ${ }^{87}$ Kangatyuq knew the priest, went to the house and gave a message written by "monakh Herman". The priest read the message, and brought Kangatyuq to the ailing daughter. And thus did the Alutiiq healer's vocation commence.

He healed as he was enabled by an unnamed "spirit" to whom he prayed. The prayer itself was a very general supplication, in the account as follows: ${ }^{88}$

I wish [or pray] you would help me, whoever you are. You let this girl come back to her parents like that rotten bird ... that I made alive, then I'll believe myself what I am.

He then proceeded by "breathing" on her mouth: ${ }^{89}$

The first time she did not move, but the second time he blew through his hands, and she opened her eyes as if she was waking up. Now Kangatyuq talked and talked, but they were not able to understand what he said. After he had blown for the third time the girl motioned to him to set her up.

These acts comprised his "rite technique" at the commencement of his vocation; and the same "technique" remained constant through his vocation, in contrast to the rites and paraphernalia that typified the shamans-of-old. "He always used to blow but never did anything else, not even sing."

Finally, his character was stable. He never harmed. So remarkable was this quality that it was emphasized in the account: "He never hurt anybody, but he

\footnotetext{
${ }^{86}$ See Pierce (1990:362-363, 476-477).

${ }^{87}$ Birket-Smith (1953:131).

${ }^{88}$ lbid.
}

${ }^{89} \underline{\text { Ibid. }}$.

${ }^{90}$ Ibid., p. 132. 
always cured people". ${ }^{91}$ His stable moral character and his "rite technique" emphasized together in the account in contrast to the shamans Apuluq and Kalushi as follows (some elements in the quotation have been given above, and will be repeated below so that their juxtaposition and comparison in the context can be seen) $:^{92}$

\begin{abstract}
He never hurt anyone, but he always cured people. He could do so even faster than Apuluq. He always used to blow but never did anything else, not even sing. "That fellow's got good medicene breath," people said. He did not know who his spirit was. His son Kalushi did not cure people like [as did] his father.
\end{abstract}

Also emphasized in this quotation was a difference regarding the spirit that enabled him: "he did not know who his spirit was." Thus "unknown", it would remain unnamed, and he did "not even sing". Singing for shamans-of-old would be a sort of summoning and invoking. This gifting spirit required no "singing". And it only healed, and so did he.

Yet while healing differently from them and better than them as emphasized in the account, he was cast in a context with shamans-of-old; and thus the transformation becomes visible through the Alutiiq healer (as through the elder of Akun) as he fulfilled the shamans' main, indeed vital, social task of healing but without other characteristics that typified shamans through the ethnographic perspective.

\title{
${ }^{91}$ Ibid.
}

${ }^{92}$ Ibid. 


\section{(4) Conclusions.}

Two perspectives on shamans-of-old in southern Alaska have been assumed. The "ethnographic perspective" focuses on a set of visible and audible characteristics that have attracted the attention of ethnographers, and brings this set out in full relief. In contrast, the "social perspective" highlights the broader base of social tasks. Within the latter perspective, men could be seen accomplishing the main social tasks without that set of characteristics, yet were referred to as "shamans".

The two perspectives create a contrast that allows the transformation to be seen, as continuity becomes visible through the social perspective, regarding the shamans' major social tasks; but discontinuity becomes equally evident through the ethnographic perspective, regarding some other characteristics of "shamans-of-old". As the latter included those rites which induced ecstatic trance by means such as very rapid body move ments, the contrast created in this chapter can be related to the one identified from patristic literature in the preceding chapter, regarding ecstatic experiences. This relationship is recapitulated within the example that spanned the chapters: having comprised the example of prophetic ecstasy (that is to say, ecstasy of a Biblical prophetic kind) in contrast to other types of ecstatic experiences in the preceding chapter, the Aleut elder Ivan Smirennikov has also comprised an example of transformation in contrast to "shamans-of-old" in the present chapter.

He was associated with regional shamans-of-old by the very term "shaman" applied to him by the Akun Aleuts; indeed, he conformed to the broadest meaning of this term as defined in my introduction to the present chapter: "possessed of spirits, he accomplished the extraordinary". Similarly the Alutiiq healer was associated with regional shamans in the same way: the term "shaman" was applied also to him. If the ethnographer had perhaps glossed the term in the latter example, 
the tradition-bearer from whom the account was collected had himself placed Kangatyuq in a context with regional shamans nonetheless. A conceptual association with regional shamans existed in the field itself in both these examples, despite the important difference that distinguished these two men.

So that these two men could be established as examples of a transformation from the ancient shamans' practices, these men had to be associated with shamans-of-old in the actual field. Equally, the two men have to be associated with Christianity, so that they may be seen moreover as examples of the transformation into Russian Orthodoxy. For the Aleut prophet, this association is visible in the following three ways: (i) his vocation commenced at his baptism; (ii) the content of his spirits' communication to him, their instruction, was Biblical; ${ }^{93}$ and (iii) his vocation was affirmed by Veniaminov. For the Alutiiq healer, the association is similarly evident as follows: (i) Kangyatyuq, after church, had himself gone into the forest to seek the monastic missionary Herman; (ii) this "very holy man" (as he was described in the account, as cited) recognized the nascent healer's gift and encouraged the vocation; and (iii) the vocation commenced in the Russian Orthodox priest's house, indeed with the clergy man's own daughter.

Thus placed contextually within Russian Orthodoxy in the very field itself, and moreover associated conceptually with shamans-of-old while differing from them: these two men provide examples of the transition from shamanism to Russian Orthodoxy. One example derives from among the Aleut people, the other from among the Alutiiq people.

\footnotetext{
${ }^{93}$ The content of the experience itself is a quality proper to the one who experienced it, that was Smirennikov. The discernment of this content is a quality proper to the one who exercised this discernment, that was Veniaminov. The two qualities have been kept distinct in this study; they have been developed as distinct themes in Chapters 4 and 5 respectively.
} 
The examples in this chapter and those in the preceding chapters suggest that transformations occurred multi-dimensionally through these cultures, the examples presented in the present study being like a few facets: the transition of ritual masks into icons; the transition of ancient ritual festivals into liturgies and liturgical festivals; and now the transition of shamans-of-old into healers and a prophet of a Biblical kind. Together these facets suggest a multidimensional, or pervasive, transformation that would be expected in a transition that was itself indigenous and corporate: one that occurred in virtually the whole of these societies in their entireties, and involved indigenous spiritual and social processes.

But would the transformation be recognized by allogenous authorities other than those like Veniaminov and Herman? Or would they seek instead to purge these people from all shamans, even all shaman stories, to "raise" the natives to "Orthodox Christianity"? The question will be reserved as the study proceeds further into the facet of the transformation that the present chapter has described. 


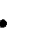




\section{CHAPTER 6}

\section{TRANSFORMATION, II}

The focus in this chapter will be upon the anchorite from Valaam whom Kangatyuq met in the forest of Elovoi, today's Spruce Island, as the same kinds of qualities that can be perceived through the social perspective were attributed also to him: associated with spirit(s) he accomplished the extraordinary, healing, foreseeing future events, and pacifying the forces of nature.

The reader may attribute these qualities to him or to the sources, as these sources' own beliefs regarding him. The effect upon the argument is one and the same; for in either case, these qualities were associated with the anchorite from Valaam in the forest of Elovoi.

A tradition will be traced in this chapter from him in the forest (as he is described by sources contemporary or nearly contemporary with him) through the Monastery of Valaam to the desert fathers (as they are described in patristic literature) and then to the Gospels. This tradition will be likened to a deep line that, embodied by him, touched a continuous line of indigenous tradition in the Kodiak area where he lived (when, for instance, he met Kangatyuq who became the "Alutiiq healer"). Finally, in a brief epilogue, this meeting will be placed within the broader historical context that was studied in Chapter 1.

Why should an entire chapter focus upon this person singularly when no one else will have been described to such length in this study? Firstly, he remained in the region much longer than any of the other initial missionaries or subsequent foreign clergy. Of the eight monastic missionaries and two church servitors who arrived at 
Kodiak in 1794 , five had died by the turn of the century.' By 1805 , the remaining servitor had also died: ${ }^{2}$ four were mentioned in a report from Kodiak that year. ${ }^{3}$ By 1819 , only three remained, ${ }^{4}$ and by 1825 , only this one: ${ }^{5}$ the anchorite himself. He reposed on the islet of Elovoi in 1836, after forty-two years in the Kodiak area from his arrival until his repose. ${ }^{6}$

'See Veniaminov (1840b:154-155 ftnt.; 1984:234-235 ftnt.). Also see Pierce (1990:201, 203, 235, 483). Archimandrite loasaph, hieromonk Makarii, hierodeacon Stefan, and a "church servitor" drowned in the wreck of the Phoenix in 1799; hieromonk luvenalii was killed on the mainland.

${ }^{2}$ See Veniaminov (1840b:155, ftnt.; 1984:235, ftnt.) who states the church servitor had drowned in the Kodiak area but does not provide a date of the drowning. Compare with the following source, Gideon, the cathedral hieromonk sent to bolster the mission as its head from 1804 to 1807 , who does not list a church servitor among the missionaries in 1805: Secret Report, Hieromonk Gideon to Metropolitan Amvrosii, 2 June 1805, in Gideon (1989:80).

${ }^{3}$ See Gideon, ibid. These four were: Hieromonk Athanasii, hierodeacon Nektarii, monastic Herman, and monastic loasaph. The latter was the youngest of these four, not to be confused with Archimandrite loasaph. I have transliterated the name Athanasii with the letters "th" to represent the " $\theta$ " in the Russian version of this name in the primary source: " $\theta$ " is found there, not " $\Phi$ ".

"Letter, Monastic Herman to hegumen Ionafan of Valaam, 13 Dec. 1819, in Valaam, ed. (1894:192-193; 1987:114-115).

${ }^{5}$ See Veniaminov (1984:234). Also see Pierce (1990:3, 201). The monastic, or monk, Ioasaph (see note 3, above) had died in the Kodiak area in 1823, and hieromonk Athanasii had been relieved, and given transportation from Kodiak, in 1825.

${ }^{6}$ The date of repose is 1836, based upon Kodiak documents from that year, according to L. T. Black (personal communication, March 1988) and R. H. Pierce (personal communication, November 1989; 1990:164). This date is given by the editor in Veniaminov (1984:502), in the index for "German (Herman)". Herman would have been approximately 79 years old, as his age was specified as 48 in 1805 (Gideon 1989:80). The date of his repose was confused as "1837" by Veniaminov twice (1840b:5, ftnt; 1840a:22); see ibid. (1984:235, ftnt.; 1978:44). The error was repeated in May 1867, by Petr, bishop at Novo Arkangel'sk and vicar of the Kamchatka diocese, in a marginal note that he affixed to another man's account (in Valaam, ed. 1894:181; 1978:108). The error was repeated on the occasion of a single church group's canonization of Herman as a saint (OCA 1970:12,66). And through them on this occasion, the mistaken date entered the United States Congressional Record in a brief "Biography of Father Herman" (Proceedings and Debates of the 91st Congress, Second Session, vol. 116, no. 133, 4 August 1970; reprinted in OCA, p. 81). 
Secondly (as a further reason for the concentration upon him), he is considered holy. Alaskans' respect for him was reported from Russian-America in 1866 when a bishop at Novo Arkangel'sk, the vicar of the Kamchatka diocese, wrote: "In general all the local inhabitants have a sincere respect for Father Herman as a holy hermit, completely convinced of his godliness." And their respect was matched by a veneration of him at Valaam in the next generation as described by the monastery in 1894: "To us the memory of this man is sacred, and everything to do with him is dear to us." ${ }^{18}$ The perception of his holiness was expressed by the Alutiiq tradition bearer, Chumovitskii, in 1936 when he referred to monakh Herman as a "very holy man"; and he is known as a saint in both locations, Alaska and Valaam, today: "St. Herman of Alaska". .

${ }^{7}$ Letter, Petr bishop of Novo Arkhangel'sk and Vicar of the Kamchatka diocese, to hegumen Damascene of Valaam, 12 May 1866, in Valaam, ed. (1978:96). See ibid. (1894:159). It is important that the descriptions of Herman's asceticism, as a "hermit", and his holiness in the sources provided by Valaam be interpreted within the greater context of these sources where he is described also as physically healthy, indeed of extraordinary stamina, and as warm-hearted and generous: for physical health, see Lazarev, lanovksii, and Larionov, in ibid.(1894:122, 142, 183; 1978:76, 87, 110); for warmth of heart, see especially, Ianovskii to Damascene, 22 Nov. 1865, 3 Sept. 1866, and 12 Dec. 1866, in ibid. (1894:143, 153, 161; 1978: 88, 93, 97). Otherwise the asceticism, if abstracted from these sources, could be intrepreted instead as Manichaeistic or Neo-Platonic. Also see Chapter 4 at notes 21 and 22, above.

For my spelling of the name "Herman" in preference to the direct transliteration, see the section on transliteration in my Introduction. For the dialectical softening of the initial consonant in Германь, a name that derives from $\Gamma \varepsilon \rho \mu \alpha v o$ s, see note 6 in Chapter 1, above.

${ }^{\circ}$ Длія нась священна память этого человька, и дорого все что до него относится (Valaam 1894a:49-50; 1978:31).

${ }^{9}$ Chumovitskii in Birket-Smith (1953:130). My reference to him as a saint is based upon the dual factors of (i) the historic evidence of veneration for Herman, and (ii) the actual occurrence of this veneration today. A formal act of canonization occurred within a church group as mentioned in note 6 , above. But because that group is not entirely recognized by the Orthodox patriarchates and autocephalous churches, that act alone is insufficient for any statement about him as a saint of the Holy Orthodox Church. Furthermore, the "O.C.A." has created other Alaskan "saints" from dubious historical evidence (see, e.g., Oleksa 1990) and without prior veneration by Alaskan people. Scholarly evidence is required for statements about Herman, a requirement that will be emphasized within the notes throughout this chapter. 
These two factors - his longevity in the Kodiak area as a missionary; and the respect, even veneration, for him as evident in Russian-America in 1866, in Valaam in 1894, and in both places today - coincide in him uniquely, and indicate that particular attention should be focused upon him in this study.

\section{(1) Biography.}

Biographical information presently available for him derives mostly from Valaam Monastery, from where most of the missionaries to Kodiak, including Herman himself, had derived. Letters received by hegumen Damascene from Sem'en Ivanovich lanovskii are valuable for their biographical content. ${ }^{10}$ Ianovski, a naval officer assigned as the chief manager of Russian-America in April 1818 and remaining in that position until September 1820," came to know the monastic missionary during that time, then wrote these letters between 1865 and 1867 in retrospect. They were published by Valaam with other source material for the centennial of the mission to Kodiak. ${ }^{12}$

Other primary sources containing biographical information as yet unpublished can be found in the Shur collection in the materials from Soviet archives on microfilm

\footnotetext{
${ }^{10}$ For the term hegumen, and its transliteration, see note 6 to Chapter 1 , above.

"A naval administration replaced the civil administration in January 1818 , at the end of the Napoleonic Wars.

${ }^{12}$ Valaam, ed. $(1894 ; 1978)$. Many of the letters in translation have been reprinted in Oleksa, ed. (1987). The collection of letters that I am referring to as Valaam, ed. (1894; 1978) comprises Appendix 1 in Valaam (1894a; 1978), a book that also includes a chapter interpreting the mission, and another chapter interpreting Aleut and Alutiiq cultures: both those chapters have been cited in Chapter 2 of my study, above. Also at the centennial, the monastery published a readable vita created by merging information from various sources into a single narrative (Valaam 1894b); but it is an uncritical and unreferenced work that merged primary source material indiscriminately with secondary. In contrast, the other publication (Valaam 1894a) distinguishes between sources, and identifies them.
} 
in the Rasmusen Library, University of Alaska at Fairbanks. A document that Herman signed, and that has yet to published, exists in the Golder collection in materials from the Holy Ruling Synod among the Russian Reproductions in the Library of Congress Manuscript Division, Washington, D.C. ${ }^{13}$ More information pertaining to Herman in the Kodiak area could be gleaned from Russian-American Company documents, some segments of which have been published in the Limestone Press Alaska History Series. ${ }^{14}$

Biographical Summary. Embarking upon the monastic life as a young man of about sixteen years old, Herman went initially to a methochion near the Gulf of Finland, a "holding" of the Sviato-Troitskaia Sergievskaia Lavra, where he remained for five or six years. He then entered the Monastery of Valaam situated on an island in vast Lake Ladoga in Karelia. There he sought greater solitude in a scete, consisting of a few monastics, as few as two or three under the guidance of a spiritual father, living deeper in the forest than the monastery house itself. Eventually with permission from the hegumen of Valaam, Nazarii, he was allowed to embark upon the eremitic, or anchoretic, life. In 1793, the same hegumen who had observed his spiritual development, attached him to the mission for Kodiak: a gift indeed as this hegumen was building up his own monastery, yet sent a man of such caliber to Kodiak.

He arrived in September 1794 among the monastics who comprised this mission; and by 1819 , he had resumed the anchoretic life in the forest, now on the islet of Elovoi, located a distance of a few versts over the sea from Kodiak Island's

\footnotetext{
${ }^{13}$ HRS/RR/LCM 564:1-5. See note 113 to Chapter 1, above.

${ }^{14}$ In translation, Pierce, ed. and trans. (1976; 1984). Scholarly work is presently being accomplished at the University of Alaska at Fairbanks particularly by professors L. T. Black and R. H. Pierce for publication in a revised edition of Valaam (1978) in the Limestone Press Alaska History Series for the bicentennial of the mission, 1994.
} 
main harbour, Pavlovskaia gavan. ${ }^{\text {is }}$ He named the site "New Valaam". ${ }^{16}$ In 1830, this name became the official designation for the eastern side of Elovoi where was he living. ${ }^{17}$

His move into the wilderness had its precedent among the desert fathers; and like theirs, his was "above all not a 'move away' from the people ... he still continued to see and counsel visitors who came to him". ${ }^{18}$ These words written with regard to St. John Climacus of the seventh century apply equally to the anchorite from Valaam of the nineteenth. People came to see him from the Kodiak area, the Alaska Peninsula, the Chugach Bay area, and the eastern Aleutian Islands. ${ }^{19}$ A few people

${ }^{15}$ Herman to Ionafan, 13 Dec. 1819, in Valaam, ed. (1894:193; 1978:115). Also see Letter, Sem'en Ivanovich lanovskii to hegumen Damascene, 22 Nov. 1865, in ibid. (1894:133; 1978:81). A verst is a "Russian measure of length, 3,500 feet", according to The Concise Oxford Dictionary, 5th ed.; or according to the Encyclopedia Britannica, 15th ed.: "0.66288 mile (1.06 kilometre)".

${ }^{16}$ Herman to lonafan, 13 Dec. 1819, and lanovskii to Damascene, 22 Nov. 1865 , in Valaam, ed. $(1894: 193,133$, respectively); also see $\underline{\text { ibid. }}(1978: 115,81)$.

${ }^{17}$ Communication, Chief Manager Ferdinand Petrovich Vrangel [Wrangel], 18 June 1831, Communication of the Governors no. 354, cited by Pierce (1978:178). Provided in Chapter 1 at note 144, this information is being repeated in the present context.

${ }^{18}$ Chryssavgis (1989:7).

${ }^{19}$ For the Kodiak area see, e.g., various sources in Valaam, ed. (1894:124, 153, 176$177,182,185 ; 1978: 76,93,105,109,111)$. For the Alaska Peninsula see ibid. (1894:148; 1978:91). For the Chugach Bay area see Birket-Smith (1953:130-131). Also see Ianovskii to Damascene, 22 Nov. 1865, in Valaam, ed. (1894:134; 1978:82): "Aleuts of both sexes with their children often came to visit him.... On Sundays and feastdays many people came to him to pray." Also see "Narrative of the Pilgrim Lazarev" in ibid. (1894:122; 1978:76). 
lived on the small island itself, some had settled there to be near him. ${ }^{20}$ He himself would visit, "frequently" at times, paddling the distance to Pavlovskaia gavan. ${ }^{21}$

In his later years, he remained at his hermitage, observing the monastic rule; $^{22}$ and there he reposed in 1836 (as mentioned above).

${ }^{20}$ Herman to Ionafan, 13 Dec. 1819; Letter, Monastic Herman to Sem'en Ivanovich Ianovskii, 20 June 1820; Narrative of the Pilgrim Lazarev finscription at Valaam dated Oct. 1864]; Konstantin Larionov, Information about Father Herman [postscript at Novo Arkhangel'sk dated 21 May 1867]: in Valaam, ed. (1894:193, 147-148, 122-123, $178-179 ; 1978: 115,91,76,106)$ respectively. Provided in Chapter 1 at note 143 to develop another theme, this information is being repeated here to develop the present topic.

${ }^{21}$ Larionov in Valaam, ed. (1894:175, 177; 1978:104, 106). Herman also had practical activities and duties, of course, particularly as the head of the surviving mission from 1807. References to these activities and duties follow.

For his protests against the Russian-American Company's administration in, especially, 1802, 1805, and 1818, see above: notes 113,115, and 116 to Chapter 1 . For his responsibilities for the remaining missionaries' own domestic concerns from 1798, a duty assigned to him by Archimandrite Ioasaph at the latter's departure for Irkutsk, see: Letter, Archimandrite loasaph to Monastic Herman, 8 June 1798, in Valaam, ed. (1894:187; 1978:111). For Herman's assignment as head of the surviving missionaries by cathedral hieromonk Gideon at the latter's departure from Kodiak in 1807, see Gideon (1989:116); for Gideon himself see note 2 to this chapter, above. And for an indication of Herman's responsibilities in the later capacity - particularly caring for poor and the ill - see the references in Pierce (1978:178); also see lanovskii to Damascene, 22 Nov. 1865, in Valaam, ed. (1894:136-137; 1978:83-84).

${ }^{22}$ Petr to Damascene, 12 May 1866, in Valaam, ed. (1894:158; 1978:96): he "conducted the Holy Services according to monastic laws". But Petr is a secondary source who erred in a matter concering Herman: see note 6 of the present chapter; also see note 56, below. The same information regarding Herman's monastic discipline, can be inferred from a primary source, Sem'en Ivanovich Ianovskii (described in the text of the present chapter in "Sources for the Attributes"), Letters to hegumen Damascene, 22 Nov. 1865 and 12 Dec. 1866, in Valaam, ed. (1894:133; 1978:81): О. Германъ ... вель строгую аскетическую жизнь; "he was living a strictly ascetic life"; and ibid. (1894:161; 1978:97): св. Старца, монаха Валаамсаго Монастыря ... подвизавшагося; "the monk of Valaam ... lived as a hermit". How does a strictly ascetic, eremitic monastic belonging to Valaam live? The monastic rule in the Greek Orthodox ecumene is standard. Virtually a single rule exists everywhere for men and women alike. Varied orders do not exist. The variation occurs in the extent to which the entire formidable rule is observed.

Herman's conformity to monastic tradition is further evident in his clothes: he wore ряса and клобукъ, according to Ianovskii to Damascene, 22 Nov. 1866 (in Valaam, ed. 1894:142; see ibid. 1978:87). These are the monastic cassock and cowl, to

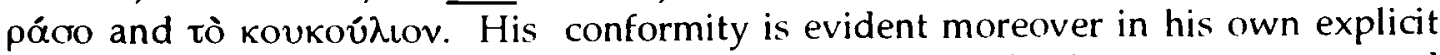
instructions about the preparation of his body for his burial at his repose, recounted by Larionov (in Valaam, ed. 1894:180; 1978:107). These instructions accord with 


\section{(2) Sources for the Missionary's Attributes.}

Among the sources collected about Herman by hegumen Damascene in the 1860 s, and published by Valaam in 1894, the following describe the attributes of healing, foreseeing, and pacifying the forces of nature: (i) naval officer Sem'en Ivanovich lanovskii, "Letters to Damascene"; (ii) Kodiak church warden Konstantin Larionov, "Information about Father Herman"; and (iii) a pilgrim named Lazarev from Valaam, "Narrative of the Pilgrim Lazarev". 23

(i) Sem'en Ivanovich lanovskii, "Letters to Damascene". While this naval officer was serving as chief manager in Russian- America from January 1818 to September 1820, he met the anchorite from Valaam, and they became close, indeed as a spiritual son to a spiritual father: "he loved me as a son", Ianovskii wrote in retrospect. $^{24}$ By Ianovskii's own account, Herman converted him from deism. ${ }^{25}$ In 1864, subsequent to his wife's death, he became monastic himself, at Kaluga, southwest of Moscow. ${ }^{26}$ And he wrote his recollections about Herman soon afterwards, between 1865 and 1867, for Damascene. ${ }^{27}$ These recollections particularly highlight Herman's interactions with imperial naval officers then in

monastic tradition, with the cowl becoming the shroud at the vigil and for the burial.

${ }^{23}$ In Valaam, ed. $(1894 ; 1978)$. Brief descriptions .of these sources are provided above, in notes 136, 142, and 143 to Chapter 1 . These descriptions will be expanded here, and incorporated into the text, as they are central to the present focus upon Herman himself. The repetition is deliberate, for clarity in the present context.

${ }^{24}$ Ianovskii to hegumen Damascene of Valaam, 22 Nov. 1865, in Valaam, ed. (1894:143; 1978:88).

${ }^{25}$ Ibid. (1894:135; 1978:82).

${ }^{26}$ Valaam (1894a:57-58; 1978:36). Also see Pierce (1990:199).

${ }^{27}$ For the motivation, see the first of his letters: Ianovskii to Damascene, 17 Oct. 1865 , in Valaam, ed. $(1894: 129 ; 1978: 79)$. 
Russian-America, to whom the anchorite from Valaam had extended his missionary ministry. ${ }^{28}$

(ii) Konstantin Larionov "Information about Father Herman". The starotsa or warden, of the Kodiak church (dates unspecified), ${ }^{29}$ included of some his own recollections in his "Information", as he recalled his parents, an Alaskan mother and a Russian father, being visited by Herman at their home while Konstantin was yet a very young child; ${ }^{30}$ and his own reminiscences continued to include his own visits to the elder in the forest of Elovoi. Larionov also collected information from various people in the Kodiak area, Alutiiq-Russians and Alutiiqs, who were older than himself.

One among them will be mentioned in this chapter in the quotations selected from Larionov: Ignatii Alig'iaga who lived alongside the anchorite at New Valaam for many years, and remained there after Herman's repose. Alig'iaga was an "Aleut". As the predicate written by Larionov was unqualified, the word could signify an Alutiiq or an Aleut; however the lack of an adjective by a writer from Kodiak may signify that Alig'iaga was an Alutiiq, a "Kodiak Aleut"; because a foreigner could be designated as, for example, a "Fox Island Aleut" or a "Fox Islander"."3!

Larionov conveyed his manuscript to the bishop at Novo Arkhangel'sk, who dated it 21 May 1867, and subsequently forwarded it to Damascene. ${ }^{32}$ The same

\footnotetext{
${ }^{28}$ For conversions, see above, note 142 to Chapter 1.

${ }^{29}$ See Aleut and Creole Churchmen in Alaska: Nineteenth and Early Twentieth Centuries, Appendix in Oleksa, ed. (1987:381).

${ }^{30}$ Larionov, in Valaam, ed. (1894:177; 1978:106).

${ }^{31}$ For an explanation of the term "Aleut", see my lntroduction.

${ }^{32}$ Petr, bishop of Iakutsk, to hegumen Damascene, 9 Sept. 1867, in Valaam, ed. (1894:171; 1978:102). Petr had been bishop and vicar of the diocese at Novo Arkhangel'sk, as cited in notes 6,8 , and 33 to this chapter, but has been cited as "bishop of Iakutsk" in the present note. The change in his designation is due to the
} 
bishop confirmed the manu script's authorship, and the author's character, "worthy of trust". ${ }^{33}$ In that year, 1867, the starotsa would have been approximately forty-two years old. ${ }^{34}$

(iii) Grigorii Mikhailov Lazarev "Narrative of the Pilgrim Lazarev". Information about the author was provided in the narrative's introductory paragraph, dated in October 1864: it provided his full name (as given here); specified his social registration, as "townsman from Tsarskoe Selo"; and repeated the text's title more completely as follows: "The narrative of the pilgrim from Valaam Monastery [...] concerning the life of the monk Herman". Clearly associated with Valaam, Lazarev had evidently made an pilgrimage to the anchorite's hermitage, where he collected this information. Lazarev's main source, identified in the narrative's intro ductory paragraph, and cited throughout the narrative, was the anchorite's disciple Gerasim who had been raised under Herman's guidance, had remained alongside him through elder's repose, and had subsequently remained on the islet ${ }^{35}$ where Lazarev met him.

Independent and varied, these sources confirm each other as each of them attributed the same general kinds of qualities to the anchorite - associated with spririt(s), he accomplished the extraordinary: healing, foreseeing, and pacifying the

following factors. He arrived at Novo Arkhangel'sk in 1860 (see Pierce 1990:398) and remained until summer 1867. His letter cited in note 8 , and remark cited in notes 6 and 33 , were dated during this period. Subsequently transferred to Iakutsk, he sent the cover letter cited in the present note. At the time of his transfer, Russian-America was being sold to Washington, D.C. The U.S. flag raising ceremonies took place on 18 October 1867.

${ }^{33}$ See Petr, bishop and diocesan vicar at Novo Arkhangel'sk, personal note and signature, in Larionov, "Information", in Valaam, ed. (1894:184; 1978:110).

${ }^{34}$ Laroniov was about 12 years old in 1835, according to his "Information" in Valaam, ed. (1894:176-177; 1978:105).

35 "Narrative of the Pilgrim Lazarev", in Valaam, ed. (1894:123, 126-127; 1978:76, 78). 
forces of nature. Furthermore they relate some of the same specific events. These sources are, thus, mutually corroborative.

While they confirm each other regarding the kinds of qualities attributed to the anchorite, they are supported also, although to lesser degrees, by other sources collected about him and published by Valaam at the same time. Certain events related by lanovskii and Larionov, are related also by P. Kashevarov. ${ }^{36}$ An event described by the pilgrim Lazarev is made more accurate by Innokentii (Ivan) Veniaminov. ${ }^{37} \mathrm{~A}$ further source has, in effect, clarified an attribute mentioned briefly by Larionov. Michael Harold Naumoff provided the clarification during a personal conversation with me at Kodiak in March 1988, without reference to Larionov's own statement (that statement was not a topic of our conversation, nor yet a focus of my interest at that time). While relating virtually the same oral tradition about Herman that had been mentioned by Larionov, Naumoff provided a significant detail. He himself had derived from the village of Afognak (a village that will mentioned again in this chapter), and was living in the town of Kodiak. He was seventy-eight years old at the time of this conversation; and he was trilingual. The conversation was in his third language, English, and was fluent. His description will be quoted in context with Larionov's statement in my text.

\footnotetext{
${ }^{36}$ Compare each in Valaam, ed. $(1894: 142,174-175,185-186)$; also in ibid. (1978:87-88, 104, 111).

${ }^{37}$ Compare "Narrative of the Pilgrim Lazarev" with Letter, Innokentii (Veniaminov), archbishop of Kamchatka, to hegumen Damascene, 1 March 1867, in Valaam, ed. (1894:128, 169-170) also in ibid. (1978:79, 101). Damascene requested verification or criticism of the event related by Lazarev that had involved Veniaminov. The latter confirmed that near Kodiak during a sea crossing from Okhotsk to Novo Arkhangel'sk in 1840, he had, at a perilous time, sought aid in a brief prayer to Herman (Herman had reposed four years earlier); the contrary weather conditions quickly subsided; and the passage was completed safely. Veniaminov added that he went to Herman's gravesite to hold a memorial service during a subsequent visit to Kodiak. He corrected Lazarev's account at one point: that he had had visions: "I did not see any visions" (ibid.).
} 


\section{(3) Definitions: Vocabulary in the Sources.}

Certain terms might require clarification before they are read below, in the quotations from these sources. The word старец, synonymous with $\gamma \varepsilon \rho \omega v$ ("elder") is used for Herman in Ianovskii's letters and Larionov's narrative. In this context, it signifies age as well as spiritual stature. By the time of the events in the letters and narrative, the monastic was already well advanced in age. His association with Ianovksii had begun in November 1819. ${ }^{38}$ The following spring, of 1820 , would be the earliest possible date for the descriptions provided by Lazarev; because, soon after Easter of that year, the first of the women "disciples", to whom Lazarev refers as numbering twelve in all, ${ }^{39}$ Sophia Vlasova, had herself just settled in proximity to the hermitage..$^{40}$ In $1819 / 20$, Herman would have been in his early fifties: his age had been specified in June 1805 as forty-eight." Ianovskii was only thirty years old in November 1819; and Vlasova was "no more than twenty" years old at Easter $1820 .{ }^{42}$ Another person who is significant in the Lazarev's narrative, Gerasim (introduced among the sources above) had been raised as an orphan at New Valaam. ${ }^{43}$ These signficant persons were at least a generation younger than Herman: he was considerably elder in age in relation to them.

Considerable age is only a single factor. He was elder in spiritual stature as well. He had had approximately forty-six years of monastic experience by time

\footnotetext{
${ }^{38}$ Ianovskii to Damascene, 22 Nov. 1865, in Valaam, ed. (1894:134; 1978:82).

${ }^{39}$ Lazarev, in Valaam, ed. (1894:123; 1978:76).

${ }^{40}$ Herman to Ianovskii, 20 June 1820, in Valaam, ed. (1894:147-148; 1978:91).

"Gideon to Amvrosii, 2 June 1805, in Gideon (1989:80).

${ }^{42}$ Herman to lanovskii, 20 June 1820, in Valaam, ed. (1894:147; 1978:91).

${ }^{43}$ Lazarev, in Valaam, ed. (1894:123; 1978:76).
} 
Ianovskii met him, as calculated as follows: if Herman had embarked on the monastic life at about the age of sixteen," then by 1805 when he was forty-eight years old, ${ }^{45}$ Herman would have had approximately thirty-two years of monastic experience, and then the greater number when lanovskii met him in 1819. Those many years of prior experience had included his formation as as skete dweller and as an anchorite at Valaam; and when lanovskii met him, the elder was "living a strictly ascetic life" in the forest of Elovoi ${ }^{46}$ Indeed he was living within a tradition recognized favourably by Valaam (as established above). He was thus an "elder" in spiritual formation and stature as well as age.

Another word for Herman in the sources is "apa", an Alutiiq word, also spelled apaa. Larionov wrote ana in his Russian text at Kodiak in the early 1860s, and defined it parenthetically as he initially applied it with regard to the elder in the forest of Elovoi: "Apa (a term used by all of us inhabitants of Kodiak, and which means in translation 'uncle' or 'father'). ${ }^{147}$ It is applied in the Kodiak area with

${ }^{44}$ lanovksii to Damascene, 22 Nov. 1865, in Valaam, ed. (1894:131; 1978:80); also see above, "Biographical Summary" Because lanovksii is a secondary source in this regard, I shall qualify the starting point, allowing it as an approximation. It is an acceptable one: the age is not unusual. Even if a margin is allowed for an extreme error, the number of years of experience would remain considerable nonetheless.

${ }^{45}$ According to the primary source, Gideon, cited above: see note 41 to this chapter.

${ }^{46}$ Ianovskii in Valaam, ed. $(1894: 133 ; 1978: 81)$, cited and quoted in note 22 to this chapter, above, where Herman's conformity to the monastic rule is established.

${ }^{47}$ Larionov, in Valaam, ed. (1894:177; 1978:105). 
regard to Herman as "grandfather" to this day;" for example, Naumoff referred to him as "apaa" in converation in $1988 .{ }^{49}$

This word corresponds in sound and in meaning with the word abba, used in patristic literature for the desert fathers, particularly those of Egypt, the Gaza, and Palestine. $^{50}$ It may be tempting to assume that the word apaa for Herman derived from abba through this monastic tradition; however, apa is the word for "grandfather" in the Yup'ik language also." While perhaps coincidental, the correspondence is significant. . $^{52}$

Larionov and Ianovskii refer in their letters to отец Германь ("Father Herman"). Ianovskii never, and Larionov only rarely, refer to him merely as Германъ ("Herman"). As a formal appellation, "father" can lack the deeper interpersonal meanings of "abba" and the spiritual depth of "elder". It is normally articulated to refer to, and to address, presbyters respectfully; and it is sometimes transferred to deacons and unordained monastics when a formal mode of reference, or of address,

${ }^{48} \mathrm{~J}$. Leer (personal communication, Fairbanks, March 1988). Leer, who is compling a Alutiiq dictionary at the Alaska Native Language Center, University of Alaska at Fairbanks, identifed the word's use for "Apaa Herman" today in the sense of "grandfather"; specified apaa as the correct orthography.

49 Personal communication, Kodiak, March 1988.

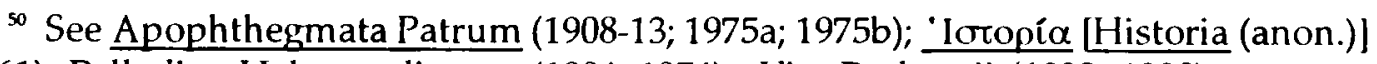
(1961); Palladius Helenopolitanus (1904; 1974); Vita Pachomii (1932; 1980).

${ }^{51}$ Jacobson (1984:75). The Alutiiq and Yup'ik languages are related; and I have heard Yupiit state that these languages can be mutually intelligible, in contrast to the Inupiaq (or Inuit) language.

${ }^{52}$ Coincidence does not preclude an inter-relationship: Russians in Kodiak who also visited Herman might have been referring to him with this word - particularly those men from the White Sea regions where many monasteries had flourished. For Russian visitors to New Valaam, see lanovskii to Damascene, 3 Sept. 1866, in Valaam, ed. (1894:153; 1978:93); also see Lazarev, in ibid. (1894:124; 1978:76). For the derivations of Russians in Russian-America, see Fedorova (1971:158-159; 1973:172-173), as cited above in note 175 to Chapter 1. For monasteries in the White Sea region, Karelia and Komi-land, see Murav'ev (1855); also see my text in the present chapter at notes 77 to 82 , below. 
is needed for them. In this context, specifically regarding "Father Herman", the formal term of respect would assimilate the other meanings of "apaa" and "elder". The word "disciple" is used in Lazarev's narrative, and also in some of lanovskii's letters, for some people who lived in proximity to the elder and learned from him. ${ }^{53}$ The translation of this term is problematic: the word ученик in the masculine gender, ученица in the feminine gender, can be translated as "pupil" as well as "disciple", and probably harkens either to an age when or to cultures where the two (disciple and pupil) are not separate concepts. ${ }^{54}$ The synonym $\mu \alpha \theta \eta \eta^{\prime} s_{\text {, }}$ $\mu \alpha \theta \eta \tilde{\tau} \rho \iota \alpha$, can be translated in either way as well: it is the word for "disciple" in Biblical and patristic texts, and it is a word for "student" in modern contexts. This is the very word for Christ's disciples in the Gospels, and is not reserved exclusively for his own: it is used also for John the Baptist's disciples (e.g., Matt. 9:14), and continues to be used through patristic literature, particularly in monastic literature, to reflect the relationship of a person who learns a way of life from someone of greater spiritual stature. In patristic literature, an elder and his disciple(s) live together, as few men will live with an elder in a scete as Herman had done at Valaam; or the elder and his disciple(s) live in proximity to each other, as the women disciples at New Valaam lived together themselves while appropriately a distance apart from the elder's own hermitage..$^{55}$

${ }^{53}$ Also see The Oxford Russian-English Dictionary 2nd edition (by Marcus Wheeler, 1984), translating ученик as: pupil, apprentice, and disciple. Also see The Oxford English-Russian Dictionary (edited by P. S. Falla, 1984), translating disciple as ученик.

${ }^{54}$ Notice the unambiguous word воспитанник for "school pupil" used by Larionov in Valaam, ed. $(1894: 172,183)$ and, significantly, by Rezanov in Tikhmenev, ed. (1863:216); for Rezanov in this context see note 62, below.

${ }^{55}$ P. Kashevarov, "Father Herman", 7 Sept. 1866, in Valaam, ed. (1894:185; 1978:110). 
In 19th century Russian-American sources, the context itself should indicate the proper translation, whether "disciple" or "pupil". For example when the diocesan vicar, a secondary source, described Herman as a schoolteacher, then the translation probably should be "pupils". 56 But when Lazarev described the elder from Valaam, then the translation should be the elder's "disciples". The latter is reinforced by the very genre of the "Narrative of the Pilgrim Lazarev": the work is equivalent in tone as well as content to a certain type of patristic literature, namely the sayings of the

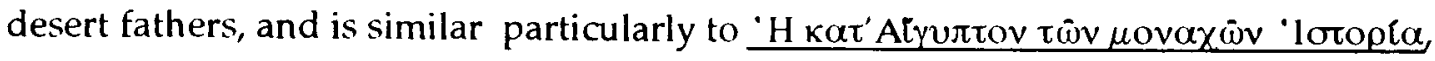
a narrative by an anonymous earlier pilgrim, one who visited "the elders and their disciples" in the Egyptian Thebaid in the fourth century." As the genre is the same, the translation should be the same.

These words - "elder", "apaa", and "disciples" - have been explained from their own contexts within the sources, before the words are read in the quotations that follow.

${ }^{5}$ Petr to Damascene, 12 May 1866, in Valaam, ed. (1894:158; 1978:95). Compare with Larionov in ibid. (1894:172; 1978:103), a primary source reporting in retrospect about New Valaam, specifying at one point in his recollections the year 1835, that was during Herman's later years, and referring to Sophia Vlasova supervising pupils. Contrast Larionov with lanovskii, another primary source but from an earlier period: the former naval officer and chief-manager did not describe Herman as a school teacher in any letter regarding that earlier period. Nor did lanovskii depict a schoolhouse in his drawing of the island of Elovoi (VM/RR/LCM, second item including a list of the buildings depicted). See the published drawing in Valaam (1978), second plate but without the list identifying the buildings. Had Herman in the later years of his life actually arranged a school as a number of youngsters were then living on Elovoi due probably to the settlement of the parents of some of these children there (as cited above), and due also to the refuge of orphans there after an epidemic which had struck during Ianovskii's brief posting (see lanovskii in ibid. 1894:136-137; 1978:83-84)? The possibility is indicated by Larionov. Or had Petr presumed a school?

"'Icropí $\alpha$ [Historia (anon.)] (1961). See Ward (1980:4): "Despite the doubts of some modern scholars, I am confident that the Historia Monachorum describes a real journey. Eighty years ago Dom Cuthbert Butler [1904] came to the same conclusion". For the authorship (anon.) see note 85 to this chapter, below. 


\section{(4) Selected Descriptions of the Attributes.}

The sources Ianovksii, Larionov, and Lazarev attribute to the elder from Valaam in the forest of Elovoi the same kinds of qualities that are visible in my study through the social perspective in the preceding chapter, as follows:

(i) associated with spirit(s);

(ii) healing;

(iii) foreseeing future events; and

(iv) pacifying the forces of nature.

I have organized the sequence here to corresponded with that in Chapter 5, allowing a difference in wording for the latter attribute (it was designated as "food location" earlier) due to a widening of the characteristic in the present context, to be explained below.

(i) Associated with spirit(s). Among other possibilities, two quotations have been selected from these sources. The first quotation deriving from lanovskii requires no explanation, as it associates the elder from Valaam directly with angels in the forest of Elovoi: ${ }^{58}$

Once I asked him: "Father Herman, how can you live on this island, alone in the forest? Do you not get lonely?"

He replied, "No, I am not alone. God is there, just as He is everywhere, and the Holy Angels are there also. How can I be lonely? With whom is it better and more pleasant to speak -- people or angels? Angels, of course.

${ }^{58}$ Ianovskii to Damascene, 22 Nov. 1865, in Valaam, ed. (1978:86). See ibid. (1894:140). 
In the next quotation, the elder who conversed with angels, is seen dispelling demons. The quotation has been selected from Lazarev who relates a description provided to him by Gerasim: ${ }^{59}$

The Elder had busied himself in his cell with handiwork when his disciple Gerasim suddenly entered without offering the customary prayer. As he came into the cell he asked for the Elder's blessing; the latter did not answer and the disciple repeated his request several times and still the Elder said nothing. The disciple stood around for several hours and finally decided to leave the cell. When he came the following day he offered the normal prayer and the Elder answered, "Amen".

The disciple asked to be blessed; the Elder did so and then sat down again to his task. Then Gerasim asked him, "Father, why did you not bless me yesterday nor answer when I asked?"

To this the elder replied, "When I first arrived on this island the devils came to my cell many times, sometimes in human form, for things they wanted; sometimes they came disguised as animals and caused me much distress and that is why I would not admit anyone unless they offered a prayer.

(ii) Healing. Associated with angelic spirits, the elder healed. To substantiate this point, the following quotation has been selected from Lazarev, and is again a description provided to him by Gerasim. The description itself is congruent with iconography and with liturgics. It begins with the elder celebrating the Epiphany with an angel. The festal icon likewise depicts angels on the banks of the Jordan attending the Epiphany (this icon was introduced in Chapter 3). Rubrics for the festal service recommend that it take place at naturally running water; and indeed it will take place at the sea or at a river even in northern climates. At a point in the liturgical celebration, the water is blessed by a clergyman who, vested and chanting, will plunge a cross into and out of the the water, if necessary through an hole in the

\footnotetext{
${ }^{59}$ Lazarev, in Valaam, ed. (1978:77). See ibid. (1894:125).
} 
ice (this symbolism was indicated in the conclusions to Chapter 3). But Herman was unordained: he was not a priest, not even a deacon. And he was alone in the description. He could not bless the water himself. Who, then, would bless it? The angel did. This blessed water became a healing agent, as the elder would afterwards collect it and distribute it to the infirm. Gerasim's description, quoted from the pilgrim Lazarev, follows:00

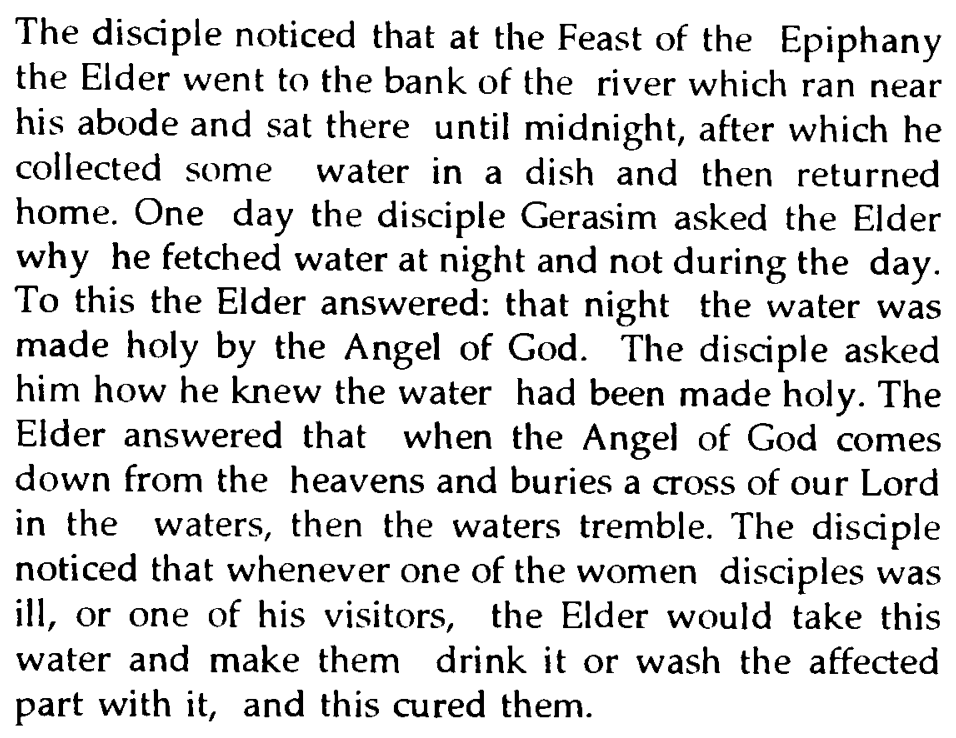

The angel participating with the elder, blessing the water for him, thus enabled him to heal afterwards with this sanctified water.

(iii) Foreseeing. Before this attribute is described from the sources, the term itself should be explained. "Foresight" can be distinguished from "prophecy", without positing them as mutually exclusive categories: the latter signifying words spoken about God within the manifestly divine presence; the former signifying the gift of foreknowledge. "Foresight" has been chosen as the term here, instead of "foreknowledge", for an emphasis upon the physical senses, or upon the participaton of the whole human person as a psychosomatic unity. And the adjective "prophetic"

${ }^{60}$ Ibid. (1978:76). See ibid. (1894:123-124). 
will be added to emphasize the characteristics of composure and cognizance that were introduced in Chapter 4.

The elder was particularly known for the gift of prophetic foresight. Thirty years subsequent to Herman's repose, the bishop and diocesan vicar at Novo Arkhangel'sk stated: "Many people have told me that he had from God the gift of second sight - telling the future." ${ }^{161}$ The attribute was yet being related thirty years later by "many people" including Ignatii Alig'iaga who had lived close to the elder at New Valaam, in the forest of Elovoi, and who provided Konstantin Larionov with the following description: ${ }^{.2}$

According to Ignatii who lives on [Elovoi] to this day, Father Herman once told him that all the people living on [Elovoi] would die and that he, Ignatii, would be left alone, and would grow old and poor, and that the people would remember Father Herman and thirty years after his death Ignatii would still be alive. He is amazed at this saying: "How could a man like us know something like this so long in advance; ...

An interruption of the quotation may bring special attention to this description's conclusion, as it introduces yet another quality, clairvoyance (as distinct from foreknowledge and from prophecy), and indicates this quality's part in the elder's ability to advise, or counsel: ${ }^{63}$

... he must have been a very special man, because he could read our thoughts, which we involuntarily revealed to him, and he would use these thoughts to teach us things.

${ }^{61}$ Petr to Damascene, 12 May 1866, in Valaam, ed. (1978:96). See ibid. (1894:158159). Petr is primary source in this regard.

${ }^{62}$ Larionov, in Valaam, ed. (1978:106-107). See ibid. (1894:178-179).

${ }^{63} \underline{\text { lbid. }}$ (1978:107). See ibid. (1894:179). 
(iv) Pacifying the forces of nature. Many descriptions exist in the sources regarding the elder pacifying the forces of nature. The most extraordinary of them have been excluded, so that they do not distract from the argument, as they surpass the descriptions from the ethnographies cited in the previous chapter: for example, when this elder is described as stopping a flood tide with an icon. ${ }^{6}$ The descriptions that have been selected are some of those regarding his interactions with wild animals including, in the last instance, his summoning of fish to become food.

Animals guises were mentioned earlier, in the quotation about demons which "sometimes ... came disguised as animals and caused much distress"; would discern the demonic behind the guise, and dispell it. His relationship with real animals was described very differently, however, as seen in the first of these descriptions; it has been selected from a letter by lanovksii: ${ }^{60}$

Others have told me how in winter they had seen bears near his dwelling, how he would feed them and then they would wander off again.

Ianovksii's amazement at Herman's feeding the bears was increased by Herman's own food shortage: he was not receiving adequate supplies from the Russian-American Company, and sometimes no supplies from them at all. Yet he was sharing his scant food with the bears during winter, the season of hunger. ${ }^{67}$

${ }^{64}$ Ibid. (1894:172-173; 1978:102-103). This icon is described as then being kept by Sophia Vlasova, the leader among the women disciples, against similar dangers (ibid.).

${ }^{65}$ Lazarev, in Valaam, ed. (1894:125; 1978:77).

${ }^{66}$ Ianovskii to Damascene, 22 Nov. 1865, in Valaam, ed. (1978:86). See ibid. (1894:140).

${ }^{67} \underline{\text { Ibid. }}$. Ianovskii is a credible primary source for the information about the food shortage: he was the company's chief manager at the time of the events he recounted. "It should be noted here", he wrote, "that the employees of the American Company [sic] issue from the stores grain and other supplies for the up-keep of the monks, but 
The next quotation is similar to the preceding one. It has been selected from Konstantin Larionov who refers again to Ignatii Alig'iaga: ${ }^{: 8}$

[The elder would] feed the birds that were constantly around his cell, and what was even more remarkable, the mink which lived under his cell. It is strange that it is normally impossible to approach this little animal when it has pups, yet Father Herman would feed them by hand. Was what we saw not miraculous, Ignatii would ask? After Herman's death the birds and animals left.

This description proceeded immediately from another regarding the gathering of the very food that the elder would feed to the birds and to the mink. It was fish, an essential stable for Herman himself. ${ }^{69}$ Regarding the collection of this food, Larionov began by describing a simple, effective fish trap that the elder would construct in springtime, where a stream swelled at the shore near the hermitage. But the subsequent process of food gathering and preparation was related by Larionov in a single sentence without a clear distinction between acts and agents. The series of events collapsed into a string of phrases as follows: ${ }^{70}$

sometimes there is no grain."

Further research could probably substantiate that the latter was more often the case: that they were rarely supplied. The monastics gathered their own food, an activity for which their own northern backgrounds - Herman's years as a scete-dweller and anchorite in the Karelian forest at Lake Ladoga, for instance would certainly have prepared them. See: the men foraging the beaches at Kodiak, according to Archimandrite Ioasaph to G. I. Shelikhov, 18 May 1795, RAC/ludin/LCM, also see ibid. in Tikhmenev (1861:103; 1979:80); for a further example see: Herman gathering fish at Elovoi, according to Ianovskii, as cited in this note. Also see the Company's pretenses about support that was itself not forthcoming, as explained in Chapter 1 at note 107, above. Herman supplemented his own food gathering with gardening (see especially Larinov, in Valaam, ed. 1894:183; 1978:109-110); and he wore a threadbare habit, according to Ianovskii to Damascene, 22 Nov. 1865, in ibid. $(1894: 136,142 ; 1978: 83,87)$.

${ }^{68}$ Larionov in Valaam, ed. (1978:109). See ibid. (1894:182).

${ }^{69}$ See Ianovskii to Damascene, 22 Nov. 1865, in Valaam, ed. (1894:140; 1978:86).

${ }^{70}$ Larionov in Valaam, ed. (1978:109). See ibid. (1894:182). 
Then the Elder would adopt the following procedure, as related by lgnatii: Apa would order the fish to be caught and stunned and then gutted and cut into two strips - of these he would take a very small portion for himself and order the remainder to be placed on a board and cut into strips to feed the birds which were constantly around his cell ... [etc.].

Who had been ordered that the fish be caught? The description is unclear. The trap was already in place. The fish would themselves swim into it. Larionov could have been referring to the people who would collect the fish from the trap; or he might have been referring to the attribute described by Naumoff who said that apaa summoned the fish: "Apaa Herman had dug a trench from the river, and he would call the fish to come up it, so he could catch them."71

Summary Statement. In these descriptions, the elder from Valaam, apaa in the forest of Elovoi, was associated with spirit(s) as he healed, foresaw future events, and pacified the forces of nature. The latter included food gathering. These attributes are of the same general kinds as those seen through the social perspective in the preceeding chapter.

\section{(5) A Line of Tradition.}

These attributes described for apaa in the forest can be identified within a "line of tradition" that extends from him securely through Valaam Monastery to the abbas in the desert, that is to say the desert fathers. It can be traced yet further, into the Gospels and Acts, and I shall indicate this depth as well. The signifance for the present study will be explained in conclusion when this "line of tradition" is placed in the context of Kodiak, and more generally Alaskan, religious history.

${ }^{71}$ Michael Harold Naumoff, personal communication, Kodiak, March 1988. Naumoff also said of aapa "He's helped me many times." 
The "line" from apaa through Valaam to the abbas can be secured by the following four supportive points. Firstly, the sources about him at "New Valaam" were attached firmly to the Monastery of Valaam, as they were collected and published by the monastery (as explained in earlier in this chapter). He was himself recognized and respected by this monastery. Valaam kept contact with him during the forty-two years that he lived in the Kodiak area, and afterwards honoured him. Hegumen Nazarii who had observed Herman's spiritual development, and who had attached him to the mission, remained in contact with him: Herman wrote to Nazarii from Kodiak. ${ }^{22}$ Nazarii's successor, hegumen Ionafan, corresponded with Herman at "New Valaam". ${ }^{3}$ lonafan's successor, hegumen Damascene, collected information about him from various credible sources in the 1860s; and when the monastery published this primary source material for the mission's centennial in an extensive appendix specifically devoted to Herman, Valaam included his own letters. ${ }^{74}$ The publication, and Damascene's collection of these sources, reflect Valaam's concern that the monastic missionary be understood with accuracy. He was thus known continuously to Valaam. In the centennial publication, the Monastery of Valaam expressed their view of him as one who had "followed the true path of introspection in isolation", ${ }^{5}$ in other words the proper way of the anchoretic life. They described

${ }^{72}$ Letter, Monastic Herman to hegumen Nazarii, 19 May 1795, HRS/RR/LCM 643:53-58.

${ }^{3}$ Herman to Ionafan, 13 Dec. 1819 in Valaam, ed. (1894:190-194; 1978:113-115). For Ionafan to Herman, see ibid. $(1894: 189 ; 1978: 113)$.

${ }^{74}$ Valaam, ed. (1894); see ibid. (1978). The publication has been mentioned in note 12 to this chapter, above.

${ }^{75}$ Valaam $(1894 a: 51 ; 1978: 31-32)$. For the author see note 9 to this chapter, above. 
him as an "enlightened and exalted personality" who had "reached a high level of spiritual experience".76

As this monastery honoured him at the centennial, subsequent to the continuous recognition of him by the hegumeni throughout the 19th century, it can be said of him that he embodied a tradition recognized by Valaam, and lived this acknowledged tradition in the forest of Elovoi. ${ }^{7}$

Secondly, Valaam Monastery itself existed in a region that had come to be known by a certain affinity with the Egyptian Thebaid as the "Russian Thebaid". The monastery had derived from an anchoretic settlement, perhaps as early as the tenth century, and had been established on the islet in Lake Ladoga certainly before the mid-twelfth century. ${ }^{78}$ By the sixteenth century, six subsidiary monasteries plus many scetes and hermitages were attached to Valaam, from Lake Ladoga to the

${ }^{76}$ Ibid. (1894a:50; 1978:31-32). Also see ibid.: "To us the memory of this man is sacred, and everything to do with him is dear to us" (quoted in my text at note 9 in this chapter, above).

7 Also see above, note 141 to Chapter 1; and note 9 to the present chapter. As factors need to be articulated to provide standards for objective statements about him, the factors provided here - that he was recognized by the hegumeni of Valaam throughout the 19th century, and was honoured by the monastery at the centennial - establish the following statement: he embodied a tradition from Valaam, and lived within this tradition in the Kodiak area as he was acknowledged and respected by the hegumeni of Valaam. This is an objective statement that distinguishes him.

${ }^{78}$ According to Murav'ev (1842:18), the Monastery of Valaam derived during the reign of Olga of Kiev, early to middle 10th century, when a Greek Orthodox anchorite named Sergius settled at the lake and was joined by a man from the region, who became his disciple and eventually became a monastic with name Германь (to be transliterated "Herman" to be consistent with the anchorite at "New Valaam" who was probably a namesake). The mid-10th century is the date given also by Valaam Monastery as the earliest possible date of this anchoretic settlement, or hermitage, but the date is not accepted as scholarly (Valaam 1983:26-27). Written records derive from the mid-12th century, by which time the anchorites Sergius and Herman were already being venerated as saints, icons had been made of them, and their relics were enshrined (ibid., p. 28). The veneration and enshrinement by the time of the written records, indicates an earlier founding of the hermitage. 
White Sea coast. ${ }^{\text {9 }}$ And this was only one among many monastic systems through the north by the later date, extending through Karelia, northernmost Great Russia, and Komi-land to the White Sea and Pechora Sea coasts above the Arctic circle. ${ }^{80}$ Earlier, for example, during the fourteenth century, as many communities were spawned throughout these far northern regions from the Sviato- Troitskaia Sergievskaia Lavra, itself located near Moscow; and more were spawned from just this single network in the early fifteenth century. ${ }^{81}$ (Herman, it may be recalled, embarked upon the monastic life in a metochion of the Sviato-Troitskaia Sergievskaia Lavra in the mid-eighteenth century.)

So numerous were the hermitages, scetes, metochia, and monasteries throughout the taiga and tundra that between the fourteenth and sixteenth centuries these regions became known as the "Russian Thebaid" by analogy to the Egyptian Thebaid that had flourished with similar monastic activity a millenium prior,

\footnotetext{
${ }^{79}$ Valaam (1983:87).
}

${ }^{80}$ Notice that these are the very regions from where many of the hunters who came to Alaska during the 18th century had themselves derived: see the text of Chapter 1 at note 27, and especially at notes 174 and 175. This fact has been noted in the present chapter, above; and it will be mentioned in this chapter's Epilogue. For a study of the many monasteries in these regions in the 14th to the 16th centuries, see Murav'ev (1855). For a list of these monasteries, see ibid. (folding table at the back, page unnumbered). But the list specifies only the main monasteries. Each had its subsidiary establishments, or network.

${ }^{81}$ According to Bolshakoff (1977:15), fifty monasteries were founded from this monastery alone: from these fifty, another forty were established in the next generation; and in the course of a century and a half, a total of 180 new establishments had derived from the original one. But Bolshakoff is at best a tertiary source, and his calculations are unreferenced. His interpretations could not be accepted earlier in this study where research had recourse to the primary sources (see Chapter 1 at note 124, above). His calculations have been presented here to indicate the extensive activity that was associated with a single one of these monasteries, in light of the information provided Murav' ev in the preceding note. It may be recalled from the "Biographical Summary", above, that Herman initially entered a metochion of this monastery. By his generation, the numbers had been reduced, however, due to the historical factors that will be mentioned in my Epilogue. 
particularly between the fourth and sixth centuries. ${ }^{82}$ The analogy was expressed in retrospect by the ecclesiastical historian, A. N. Murav'ev, ${ }^{83}$ one he may well have assumed from monastic traditions in those regions. He expressed it as an ecclesiastical historian established within the Russian church, contemporary with the later phase of Russian-America. His expression thus provides the link between Valaam, this monastery's roots in the "Russian Thebaid", and the Egyptian Thebaid.

The third point that can secure the line is the very genre of one of the main sources, "The Narrative of the Pilgrim Lazarev", that is akin both in tone and in content to certain patristic literature regarding the desert fathers. For example in ${ }^{\prime} \mathrm{H}$

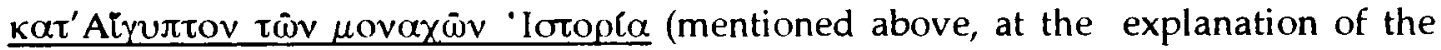
term "disciple"). The anonymous writer made a pilgrimage to elders' hermitages in the Egyptian desert in the fourth century, and wrote about their "wonders", $\theta \alpha u ̛$ $\mu \alpha \tau \alpha$, and their sayings, mostly from their disciples. ${ }^{84}$ Likewise, Lazarev in the nineteenth century made a pilgrimage to the hermitage in the forest, and wrote about this "elder's" wonders and sayings from accounts from "disciples".

Finally, the line is secured by the kinds of wonders described alike about this apaa in the forest and about the abbas in the desert. Four "categories of wonders"

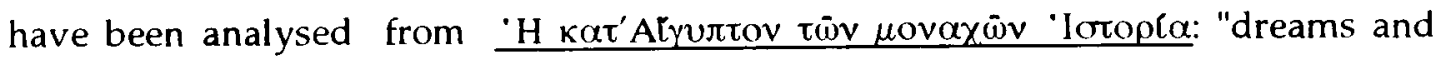
visions", "healing", "clairvoyance", and "nature miracles". 85 These "categories" are fundamentally the same as the kinds of attributes that have been quoted in this

\footnotetext{
${ }^{82}$ See especially Chitty (1964).
}

${ }^{83}$ Murav'ev (1855).

${ }_{84}$ :Ioropía [Historia (anon.)] (1961). For the historicity of the pilgrimage, or journey, see note 57 to this chapter, above. For the authorship and dating, see note 86 , below.

${ }^{85}$ Ward (1980:40). 
chapter for apaa Herman. The wording differs in some while content is fundamentally the same throughout: the "dreams and visions" involve associations with spirit(s); the "clairvoyance" includes many instances of prophetic foresight, as well as instances of clairvoyance itself; and the "nature miracles" are instances of natugre being pacified, indeed these instances are virtually identical except that a desert lion or hyena occurs in the desert, a bear or mink in the forest. It should be emphasized that Herman's affinity has been established upon three independent sources about him.

Descriptions from the Desert. To indicate the affinity more vividly, a few descriptions of these "wonders" from the desert will be quoted from the $\underline{\tau \omega} v$

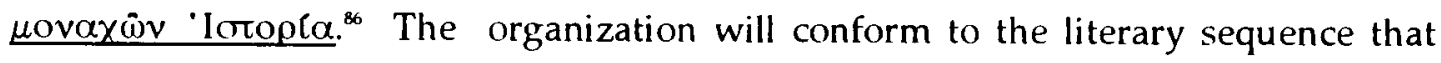
guided the earlier descriptions: (i) associated with spirit(s); (ii) healing; (iii) foreseeing; and (iv) pacifying the forces of nature.

(i) Associated with spirit(s):

Abba Anouf said to them, ... "an angel has fed me the heavenly food everyday ... an angel has been with me always, showing me the dynamics of the cosmos; the light of my understanding was not extinguished. Every request of mine to God, I received straightaway." ${ }^{87}$

${ }^{86}$. Icropí $\alpha$ Historia (anon.)] has been chosen for the following descriptions because its has already been cited in this chapter, particularly for its affinity with the "Narrative of the Pilgrim Lazarev". The author of the 'I ${ }_{0}$ opi $\alpha$ is "anonymous" according to Ward (1980:6-7) who has accepted the research by Butler (see note 57,

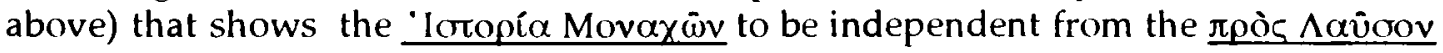
'Ioropi $\alpha$ into which it had been incorporated. Also, Festugière, whose edition will be cited (below), has presented it as an anonymous work independent from Palladius's own. For the relationship of the Greek text with the Latin rendition authored by Rufinus, and for the dating of both, see Ward (1980:7-9).

87 Ioropía xi.5-6 (1961:91). 
[Dohn of Lycopolis], like a father counseling his children, ... explaining to them many ... things about the exercise [of asceticism], edified them greatly. ... "Firstly, exercise [yourselves in] humility ... so that you not be led astray by demons raising up images before you. But if anyone should come to you, whether a brother, or a friend, or a sister, or a wife, or a father, or a teacher, or a mother, or a child, or a servant, stretch out your hands in prayer at once; and should it be a phantasm it will flee from you. ${ }^{88}$

(ii) Healing:

Blessed John [Lycopolis] did not accomplish cures himself; instead he healed more often by giving oil to the ill. ... He sent [a certain woman, for example] some oil; and as she said, having anointed her eyes herself three times, she regained her sight after the third day, and gave thanks manifestly to God. ${ }^{89}$

(iii) Foreseeing:

[Abba Anouf, "the great confessor" said to his spiritual sons, themselves already advanced in such matters]: "Blessed be God, who has made your conditions and conduct known to me" Telling of the deeds or achievements of each of them, he then described even his own [to them ... and said,] "God has hidden nothing that he has not made known to me. Light has never left my eyes." ${ }^{110}$

(iv) Pacifying the forces of nature:

Another time, they say, Macarius was praying in the cave in which he dwelled in the desert. There happened to be a cave of a hyena nearby. Once while he was at prayer, it suddenly imposed, and began licking his feet; then taking him gently by the edge [of his cassock] it drew him towards her own cave. He

${ }^{88}$ Ibid. i.56, i.59-60 (1961:31, 32-33).

${ }^{89}$ Ibid. i.12 (1961:12-13).

${ }^{90}$ Ibid. xi.5-6 (1961:91). 
followed her saying, "What does this beast want?" It led him as far as her own cave, went in, and brought out to him her own cubs, born blind. Having prayed for them, he gave them back to the hyena with their sight healed. And as a gift, in thanksgiving, she brought to him a large skin of a great ram, and laid it at his feet. Smiling at her, as she was sensible and sensitive, he took the gift, and spread it beneath himself. This skin is preserved by someone yet today."

It is hoped that these few selected descriptions will suffice to establish the affinity, ${ }^{92}$ thus to indicate the "line of tradition" from apaa in the forest of Elovoi to the abbas in desert of the Thebaid.

This "line" can be traced yet further, into the very Gospels and Acts themselves, as I shall do briefly to indicate the depth of this tradition, prior to my placing it in context in the Kodiak area.

(i) Associated with spirit(s):

And the angel answering said unto him [Zacharias, father of John the Baptist] I am Gabriel, that stand in the presence of God; and am sent to shew thee these glad tidings. (Luke 1:19)

Then was Jesus led up of the Spirit into the wilderness to be tempted of the devil. (Matt. 4:1)

And he [Christ] was there in the wilder ness forty days, tempted of Satan; and was with the wild beasts; and the angels came and ministered unto him. (Mark 1:13)

(ii) Healing:

For an angel went down at a certain season into the pool [of Bethesda], and troubled the water: whosoever then first after the troubl ing of the water stepped in

${ }^{91}$ Ibid. xxi.15 (1961:127).

${ }^{92}$ Also see Apophthegmata Patrum (1908-13; 1975a; 1975b); Palladius Helenopolitanus (1902; 1974); Vita Pachomii (1932; 1980). 
was made whole of whatsoever disease he had. (John $4: 4)$

When he [Christ] had thus spoken, he spat on the ground and made clay the spittle, and he anointed the eyes of the blind man with the clay, and said unto him, "Go, wash in the pool of Siloam" (which is by interpretation, Sent). He went his way therefore, and washed, and came seeing. (John 9:6-7)

\section{(iii) Foreseeing:}

And it shall come to pass in the last days, saith God, I will pour out of my Spirit upon all flesh: and your sons and your daughters shall prophesy, and your young men shall see visions, and your old men shall dream dreams. (Acts 2:17; cf. Joel 2:28-32)

(iv) Pacifying the forces of nature:

And he [Christ] said unto them [His disciples], "Cast the net on the right side of the ship, and ye shall find." They cast therefore, and now they were not able to draw it for the multitude of the fishes. (John 21:6)

\section{(6) Conclusions.}

A "line of tradition" becomes evident that extended from apaa in the forest to the abbas of the desert: in other words, from this anchorite through the Monastery of Valaam in the "Russian Thebaid" into the Egyptian Thebaid. Effort has been taken in this study to secure him objectively within this tradition, ${ }^{93}$ a tradition that can be referred to as patristic.

When this patristic tradition is likened to a vertical line, and when the indigenous tradition in the Kodiak area is likened to a horizontal line, then the

${ }^{93}$ The reason for this effort has been given in note 9 to the present chapter, and also in note 141 to Chapter 1 . 
vertical can be seen meeting the horizontal in the forest of Elovoi. This meeting became evident when this "very holy man" met Kangatyuq. ${ }^{\text {A }}$ It was not necessarily their first meeting, but was itself the only one in the account, and indeed a key point that marked a transformation. From this point, according to the Alutiiq account, Kangatyuq became a healer; and he has comprised one of the primary examples of transformation as seen through the social perspective upon "shamans" in southern Alaska. The continuous horizontal line, therefore, can be said to have been transformed by the vertical in this instance.

This simile, of the meeting of these lines, can be extended to the other, more extensive example of transformation: the Aleut prophet whose vocation was inaugurated at baptism by the monastic Makarii, also from the "Thebaid". As the lines met in both instances, the horizontal was transformed at the intersection. The depth of the vertical has been indicated in the present chapter; the breadth of the horizontal was indicated through the complementary perspectives in the preceding chapter.

The simile of the intersecting lines may highlight the meeting among spiritually gifted people in the transition from shamanism to Russian Orthodoxy in Alaska, a coming together of spiritually gifted indigenous people with spiritually gifted allogenous people: ${ }^{95}$ Kangatyuq, the Chugach healer who became the Alutiiq healer, met the elder of Valaam; the Akun Islander, who became an Aleut prophet, met the hieromonk also, from the "Thebaid". Makarii received attention in the first

93 Birket-Smith (1953:130). Introduced in the preceding chapter, this account is being incorporated into the present context.

${ }^{95}$ See my text in Chapter 1 at note 167: "Once the [intrinsic processes] are highlighted, then scholarly interpretations should begin to emphasize the meeting of, and synergy between, spiritually gifted indigenous people ... and spiritually gifted allogenous people. Among the latter was, most notably, the forest-dwelling monastic of Valaam, monakh Herman." 
chapter. Greater attention has been focused upon Herman, because he remained longer than any other missionary, and furthermore because sources exist for the attribution to him of the same general kinds of qualities that are visible along both the vertical line and (from the social perspective) the horizontal line.

Indeed he appeared at the very intersection of the vertical with the horizontal, as these same general kinds of qualities were attributed to him in the forest of Elovoi: associated with spirits, he healed, foresaw, and pacified the forces of nature. And within the line patristic tradition, he is holy: he spoke only to angels, and spurned other types of spirits; he healed only; pacifying the forces of natures, he also assisted the poor, and was an advocate for the needy; and he converted a number of the deistic to Christ. Thus at this very point where he stood, where the vertical and horizontal lines met, he becomes an example of the transformation himself; and he joins with other examples as, together, they correspond with earlier phenomena, now transformed.

"Correspondence" signifies a complementary similarity, it does not signify equivalence. Differences are also evident, just as they were evident in the examples of transformation through the social perspective, and just as they were evident earlier in the example of transformation of ritual masks into icons. The differences were marked in those examples by words as well as concepts: icons were not referred to as idols, because they differ in spiritual orientation and in practice; ${ }^{*}$ the prophet was not referred to as a shaman by Veniaminov, for fundamentally the same reasons." Neither was this saint, the elder from Valaam, ever referred to as a "shaman" by any source, not even among the Chugach "shaman stories" in which he figured. Even in the latter, he was referred to as "a very holy man, монах

\% See note 57 to Chapter 2, above.

"See above, Chapter 4, sec. 3, subsection titled "An Analysis of the Interaction". 
Германъ $" .98$ It would be inappropriate and incorrect to assert either that he was or that he was interpreted as a "shaman". Such an assertion would gloss over the evidence and misrepresent the idea that is being put forward here. No one knows how the Alaskans interpreted him beyond the sources that have been cited; and none of these sources referred to him as a shaman. These differences, and the marking of the difference by words, are very important. Yet so is the correspondence."

A certain correspondence is evident in him also, and it needs to be seen if his place in the transition is to be perceived: a place belonging to this missionary who remained here longest in a transition that was itself an indigenous movement.

\section{(7) Epilogue: a Paradox.}

The patristic tradition that he embodied derived from roots deeper historically than the type of colonialism which the invaders were intent upon instituting; and this colonialism, being projected now into the Kodiak area and impacting upon the Aleutian Islands, had at its inception in Russia herself, less than a century earlier, been meant to change her indigenous cultures also, including those in the "Russian Thebaid". Attempts to effect change had not been confined to Petersburg alone. During the second half of the seventeenth century, Moscow had imposed ecclesiastical reforms; and a subsequent Swedish invasion and occupation of Karelia until the second decade of the eighteenth century had had its effects. Petersburg's attempt to

\footnotetext{
${ }^{98}$ Birket-Smith (1953:130), as cited also above.

${ }^{99}$ Compare the following statement in the conclusions to Chapter 3, regarding icons and ritual masks: "Important differences notwithstanding ... it may well be argued that, for the sake of the transition, the correspondence comprises the more important fact."
} 
impose change followed those previous waves, but was unique from them due to the internal colonization which it would wrought. ${ }^{100}$ Previously, Moscow's heavy-handedness had been mostly to impose reforms in rubrics (a reform which many of the culturally conservative peoples of these regions would not accept); and the Swedish occupation, destructive in the radical theism and the iconoclasm to which it was fixed, had resulted from a foreign invasion. But Petersburg's impositions were meant to impose sweeping changes throughout the cultural fabric of her peoples, and it came from within Russia herself.

The result was a dichotomy that rent Russia's fabric at her extremes. As Professor Florovsky perceived, "Peter's reforms signified a displacement or even a rupture in Russia's spiritual depths." ${ }^{101}$ It created the tension that propelled much of the masterful Russian literature during this era: Dostoyevsky, Gogol and Tolstoy all wrote contemporaneously with Russian-America, each depicting the same tension. It was being expressed also by the Slavophiles: indeed, the tensions between "Slavophiles" and "Westernizers" constituted a major philosophical dynamic within

\footnotetext{
${ }^{100}$ An expedient example of this "internal colonization" (as I have termed it) is provided by an innovation from Petersburg: enlisted serfdom. The significant word is "enlisted": segments of Russia's indigenous peasantry were listed as taxable property which could be bought and sold or transferred by an increasingly foreign or foreignizd gentry. Under Peter 1 this institution was imposed upon central European Russia, and under Catherine II it was extended to the Ukraine. The history of enlisted serfdom was coterminus with the history of Russian-America. Peter I sponsored Bering's first voyage. Catherine Il oversaw the initial enterprises across the Aleutian Islands, and she was the monarch at the colonization of Kodiak Island. Serfdom was abolished by decree in 1864; and in 1867, Alaska was sold to Washington, D.C. (The information in this note is generally accepted; for an interesting reference, see Platonov (1925:267-310).) Coterminous histories do not necessarily mean identical histories. Enlisted serfdom was not extended into Russian-America; and Alaskans fared better in this sense than did those Russians who suffered that institution -- a consideration that could be relevant to further studies of this mission. Did the imposition of serfdom upon Russian people influence these missionaries' alliances with the Aleut and Alutiiq peoples? To what extent were these alliances an extension of these missionaries' own families' self-defense against the same forces?
}

${ }^{101}$ Florovsky (1979:114-161), in a chapter he titled "The St. Petersburg Revolution". 
Russia, again contemporaneous with Russian-America. Khomyakov, for instance, was born in 1804 and died in 1860 . The concern of these writers was not merely with the class divisions which were being expressed at the same time by Dickens and Hugo, and which would be grossly exploited by the Marxists. Marx was not Russian. Russia's own novelists were expressing a cultural distinction between her own indigenous peoples and her foreign and foreignized rulers.

Terminology for this internal colonization can be gained from the (later) historian Arnold Toynbee who recognized "Orthodox Christian Society" and "Western Society" as distinct realities among various "living species of societies" worldwide. $^{102}$ He subsumed this distinction to an overall theory of history that he was propounding; but it is not that theory, nor yet his view of the divergence of the two relevant "species", 100 that comprise the useful factors here. Quite apart from them, his terminology remains relevant itself, as he distinguished "Orthodox Christian Society" from "Western Society". These are his terms verbatim. ${ }^{\text {jos }}$ The terminology

\footnotetext{
${ }^{102}$ Toynbee (1935:63-67).
}

${ }^{103} \mathrm{He}$ interpreted the divergence of "Western Society" from "Orthodox Christian Society" as a gradually widening theological divide, and thus conveyed a "gentle-rift-theory" (as I would term it). Overlooked in this theory is the impact of the barbaric invasions of the West, beginning in the fourth century A.D., which violently severed the Latin world from the Greek, and influenced the character of the "Latin Church" that subsequently developed. For a view of this history, see especially Romanides (1981); also see id. (1989): the author was Professor of History at the Univeristy of Thessalonika, now retired.

${ }^{104}$ See Toynbee's original work published at Oxford (as cited). Emphasizing a recognition of Christianity in a "species of society" other than Western, his terms are valuable for a study such as mine; and I shall incorporate them into my Conclusions. But compare the edition abridged by D. C. Somervell; and see Toynbee's preface to that abridgement (id. 1946), where Toynbee politely disclaims it while commending the work as rather independent from his own. In the abridgement (e.g., p. 8), his original term "Western Society" was changed to "Western Christian Society" and to "Western Christendom". Why was it changed? The abridgement was issued under the auspices of the Royal Institute of International Affairs, where Toynbee had a leading position; he was also the Director of the Research Department of the British Foreign Office (1943-1946). 
can be applied to the dichotomy that was being expressed inside Russia by her own writers; the terminology can be extended to the contrasting movements from Russia across the Aleutians into Alaska. ${ }^{105}$ Toynbee, however, assigned Russia uniformly to the "species of Orthodox Christian societyin", an assignment indicating that, from a distant perspective, the dichotomy was not particularly evident: a creative synthesis had also taken place. ${ }^{100}$

Russia's own cultures including those of the taiga and tundra, remained resilient and creative, indeed; as evinced by the runes collected in Karelia by Elias Lönnrot between 1828 and 1844 , inspiring him to compose the Finnish Kalevala, that heroic saga of the Far North. ${ }^{107}$ It is significant that the dates of his collection were contemporaneous with Russian-American history: exactly synchronous with Netsvetov's ministry in the Atka parish, and roughly equivalent with Veniaminov's

${ }^{105}$ See my Chapter 1, sec. 6 at notes 95-100, and sec. 8, above.

106 See Chapter 1, above, where the cultural dynamics in Russian-America and in Russian Asia are indicated: multilingualism was normal, and the indigenous peoples remained confidently artistic. Also consider arts such as the ballet and the philharmonic in Moscow and Peterburg: they are hardly foreign institutions upon indigenous soil. Instead, they are perfections of fully appropriated characteristics, themselves "Russian-ized"; and the same can be said of the novel, the very art form in which the dichtomy was so masterfully expressed. Creative synthesis was manifest across the breadth of Russia.

${ }^{107}$ See Pentikäinen (1989:229). I am aware that types of runes differ, as do types of dogmas. I am not referring to warsome runes or to an elitist religious dogma, a combination of which would be predictably aggressive. See my notes 28 and 29 to Chapter 2, above. For a study of a transformation of "runes" (I am extending the term), see Pharos (1981) who identifies the transformation of ancient Greek $\mu о \iota \rho \lambda_{0} \gamma \iota \alpha$, "words of fate", into the Greek Orthodox folk laments, oi $\theta \rho \bar{\eta} v o r$ iñs

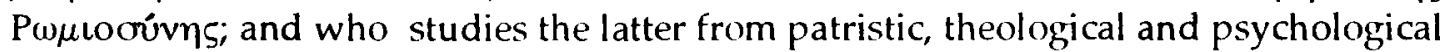
viewpoints. Have the Karelian runes benefitted from this kind of study? Pentikäinen (1978) has produced an interesting study of a rune singer, including her belief system or perhaps an aspect of it; and has isolated an emphasis upon "fate" in her singing. But how should a humble person who has suffered be expected to sing from pain and to express despair, if not in "words of fate" on the one hand? -- and one the other hand in hymns of hope, as Karelian runes are intoned in a larger context where the hymns are also chanted. This other aspect of a rune singer's experience was not sufficiently studied. While the runes allow pain to pour out in "words of fate", the hymns would shed the light of Christian hope. 
ministry in the Unalaska parish. Mid-way between Lönnrot's dates of collection, the elder of Valaam reposed in the forest of Elovoi. These runes continued to be sung well into the twentieth century. In 1910, for example, a rune singer "following the White Sea Karelian way of life .... gladly recalled the White Sea Karelian times and customs, weddings, healers, and hunters"108

An intrinsic relationship is evident between these runes and the religion in these regions, as Lönnrot collected from religious people and religious sites. His first compilations were primarily of "the voices of old men from White Sea Karelia and, in general, North Karelia". ${ }^{109}$ In the White Sea region, he went directly to the Monastery of Saari (Holy Island) and the Monastery of Skiita. ${ }^{110}$ In North Karelia, his major contributor was a "churchkeeper"." His subsequent compilations were in Olonets, Ingria, and South Karelia." ${ }^{12}$ Centrally located as if at the nucleus encircled by these regions -- North Karelia, Olonets, Ingria, South Karelia ${ }^{113}$-- stands the Monastery of Valaam whose monastics were related by kinship and other social bonds to the indigenous peoples here. ${ }^{114}$

It was from this monastery and the nearby Monastery of Konev -- both at this nucleus, both of the "Thebaid" -- that the missionaries were sent into Grigorii

${ }^{108}$ Pentikäinen, p. 104.

${ }^{109}$ Ibid., p. 121.

${ }^{110}$ lbid., p. 126.

"' Ibid., p. 99.

${ }^{112}$ Ibid., p. 126.

${ }^{113}$ See map in ibid., p. 228.

"14 Ambrosius of Valamo, "The Years since 1715", in Valaam (1983:39-40). But not all monastics were related in this way: Archimandrite loasaph Bolotov was attached to Valaam; and another contrast can be found in Townsend (1974:10-13), hieromonk Nikita who was the parish priest at Kenai in the 1880s, also from Valaam. 
Shelikhov's colony, itself an extension of the empire conceived by Peter I. He had begun constructing his capital city in 1703. Shelikhov extended, or rather he imagined himself extending, those social designs to Kodiak in 1784. These missionaries were sent into that colony not in conformity with Shelikhov's schemes but in disparity from his specific request. ${ }^{115}$ To presume that this religious mission was part of those colonial designs would be to obscure the initial disparity and the later tensions. A conformity may have existed with the missionaries' leader Archimandrite loasaph,;16 but otherwise this "religious mission" was not entirely conformed to the "colonial mission".

These missionaries allied with the indigenous peoples of Kodiak and the Aleutians, and thus, in effect, allied against an extension of the same colonialism which would, if it were able, impose change also upon the indigenous peoples and cultures of the "Thebaid" from where the missionaries had themselves derived. This is the paradox.

Once the paradox opens, an irony unfolds when certain sources expected these missionaries to have conformed themselves to the colonial designs. For instance Nikolai P. Rezanov, the Court Chamberlain and a major shareholder in the company on a tour of inspection in Russian-America, complained in 1805 against the surviving missionaries because they were not following the government's plan. He became intent upon explaining to them himself "of what missionary work should consist". ${ }^{17}$

${ }^{115}$ Explained in Chapter 1, above: see the text at notes 106-107.

${ }^{116}$ For the ambiguity about loasaph, see note 113 to Chapter 1, above; also see Mousalimas (n.d.c).

${ }^{117}$ Nikolai P. Rezanov, Letter to the Directors of the Russian-American Company, 6 Nov. 1805, in Tikhmenev, ed. (1979:168); see ibid. (1 
Considering them ineffective at "developing the savages", he contrasted them as follows: 18

Our monks have never followed the path of the Jesuits in Paraguay by trying to develop the mentality of the savages, and have never known how to enter into extensive plans of the Government or company. They have just been "bathing" the Americans and when, due to their ability to copy, the latter learn in half an hour to make the sign of the cross, our missionaries return, proud of their success, thinking their job is done.

His reference to the "bathing" is to baptism by immersion. It may be recalled that among those "merely bathed" was the Akun Islander who became the Aleut prophet:"19 and that he had been baptized by a missionary hieromonk who proceeded with Aleut leaders to lodge a complaint of their own.

Georg Heinrich von Langsdorff, a doctor of medicine degreed at Göttingen, himself of a baronial family, who toured some sites in Russian-America with Rezanov, then traveled with him into Spanish-California, commended a religious mission in the San Francisco Bay area for "spreading the Christian religion" in systematic cooperation with their own government; $; 20$ but he disparaged the Russian Orthodox missionaries' effect in the Kodiak area just as Rezanov did (the criticism could be a paraphrase): ${ }^{21}$

Of the Russio-Greek religion they [the natives] scarcely know anything more than how to make the sign of the

${ }^{118}$ Ibid. (1979:167); see (1863:214).

${ }^{119}$ See note 70 to Chapter 5, above.

${ }^{120}$ Langsdorff (1814:170-171; (1812:147-148).

${ }^{121}$ Id. (1814:64); see (1812:58). Langsdorff (1814:47; see 1812:42) made a similar statement with regard to the Unalaska Aleuts:

Many of them have been baptized, and are nominally professors of the Russio-Greek faith, of which, however, they understand nothing more than making the sign of the cross. There is no such thing among them as an ecclesiastic, or a house of prayer. 
Cross, yet there is a church and an ecclesiastical establishment.

The "ecclesiastical establishment" at that time consisted of four missionaries. Among them was "монах Германъ"122 who was standing at the centre of such judgements, at the intersection where a line of patristic tradition was meeting a line of Alaskan tradition within a transition that was itself an indigenous movement from shamanism to Russian Orthodoxy in Alaska.

${ }^{122}$ A "very holy man, монах Германь", according to Makarii Chumovitskii in Birket-Smith (1953:130). 


$$
\text { - }
$$




\section{CONCLUSIONS}

\section{"The Christianization of the Religion of their Ancestors"}

A twofold question has been involved throughout these chapters: how did the transition occur; and what were its implications for the ancient cultures?

\section{How did the transition occur?}

Initial Contacts, First Baptisms (Chapter 1). This faith and its practices were conveyed by other Far Northern peoples, and were engrafted in Alaska among the Aleut and Alutiiq peoples within their own ancestral cultures. The transition was indigenous and corporate: involving indigenous spiritual and social processes, and occurring through the whole bodies of peoples' societies, or kinship polities.

Correspondence (Chapter 2). It could be an indigenous, corporate movement because vital characteristics in these ancestral cultures corresponded to vital characteristics in Russian Orthodoxy, so that participants in these cultures could engage and could retain this faith and its practices.

Point of Comprehension (Chapter 3). A vital point of engage ment was the dynamic of participation: the divine participating in representations and in nature; nature and representations participating in the divine. These dynamics are central to Orthodoxy: to grasp this faith therefore, one must be able to comprehend these dynamics; and precisely this ability existed in these ancestral Alaskan cultures, where these dynamics were centrally operative, within events that affected the whole society. 
Ecstasy (Chapter 4). The human propensity and potential for these dynamics were recapitulated in the ecstatic experiences of the shamans. The question arose, however, as to whether there was a sound theological reason to expect a transformation of this phenomenon; and indeed there was. Principles in patristics were applied to discern the form and content of ecstatic experiences; and these patristic principles were shown to have been applied in Alaska by Veniaminov who was thus able to discern an Orthodox prophet of extraodinary gifts among the Aleuts.

Change in the transition occurred in the form and content of the ecstatic experience, in other words change occurred in the manner of the ecstasy and its spiritual orientation. Further development of this theme would articulate the meaning of this change. For example, it would study the patristic literature regarding the spiritual ascent/descent, and would compare it with shamans' practices.

Transformation (Chapters 5-6). This Aleut prophet, the elder of Akun, provided the first extended example of the transformation of this phenomenon himself. While functioning within a moral and spiritual content that was exemplary, and being enabled by angels (as Veniaminov discerned them to be), this Aleut elder fulfilled the major social tasks associated with shamans of old - he healed, foresaw future events, and located food supply. And as he did this within the ancestral culture, the Akun Aleuts were referring to him as a "shaman", his own differences from the shamans-of-old notwithstanding.

Another extended example was provided by the Alutiiq healer Kangatyuq who likewise was referred to as a "shaman", although the form of his practice also differed from shamans-of-old, as the folk history about him emphasized: he only healed, and he healed only by prayer and breath. His vocation was encouraged by 
none other than apaa Herman who fulfilled these same social tasks in the Kodiak area forest himself: healing, foreseeing, pacifying the forces of nature -- dynamics traced into the deep ground of patristic tradition.

Other examples of transformation were provided earlier in the study, including that of ritual masks into icons, and of ritual festivals into liturgical festivals.

\section{Transition or Transformation?}

Employed particularly for syntax, the phrase "transition to" would be inappropriate were it to connote those theories of evolution which derive from narrow ethnocentric presuppositions. Predicated upon notions of development through stages of culture, such theories assign Christianity to a culture form, namely Western European: and that form is assigned to a high level on an evolutionary scale, a scale which is itself established mainly upon a materialist basis. Such theories do not apply here. The West is not the Orthodox heartland: therefore "Western Society" can not be a standard for measuring "Orthodox Christian Society".'

Those theories which the term "transition" might connote are furthermore inapplicable because of the general continuity and transformation of many ancient cultures within the Greek Orthodox Christian ecumene where traditional dance, foods, folkore, language, feasting, mourning, healing continued, and continue yet. Still these ancestral cultures are lived with vitality.

Instead of a transition from one type of culture to another type of culture, a transformation took place among the Aleut and Alutiiq people (and among other Far

${ }^{1}$ For the terms within quotation marks, incorporated from Arnold Toynbee, see my Epilogue in the preceding chapter, especially note 107. 
Northern peoples as well) within a unity of their respective ancestral cultures, and within a continuity of sacralized cosmos. Within this unity and continuity, the term "transition" can be applied to specific phenomena: for example, it can be applied to the transition from some shamans' rites to patristic ecstasy. In this specific sense there was a transition, while overall a continuity and transformation took place.

\section{Implications.}

Through their Russian Orthodoxy (chosen and main tained as an inheritance for them by their ancestors), modern Alaskans have an unsevered communion with their deepest ancestral past -- that is, as long as their churches remain their own. Here is a viable way of life with roots in deepest antiquity and with fruit in the modern world. Or alternatively expressed, here is deepest antiquity existing unsevered, transformed.

This implies a "Christianization' of the religion of their ancestors"' -- the quotation from Mircea Eliade with reference to his own Romanian ancestry, applies here as well. Referring to a whole body of traditions (designs, lore, food, song, dance) belonging to Romanian culture, and those belonging to neighbouring Orthodox Slavic culture, he expressed the continuity that he perceived: ${ }^{3}$

[they] incorporated into their new faith the cosmic religion that they had preserved from prehistoric times.

He differentiated this process -- the Christianization of the ancestral religion --- from the antithesis which would be the paganization of Christianity: ${ }^{4}$

For the peasants of Eastern Europe this in no sense implied a 'paganization' of Christianity, but, on the

\footnotetext{
${ }^{2}$ Eliade (1988:38).

${ }^{3} \underline{\text { Id. }}$ (1959:164).

느. (1988:38).
} 
contrary, a 'Christianization' of the religion of their ancestors. When the time comes for the history of this 'popular theology' to be written on the evidence that can be traced in seasonal festivals and religious folklores, it will be realized that 'cosmic Christianity' is not a new form of paganism or a pagan-Christian syncretism. Rather it is an original religious creation, in which eschatology and soteriology are given cosmic dimensions.

The same applies to the hunters of the Far North whose theologizing became evident in this study with the folk history regarding the "Alutiiq healer" (as I termed Kangatyug in Chapter 5). Within a genre of regional folklore, this account reflected elements from the patristic tradition. Some have already been indicated. ${ }^{5}$ Another can be highlighted in conclusion. The folk history had Kangatyug meet "монах Германь" in the forest as follows: ${ }^{6}$

They caught sight of a bright ray of light shining on a small log cabin. They walked in and saw an old man praying on his knees. The old man asked them: "How did you come here? Are you dead or alive?" Only dead persons came there, and the old man [the elder] was able to see dead people.

With a qualification, this passage becomes like other accounts regarding apaa Herman; and these accounts are themselves equivalent to descriptions regarding the desert fathers, ${ }^{8}$ including descriptions in The Life of St. Anthony of Egypt. ${ }^{9}$ The

\footnotetext{
${ }^{5}$ See the Conclusions to Chapter 5 , above.

${ }^{6}$ In Birket-Smith (1953:130-131).

${ }^{7}$ See the quotations in Chapter 6 at notes 64 and 65, above. Also see Larionov in Valaam (1978:105).

${ }^{8}$ See, e.g., the quotation in Chapter 6 at note 88 , above.

${ }^{9}$ Bíos 'Avtovíov $x \times x v, x l$ in Athanasius Alexandrinus (1857:889-891); see ibid. vi, viii, xiii, xxv-xvi, colsi 849-852, 853-856, 861-864, 881-884. Also see my text Chapter 4 at notes 59-60, above. Compare with Sts. Cyril of Jerusalem, John of the Ladder, and Diadochus of Photice, in Chapter 4 at notes 61-63, above. I should, perhaps, mention that I am aware of the interesting work by Rubenson (1990) who would describe the vita as Origenistic. But, notice, that while I value the vita, I have consistently countered Neo-Platonism, of which Origenism is a manifestation. Does
} 
qualification involves the ethnographer's statement that "only dead people came there". It may be recalled that the ethnographer, Birket-Smith, had collected this folk history from the tradition bearer Makarii Fedorovich Chumovitskii through an ad hoc interpreter. Contrary to the written statement, people visited as Kangatyuq did in this instance. Once the adverb "only" is omitted from the statement, and the phrase "dead people" is substituted by the more comprehensive term "spirits", then the passage becomes equivalent to the other accounts. And the question assigned in this passage to apaa Herman -- who asks Kangatyug, "Are you dead or alive?" -clearly reflects the exercising of discernment that was attributed to him more precisely in other sources (as cited) and that had been described for the desert fathers as well (as cited): it was a discernment of humans and angels on the one hand from demons, on the other hand, which would assume various guises to distract people who have embarked upon the descent into the heart, the ascent to heaven. Perhaps the affinity between the accounts regarding the apaa in the forest of Elovoi and those regarding the apaa in desert of Egypt is closer yet, as The Life of St. Anthony itself derives from an oral tradition, a folk history.

It is significant that Chumovitskii was misinterpreted. An Alutiiq-Russian, he was categorized as a "Chugach Eskimo" by the ethnographer, and his folk history was placed among the "shaman stories".." The misinterpretation indicates the existence of a "distant perspective". While perhaps well meaning, Birket-Smith was simply too far removed, so that his "distant perspective" encompassed elements of Greek Orthodox patristics and Alaskan shamanism indiscriminately. How would this perspective, if projected from the forest to the desert, have observed the Egyptian

it follow, therefore, that an acceptance of the vita involves an acceptance of Origenistic presuppositions?

${ }^{10}$ See Chapter 5 at note 80 , above. 
healing, or conversing with angels, or expelling demons? And if projected earlier to Galilee, how would it have observed these acts there?

From a closer perspective however, one would recognize the tradition that the elder tradition bearer Chumovitskii was communicating, particularly when he distinguished between Orthodox rites of healing and the typical shamans' rites; ${ }^{11}$ and also when he described the same phenomena about apaa Herman that occur about abba Anthony, and that recur through the patristic tradition.

From an insightfully close perspective a man from Siberia, Ivan Veniaminov, recognized the prophet of Akun within virtually unchanged Aleut material culture, a prophet in whom an extraordinarily thorough Christianization of the Aleutian ancestral ways was evident.

\section{A Question of Categories.}

A problem with the "distant perspective" is that it identifies Christianity with "Western Society"; and therefore applies an inappropriate typology to studies of "Orthodox Christian Society", including Alaska. The field then becomes confused, sometimes understandably as when Birket-Smith confused some subtle yet essential distinctions, but other times to a degree no less than ludicrous, when, for example, Christianity is termed "the white man's religion", or euphemistically more recently "the European religion".

Neither located within "Western Society", nor predicated upon European culture, the Greek Orthodox Christian ecumene embraces, and has always embraced, an essential plurality in unity: a rich tapestry of types of cultures in the kalivya (huts or tents) of herders, and in the honeycombed villages of cultivators; in the fixed

\footnotetext{
"See Chapter 5, sec. 3.ii.
} 
neighbourhoods of city-dwellers, and in the seasonal camps of hunter-gatherers; in houses and iurts even palaces.

A timely call has been voiced for a re-evaluation of ethnocentric notions about Christianity. ${ }^{12}$ For "Western Society", a re-evaluation could mean the discovery that Christianization does not imply, and has never implied, Westernization. For "Orthodox Christian Society" it would involve re-discovery and a re-orientation; and for those on the Aleutians, in the Kodiak area, throughout Alaska and throughout the Far North, it involves self-recognition as well as self-realization.

This religion is, and has always been, these peoples' own. This faith and its practice are rooted, and have always been rooted, in the peoples' own ancestral way of life and own communities -- not in foreign hierarchies, not in elitist academies, not in state administrations. If these ancestral cultures would be categorized as "primitive" (by the same authorities who would teach us their academic theories regarding cultural "evolution"), then equally would the Galileans be categorized likewise; and if the Galileans were, then so should their religion be. Who, then, would be the advanced and who the primitive?

\footnotetext{
${ }^{12}$ James (1988).
} 

BIBLIOGRAPHY 


\section{BIBLIOGRAPHY}

Afonsky, Gregory.

1990. "Orthodoxy in Alaska". In Russia in North America: The Proceedings of the 2nd International Conference on Russian-America, pp. 289-297. Edited by Richard A. Pierce. Kingston, Ont.: The Limestone Press.

1977. A History of the Orthodox Church in Alaska (1794-1917). Kodiak: St. Herman's Theological Seminary.

Alekseev, A. I.

1987. The Odyssey of a Russian Scientist: I.G. Voznesenskii in Alaska, California and Siberia, 1839-1849. Translated by Wilma C. Follette. Edited by Richard A. Pierce. Kingston, Ont.: The Limestone Press.

Alexander, Paul J.

1958. Patriarch Nicephorus of Constantinople: Ecclesiastical Policy and Image Worship in the Byzantine Empire. Oxford: The Clarendon Press.

Al'kor, Ia. P. [Ia. P. Koshkin] and A. K. Drezen, eds.

1935. Колониальная Политика царизма на Камчатке и Чукотке в XVIII Beke. Leningrad: Institute of the Peoples of Siberia.

Allenbach, J., et al., eds.

1975-87 Biblia Patristica: Index des Citations et Allusions Bibliques dans la Littérature Patristique. 4 volumes. Centre $d^{\prime}$ Analyse et de Documentation Patristiques. Paris: Éditions du Centre Nationale de la Recherche Scientifique.

Amarok, William Allen and Michael J. Oleksa.

1983. "The Suppression of the Aleuts: the Conflict in Alaskan Education, 1876-1916." Paper presented at the Center for Cross-Cultural Studies, College of Human and Rural Development, University of Alaska at Fairbanks.

Andreev, A. I., ed.

1948. Русские Открытия в Тихом Океане и Северной Америке в XVIII Beke. Moscow: Official Press for Geographical Literature.

Apophthegmata Patrum.

1975a. The Wisdom of the Desert Fathers: Apophthegmata Patrum: (the Anonymous Series). Translated by Benedicta Ward. Fairacres, Oxford: SLG Press. 
$1975 b$.

The Sayings of the Desert Fathers, the Alphabetical Collection. Translated by Benedicta Ward. London: A. R. Mowbray.

1908-13. Apophthegmata Patrum: the Anonymous Series. Edited by F. Nau. In "Histoires des Solitaires Égyptiens". Revue de l'Orient Chrétien, 2nd series, vol. 3 (xii), no. 1, pp. 47-57; vol. 4 (xiv), no. 4, pp. 357-379; vol. 7 (xvii), no. 2, pp. 204-211; vol. 8 (xviii), no. 2, pp. 137-146. Paris: Bureaux des Oeuvres d' Orient. Leipzig: Otto Harrassowitz.

Arbman, Ernest.

1963-70 Ecstasy or Religious Trance, in the Experience of Ecstatics from the Psychological Point of View. 3 Volumes. Translated by D. Burton. Edited by A. Hultkrantz. Upsala: Norstedts/Svenska Bokforlaget.

Aristoteles [A ristotle].

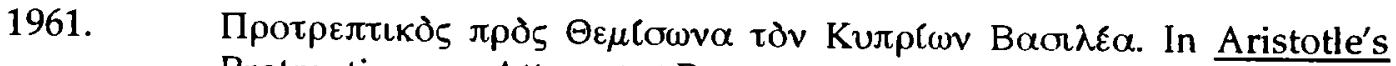
Protrepticus: an Attempt at Reconstruction. Edited by Ingemar During. Studia Graeca et Latina Gothoburgensia XII. Acta Universitatis Gothoburgensis. Stockholm: Elanders.

Arutiunov, S. A.

1988. "Koryak and Itel'men: Dwellers of the Smokey Coast". In Crossroads of Continents: Cultures of Alaska and Siberia, pp. 31-35. Edited by William W. Fitzhugh and Aron Crowell. Washington, D.C. and London: The Smithsonian Institution Press.

Athanasius Alexandrinus.

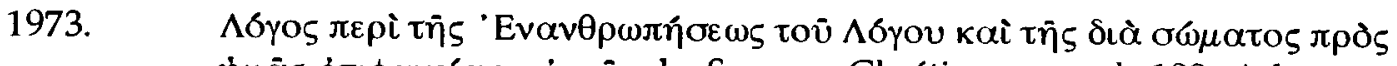

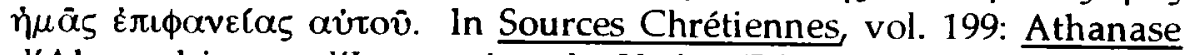
d'Alexandrie: sur l'Incarnation du Verbe. Edited and translated by Charles Kannengiesser. Paris: Cerf.

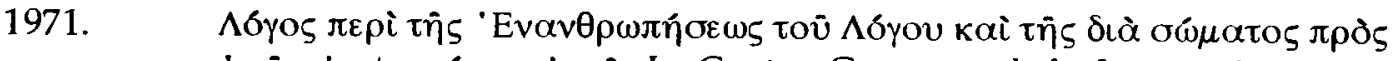

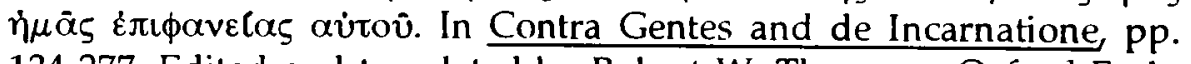
134-277. Edited and translated by Robert W. Thomson. Oxford Early Christian Texts. Oxford: The Clarendon Press.

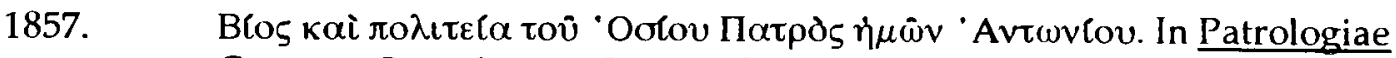

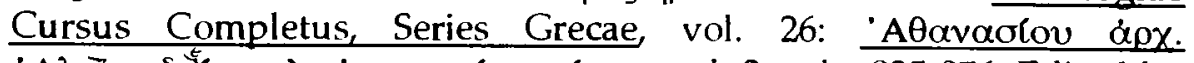

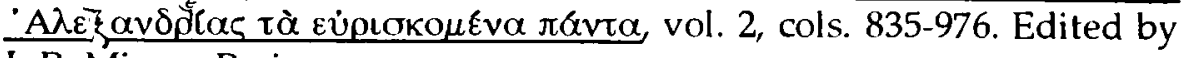
J. P. Migne. Paris.

Athenagoras Atheniensis.

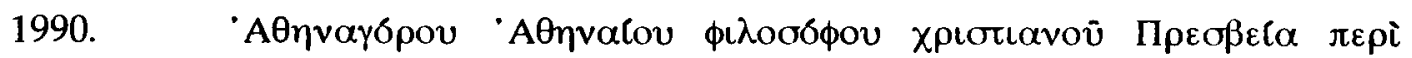
Xpıotıoviov. In Athenagoras: Legatio pro Christianis. Edited by Miroslav Marcovich. Patristische Text und Studien, 31. Berlin and New York: Walter de Gruyter. 


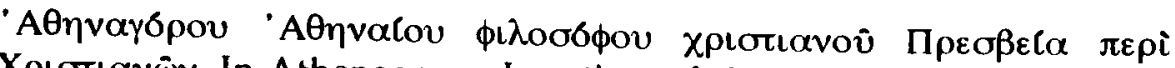

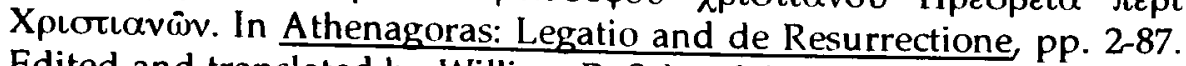
Edited and translated by William R. Schoedel. Oxford Early Christian Texts. Oxford: The Clarendon Press.

Augustinus Hipponensis.

1969. Enchridion ad Laurentium de fide et spe et caritate. Edited by E. Evans. In Corpus Christianorum, Series Latina, vol. 46: Sancti Aureli Augustini Opera (pars xii, 2), pp. 49-114. Turnholt: Brepols.

1956. Letter to Valentine [c. Easter 426 or 427]. Translated by Wilfred Parsons. In The Fathers of the Church, a new translation, vol. 32: St. Augustine, Letters pp. 57-62. NY: The Fathers of the Church.

1953. Enchiridion or Manual to Laurentius. Translated by Ernest Evans. London: S.P.C.K.

1930. Epistula [ccxiv] ad Valentinum: Letter to Valentinus (A.D. 426 or 427). Edited by A. Goldbacher [reprinted from CSEL, see below: id. (1911)]. Translated by James Houston Baxter. In: St. Augustine, Select Letters, pp. 405-415. The Loeb Classical Library. London: Wm. Heinemann. NY: G. P. Putnam's Sons.

1913. De peccatorum meritis et remissione, et de Baptismo Paruulorum. Edited by C. F. Urba and J. Zycha. In Corpus Scriptorum Ecclesiasticorum Latinorum, vol. 60: Sancti Aureli Augustini Opera (sect. viii, pars 1) pp. 1-151. Academiae Litterarum Caesareae Vindobonensis. Vienna: F. Tempsky. Leipzig: G. Freytag.

1911. Epistula ccxiv [214] ad Valentinum. Edited by A. Goldbacher. In Corpus Scriptorum Ecclesiasticorum Latinorum, vol. 57: Sancti Aureli Augustini Operum sectio II: S. Augustini Epistulae (clxxxv-cclxx), pp. 380-387. Academiae Litterarum Caesareae Vindobonensis. Vienna: F. Tempsky; Leipzig: G. Freytag. Reprinted in id. (1930).

1902. De peccato originali. Edited by C. F. Urba and J. Zycha. In Corpus Scriptorum Ecclesiasticorum Latinorum, vol. 42: Sancti Aureli Augustini Opera (sect. viii, pars 2) pp. 167-206. A cademiae Litterarum Caesareae Vindobonensis. Prague and Vienna: F. Tempsky. Leipzig: G. Freytag.

1887. "On the Merits and Remissions of Sins, and on the Baptism of Infants [de peccatorum meritis ... et ... Baptismo]"; "On Original Sin [de peccato originali]"; and "Two Letters written by Augustine to Valentinus and the Monks of Adrumentum [Ep. 214 and 215]". Tranlasted by Peter Holmes and Robert Ernest Wallis; translation revised by Benjamin B. Warfield. In A Select Library of Nicene and Post-Nicene Fathers of the Christian Church, vol. 5: Saint Augustine: Anti-Pelagian Writings pp. 15-78, 237-255, 347-440. Edited by Philip Schaff. NY: The Christian Literature Company; reprinted Grand Rapids: Wm. B. Eerdmans, 1956. 
Aulén, Gustaf E. H.

1931. Christus Victor: A Historical Study of the Three Main Types of the Idea of the Atonement. London: SPCK. Reprinted, London: SPCK, 1950.

Bancroft, Hubert Howe.

1886. The Works of Hubert Howe Bancroft, vol. 33: The History of Alaska, 1730-1885. San Francisco: A. L. Bancroft \& Co.

Barnes, Timothy David.

1971. Tertullian: A Historical and Literary Study. Oxford: The Clarendon Press.

Bashkina, N. N. et al. eds.

1980. Россия и США:Становление Отношений 1765-1815. Moscow: Nauka.

[1980] The United States and Russia: the beginnings of relations, 1765-1815.

[Translation of sources in Bashkina, Poссия и СШA.] Edited by David

F. Trask, et al. Washington, D.C.: U.S. Government Printing Office.

Basilius Caesariensis.

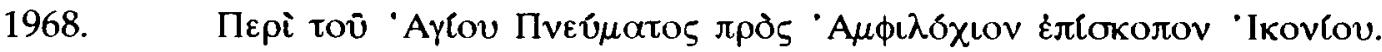
In Sources Chrétiennes, vol. 17: Basile de Césarée sur la Saint-Esprit. 2nd edition. Edited and translated by Benoit Pruche. Paris: Cerf.

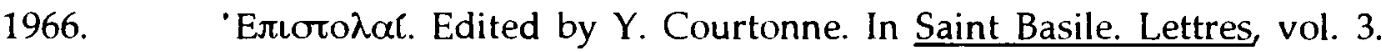
Paris: Sociétée d'Edition "Les Belles Lettres".

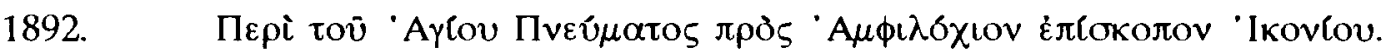
In The Book of Saint Basil the Great, Bishop of Caesarea in Cappadocia, on the Holy Spirit, written to Amphilocius, Bishop of Iconium, against the Pneumatomachi. Edited by C.F.H. Johnston. Oxford: The Clarendon Press.

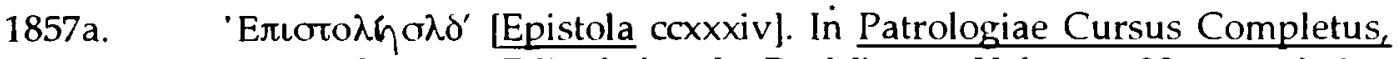
Series Graeca. Edited by J. P. Migne. Volume 30: Baor $\underline{\text { B }\{\text { lou }}$

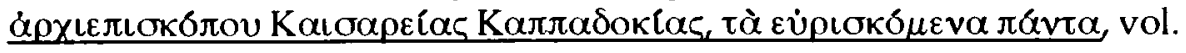
4, cols. 367E-872A. Paris.

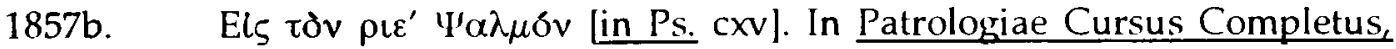

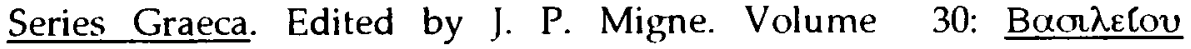

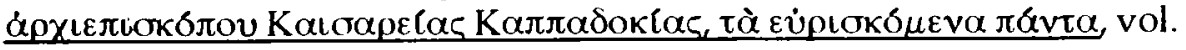
2, cols. 103B-116A. Paris. 


\section{Basilov, Vladimir N.}

1989. Introduction. In Nomads of Eurasia, ed. Vladimir N. Basilov, trans. Mary Fleming Zirin. Natural History Museum of Los Angeles County. Seattle and London: University of Washington Press.

Beaglehole, J. C., ed.

1967. The Journals of Captain James Cook on his Voyages of the Discovery: the Voyage of the Resolution and Discovery, 1776-1780. The Hakluyt Society, extra series, 36. Cambridge: Cambridge University Press.

Bebis, Georgius S.

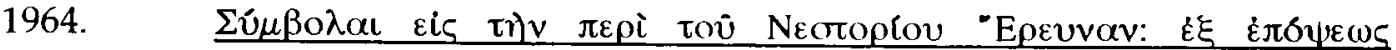

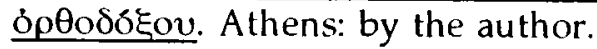

Befu, Harumi.

1970. "An Ethnographic Sketch of Old Harbor, Kodiak: an Eskimo Village". Arctic Anthropology 6 (2): 29-42.

Bergsland, Knut.

1990. Introduction. In Unangam Ungiikangin kayux Tunusangin: Unangan Uniikangis ama Tunuzangis: Aleut Tales and Narratives, pp. 1-56. Compiled by Vladimir Iokhel'son [Waldemar Jochelson]. Edited by Knut Bergsland and Moses L. Dirks. The Alaska Native Language Center. Fairbanks: University of Alaska.

1986. "Comparative Eskimo-Aleut Phonology and Lexicon." Aikakauskirja Lournal: Suomalais-Ugrilaisen Seuran/ de la Société Finno-Ougrienne [Helsinki] 80: 63-80.

1980. Atkan Aleut - English Dictionary. National Bilingual Materials Development Center, Rural Education. Anchorage: University of Alaska.

Berkh, V. N.

1979. The Wreck of the Neva [писаниie Hещастнаго [sic (Несчастнаго)] Кораблекрушенія фрегата Россійко-Американсой Компаніи Невн (St. Petersburg: 1817)]. Translated by Antoinette Shalkop. Anchorage: The Alaska Historical Society and Sitka Historical Society.

Berkowitz, Luci and Karl A. Squitier.

1990. Thesaurus Linguae Graecae: Greek Authors and Works. 3rd edition. Oxford and N.Y.: Oxford University Press. 
Berreman, Gerald D.

1964. "Aleut Reference Group Alienation, Mobility, and Acculturation." American Anthropologist 66 (2): 231- 250.

1955. "Inquiry into Community Integration in an Aleutian Village". American Anthropologist 57 (1): 49-59.

1953. "A Contemporary Study of Nikolski: an Aleutian Village". Masters Thesis, Department of Anthropology, University of Oregon.

Bettenson, Henry, ed.

1963. Documents of the Christian Church. 2nd edition. London: Oxford University Press.

Biblia Latina.

1949. Nouum Testamentum Domini Nostri lesu Christi Latine, 4th part. 2nd edition. Edited by J. Wordsworth and H. J. White. Oxford: The Clarendon Press.

Birket-Smith, Kaj.

1953. The Chugach Eskimo. Ethnografisk Raekke, 6. Copenhagen: Nationalmuseets Skrifter.

Birket-Smith, Kaj, and Frederica de Laguna.

1938. The Eyak Indians of the Copper River Delta, Alaska. Copenhagen: Det Kgl. Danske Videnskabernes Selskab.

Black, Lydia T.

1992. "The Conquest of Kodiak". Anthropological Papers of the University of Alaska 24 (in print).

1989. "Russia's American Adventure". Natural History (Dec.): 46-57.

1984. Atka: an Ethnohistory of the Western Aleutians. Kingston, Ont.: The Limestone Press.

1982a. Aleut Art: Anangam Aguqaadangin. Anchorage: Aleutian/ Pribilof Islands Association.

1982b. "The Curious Case of the Unalaska Icons". Alaska Journal (Spring): 7-11.

1981a. "The Daily Journal of Rev. Father Juvenaly". Ethnohistory 28 (1): 33-58.

1981b. "The Nature of Evil: of Whales and Sea Otters". In Indians, Animals, and the Fur Trade, pp. 111-151. Edited by Shepard Krech III. Athens: University of Georgia Press. 
1980. "Early History". Alaska Geographic, vol. 7, no. 3: The Aleutians, pp. 82-105. Edited by Lael Morgan.

1978. "Epilogue to Ivan Pan'kov -- an Architect of Aleut Literacy". Orthodox Alaska 7 (4): 29-33.

1977a. "Ivan Pan'kov -- an Architect of Aleut Literacy". Arctic Anthropology 14 (1): 94-107.

1977b. "The Konyag (the inhabitants of the island of Kodiak) by loasaf [Bolotov] (1794-1799) and by Gideon (1804- 1807)." Arctic Anthropology 14 (2): 79-103.

Bolshakoff, Serge.

1977 Russian Mystics. Cistercian Studies Series, 26. Kalamazoo: Cistercian Publications. London: A. R. Mowbray.

1943 The Foreign Missions of the Russian Orthodox Church. London and New York: S.P.C.K.

Bourguignon, Erika.

1974. "Cross-Cultural Perspectives on the Religious Use of Altered States of Consciousness". In Religious Movements in Contemporary America, pp. 228-243. Edited by Irving 1. Zaretsky and Mark P. Leone. Princeton: Princeton University Press.

1973. "Introduction: A Framework for the Comparative Study of Altered States of Consciousness". In Religion, Altered States of Consciousness, and Social Change, pp. 3-35. Edited by Erika Bourguignon. Columbus: Ohio State University Press.

Bright, William, ed.

1880. Concilium Arausicanum Secundum, de Gratia et Libero Arbitrio [A.D. 529]. In Select Anti-Pelagian Treatises of St. Augustine, and the Acts of the Second Council of Orange, pp. 384-392. Oxford: The Clarendon Press.

Brown, Peter.

1967. Augustine of Hippo: A Biography. London: Faber and Faber.

Bryant, Charles.

1870. Reports. In Ex. Doc. no. 32. 41st Congress, U.S. Senate, 2nd Session (20 January). Washington, D.C.

Buynitzky, S. N.

1871. "St. Paul Island, Alaska" In Ex. Doc. no. 122. 41st Congress, U.S. House of Representatives, 3rd Session (11 February). Washington, D.C. 
Calvin, Jean [John].

1962. Opera Selecta, vol. 3: Institutionis Christianae religionis 1559 libros I et

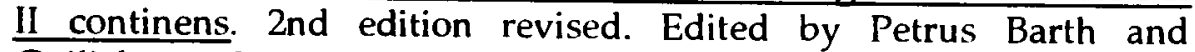
Guilielmus Niesel. Berlin: Chr. Kaiser.

1961. Concerning the Eternal Predestination of God. Translated by J. K. S. Reid. London: James Clerke and Co.

1870. De aeterna Dei praedestinatione. In Corpus Reformatum, vol. 36: Ioannis Calvini: opera quae supersunt omnia vol. 8, cols. 258-366. Edited by Guilielmus Baum, et al. Braunschweig: M. Bruhn.

1845. Institutes of the Christian Religion, vol. 1. Translated by Henry Beveridge. Calvin Translation Society. Edinburgh: Edinburg Printing Co. Reprinted: 1949, London: James Clarke and Co.

1552. De aeterna Dei praedestinatione. In Ioannis Caluini opuscula omnia in unum volumen collecta: quibus accessit libellius [de. aet. Dei praedes.], pp. 879-946. Edited by N. des Gallars [Nicolaus Gallasius]. Geneva.

Cassianus abbas Massiliensis [John Cassian].

1894. The Conferences". Translated by Edgar C. S. Gibson. In A Select Library of Nicene and Post-Nicene Fathers. Edited by Philip Schaff and Henry Wace. Volume 11: ... John Cassian pp. 291-545. Oxford: James Parker \& Co. NY: The Christian Literature Co.

1886. Conlationes. Edited by Michael Petschenig. In Corpus Scriptorum Ecclesiasticorum Latinorum vol. 13: Iohannis Cassianis Opera. Academiae Litterarum Caesareae Vindobonensis. Vienna: C. Gerold.

Chadwick, Henry.

1986. Augustine. Oxford: Oxford University Press.

1966. Early Christian Thought and the Classical Tradition: Studies in Justin, Clement and Origin. Oxford: The Clarendon Press. Reprinted Oxford: The Clarendon Press, 1987.

1951. "Eucharist and Christology in the Nestorian Controversy". The Iournal of Theological Studies 2 (2): 145- 164.

Chadwick, Owen.

1968. Iohn Cassian. 2nd edition. London: Cambridge University Press.

Chaffin, Yule, Trisha Hampton Krieger, Michael Rostad.

1983. Alaska's Konyag Country: Kodiak from Sea Otter Settlement to King Crab Capitol. Anchorage: Alaska Northwest Publishing. 
Chickalusion, Maxim.

1982. Kustatan Bear Story: Qezdeghnen Ggagga. Alaska Native Language Center. Fairbanks: University of Alaska.

\section{Chitty, Derwas J.}

1964. The Desert a City: an Introduction to the Study of Egyptian and Palestinian Monasticism under the Christian Empire. Oxford: Basil Blackwell.

Christou, Panagiotes $\mathrm{K}$.

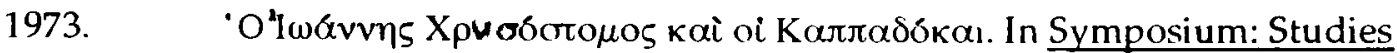

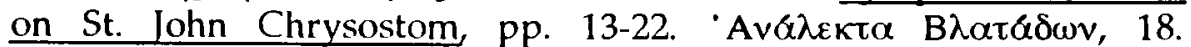

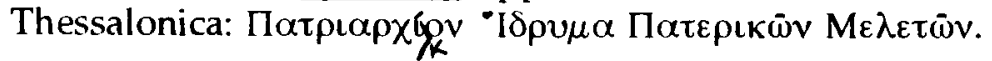

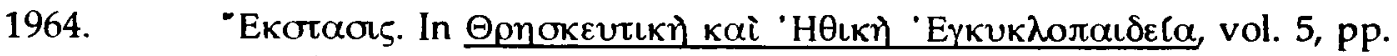
534-539. Athens: A. Martinos.

Chryssavgis, Ioannes [John].

1989. Ascent to Heaven: the Theology of the Human Person according to Saint John of the Ladder. Brookline, MA.: Holy Cross Orthodox Press.

1983. "The Theology of the Human Person in St. John Climacus." D.Phil. dissertation, Faculty of Theology, Oxford University.

Clark, Donald W.

1987. "On a Misty Day You Can See Back to 1805: Ethnohistory and Historical Archaeology on the Southeastern Side of Kodiak Island, Alaska." Anthropological Papers of the University of Alaska 21 (1-2): 105-132.

1984. "Pacific Eskimo: Historical Ethnography". In Handbook of North American Indians. Edited by William C. Sturtevant. Volume 5: Arctic, pp. 185-197. Edited by David Damas. Washington, D.C.: The Smithsonian Institution.

Clemens Alexandrinus.

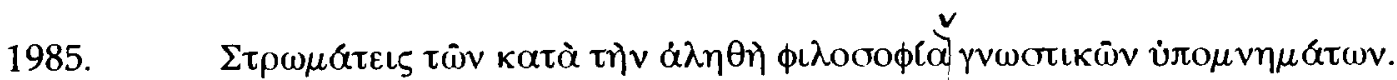
In Clemens Alexandrinus, vol 2: Stromata 1-VI. Edited by Otto Stahlin et al. Die Griechischen Christlichen Schriftsteller, 52. Berlin: Akademie Verlag.

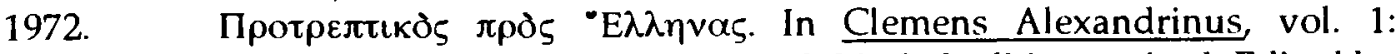
Protrepticus und Paedagogus pp. 3-86. 3rd edition revised. Edited by Otto Stahlin and Ursula Treu. Die Griechischen Christlichen Schiftsteller, 12. Berlin: Akademie Verlag. 
1919. Exhortation to the Greeks. Edited and translated by G.W. Butterworth. London: Loeb Classical Library. Reprinted 1979.

Clerq, Caroli de, ed.

1963. Concilium Arausicanum, 529 (Secundum). In Corpus Christianorum, Series Latina, vol. 148A: Concilia Galliae, A. 511 A. 695, pp. 53-76. Turnholt: Brepols.

Cook, James.

1784. Voyage to the Pacific ... 1776 [tol 1780 vol. 2. London: W. \& A. Strahan.

Cramer, J. A., ed.

1844. Catenae Graecorum Patrum in Novum Testamentum vol. 3: In Acta Ss. Apostolorum. Oxford: Oxford University Press.

Cross, F.L. and E.A. Livingstone.

1983. The Oxford Dictionary of the Christian Church. 2nd edition revised. Oxford: Oxford University Press.

Crowell, Aron.

1988. "Prehistory of Alaska's Pacific Coast." In Crossroads of Continents: Cultures of Siberia and Alaska, pp. 130- 141. Edited by Willaim W. Fitzhugh and Aron Crowell. Washington, D.C. and London: The Smithsonian lnstitution Press.

Cyrillus Alexandrinus.

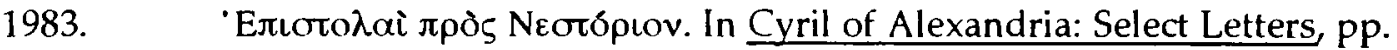
2-33. Edited and translated by Lionel R. Wickham. Oxford Early Christian Texts. Oxford: The Clarendon Press.

Cyrillus Hierosolymitanus.

1894. "The Catechetical Lectures". Translated by Edwin Hamilton Gifford. In A Select Library of Nicene and Post-Nicene Fathers of the Christian Church 2nd series. Edited by Henry Wace and Philip Schaff. Volume 7: S. Cyril of Jerusalem ... Oxford: James Parker. N.Y.: The Christian Literature Co.

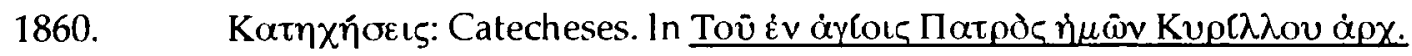

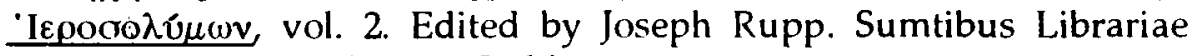
Lentnerianae. Munchen: E. Stahl.

Czaplicka, Maria A.

ms. Notes untitled. In: PS-III-B-1, Asiatic Russia, Tylor Library, Social Anthropology Institute, Oxford University. 
n.d. My Siberian Year [1914-1915]. London: Mills \& Boon.

1917. "On the Track of the Tungus". The Scottish Geographical Magazine 33 (July): 289-303.

1914. Aboriginal Siberia: a Study in Social Anthropology. Oxford: The Clarendon Press.

Dal, Vladimir.

1882. Толковый Словарь Живого Великорусского Языка, vol. 3. St. Petersburg and Moscow; reprinted Moscow, 1980.

Dall, William H.

1884. "On Masks, Labrets, and Certain Aboriginal Customs". In The Third Annual Report of the Bureau of Ethnology, 1881-1882, pp. 73-202. Washington, D.C.: The Smithsonian Institution.

1870. Alaska and Its Resources. London: Sampson, Low, Son \& Martin.

Daniélou, Jean.

1973. A History of Early Christian Doctrine before the Council of Nicaea vol. 2: The Gospel Message and Hellenistic Culture. Translated and edited by John Austin Baker. London: Darton, Longman and Todd. Philadelphia: The Westminster Press.

Dauenhauer, Nora Marks, and Richard Dauenhauer.

1991. "Spiritual Aspects of Tlingit Oratory". Paper presented at the International Association for the History of Religions, Regional Conference on Circumpolar and Northern Religions, University of Helsinki.

1990. Classics of Tlingit Oral Literature, vol. 2: Haa Tuwunaagu Yis, for Healing Our Spirit: Tlingit Oratory. Seattle and London: University of Washington Press. Juneau: Sealaska Heritage Foundation.

1988a. "Because We Cherish You': Treatment of Shaman Spirits in Contemporary Tlingit Oratory". Paper presented at the 12th International Congress of Anthropological and Ethnological Sciences, Symposium on Shamanism, 24-31 July 1988.

1988b. $\quad$ "Treatment of Shaman Spirits in Contemporary Tlingit Oratory." In Shamanism: Past and Present 2, pp. 317-330. Edited by Mihaly Hoppál and Otto von Sadovszky. Budapest: Angeles: Ethnographic Institute of the Hungarian Academy of Sciences. Los Angeles: ISTOR Books.

1987. Classics of Tlingit Oral Literature, vol. 1: Haa Shuka, Our Ancestors: Tlingit Oral Narratives. Seattle and London: University of Washington Press. Juneau: Sealaska Heritage Foundation. 
Dauenhauer, Richard.

1980. Conflicting Visions in Alaskan Education. Paper presented at the Alaska Pacific University, Anchorage, Alaska.

Davis, Nancy Yaw.

1984. "Contemporary Pacific Eskimo". In Handbook of North American Indians. Edited by William C. Sturtevant. Volume 5: Arctic, pp. 198-204. Edited by David Damas. Washington, D.C.: The Smithsonian Instutition.

1971. "The Effects of the 1964 Earthquake, Tsunami, and Resettlement on Two Koniag Eskimo Villages". Ph.D. dissertation, Department of Anthropology, University of Washington. Ann Arbor: University Microfilms.

1970. "The Role of the Russian Orthodox Church in Five Pacific Eskimo Villages as Revealed by the Earthquake." In The Great Alaska Earthquake: Human Ecology, pp. 125- 146. National Research Council, Division of Earth Sciences, Committee on the Alaska Earthquake. Washington, D.C.: National Academy of Sciences.

Davydov, Gavriil Ivanovich.

1977. Two Voyages to Russian-America, 1802-1807 [Двукратное ПутешестBie в Aмepикy, 1-2 (St. Petersburg, 1810-1812)]. Translated by Colin Bearne. Edited by Richard A. Pierce. Kingston, Ont.: The Limestone Press.

Desson, Dominique.

1988. "Alphonse Louis Pinart: Ethnographic Notes on Masks." Paper presented to the Alaska Anthropology Association, Fairbanks, 25-26 March; and at the First Kodiak Island Culture Heritage Conference, 28-30 March.

Diadochus Photicensis.

1979. "On Spiritual Knowledge and Discrimination: One Hundred Texts". In The Philokalia, vol. 1: The Complete Text compiled by St. Nikodemos of the Holy Mountain and St. Makarios of Corinth pp. 263-265. Translated by G. E. H. Palmer, Philip Sherrard, and Kallistos Ware. London and Boston: Faber \& Faber.

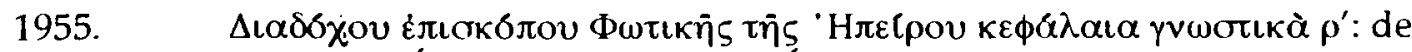
Diadoque Évêque de Photicé en Épire, cent chapitres. In Diadoque de Photicé, Oeuvres Spirituelles. Edited and translated by Édouard des Places. Sources Chrétiennes, 5 bis. Paris: Cerf.

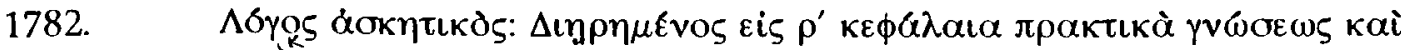

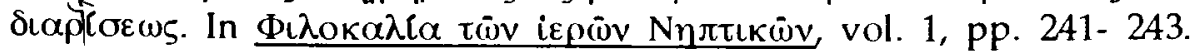


Compiled by Nicodemus of the Holy Mountain and Macarius of Corinth. Venice. Reprinted Athens: Aster, 1957.

Didymus Alexandrinus.

1863. Fragmenta ex Didymi Expositione in Actus Apostolorum. Edited by J. Christopher Wolf. In Patrologiae Cursus Completus, Series Grecae.

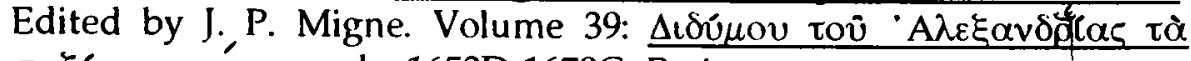
$\sigma \omega \zeta \delta \mu \varepsilon v \alpha \pi \alpha v \tau \alpha$, cols. 1653D-1678C. Paris.

Diószegi, V. and M. Hoppál, eds.

1978. Shamanism in Siberia. Bibliotheca Uralica, 1. Budapest: Akadémiai Kiadò.

Dirks, Moses.

1988. Foreword (Atka, Alaska, September 1987). In Oliver, Ethel Ross, Journal of an Aleutian Year. Seattle and London: University of Washington Press.

Dmytryshyn, Basil, E. A. P. Crownhart-Vaughan, and Thomas Vaughan, eds. and trans.

1989. To Siberia and Russian America: Three Centuries of Russian Eastward Expansion. Volume 3: The Russian American Colonies: A Documentary Record, 1798- 1867. The Oregon Historical Society. Portland: Western Imprints.

1988. To Siberia and Russian America: Three Centuries of Russian Eastward Expansion. Volume 2: Russian Penetration of the North Pacific Ocean: A Documentary Record, 1700-1797. The Oregon Historical Society. Portland: Western Imprints.

1985. To Siberia and Russian America: Three Centuries of Russian Eastward Expansion. Volume 1: Russia's Conquest of Siberia: A Documentary Record, 1558-1700. The Oregon Historical Society. Portland: Western Imprints.

Dodds, E. R.

1965. Pagans and Christians in an Age of Anxiety: some Aspects of Religious Experience from Marcus Aurelius to Constantine. The Wiles Lectures [at Queen's University, Belfast]. Cambridge: Cambridge University Press. Reprinted, New York: W. W. Norton \& Co., 1970.

Dostoyevsky, Fedor. :

1982. The Brothers Karamazov. Translated by David Magarshack. London: Penguin Classics.

1971. The Devils [The Possessed]. Translated by David Magarshack. London: Penguin Classics. 
Dragas, Georgius Dionysius.

1991. "St. Athanasius on Christ's Sacrifice." In Sacrifice and Redemption: Durham Essays in Theology pp. 73-100. Edited by S. W. Skyke. Cambridge: Cambridge University Press.

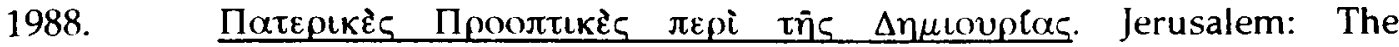
Patriarchate of Jerusalem.

1985. St. Athanasius contra Apollinarem. Athens: [Church and Theology 6].

Dumond, Don E.

1977. The Eskimos and Aleuts. Revised edition. London: Thames and Hudson.

Duncalf, Frederic.

1969. "The First Crusade: Constantinople to Antioch". In A History of the Crusades. Edited by Kenneth M. Setton. Volume 1: The First Hundred Years, pp. 253-279. Edited by Marshall W. Baldwin. Madison and London: University of Wisconsin Press.

During, Ingemar.

1961. Aristotle's Protrepticus: An Attempt at Reconstruction. Acta Universitatis Gothobrugensis, Studia Graeca et Latina Gothoburgensia, 12. Stockholm: Elanders.

Edmonds, H. M. W.

1966. "The Eskimo of St. Michael and vicinity as related by H. M. W. Edmonds". Edited by Dorothy Jean Ray. Anthropological Papers of the University of Alaska 13 (2): 1- 143.

Eliade, Mircea.

1988. "Survivals and Camouflages of Myth". In Symoblism, the Sacred, and the Arts, pp. 32-52. Edited by Diane Apostolos-Cappadona. Reprinted from Myth and Reality, pp. 161-193. New York: Harper and Row, 1963.

1987. "Shamanism: an Overview". The Encyclopeda of Religion, vol. 13, pp. 202-208. Edited by Mircea Eliade. New York: The MacMillan Publishing Company.

1982. Ordeal by Labyrinth: Conversations with Claude-Henri Roquet. Translated by Derek Coltman. Chicago: University of Chicago Press.

1964. Shamanism: Archaic Techniques of Ecstasy. Translated by Willard R. Trask. Princeton: Princeton University Press. 
1959. The Sacred and the Profane: The Nature of Religion. Translated by Willard R. Trask. San Diego: Harcourt Brace Jovanovich.

Eliade, Mircea, ed.

1987. The Encyclopedia of Religion. New York: The MacMillan Publishing Company.

Elliot, Henry W.

1881. The History and Present Condition of the Fishery Industries: The Seal Islands. Department of the Interior, Tenth Census of the United States. Washington, D.C.: Government Printing Office. Reprinted, Kingston, Ont: The Limestone Press, 1976.

Epiphanius Constantiensis (Salamiensis, Cypriota).

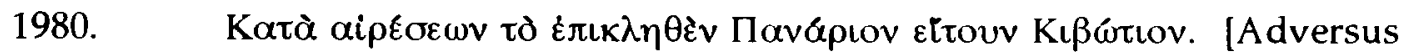
haereses]. In Epiphanius, vol. 2: Panarion haer. 34-64. Edited by Karl Holl. Revised edition by Jurgen Dummer. Die Griechischen Christlichen Schriftsteller, 31. Berlin: Academie-Verlag.

Evans-Pritchard, E. E.

1981. A History of Anthropological Thought. Edited by André Singer. London: Faber and Faber.

1965. Theories of Primitive Religion, Oxford: The Clarendon Press.

1963. "The Comparative Method in Social Anthropology". The L. T. Hobhouse Trust Lecture delivered at the School of Economics and Political Sciences, University of London. London: Athlone Press.

1956. Nuer Religion. Oxford: Oxford University Press. Reprinted, Oxford, 1977.

Farquharson, A. S. L.

1951. Marcus Aurelius: his Life and his Works. Edited by D. A. Rees. Oxford: Basil Blackwell.

Fassett. H. C.

1890. "Sea Otter Hunting: How the Aleuts Conduct the Chase." The San Francisco Chronicle, 28 December. Reprinted in Robert F. Heizer, "The Aleut Sea Otter Hunt in the Late Nineteenth Century", Anthropological Papers: of the University of Alaska 8 (2 [May 1960]): 131-135.

Fedorova, Svetlana G.

1973. The Russian Population in Alaska and California, late 18th century 1867 Русское Население, Аляски и Калифорнии, конец XVIII века 
- $1867 \Gamma$. (Moscow: Nauka, 1971)]. Translated and edited by Richard A. Pierce and Alton S. Donnelly. Kingston, Ont:: The Limestone Press.

1971. Русское Население, Аляски и Калифорнии, конец XVIII века $1867 \Gamma$. Moscow: Nauka.

Fienup-Riordan, Ann.

1990a. Eskimo Essays: Yup'ik Lives and How We See Them. New Brunswick, NJ, and London: Rutgers University Press.

1990b. "The Bird and the Bladder: the Cosmology of Central Yup'ik Seal Hunting". Etudes/Inuit/Studies 14 (1-2): 23-38.

1988. "Eye of the Dance: Spiritual Life of the Bering Sea Eskimo". In Crossroads of Continents: Cultures of Siberia and Alaska, pp. 256-270. Edited by William W. Fitzhugh and Aron Crowell. Washington, DC: The Smithsonian Institution.

1986. "Nick Charles, Sr.". In The Artists behind the Work: Life Histories of Nick Charles, Sr., Frances Demientieff, Lena Sours, Jennie Thlunaut pp. 25-57. By Ann Fienup-Riordan et al. Fairbanks: University of Alaska Museum.

1983. The Nelson Island Eskimo: Social Structure and Ritual Distribution. Anchorage: Alaska Pacific Univeristy Press.

Fischer, Boniface.

1977. Novae Concordontiae Bibliorum Sacrorum iuxta vulgatum versionem critice editam, vol. 4. Tubingen: F. Frommann.

Fisher, Raymond H.

1943. The Russian Fur Trade, 1500-1700. Berkeley and Los Angeles: University of California Press.

Fitzhugh, William W., and Aron Crowell, eds.

1988. Crossroads of Continents: Cultures of Siberia and Alaska. Washington, D.C. and London: The Smithsonian Institution Press.

Fitzhugh, William W., and Susan A. Kaplan, eds.

1982. Inua: Spirit World of the Bering Sea Eskimo. Washington, D.C., and London: The Smithsonian Institution Press.

Florovsky, George.

1979. The Collected Works of George Florovsky, vol. 5: Ways of Russian Theology part 1. Translated by Robert L. Nichols. Belmont, MA: Nordland Publishing. 
Fortesque, Michael, ed.

ms. Comparative Eskimo Dictionary. University of Copenhagen.

Freeze, Gregory L.

1985. Introduction. In I. S. Belliustin: Description of the Clergy in Rural Russia, a Memoir of a Nineteenth-Century Parish Priest. Ithaca and London: Cornell University Press.

Frost, O. W., ed.

1988. Iournal of a Voyage with Bering, 1841-1742, by Georg Wilheim Steller. Translated by Margitt A. Engel and O. W. Frost. Stanford: Stanford University Press.

Garrett, Paul.

1979. St. Innocent, Apostle to America. Crestwood, N.Y.: St. Vladimir's Seminary Press.

Geerard, Mauritii.

1974-87. Clauis Patrum Graecorum. 5 volumes. Turnhout: Brepols.

Geoghegan, Richard Henry, ed. and trans.

1944. The Aleut Langauge: the Elements of Aleut Grammar with a Dictionary in two parts containing Basic Vocabularies of Aleut and English. Edited by Fredericka I. Martin. Washington, D.C.: United States Department of the Interior. Reprinted, Seattle: Shorey Publications, 1973.

Germanus Constantinopolitanus.

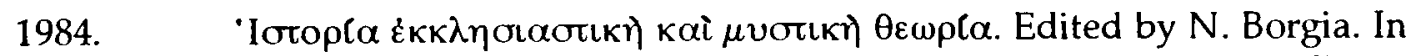
"Il commentario liturgico di S. Germano patriarca Constantinopolitano e versiona latina di Anastasio Bibliotecario", Studi Liturgici 1. Grottaferrata, 1912. Reprinted in St. Germanus of Constantinople: On the Divine Liturgy. Commentary by Paul Meyendorff. New York: St. Vladimir's Seminary Press.

Gershom, Yonassan.

1987. "Shamanism in the Jewish Tradition". In Shamanism: an Expanded View of Reality, pp. 181-188. Compiled by Shirley Nicholson. Wheaton, IL and London: Theosophical Publishing House.

Gibson, J. R.

1969. Feeding the Russian Fur Trade: Provisionment of the Okhotsk Seaboard and the Kamchatka Peninsula, 1639- 1856. Madison: University of Wisconsin Press. 


\section{Gideon (Hieromonk).}

1989. The Round the World Voyage of Hieromonk Gideon, 1803- 1809. Translated by Lydia T. Black. Edited by Richard A. Pierce. Alaska State Library Historical Monograph. Kingston, Ont., and Fairbanks, AK: The Limestone Press.

Gilbert, George.

1982. The Journal of Midshipman George Gilbert. Edited by Christine Holmes. Honolulu: University Press of Hawaii.

Glare, P. G. W., ed.

1982. Oxford Latin Dictionary. Oxford: The Clarendon Press; reprinted 1992.

Glazik, Josef.

1954. Die Russisch-Orthodoxe Heidenmission seit Peter dem Grossen. Munster: Aschendorffsche Verlagsuchhandlung.

Golder, Frank A

1925. Preface. In Sergei Fedorovich Platonov, History of Russia, pp. v-vii. London: McMillan \& Co.

1917. "Guide to Materials for American History in Russian Archives". Carnegie Institution Publications, 239. Washington, D.C.: The Carnegie Institution.

1914. Russian Expansion on the Pacific: an Account of the ... Expeditions made by the Russians along the Pacific Coast of Asia and North America, 1641-1850. Cleveland: Arthur H. Clarke, Co.

1909. "Eskimo and Aleut Stories from Alaska." Journal of American Folklore 22 (83): 10-24.

1907a. "A Kadiak [sic] Island Story: the White-Faced Bear" Iournal of American Folklore 20 (79): 296-299.

1907b. $\quad$ "Tlingit Myths". Lournal of American Folklore 20 (79): 290-296.

1907c. "The Songs and Stories of the Aleuts with Translations from Veniaminov." Iournal of American Folklore 20 (77): 132-142.

1905. "Aleutian Stories." Lournal of American Folklore 18 (70): 215-222.

1903a. "Tales from Kodiak Island, II." Journal of American Folklore 16 (61): 85-103.

1903b. "Tales from Kodiak Island." Lournal of American Folklore 16 (60): 16-31. 
Graves, Kathleen.

1981. "Russian New Year in Port Graham." Tundra Times (7 January), pp. 5, 10.

Gregorius Thessaloniensis (Palamas).

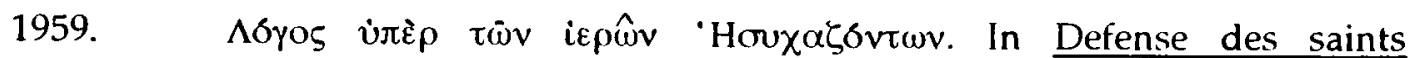
hesychastes. Edited by John Meyendorff. Spicilegium Sacrum Lovaniense, Etudes et documents, 30-31. Louvain.

Hale, Charles R.

1877. "Innocent of Moscow, the Apostle of Kamchatka and Alaska". The American Church Review 29: 402-419. Edited by Edward B. Boggs. $\overline{N Y:}$ No. 7 Cooper Union. London: Trubner \& Co.

Hammerich, Louis L.

1954. "The Russian Stratum in Alaskan Eskimo". Slavic Word 3 [Word, The Linguistic Circle of New York, 10 (4)]: 401- 428.

Hatch, Edwin and Henry A. Redpath.

1906. A Concordance to the Septuagint .... Supplement. Oxford: The Clarendon Press.

1897. A Concordance to the Septuagint and other Greek versions of the Old Testament (including Apocryphal Books), part 1. Oxford: The Clarendon Press.

Hawkes, Ernest William.

1914. "The Dance Festivals of the Alaskan Eskimo." University of Pennsylvania Museum Anthropological Publications 6 (2): 3-45.

1913. The Inviting-in Feast of the Alaskan Eskimo. Geological Survey Memoir, 45. Ottawa: Canada Deptartment of Mines.

Hinckley, Jr., Theodore Charles.

1961. The Alaska Labors of Sheldon Jackson, 1877-1890. Ph.D. dissertation, Department of History, Indiana University. Ann Arbor: University Microfilms.

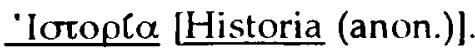

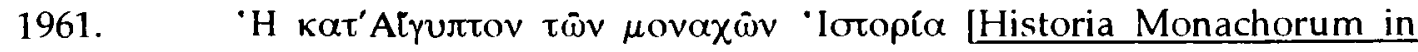
Aegyptol. Edited by A. J. Festugière. Subsidia Hagiographica, 34. Brussels: Société des Bollandistes. 
Holmberg, Heindrich Johan.

1985. Holmberg's Ethnographic Sketches. The Rasumuson Library Historical Translation Series, 1. Fairbanks: University of Alaksa Press.

1856. "Ethnographische Skizzen über die Völker des Russischen Amerika". Acta Societatis Scientiarum Fennicae, vol. 4, pp. 410-417. Helsinki: $\mathrm{H}$. C. Friis.

1855. Ethnographische Skizzen über die Völker des Russischen Amerika. Helsinki: H. C. Friis.

"Holy Ruling Synod [of the Russian Church] Documents".

mss. "Holy Ruling Synod Documents." In "Russian Reproductions". The United States Library of Congress Manuscript Division. Washington, D.C.

Hosley, Edward H.

1966. "Factionalism and Acculturation in an Alaskan Athapaskan Community". Ph.D. dissertation, Department of Anthropology, University of California at Los Angeles. Ann Arbor: University Microfilms.

1961. "The McGrath Ingalik". Anthropological Papers of the University of Alaska 9 (2): 93-113.

Huggins, Eli Lundy.

1981. Kodiak and Afognak Life, 1868-1870. Edited by Richard A. Pierce. Kingston, Ont.: The Limestone Press.

Hutchinson, Isabel.

1942. The Aleutian Islands: America's Back Door. 2nd edition. London: Blackie \& Sons.

Hultkrantz, Aake.

1990. "Arctic or Circumpolar Religions". Paper presented at the IAHR (International Association for the History of Religion) Regional Conference on Circumpolar and Northern Religion. University of Helsinki, Department of the Study of Religion.

1978. "Ecological and Phenomenological Aspects of Shamanism." In Shamanism in Siberia pp. 27-58. Edited by V. Diózegi and M. Hoppál. Bibliotheca Uralica, 1. Budapest: Akadémiai Kiadò.

1973. "A Definition of Shamanism". Temenos: Studies in Comparative Religion. [Finnish Society for the Study of Comparative Religions, Helsinki] 9: 25-37. 
Iakutsk Church Brotherhood.

1897. Gкутское Церковное Братство во имя Христа Спасителя вь 1895/96 г. lakutsk: Iakutsk Oblast Press.

Inge, William Ralph.

1918. The Philosophy of Plotinus. The Gifford Lectures at St. Andrew's, 1917-1918. 2 volumes. London: Longman's, Green \& Co.

1912. "Ecstasy". Encyclopedia of Religion and Ethics vol. 5, pp. 157-159. Edited by James Hastings. Edinburg: T. \& T. Clark.

1905. Studies of English Mystics. St. Margaret's Lectures, 1905. London: John Murray.

1899. Christian Mysticism, considered in eight lectures delivered before the University of Oxford. The Bampton Lectures, 1899. London: Methuen \& Co.

lnouye, Ronald $\mathrm{K}$.

1990. "Starring and Slava: a Legacy of Russian America". In Russia in North America: Proceedings of the 2nd International Conference on Russian America, pp. 358-378. Edited by Richard A. Pierce. Kingston, Ont. and Fairbanks, AK: The Limestone Press.

Ioannes Chrysostomus.

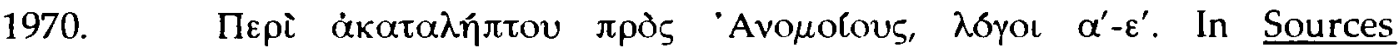
Chrétiennes, vol 28: Jean Chrysostom. Sur l'incompréhensibilité de Dieu, vol. 1: Homélies I-V. Edited by Anne-Marie Malingrey. Paris: Cerf.

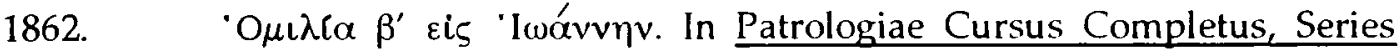

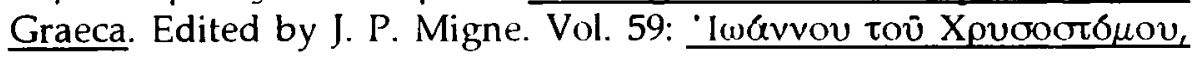

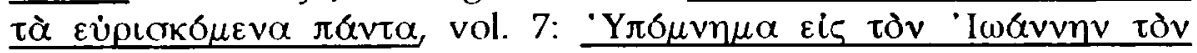

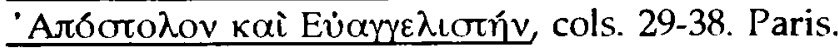

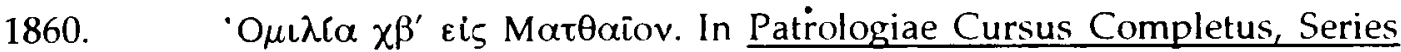
Graeca. Edited by J. P. Migne. Vol. 57-58: 'Iwórvvou toṽ Xpvoocró $\mu$ ov,

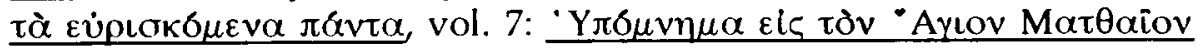

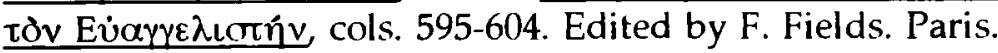

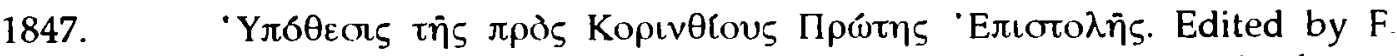
Fields. In Joannis Chrysostomi, Interpretatio omnium epistolarum Paulinarum, vol. 2. Oxford: J. H. Parker.

Ioannes Damascenus.

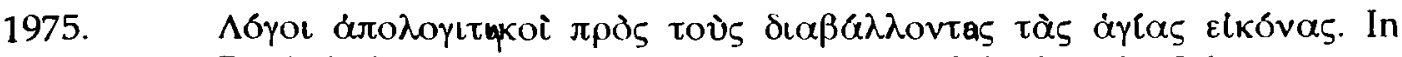
Patristische Texte und Studien, vol. 17: Die Schriften des Johannes von 
Damaskos. Edited by P. Bonifatius Kotter. Berlin and New York: Walter de Gruyter.

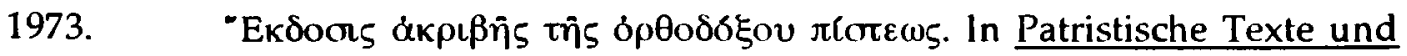
Studien vol. 12: Die Schriften des Johannes von Damaskos. Edited by P. Bonifatius Kotter. Berlin and New York: Walter de Gruyter.

Iokhel'son, Vladimir [Waldemar Jochelson].

1933. History, Ethnography and Anthropology of the Aleut lexpanded from the reports of the Kamchatka-Aleutian Expedition of the Imperial Russian Geographical Society, 1909-1910]. Carnegie Institution Publications, 432. Washington, D.C.: The Carnegie Institution.

lustinus martyr.

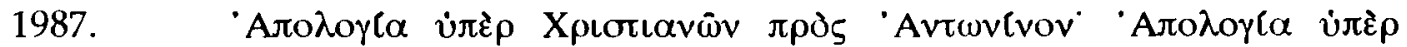

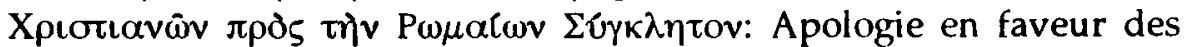
chrétiens adressée à Antonin; Apologie en faveur des chrétiens adressée au Sénat de Rome. In Saint Justin, Apologies, pp. 98-195. Edited and translated by André Wartelle. Paris: Etudes Augustiniennes.

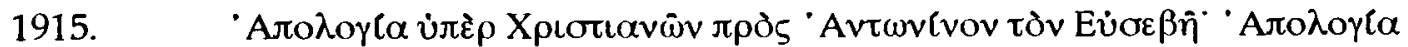

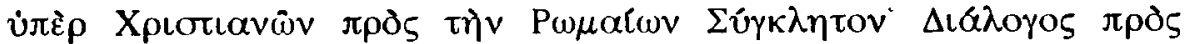

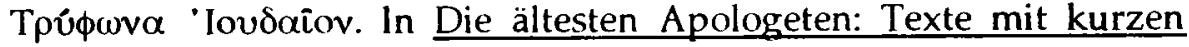
Einleitungen, pp. 26-265. Edited by Edgar Goodspeed. Göttingen: Vandenhoeck and Ruprecht. Reprinted, New York, 1950.

Ivashintsov, N. A.

1980. Russian Round-the-World Voyages, 1803-1849 . Translated by Glynn R. Barratt. Edited by Richard A. Pierce. Kingston, Ont.: The Limestone Press.

Jacobson, Steven A.

1984. Yup'ik Eskimo Dictionary. The Alaska Native Language Center. Fairbanks: University of Alaska.

Jaeger, Werner.

1947. The Theology of the Early Greek Philosophers. The Gifford Lectures, 1936. Oxford: The Clarendon Press.

James, Wendy.

1988a. "Introduction". In Vernacular Christianity: Essays in the Social Anthropology of Religion presented to Godfrey Lienhardt, Edited by Wendy James and Douglas H. Johnson. Journal of the Anthropological Society of Oxford JASOl Occasional Papers, 7. Oxford: JASO. 
1988b. The Listening Ebony: Moral Knowledge, Religion, and Power among the Udak of Sudan. Oxford: The Clarendon Press.

Johnson, Edgar $\mathrm{N}$.

1975. "The German Crusade in the Baltic". In A History of the Crusades. Edited by Kenneth M. Setton. Volume 3: The Fourteenth and Fifteenth Centuries pp. 545-585. Edited by Harry W. Hazard. Madison and London: University of Wisconsin Press.

Johnson, John F. C., ed.

1984. Chugach Legends: Stories and Photographs of the Chugach Region. Anchorage: The Chugach Alaska Corporation.

Jonas, Hans.

1963. The Gnostic Religion: the Message of the Alien God and the Beginnings of Christianity. Second edition revised. Boston: The Beacon Press.

Jones, Dorothy Miriam.

1980. A Century of Servitude: Pribilof Aleuts under U.S. Rule. Washington, D.C.: University Press of America.

1976. Aleuts in Transition: a Comparison of Two Villages. University of Alaska Institute of Social, Economic, and Government Research, Seattle and London: University of Washington Press.

1969. "A Study of Social and Economic Problems in Unalaska, an Aleut Village'. Ph.D. dissertation in Social Work, University of California at Berkeley. Ann Arbor: University Microfilms.

Kamenskii, Anatolii.

1985. Tlingit Indians of Alaska. Translated by Sergei Kan. Fairbanks: University of Alaska Press.

Kan, Sergei.

1990. "Recording Native Cultures and Christianizing the Natives - Russian Orthodox Missionaries in Southeastern Alaska". In Russia in North America: The Proceedings of the 2nd International Conference on Russian-America, pp. 298-313. Edited by Richard A. Pierce. Kingston, Ont.: The Limestone Press.

1983. "Words that Heal the Soul: Analysis of the Tlingit Potlatch Oratory". Arctic Anthropology 20 (2): 47-59. 
[KANA] Kodiak Area Native Association.

1987. "Oral history project undertaken by KANA for the Old Harbor Tribal Council History as part of their supplemental funding for [B.I.A.] 104(a) Grant No. E01G14207009", pp. 65-66; Cover letter from the Kodiak Area Native Association (KANA) to the Juneau Area Office of the B.I.A. dated 29 Sept. 1987.

Kashevarov, Andrew P.

1987. "John Veniaminov, Innocent, Metropolitan of Moscow and Kolomna". Alaska Magazine 1:2-4 (1927). Reprinted in Michael Oleksa, ed., Alaskan Missionary Spirituality pp. 341-362. New York: Paulist Press.

Kilbuck, John, and Edith Kilbuck.

1988. The Yup'ik Eskimos. Edited by Ann Fienup-Riordan. Kingston, Ont.: The Limestone Press.

King, James.

1784. A Voyage to the Pacific Ocean performed under the direction of Captains Cook [...l, 1776 [tol 1780 vol. 3. London: W. \& A. Strahan.

Kobtzeff, Oleg.

1984. "La Colonisation Russe en Amérique du Nord, 18-19 siecles." Doctoral dissertation, University of Paris 1 (Sorbonne).

Kodiak (anon.).

1985. The Arctic Willow: A History of an Alaskan Seminary, St. Herman's Theological School. Kodiak: $\mathrm{C}$ and M Printing Co.

Kontoglou, Photius [Fotis].

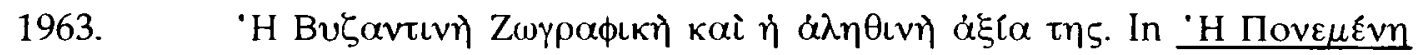
Puruooúvn, pp. 96-119. Athens: Astir.

Koranda, Lorraine D.

1968. "Three Songs for the Bladder Festival, Hooper Bay." Anthropological Papers of the University of Alaska 14 (1): 27-31.

Korsakovskii, Petr, and Ivan Ya. Vasilev.

1988. Russian Exploration in Southwest Alaska: the Travel Journals of Petr Korsakovskiy (1818) and Ivan Ya. Vasilev (1829). Translated by David H. Kraus. Edited by Marin W. Falk. The Rasmusen Library Historical Translation Series, 4. Fairbanks: University of Alaska Press. 
Kotzebue, Otto.

1821.

A Voyage of Discovery into the South Sea and the Beering's [sic] Straits ... 1815-1818. 3 volumes. London: Longman, Hurst, Rees, Orme and Brown.

Kovach, Michael George.

1957. "The Russian Orthodox Church in Russian-America". Ph.D. dissertation. University of Pittsburg [Pennsylvania].

Krasheninnikov, Stepan P

1764. The History of Kamtschatka and the Kurilski Islands DПисаниe ... Камчатки ... (St. Petersburg, 1754)]. Translated by James Grieve. Glocester [sic]: R. Raikes. Reprinted, Chicago: Quandrangle Books, 1962; Surrey: Richmond Publishing, 1973.

Krause, Aurel.

1956. The Tlingit Indians. Translated by Erna Gunther. Seattle: University of Washington Press.

Krause, Michael E.

1988. "Many Tongues - Ancient Tales" In Crossroads of Continents: Cultures of Siberia and Alaska, pp. 145- 150. Edited by William W. Fitzhugh and Aron Crowell. Washington, D.C., and London: The Smithsonian Institution Press.

1980. Alaska Native Languages: Past, Present, and Future. Alaska Native Language Center Research Papers, 4. Fairbanks: University of Alaska.

1973. "Eskimo-Aleut". In Current Trends in Linguistics, vol. 10: Linguistics in North America, pp. 796-902. Edited by Thomas A. Sebeok. The Hague and Paris: Mouton.

Krech, Shepard III.

1989. The Travels and Collections of the fifth Earl of Lonsdale 1888-9. London: British Museum Publications.

Krey, August C., ed. and trans.

1921. The First Crusade: the Accounts of Eye-Witnesses and Participants Oxford: Oxford University Press. Princeton: Princeton University Press.

Lada-Mocarski. Valerian.

1969. Bibliography of Books on Alaska published before 1868. New Haven and London: Yale University Press. 
Laguna, Fredrica de.

1972. Under Mount Saint Elias: The History and Culture of the Yakutat Tlingit. Washington, D.C.: The Smithsonian Institution.

1956. "Chugach Prehistory: the Archaeology of Prince William Sound, Alaska." University of Washington Publications in Anthropology 13.

Lampe, W. H., ed.

1961. Patristic Greek Lexicon. Oxford: The Clarendon Press.

Langsdorff, Georg Heinrich.

1814. Voyages and Travels to Various Parts of the World during the years $1803,1804,1805,1806$, and 1807 part 2: The Voyage to the Aleutian Islands and the Northwest Coast of America, and return by land over the Northeast parts of Asia, through Siberia. London: Henry Colburn.

1812. Bemerkungen auf einer Reise um die Welt in den Jahren 1803 bis 1807 vol. 2. Frankfurt: Friedrich Wilmans.

Lantis, Margaret.

1990. "The Selection of Symbolic Meaning." Etudes/ Inuit/Studies 14 (12):169-190.

1984. "Aleut". In Handbook of North American Indians. Edited by William C. Sturtevant. Vol. 5: Arctic, pp. 161-184. Edited by David Damas. Washington, D.C.: The Smithsonian Institution.

1966. Alaskan Eskimo Ceremonialism. American Ethnographical Society Monograph, 11. Seattle.

1950. "The Religion of the Eskimos." In Vergilius Ferm, ed., Forgotten Religions, pp. 311-339. New York: The Philosophical Library.

1946. "Social Culture of the Nunivak Eskimo." Transactions of the American Philosophical Society, new series, 35 (3): 153-323.

1938. "The Mythology of Kodiak Island, Alaska." Lournal of American Folklore 51 (200): 123-172.

Lantzeff, George V., and Richard A. Pierce.

1973. Eastward to Empire: Exploration and Conquest on the Russian Open Frontier to 1750 . Montreal: McGill-Queen's University Press.

Laughlin, William S.

1980. Aleuts: Survivors of the Bering Land Bridge. N.Y.: Holt, Rine., Winston. 
Lavrischeff, T. I.

1928. "Two Aleut Tales." American Anthropologist, new series, 30: 121-124.

Lawson, John.

1948. The Biblical Theology of Saint Irenaeus. London: The Epworth Press.

Layattienakoff [Goforth], Alexander.

1987a. "Ounalashka and Akutan". In Theata 12: 39-44. Department of Cross Cultural Communications, University of Alaska at Fairbanks.

1987b. $\quad$ "Spraznekum". In Theata 12: 296-300. Department of Cross Cultural Communications, University of Alaska at Fairbanks.

Ledyard, John.

1963. John Ledyard's Journal of Captain Cook's Last Voyage. Edited by James Kenneth Munford. Oregon State Monographs, Studies in History, 3. Corvallis: Oregon State University Press.

Leer, J., ed.

ms. Alutiiq Dictionary. The Alaska Native Language Center, University of Alaska, Fairbanks.

Lemaitre, J. [Irénée Hausherr].

1953. "Mystique Extatique: Contemplation chez les Grecs et autres Orientaux Chétiens". In Dictionnarie de Spiritualité, vol. 2, cols. 1862-1872 Edited by $M$. Viller et al. La Faculté de Théologie d' Enghien (Belgium). Paris: Beauchesne.

Lessa, William A. and Evon Z. Vogt.

1979. "The Purposes of Shamanism: Introduction", in A Reader in Comparative Religion: an Anthropological Approach. 4th edition. NY: Harper and Row.

Levin, M. G. and L. P. Potapov.

1964. The Peoples of Siberia. Translated by Scripta Technica. Edited by Stephen Dunn. Institute of Contemporary Russian Studies. Chicago: Fordham University.

Lévy-Bruhl, Lucien.

1985. How Natives Think [Les Fonctions dans les Sociétes Inférieures (Paris, 1918)]. Translated by Lilian A. Clare. 3rd edition reprinted. Princeton: Princeton University Press. 
1975. The Notebooks on Primitive Mentality. Translated by Peter Riviere. Oxford: Basil Blackwell.

1949. Les Carnets de Lévy-Bruhl. Bibliothèque de Philosophie Contemporaine. Paris: Presses Universitaires de France.

1918. Les Fonctions dans les Sociétes Inférieures. 3rd Edition. Bibliothéque de Philosophie Contemporaine: Travaux de l'Année Sociologique publiés sous la direction de M. E. Durkheim. Paris: Alcan.

Lewis, Ian M.

1971. Ecstatic Religion: an Anthropological Study of Spirit Possession and Shamanism. Harmandsworth, Middlesex: Pelican Anthropological Library.

Liapunova, R. G.

1987. "Relations with Natives of Russian America". In Russia's American Colony. Edited by S. Frederick Starr. Durham: Duke University Press.

Liddel, Henry George, and Robert Scott, comps.

1940. A Greek-English Lexicon, new edition. Edited by Henry Stuart Jones. Oxford: The Clarendon Press.

Lienhardt, Godfrey.

1964. Social Anthropology. The Home University of Modern Knowledge, 253. London, N.Y, Toronto: Oxford University Press.

1961. Divinity and Experience: the Religion of the Dinka. Oxford: The Clarendon Press.

Litke, Frederic [Lutke, Frederic].

1987. A Voyage Around the World, 1826-1829, vol. 1: To Russian A merica and Siberia. Translated by Renée Marshall and Joan Moessner. Edited by Richard A. Pierce. Kingston, Ont.: Limestone Press.

1835. Voyage autour du Monde, execute par ordre de sa Majeste l'Empereur Nicolas I ${ }^{\text {er }} \ldots$ dans les annees $1826[-] 1829 \ldots$ 1. Paris: Didot Freres.

Lopez de Haro, Gonzalo.

ms. Diario de Navigación que con el auxilio Divino, y protección de nuestra Señora del Carmen, espera hacer, el primer Piloto de la Real Armada, y Capitán del Paquebot, de S. M. nombrado San Carlos (alias el Filipino) ..., 29 June 1 July 1788. Department of Manuscripts, the Huntington Library, San Marino, CA. 
Lot-Falck, Eveline.

1957. "Les masques Eskimo et Aléoutes de la collection Pinart." Journal de la Société des Américanistes, new series, 46: 5-43.

Louth, Andrew.

1989. Denys the Areopagite. Outstanding Christian Thinkers Series. Wilton, CT: Morehouse-Barlow.

1981. The Origins of the Christian Mystical Tradition from Plato to Denys. Oxford: The Clarendon Press.

Makarova, Raisa V.

1975. Russians on the Pacific, 1743-1799 Русские на Тихом Океане во Второй половине XVIII в. (Moscow: Nauka, 1968)]. Translated and edited by Richard A. Pierce and Alton S. Donnelly. Kingston, Ont.: The Limestone Press.

1968. Русские на Тихом Океане во второй половине XVIII в. Moscow: Nauka.

Mansi, Johannes Dominicus, ed.

1767. Sacrorum Conciliorum Nova et Amplissima Collectio vol. 13: 787 A.D. - 841 A.D. Florence.

[ Marriott, C., ed. ]

1851. A Library of Fathers of the Holy Catholic Church, anterior to the division of East and West, vol. 33: The Homilies of S. John Chrysostom, archbishop of Constantinople, on the Acts of the Apostles, part 1: Hom. i-xxviii. Translated by Members of the English Church [J. Walker, J. Sheppard, and H. Browne]. Oxford: John Henry Parker. London: F. \& J. Rivington.

Marsh, Gordon $\mathrm{H}$.

1967. "A Comparative Survey of Eskimo-Aleut Religion" [abridged version of id. 1954]. In The North American Indians: a Sourcebook pp. 143-159. Edited by Roger C. Owen, et. al. London and NY: MacMillan.

1954. "A Comparative Survey of Eskimo-Aleut Religion". Anthropological Papers of the University of Alaska 3 (1): 21-36.

Martin, Louise.

1986. Michael Z. Vinokouroff: A Profile and Inventory of his Papers (Ms 81) and Photographs (PCA 243) in the Alaska Historical Library. Juneau: Alaska Deptartment of Education, Division of State Libraries. 
Mather, Elsie P.

1985. Cauyarnariug. Bethel, AK.: The Lower Kuskokwim School District,

McClanahan, A. J., ed.

1986. Our Stories, Our Lives: a Collection of Twenty-Three Transcribed Interviews with Elders of the Cook Inlet Region. The Cook Inlet Region, Inc. [CIRI] Foundation. Anchorage: CIRI.

Mclntyre, H. H.

1870. "Alaska". In Ex. Doc. no. 36. 41st Congress, U.S. House of Representatives, 2nd Session (11 January). Washington, D.C.

Merculieff, llarion.

1984. Narration. Amiq: The Aleut People of the Pribilof Islands, a Culture in Transition, 1981-1983. Documentary film directed and produced by Susanne Swibold and Helen Corbett. Alberta, Canada: Flying Tomato Productions.

Meyendorff, Paul.

1984. Introduction. In St. Germanus of Constantinople on the Divine Liturgy. Crestwood, N.Y.: St. Vladimir's Seminary Press.

Miyaoka, Osahito.

1978. "Alaska Native Languages in Transition". In Alaska Native Culture and History pp. 169-203. Edited by Yoshinobu Kotani and William B. Workman. Senri Ethnological Studies, 4. Osaka: National Museum of Ethnology.

Moore, Katrina $\mathrm{H}$.

1979. "Spain Claims Alaska, 1775". In The Sea in Alaska's Past Conference Proceeding, pp. 62-74. History and Archaeology Publication Series, no. 25. Anchorage: Office of History and Archaeology, Alaska Division of Parks.

Morrow, Phyllis.

1990. "Symbolic Actions, Indirect Expressions: Limits to Interpretation in Yupik Society." Etudes/Inuit/Studies 14 (1-2):141-158.

1984. "It is a Time for Drumming: A Summary of Recent Research on Yup'ik Ceremonialism." 'Etudes/Inuit/ Studies 8: 113-140. 
Mousalimas, Soterios A.

n.d.a Introduction. In The Journals of Ivan Veniaminov from Sitka and Unalaska, 1823-1837. The Rasmuson Library Historical Translation Series, University of Alaska, Fairbanks (in print).

n.d.b Grigorii lvanovich Shelikhov: In his own Words, the First Missionary (Kodiak, Alaska)". Greek Orthodox Theological Review (in print).

n.d.c "The Ambiguity about Archimandrite loasaph in the 'Spiritual Mission' to Kodiak, Alaska, 1794". Greek Orthodox Theological Review (in print).

n.d.d "Ecstasy" in Epiphanius of Constantia [Salamis] and Didymus of Alexandria". In Studia Patristica 24-28 [Proceedings of the 11th International Conference on Patristic Studies, Oxford University, 19-24 August 1991]. Louvain: Peeters (in print).

n.d.e "Непрернвность и Прерывность в Религиозных Культах Аляски." Translated by Ekaterina Y. Pogibeleva. lakut State University (in print).

1991. "The Account from Old Harbor regarding the Baptism of the Kodiak Alutiiq, 1794/95". Greek Orthodox Theological Review 36 (2): 155-168.

1990a. "The Concept of Participation in Lévy-Bruhl's 'Primitive Mentality". Iournal of Anthropological Studies at Oxford 21 (1): 33-46.

1990b. "The Divine in Nature: Animism or Panentheism?" Paper presented at the International Association for the History of Religion Regional Conference on Circumpolar and Northern Religion. Department of the Study of Religion. The University of Helsinki.

1990c. "The Name, an Icon: Naming as Imaging in Southwestern Alaska". Paper presented at the 7th International Inuit Studies Conference, Symposium on Inuit Symbolism and Iconography. The University of Alaska at Fairbanks.

1990d. "Russian Orthodox Missionaries and Southern Alaska Shamans: Interactions and Analysis". In Russia in North America: Proceedings of the 2nd International Conference on Russian-America, pp. 314-322. Edited by Richard A. Pierce. Kingston, Ont. and Fairbanks, AK: The Limestone Press.

1990e. "'...If Reports Can Be Believed, Russian Priests Destroyed All the Masks They Could Find." Etudes/ Inuit/Studies 14 (1-2): 191-208.

1990f. "The Formation of the Unalaska Parish". Greek Orthodox Theological Review 36 (1): 21-35.

1989a. "Shamans of Old in Southern Alaska." Paper presented at the 12th International Congress on Anthropological and Ethnological Sciences. In Shamanism: Past and Present 2, pp. 307-316. Edited by Mihaly Hoppál and Otto von Sadovszky. Budapest and Los Angeles: Ethno- 
Hoppál and Otto von Sadovszky. Budapest and Los Angeles: Ethnographic Institute of the Hungarian Academy of Sciences, and ISTOR Books.

1989b. "Contrasting Theological Outlooks on Ancient Kodiak Culture." Paper presented at the 1st Kodiak Island Culture Heritage Conference. In Greek Orthodox Theological Review 34 (4): 365-378.

1988a. "Continuity and Discontinuity in Belief Systems in Southern Alaska". Paper presented at the 15th Annual Meeting of the Alaska Anthropological Association, Fairbanks, Alaska, 25-27 March 1988.

1988b. "Patristics and Missionary Work: an Example from the Russian Orthodox Mission in Alaska." Paper presented at the 10th International Conference on Patristic Studies, Oxford. In Greek Orthodox Theological Review 33 (3): 327-334.

1988c. "An Aleut among the Yup'ik [Yupiit]: Alaskan Cosmologies in Contact." Paper presented at the Conference on the Cosmologies of Polar Peoples, University of Edinburgh. In Shadow: Journal of the Traditional Cosmology Society 5 (2): 38-44.

1987. "The Consequences of Nestorius' Metaphysics." Greek Orthodox Theological Review 32 (3): 279-284.

1980. "The Defense of the Council of Chalcedon in the Patriarchate of Jerusalem, 415-518 A.D.". M.Div. thesis, Holy Cross Greek Orthodox School of Theology, Brookline, MA.

Müller, Gerhard Friedrich.

1986. Bering's Voyages: the Reports from Russia. Translated by Carol Urness. Edited by Marvin W. Falk. The Rasmusen Library Historical Translation Series, 3. Fairbanks: University of Alaska Press.

[Murav'ev] Mouravieff, A. N.

1855. Русская Өиваида на Съверъ. Moscow: S.P.B.

1842. A History of the Church in Russia. Translated by R. W. Blackmore. Oxford: John Henry Parker.

Nelson, Edward William.

1899. "The Eskimo about Bering Strait" 18th Annual Report, Bureau of Ethnology. Washington, DC: The Smithsonian Institution.

Netsvetov, Iakov.

1984a. The Journals of Iakov Netsvetov: The Yukon Years, 1845- 1863. Translated by Lydia T. Black. Kingston, Ontario: The Limestone Press. 
1984b. "Notes on the Former Customs and Beliefs of the Atkha Aleuts" ["Записки ... Атхинскихъ Алеутовъ" (St. Petersburg, 1840)]. Edited by Ivan Veniaminov. In Ivan Veniaminov, Notes on the Islands of the Unalaska District, pp. 365-379. Translated by Lydia T. Black and R. H. Geoghegan. Edited by Richard A. Pierce. Kingston, Ont.: The Limestone Press.

1980. The lournals of lakov Netsvetov: The Atkha Years, 1828- 1844. Translated by Lydia T. Black. Kingston, Ont.: The Limestone Press.

1840. "Записки о Прежнихъ [Обычаях и Верах] А тхинскихъ Алеутовъ." Edited by Ivan Veniaminov. In Ivan Veniaminov, Записки объ Ост ровахъ Уналашкинскаго Отдьла, part 3, pp. 1-19. St. Petersburg: [the Russian-American Company].

Niarchos, Constantine G.

1991. "Aristotle's Categories in St. John of Damascus' Dialectica." Paper presented at the 11th International Conference on Patristic Studies, Oxford.

Nicephorus Constantinopolitanus.

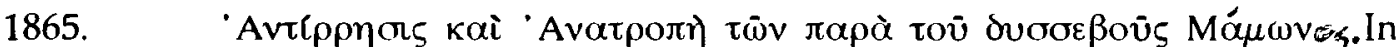
Patrologiae Cursus Completus Series Graeca. Edited by J. P. Migne.

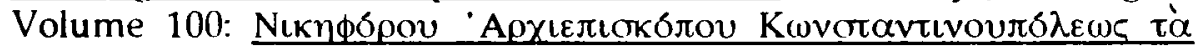
$\varepsilon \dot{v} \rho\llcorner\sigma \kappa \delta \mu \varepsilon v \alpha \pi \alpha ́ v \tau \alpha$, cols. 205-534. Paris.

O.C.A. [ "Orthodox Church in America" (sic) ].

1970. Booklet for the Canonization of Saint Herman of Alaska. Syosset, NY: by the author.

Oleksa, Michael James.

1990. "The Death of Hieromonk Juvenaly" In Russia in North America: Proceedings of the 2nd International Conference on Russian-A merica, pp. 322-257. Edited by Richard A. Pierce. Kingston, Ont. and Fairbanks, AK: The Limestone Press.

Oleksa, Michael James, ed.

1987. Alaskan Missionary Spirituality. Sources of American Spirituality. N.Y.: The Paulist Press.

Oliver, Ethel Ross.

1988. Lournal of an Aleutian Year. Seattle: University of Washington Press.

Origenes.

1936. Origen on First Principles. Translated by G. W. Butterworth. London: SPCK. 
Osgood, Cornelius.

1937. The Ethnography of the Tanaina [Dena'inal. Yale University Publication in Anthropology, 16. New Haven: Yale University Press.

Oswalt, Wendell.

1963a. Napaskiak: an Alaskan Eskimo Community. Tuscon: University of Arizona Press.

1963b. Mission of Change in Alaska: Eskimos and Moravians on the Kuskokwim. San Marino, CA: Huntington Library.

Padgen, Anthony.

1982. The Fall of Natural Man: the American Indian and the Origins of Comparative Ethnology. Cambridge Iberian and Latin American Studies. Cambridge: Cambridge University Press.

Palladius Helenopolitanus.

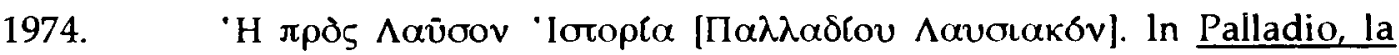
Storia Lausiaca. Edited by G. J. M. Bartelink. Translated by Marino Barchiesi. Vite dei Santi, 2. [Milan and Verona]: Fondazione Lorenzo Valla.

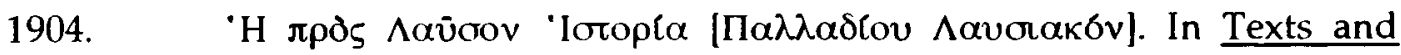
Studies: Contributions to Biblical and Patristic Literature. Edited by J. Armitage Robinson. Vol. 6, no. 2: The Lausiac History of Palladius, II. Edited by Cuthbert Butler. Cambridge: Cambridge University Press.

Palmer, G. E. H., Philip Sherrard, and Kallistos Ware, trans.

1979. The Philokalia, vol. 1. London and Boston: Faber and Faber.

Pascal, Pierre.

1976. The Religion of the Russian People. Translated by Rowan Williams. London: Mowbrays.

Pentikäinen, Juha Y.

1989. Kalevala Mythology. Translated and edited by Ritva Poom. Bloomington: Indiana University Press.

1978. "Oral Repretoire and Worldview: an Anthropological Study of Marina Takalo's Life History" Folklore Fellows Communication 219.

Percival, Henry R., trans. and ed.

1900. "The Seven Ecumenical Councils of the Undivided Church: their Canons and Dogmatic Decrees." In A Select Library of Nicene and Post-Nicene Fathers of the Christian Church second series, vol. 14: The 
Seven Ecumenical Councils of the Undivided Church. Oxford: James Parker. N.Y.: The Christian Literature Co.

Petrivelli, Alice.

n.d. Forword. In the Journals of Ivan Veniaminov from Unalaska and Sitka, 1823-1837. The Rasmuson Library Historical Translation Series, University of Alaska at Fairbanks (in print).

Petroff, Ivan.

1884. "Alaska: Its Population, Industries, and Resources". In Census of 1880 vol. 8. U.S. Department of the Interior, Census Office. Washington, D.C.: Government Printing Office.

1881. "Population and Resources of Alaska", Ex. Doc. no. 40. 46th Congress, U.S. House of Representatives, 3rd Session (15 January), vol. 18. Washington, D.C.

Petterson, A.

1990. Athanasius and the Human Body. Bristol: The Bristol Press.

Pharos, Philotheos.

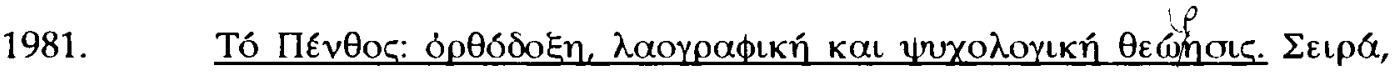

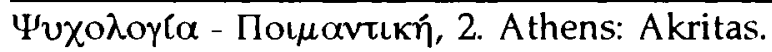

Pheidas, Vlasios.

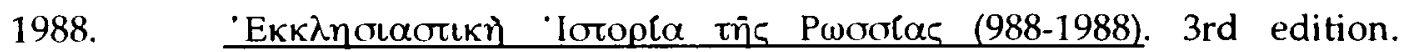

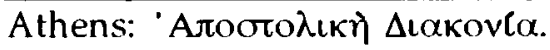

Pierce, Richard A.

1990. Russian-America: A Biographical Dictionary. Kingston, Ont. and Fairbanks, AK: The Limestone Press.

1986. Builders of Alaska: The Russian Governors, 1818-1867. Kingston, Ont.: The Limestone Press.

1981a. Introduction. In A Voyage to America, 1783-1786 by Grigorii I. Shelikhov. Kingston, Ont.: The Limestone Press.

1981b. Introduction. In Eli Lundy Huggins, Kodiak and Afognak Life, 1968-1870. Kingston, Ont.: The Limestone Press.

1978. Notes. In Valaam Monastery, The Russian Orthodox Religious Mission in America, pp. 176-181. Kingston, Ont.: The Limestone Press.

1964. "A note on 'Ivan Petroff and the Far Northwest'". Journal of the West 3 (4): $436-439$. 
Pierce, Richard A., trans. and ed.

1984. The Russian-American Company: Correspondence of the Governors, Communication Sent: 1818. Kingston, Ont.: The Limestone Press.

Pierce, Richard A., ed.

1976. Documents on the History of the Russian-American Company. Translated by Marina Ramsay. Kingston, Ont.: The Limestone Press.

Pinart, Alphonse.

ms. Field Notes from the Kodiak Island Region, 1871-72. Bancroft Library, University of California at Berkeley.

1874a. "Les Aléoutes et leur Origine". Mèmoires de la Société d'Ethnographie: Revue Orientale et Américaine 1st. series, 12: 155-165.

1874b. $\quad$ "Voyage de la Cote Nord-Ouest d'Amerique d'Ounalashka a Kodiak (lles Aléoutienne et Péninsule d'Aliaska)." Extract, Bulletin de la Société de Géographie (Dec. 1873). Paris: Ch. Delagrave.

1873a. "Les Aléoutes, leurs origines et leurs légendes." Actes de la Société d'Ethnographie, 2nd series, 7 (3) [June 1872]: 87-92.

1873b. "Eskimaux et Koloches: Idées Religieuses et Traditions de Kaniagmioutes". Revue d'Anthropologie 2: 673-680.

Platonov, Sergei Fedorovich.

1925. History of Russia. Translated by E. A. Aronsberg. Edited by F A. Golder. London: Macmillan Press.

Porter, Robert P.

1893. Report on the Population and Resources of Alaska at the Eleventh Census: 1890. U.S. Department of the Interior, Census Office. Washington, D.C.: Government Printing Office.

Prokopovich, Feofan.

1723. The Russian Catechism composed [by F. Prokopovich] and published by order of the Czar. Translated by J. T. Phillips. London.

Prossoff [Prokoff], Alexei.

1988. "Alex Prossoff's Story" [personal account dictated on 16 March 1947]. In Ethel Ross Oliver, lournal of an Aleutian Year, Appendix 2, pp. 241-248. Seattle and London: University of Washington Press. 
Pullar, Gordon L.

1991. "Ethnic Identity, Cultural Pride, and Generations of Baggage: a Personal Experience". Paper presented in the Symposium on the Spirituality of Alaska Native Peoples Past and Present, 18th Annual Meeting, Alaska Anthropological Association.

Pyong-choon, Hahm.

1988. "Shamanism and the Korean World-View, Family Life-Cycle, Society and Social Life". In Shamanism: the Spirit World of Korea, pp. 60-97. Edited by Richard W. I. Guisso and Chai-shin Yu. Studies in Korean Religions and Culture, 1. Berkeley: Asian Humanities Press.

Radchenko, lurii.

1981. "Extract from 'Kolumbu Rosskomu ...". Translated by Marina Ramsay. In Grigorii I. Shelikhov, A Voyage to America, 1783-1786. Appendix 9, pp. 138-145. Edited by Richard A. Pierce. Kingston, Ont.: The Limestone Press.

1979. "Колумбу Росскому ..." Панорама Искусств 78: 341-351.

Ransom, Jay Ellis.

1947. "Stories, Myths, and Superstitions of Fox Island Aleut Children." Lournal of American Folklore 60 (235): 62- 72.

1945a. "Writing as a Medium of Acculturation among the Aleut". Southwestern lournal of Anthropology 1 (1): 333-344.

1945b. "Aleut Religous Beliefs: Veniaminov's Account." \ournal of American Folklore 58 (230): 346-349.

Ransom, Jay Ellis [ed.].

1941. "Wreck of the Umnak Native [by Afenogin Ermelov, translated from Aleut by Gregory Kochergin]." Alaskan Sportsman 7 (2) [February issue, Ketchikan, AK].

Rathburn, Robert R.

1981. "The Russian Orthodox Church as a Native Institution among the Koniag Eskimo of Kodiak Island, Alaska". Arctic Anthropology 18 (1): $12-22$.

Ray, Dorothy Jean.

1981. Aleut and Eskimo Art: Tradition and Innovation in South Alaska. Seattle: University of Washington Press.

1967. Eskimo Masks. Seattle: University of Washington Press. 
Ray, Dorothy Jean, ed.

1968. "St. Michael Eskimo Myths and Tales: Collected by J. Henry Turner and J. M. Edmonds." Anthropological Papers of the University of Alaska 14 (1): 43-83.

Rexine, John E.

1985. "Daimon in Classical Greek Literature". Greek Orthodox Theological Review 30 (3): 335-362.

Romanides, Ioannes S.

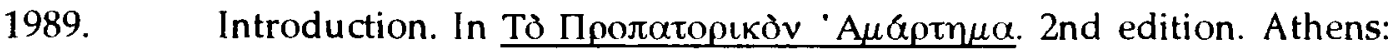
Domos.

1981. Franks, Romans, Feudalism and Doctrine: an Interplay between Theology and Society. The Patriarch Athenagoras Memorial Lectures, 1980. Brookline, MA: Holy Cross Orthodox Press.

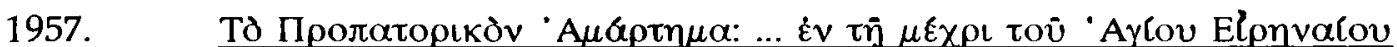

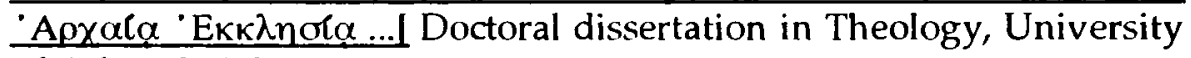
of Athens]. Athens: 'Arooro $\lambda \iota \kappa \eta े$

Rostad, Michael.

1988. Time to Dance: Life of an Alaska Native [llarion Matfayl. Anchorage: A. T. Publishing.

Rubenson, Samuel.

1990. The Letters of St. Anthony: Origenist Theology, Monastic Tradition and the Making of a Saint. Bibliotheca Historio- Ecclesiastica Lundensis, 24. Lund: Lund University Press.

Rudolph, Kurt.

1983. Gnosis: the Nature and History of an Ancient Religion. Translated by Robert McLachlan. Edinburgh: T. \& T. Clark, Ltd.

Runciman, Steven.

1969a. "The First Crusade: Constantinople to Antioch" In A History of the Crusades. Edited by Kenneth M. Setton. Volume 1: The First Hundred Years, pp. 280-304. Edited by Marshall W. Baldwin. Madison and London: University of Wisconsin Press.

1969b. "The First Crusade: Antioch to Ascalon". In A History of the Crusades. Edited by Kenneth M. Setton. Volume 1: The First Hundred Years pp. 308-342. Edited by Marshall W. Baldwin. Madison and London: University of Wisconsin Press. 
1969c. "The Crusader States, 1243-1291". In A History of the Crusades. Edited by Kenneth M. Setton. Volume 2: The Later Crusades, 1189-1311 pp. 557-598. Edited by Robert Lee Wolff and Henry W. Hazard. Madison and London: University of Wisconsin Press.

1954. A History of the Crusades. Volume 3: The Kingdom of Acre. Cambridge: Cambridge University Press.

1952. A History of the Crusades. Volume 2: The Kingdom of Jerusalem. Cambridge: Cambridge University Press.

1951. A History of the Crusades. Volume 1: The First Crusade and the Foundation of the Kingdom of Jerusalem. Cambridge: Cambridge University Press.

"Russian American Company Documents".

mss. $\quad$ "Russian American Company Documents". In the Gennadii V. Iudin [Yudin] collection. The Library of Congress Manuscript Division. Washington, D.C.

Sahas, Daniel J.

1986. Icon and Logos: Sources in Eighth Century Iconoclasm: an annotated translation of the Sixth Session of the Seventh Ecumenical Council (Nicea, 787) ... Toronto, Buffalo, London: University of Toronto Press.

Salomatov, Lavrentii, trans.

1959. The Gospel according to St. Mark [in Atkan Aleut]. In The Transactions of the American Philosophical Society at Philadelphia, new series, 49 (3): Aleut Dialects of Atka and Attu, pp. 87-103.

Sardy, Mari.

1985/86. "Early Contact between Aleuts and Russians, 1741- 1780". Alaska History 1 (2): 43-58.

Sarychev, Gavriil [Sarytschew, Gawrila].

1807. Account of a Voyage of Discovery to the Northeast of Siberia, the Frozen Ocean, and the Northeast Sea. Volume 2. In A Collection of Modern and Contemporary Voyages and Travels, vol. 6. London.

1802.

Путешествіе Флота Капитана Сарычева ... Сь 1785 по 1793 годь, 2 vols. St. Petersburg.

Sauer, Martin.

1802. An Account of a Geographical and Astronomical Expedition to the Northern Parts of Russia ... performed ... by Commodore Joseph Billings in the years 1785-1794. London: A. Strahan. 
Schaff, Philip, ed.

1899. Nicene and Post-Nicene Fathers of the Christian Church, 1st series, vol. 11: Saint John Chrysostom: Homilies on the Acts of the Apostles ... N.Y.: Charles Scribner's Sons. Reprinted Grand Rapids: Wm. B. Eerdmans Publishing Co., 1956.

Shade, Charles I.

1951. "The Girls' Puberty Ceremony of Umnak, Aleutian Islands." American Anthropologist 53: 145-148.

1949. "Ethnological Notes on the Aleuts". B.A. Honours Thesis, Harvard University.

Shelikhov, G. I.

1981. Voyage to America, 1783-1786 Россійскаго Купца Григорья Шелехова Странствованиіе въ 1783 гопу ... (St. Petersburg, 1791; 2nd ed. 1792; 3rd. ed. rev. 1793)]. Translated by Marina Ramsey. Edited by Richard A. Pierce. Kingston, Ont.: The Limestone Press.

Sherrard, Philip.

1990. "Confronting the Ecological Challenge." The Southeastern Review 1 (1): 139-148.

1987. The Eclipse of Man and Nature: an Enquiry into the Origins and Consequences of Modern Science. West Stockbridge, MA: The Lindisfarne Press.

1967. "The Art of the Icon." In A.M. Allchin, ed., Sacrament and Image: Essays in the Christian Understanding of Man. London: The Fellowship of St. Alban and St. Sergius.

Sherwood, Morgan B.

1964. "A Note on the Petroff Note". Journal of the West 3 (4): 440.

1963. "Ivan Petroff and the Far Northwest". Journal of the West 2 (3): 305-315.

Shirokogoroff, S. M.

1935. Psychomental Complex of the Tungus. London: Kegan Paul, Trench, Truber \& Co.

1924. "What is Shamanism?" The China Journal of Science and Arts 2 (3-4): 275-279, 368-371.

1923. "General Theory of Shamanism among the Tungus." Journal of the North China Branch of the Royal Asiatic Society 54: 246-249. 
Shishigin, E. S.

1991.

Распространение Христианства в Якутии. Якутский Государственный Объединенный Музей Истории и Культуры Наропов Севера. lakutsk.

Siikala, Anna-Leena.

1987. "The Rite Technique of the Siberian Shaman". Folklore Fellows Communications 93 (220).

Sitnikov, L. A.

1990. Григорий И. Шеликов. Irkutsk: Eastern Siberian Book Publishers.

Smirnoff, Eugene.

1903. A Short Account of the Historical Development and Present Position of Russian Orthodox Missions. London: Rivingtons.

Smith, Barbara S.

1980. Russian Orthodoxy in Alaska: a History, Inventory, and Analysis of the Church Archives in Alaska with an Annotated Bibliography. Anchorage: The Alaska Historical Commission.

Sonne, Brigitte.

1988. Agayut: Nunivak Eskimo Masks and Drawings from the 5th Thule Expedition, 1921-24, collected by Knud Rasmussen. Report of the Fifth Thule Expedition, vol. 10, part 4. Copenhagen: Gyldendal.

Sovoroff, Sergei.

1976. "History from Nikolski and Umnak, including the Story of the Nikolski Tree". Translated [from Aleut] by Ishmail Gromoff and Nick Galaktionoff. Johnson O'Malley Cultural Enrichment Program, Unalaska City School.

Spaulding, Philip T.

1955. "An Ethnohistorical Study of Akutan: an Aleut Community". Masters Thesis, Department of Anthropology, University of Oregon.

Stamey, Roy.

1979. "The Restoration of the St. Nicholas Russian Orthodox Church, Juneau, Alaska". Orthodox Alaska 8 (3-4): 73- 78. 
Starr, Jerome Lincoln.

1961. "The Cultural and Educational Development of Aborigines and Settlers in Russian-America, 1784-1867". Ph.D. dissertation in Education, New York University. Ann Arbor: University Microfilms.

Stepanus deaconus Constantinopolitanus.

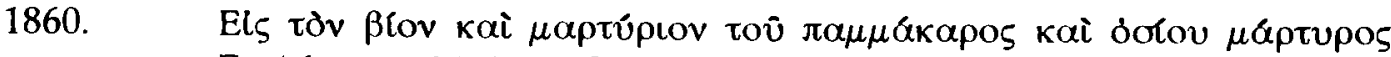

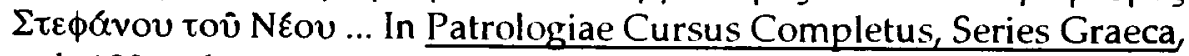
vol. 100, cols. 1069-1186. Edited by J. P. Migne. Paris.

Swanton, John R.

1908. "Social Conditions, Beliefs and Linguistic Relationships of the Tlingit Indians." In 26th Annual Report, 1904-1905, of the Bureau of American Ethnology, pp. 391-485. Washington, D.C.: The Smithsonian Institution.

Sweetland, Monroe M.

ms. $\quad$ "Faith of Our Fathers, Living Still: In Spite of Dungeon, Fire and Sword ..." [written in 1945]. In the possession of Barbara Sweetland Smith, Anchorage, AK.

Taft, $R$.

1980-1981 "The Liturgy of the Great Church: an Initial Synthesis of Structure and Interpretation on the Eve of Iconoclasm." Dumbarton Oak Papers 34-35: 45-78.

Taylor, Kenneth L.

1966. "A Demographic Study of Karluk, Kodiak Island, Alaska." Arctic Anthropology 3 (2): 211-240.

Tertullian.

1960. Q. Septimii Florentis Tertulliani de Resurrectione Carnis Liber: Tertullian's Treatise on the Resurrection. Edited and translated by Ernest Evans. London: S.P.C.K.

1950. On the Soul [de Anima]. Translated by Edwin A. Quain. In The Fathers of the Church, vol. 10: Tertullian Apologetical Works, pp. 179-309. Washington, D.C.: Catholic University of America Press.

1947. Quinti Septi Florentis Tertulliani de Anima. Edited by J. H. Waszink. Amsterdam: J. M. Meulenhoff.

1870. "A treatise on the Resurrection in the Flesh [de res. car.]" and "A treatise on the Soul [de anima]". Translated by Peter Holmes. In The Ante-Nicene Christian Fathers. Edited by Alexander Roberts and James 
Donaldson. Volume 15: Writings of Tertullian, vol 2, pp. 215-332 and 410-541. Edinburgh: T. and T. Clarke.

Theodorus Studita.

1981. On the Holy Icons. Translated by Catharine P. Roth. Crestwood, N.Y.: St. Vladimir's Seminary Press.

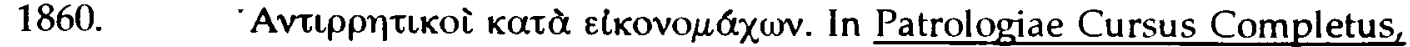

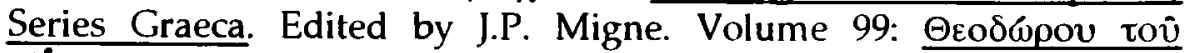

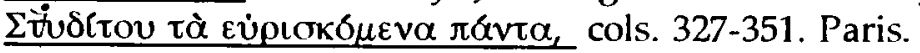

Theophilus Antiochensus.

1970. Ad Autolycum. Edited and translated by Robert M. Grant. Oxford Early Christian Texts. Oxford: The Clarendon Press.

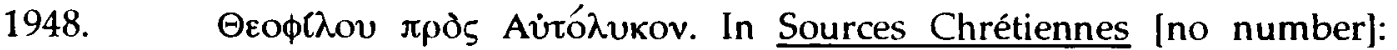
Théophile d' Antioche: Trois Livres à Autolycus. Edited by G. Bardy. Paris: Cerf.

Thunberg, Lars.

1985. Man and the Cosmos: the Vision of St. Maximus the Confessor. Crestwood, NY: St. Vladimir's Seminary Press.

1965. Microcosm and Mediator: the Theological Anthropology of Maximus the Confessor. Acta Seminarii Neotestamentici Upsaliensis XXV. Copenhagen: Gleerup, Lund and Munksgaard.

Tikhmenev, P. A.

1978. A History of the Russian-American Company पсторичеcкoe Обозрьніе Образованія Россійско-Американской Компан ии и п竞ствій ея по настоящаго времени, parts 1 and 2 (St. Petersburg, 1861 and 1863)]. Translated and edited by Richard A. Pierce and Alton S. Donnelly. Seattle: University of Washington Press.

Tikhmenev, P. A., ed.

1979. A History of the Russian-American Company vol. 2: Documents Историческое 0бозрьніе Образованія .... part 3: Приложеніе (St. Petersburg, 1863)]. Translated by Dmitri Krenov. Edited by Richard A. Pierce and Alton S. Donnelly. Kingston, Ont.: The Limestone Press.

1863. Историческое Обозрьн іе Образованія Россійск-Американской Компаніи и пьйствій ея до настоящаго времени part 3: Приложеніе. St. Petersburg.

Torres, Felix.

1985. "Rois Chasseurs, un Essai de Définition de la Structure Sociale Aléoute." Inter-Nord 17: 115-129. 
Townsend, Joan Broom.

1979. "Indian or Eskimo?" Interaction and Identity in South Alaska." Arctic Anthropology 16 (2): 160-182.

1975. "Mercantilism and Societal Change: an Ethnohistorical Examination of Some Essential Variables." Ethnohistory 22 (1): 21-32.

1974. "Journals of Nineteenth Century Russian Priests to the Tanaina [Dena'ina]: Cook Inlet, Alaska". Arctic Anthropology 11 (1): 1-30.

$1965 . \quad$ "Ethnohistory and culture change of the Iliamna Tanaina [Dena'ina]." Ph.D. dissertation, University of California at Los Angeles.

Toynbee, Arnold J.

1946. Preface. In A Study of History by Arnold Toynbee. Abridgement of volumes $1-4$ by D. C. Somervell. The Royal Institute of International Affairs. London, New York, Toronto: Oxford University Press.

1935. A Study of History vol.1: Introduction. 2nd. edition. Oxford: Oxford University Press.

Tugolukov, V. A.

1978. "Some Aspects of the Beliefs of the Tungus (Evenki and Evens)." Translated by S. Simon. In Shamanism in Siberia, pp. 419-428. Edited by V. Diózegi and M. Hoppál. Budapest: Akadémiai Kiadò.

Turner, Christie G. II.

1976. "The Aleuts of Akun Island." Alaska Journal 6 (1): 25- 31.

Turner, Edith.

1989. "From Shamans to Healers: The Survival of an Inupiaq Eskimo Skill". Athropologica 21 (1): 3-24.

Unangam Ungiikangin kayux Tunusangin.

1990. Unangam Ungiikangin kayux Tunusangin: Unangam Uniikangis ama Tunuzangis: Aleut Tales and Narratives. Compiled by Vladimir Iokhel'son [Waldemar Jochelson]. Edited by Knut Bergsland and Moses L. Dirks. The Alaska Native Language Center. Fairbanks: University of Alaska.

Underhill, Evelyn.

1930. Mysticism: a Study in the Nature and Development of Man's Spiritual Consiousness. 12th edition revised. London: Methuen \& Co. Reprinted 1967. 
Uspenskii [Ouspensky], Leonide.

1982. La Théologie de l'icône dans l'Eglise orthodoxe. Paris: Cerf.

1960. Essai sur la Théologie de l'icône dans l'Eglise orthodoxe. Recueil d'Etudes Orthodoxes, 2. Paris: Editions de l'Exarchat Patriarchal Russe en Europe Occidentale.

Valaam Monastery.

1983. Valamo and Its Message. Helsinki: Valamo-Seura. London: R. M. Nicholas.

1978. The Russian Orthodox Religious Mission in America, 1794-1837 Ючеркъ изъ Исторіи ... (St. Petersburg, 1894)]. Translated by Colin A. Bearne. Edited by Richard A. Pierce. Kingston, Ont.: The Limestone Press.

1894a. Очеркъ изъ Исторіи Американской Православной Пуховной Миссіи (Капьякской Миссін 1794-1837 гг.). St. Petersburg: М. Merkushev.

1894b. Жизнь Валаамскаго Монаха Германа, Американскаго Миссіонера. St. Petersburg.

Valaam Monastery, ed.

1978. Documents [Приложенія]. Appendix 1 in The Russian Orthodox Religious Mission in America, 1794-1837 [Oчерк в изъ Исторіи ... (St. Petersburg, 1894)]. Translated by Colin A. Bearne. Edited by Richard A. Pierce. Kingston, Ont.: The Limestone Press.

1894. Приложенія. Appendix 1 in Очеркъ изъ Исторіи Американско Православной Духовной Миссіи (Кадьякской Миссін 1794-1837 ГГ.) pp. 121-194. St. Petersburg: M. Merkushev.

"Valaam Monastery Documents".

mss. "Valaam Monastery Documents" In "Russian Reproductions". The United States Library of Congress Manuscript Division. Washington, D.C.

Vancouver, George.

1984. A Voyage of Discovery to the North Pacific Ocean and Round the World, 1791-1794, vol. 4. Edited by W. Kaye Lamb. The Hakluyt Society. London.

1798. A Voyage of Discovery to the North Pacific Ocean and Round the World, 1791-1794, vol. 3. London: [for] G. G. and J. Robinson and J. Edwards. 
Van Stone, James W.

1979. "Athabascan-Eskimo Relations in West-Central Alaska: an Ethnohistorical Perspective." Arctic Anthropology 16 (2): 152-159.

1967. "Eskimos of the Nushagak River: an Ethnographic History." University of Washington Publications in Anthropology 15.

1964. "Some Aspects of Religous Change among Native Inhabitants in West Alaska and the Northwest Territories." Arctic Anthropology 2 (2): 21-24.

1960. "Three Eskimo Communities". Anthropological Papers of the University of Alaska 9 (1): 17-56.

Van Stone, James W., ed.

1977. A. F. Kashevarov's Coastal Explorations in Northwest Alaska, 1838. Translated by David H. Kraus. Fieldiana Anthropology 69. Chicago: The Field Museum of Natural History.

1973. V. S. Khromchenko's Coastal Explorations in Southwestern, Alaska, 1822. Translated by David H. Kraus. Fieldiana Anthropology 64. Chicago: The Field Museum of Natural History.

Veniaminov, Ivan [loann; later: Innokentii].

n.d. Journals from Sitka and Unalaska, 1823-1837. The Rasmuson Library Historical Translation Series, University of Alaska, Fairbanks (in print).

1984. Notes on the Islands of the Unalashka District Ваписки ... (St. Petersburg, 1840)]. Translated by Lydia Black and R.H. Geoghegan. Edited by Richard A. Pierce. The Rasumusen Library Translation Program for the University of Alaska at Fairbanks. Kingston, Ont.: The Limestone Press.

1977. Letter to the Archbishop of Irkutsk, June 1828. Transcript in Miscellaneous Papers, Russian Church, Alaska Historical Library Archives. [Original ms. at Tobol'sk, filed 5 November 1829.] Translated by Lydia T. Black. In Lydia T. Black, "Ivan Pan'kov - an Architect of Aleut Literacy", Arctic Anthropology 14 (1): 100-102.

1975. "The Russian Orthodox Church in Alaska: Innokentii Veniaminov's Supplementary Account (1858)." Translated by Robert Croskey. Pacific Northwest Quarterly 65 (1): 26-29.

1972. "The Condition of the Orthodox Church in Russian America: Innokentii [Ivan] Veniaminov's History of the Russian Church in Alaska" ["Состояніе Православно Церкви ...", in Иннокентій... его Tворенiя, vol. 2, ed. Ivan Barsukov (Moscow, 1887), pp. 1-42]. Translated and edited by Robert Nichols and Robert Croskey. Pacific Northwest Quarterly 63 (2): 41 - 54. 
1944. "The Elements of Aleut Grammar" and "A Grammatical Essay on the Aleut Language" [in Опытъ Грамматики Алеутско-Лисьевскаго द्वзка (St. Petersburg: Academy Nauk, 1846]. Translated by Richard Henry Geoghegan. In The Aleut Language, pp. 13-83. Edited by Fredericka I. Martin. Washington, D.C.: U.S. Department of the Interior. Reprinted, Seattle: Shorey Publications, 1973.

1840a. "Состояніе Православной Церкви въ Россійской Америк'". St. Petersburg: the Imperial Academy of Sciences. Extract from the Journal of the Ministry of Public Education vol. 26, no. 5 (1840), pp. 15-58.

1840b. Записки объ Островахъ Уналашкинскаго Отпђла, part 2. St. Petersburg: [the Russian-American Company].

Veniaminov, Ivan [Ivan Pan'kov, et al.], trans.

1840. Евангеліе написанное Апостоломъ Мат бемъ, съ Русскаго языка на Aлеутско-Лисьевской. Moscow: Synodal Press.

Veniaminov, Ivan and Iakov Netsvetov, trans.

1840. Начатки Христіанскаго Ученія. St. Petersburg: Synodal Press.

Vernadsky, George.

1959. The Origins of Russia. Oxford: The Clarendon Press.

Vita Pachomii (anon.)

1980. "The First Greek Life". In Pachomian Koinonia, vol. 1: The Life of Saint Pachomius, pp. 297-407. Translated by Armand Veilleux. Cistercian Studies Series, 45. Kalamazoo: Cistercian Publications.

1932.

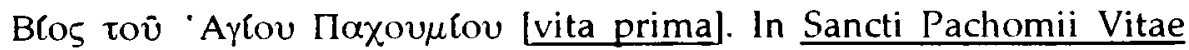
Graecae, pp. 1-96. Edited by F. Halkin et al. Subsidia Hagiographica, 19. Brussels: Société des Bollandistes.

Voulgarakes, Elias A.

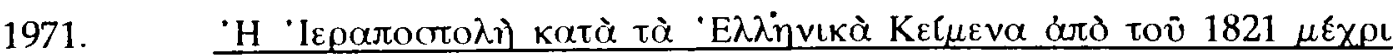

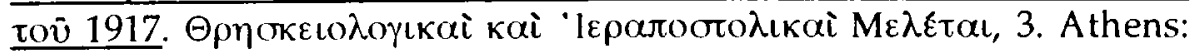
Poreuthentes.

Ward, Benedicta.

1980. Introduction. In The Lives of the Desert Fathers: the Historia

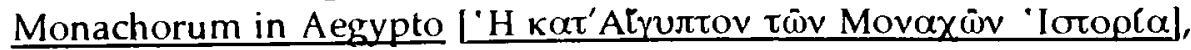
translated by Norman Russell. London and Oxford: Mowbray. USA: Cistercian Publications. 
Ware, Kallistos [Timothy].

1984. "Philocalie". In Dictionnaire de Spiritualité vol. 12, part 1, cols. 1335-1352. Edited by M. Viller, et al. Paris: Beauchesne.

1976. "The Theology of the Icon: a Short Anthology." Eastern Christian Review 8 (1): 3-10.

1963. The Orthodox Church. Middlesex: Penguin Books. Reprinted with revisions 1986.

Ware, Kallistos and Mother Mary [sic], trans.

1978. The Lenten Triodon. London: Faber and Faber.

1969. The Festal Menaion. London: Faber and Faber.

Wartelle, André.

1987. Introduction. In Saint Justin, Apologies: Introduction, Texte, Critique, Traduction, Commentaire et Index, pp. 15-94. Paris: Etudes Augustiniennes.

Williams, Norman Powell.

1950. "The Origins of the Sacraments." In Essays Catholic and Critical by Members of the Anglican Communion pp. 367-423. Edited by Edward Gordon Selwyn. 3rd edition. London: S.P.C.K.

1927. The Ideas of the Fall and of Original Sin: A Historical and Critical Survey. The Bampton Lectures. London: Longman, Green and Co.

Worl, Rosarita.

1988. "Alaska Natives Today". In Crossroads of Continents: Cultures of Siberia and Alaska, pp. 319-325. Edited by William W. Fitzhugh and Aron Crowell. Washington, D.C., and London: The Smithsonian Institution.

Wrangell, Ferdinand Petrovich.

1980. Russian America: Statistical and Ethnographic Information. Translated by Mary Sadouski. Edited by Richard A. Pierce. Kingston, Ont.: The Limestone Press.

1839. Statistische und Ethnographische Nachrichten über die Russischen Bestizungen an der Nordwestkuste von A mericka. St. Petersburg: The Imperial Academy of Sciences. 
Yannoulatos, Anastasios.

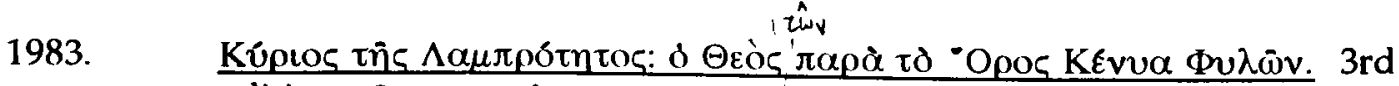

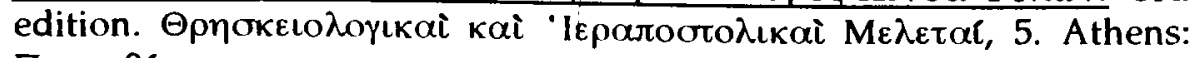

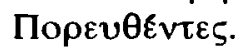

Zaehner, R. C.

1957. Mysticism - Sacred and Profane. Oxford: The Clarendon Press.

Zagoskin, Lavrentii.

1967. Lieutenant Zagoskin's Travels in Russian-America. Edited by Henry N. Michael. Anthropology of the North, Translations from the Russian Sources, 7. Toronto: The Arctic Institute of North America. 